\title{
IntechOpen
}

\section{Normal and Malignant B-Cell}

Edited by Mourad Aribi

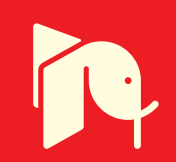





\section{Normal and Malignant B-Cell}

Edited by Mourad Aribi 

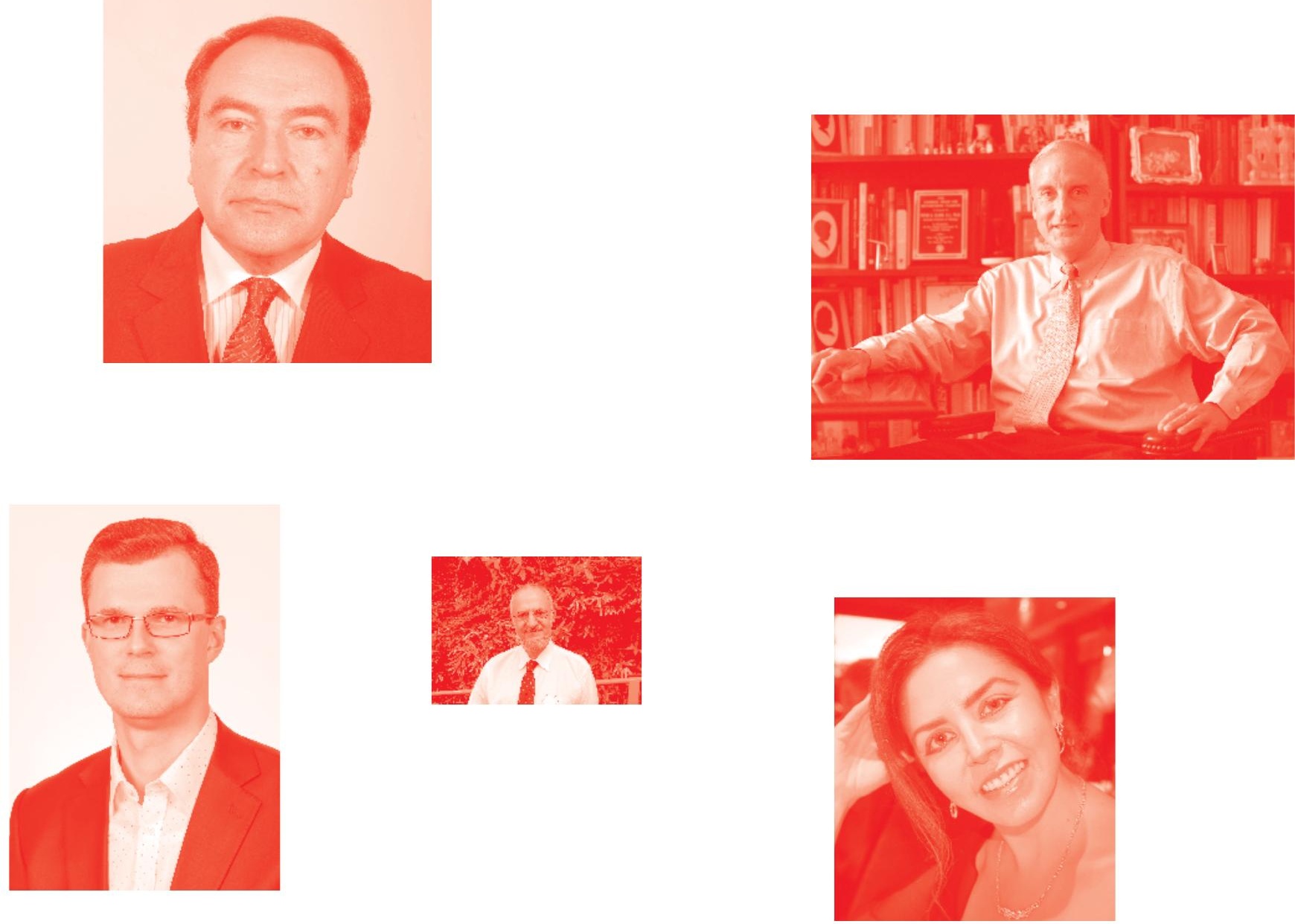

Supporting open minds since 2005
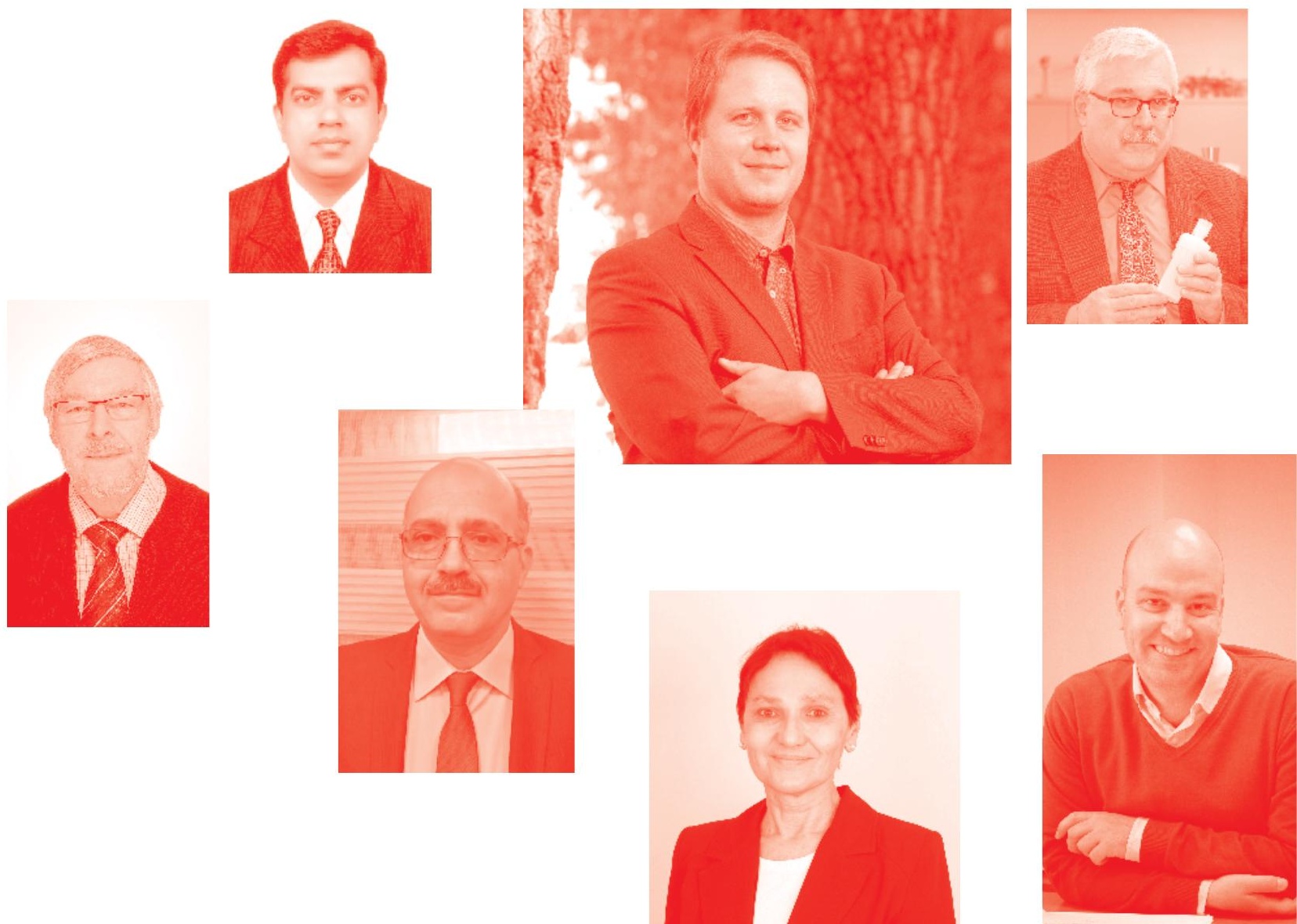
Normal and Malignant B-Cell

http: //dx. doi. org/10.5772/intechopen. 78445

Edited by Mourad Aribi

Contributors

Chulkova Svetlana Vasilievna, Lyudmila Yuryevna Grivtsova, Nikolay Nikolayevich Tupitsyn, Ivan Sokratovich Stylidi, Zamira Magometovna Galaeva, Željka Škunca, Olga Chernysheva, Alexander Popa, Stefan Patrascu, Ana Maria Patrascu, Ionela Rotaru, Valeriu Surlin, Subramanian Kalaivani Selvi, B. H. Srinivas, Sadhanandham Shrinuvasan, Mourad Aribi

( ) The Editor(s) and the Author(s) 2020

The rights of the editor(s) and the author(s) have been asserted in accordance with the Copyright, Designs and Patents Act 1988. All rights to the book as a whole are reserved by INTECHOPEN LIMITED. The book as a whole (compilation) cannot be reproduced, distributed or used for commercial or non-commercial purposes without INTECHOPEN LIMITED's written permission. Enquiries concerning the use of the book should be directed to INTECHOPEN LIMITED rights and permissions department (permissions@intechopen.com).

Violations are liable to prosecution under the governing Copyright Law .

\section{(cc) BY}

Individual chapters of this publication are distributed under the terms of the Creative Commons Attribution 3.๑ Unported License which permits commercial use, distribution and reproduction of the individual chapters, provided the original author(s) and source publication are appropriately acknowledged. If so indicated, certain images may not be included under the Creative Commons license. In such cases users will need to obtain permission from the license holder to reproduce the material. More details and guidelines concerning content reuse and adaptation can be found at http : //www . intechopen . com/copyright-policy . html .

\section{Notice}

Statements and opinions expressed in the chapters are these of the individual contributors and not necessarily those of the editors or publisher. No responsibility is accepted for the accuracy of information contained in the published chapters. The publisher assumes no responsibility for any damage or injury to persons or property arising out of the use of any materials, instructions, methods or ideas contained in the book.

First published in London, United Kingdom, 2020 by IntechOpen IntechOpen is the global imprint of INTECHOPEN LIMITED, registered in England and Wales, registration number: 11086078 , 7th floor, 10 Lower Thames Street, London,

EC3R 6AF, United Kingdom

Printed in Croatia

British Library Cataloguing-in-Publication Data

A catalogue record for this book is available from the British Library

Additional hard and PDF copies can be obtained from orders@intechopen.com

Normal and Malignant B-Cell

Edited by Mourad Aribi

p. $\mathrm{cm}$.

Print ISBN 978-1-78985-430-5

Online ISBN 978-1-78985-601-9

eBook (PDF) ISBN 978-1-78985-602-6 


\section{We are IntechOpen, \\ the world's leading publisher of Open Access books}

\section{Built by scientists, for scientists}

\section{$4,600+$}

Open access books available

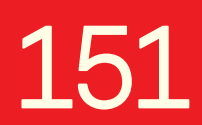

Countries delivered to

\section{$120,000+$}

International authors and editors

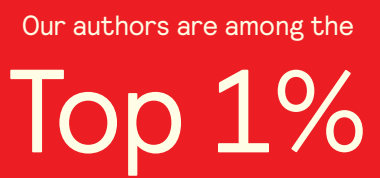

most cited scientists

Contributors from top 500 universities
$135 \mathrm{M}+$

Downloads
$12.2 \%$

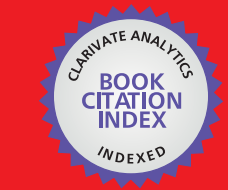

WEB OF SCIENCE ${ }^{\text {M }}$

Selection of our books indexed in the Book Citation Index in Web of Science ${ }^{\mathrm{TM}}$ Core Collection (BKCI)

\section{Interested in publishing with us? \\ Contact book.department@intechopen.com}

Numbers displayed above are based on latest data collected.

For more information visit www.intechopen.com 



\section{Meet the editor}

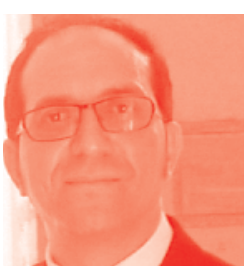

Dr. Mourad Aribi, PhD, Dr. Hab., HDR, is a professor of immunology at the University of Tlemcen (Algeria), and the founder and director of the Laboratory of Applied Molecular Biology and Immunology (W0414100). His creativity allowed him to construct for the first time Master's and $\mathrm{PhD}$ training programs in immunology at his university, welcoming students and young researchers from different regions and countries. His current research focuses on the modulation of cell-mediated and inflammatory immune responses in autoimmune diseases, cancer diseases, and infectious diseases. Thanks to his interdisciplinary skills, he was able to develop numerous high-level bilateral and multilateral collaboration projects with large teams, in particular with partners from CNRS and INSERM (Montpellier, Marseille, Burgundy-Franche-Comté, France), Institute for Immunodeficiency (Freibourg, Germany), and, more recently, with partners from Harvard Medical School (Boston, USA). He is a regular reviewer for many international scientific journals and is also a member of the editorial board of Frontiers in Immunology (the official journal of the International Union of Immunological Societies). 



\section{Contents}

Preface

Section 1

B-Cells

Chapter 1

Introductory Chapter: B-Cells

by Mourad Aribi

Chapter 2

Immunogenetic Aspect of B-Cell Antigen Receptor Diversity Generation by Mourad Aribi

Section 2

B-Cell Lymphomagenesis

Chapter 3

B-Cell Lymphomas

by Subramanian Kalaivani Selvi, B.H. Srinivas and Sadhanandham Shrinuvasan

Chapter 4

B Cell Lymphomagenesis

by Željka Škunca

Chapter 5

Diffuse Large B-Cell Lymphoma

by Patrascu Ana Maria, Ionela Rotaru, Valeriu Surlin and Stefan Patrascu

Section 3

Minimal Residual Disease and Acute Leukemia

Chapter 6

B-Cell Precursors: Immunophenotypic Features in the Detection of Minimal Residual Disease in Acute Leukemia by Olga Chernysheva, Lyudmila Yuryevna Grivtsova, Alexander Popa and Nikolay Nikolayevich Tupitsyn 
Section 4

Splenectomy Associated Changes in B-Cell Subsets

Chapter 7

Splenectomy in Gastric Cancer: Influence of B Lymphocytes

by Chulkova Svetlana Vasilievna, Lyudmila Yuryevna Grivtsova,

Ivan Sokratovich Stylidi, Nikolay Nikolayevich Tupitsyn

and Zamira Magometovna Galaeva 


\section{Preface}

This book is a collection of harmonious chapters contributed by different authors. It sets out to describe the B-cell during different stages of ontogeny and the molecular mechanisms of its antigen receptor diversity. It also discusses the main clinical and etiopathogenic aspects when it is transformed into a malignant cell.

The current book is structured into seven chapters:

The Introductory chapter describes succinctly the main features of immunoglobulins, phases of B-cell ontogeny, and B-lymphoid lineage markers, as well as diseases related to B-cell abnormalities.

Chapter 2 focuses on the molecular description of the immunogenetic mechanisms responsible for the generation of B-cell antigen receptor diversity by giving a brief overview of immunoglobulin gene organization and gene rearrangements.

Chapter 3 focuses on clinical and etiopathogenic features, prognosis, treatment, and WHO classification of B-cell lymphomas.

Chapter 4 provides a general description of B-cell lymphomagenesis.

Chapter 5 reviews the morphological, clinical, and etiopathogenic aspects, as well as the therapeutic features, of diffuse large B-cell lymphoma.

Chapter 6 describes the importance of immunophenotypic characterization of B-cell precursors using flow cytometry in the detection of minimal residual disease in acute leukemia.

Chapter 7 specifically investigates the influence of splenectomy on the composition of B-cell subpopulations.

I really hope that this book will be interesting and useful for clinicians, biologists, researchers, teachers, and graduate students of both doctoral and master's degrees in the field of immunology.

I would like to thank all the collaborators who participated in the conception of this book. I would also like to express my warmest thanks to Ms. Sandra Maljavac, Author Service Manager, for her great patience in developing this work and the coordination with the authors. I would like to thank her and the team of IntechOpen for their trust and help in making this book.

Mourad Aribi

Laboratory of Applied Molecular Biology and Immunology,

University of Tlemcen,

Algeria 

Section 1

B-Cells 



\title{
Introductory Chapter: B-Cells
}

\author{
Mourad Aribi
}

\section{Introduction}

Etymologically, the "B" from B-cells, also referred to as B lymphocytes, stands from the name of bursa of Fabricius, a lymphoid organ found only in birds, as reported, in 1956, by Bruce Glick and Timothy Chang [1, 2], but not from the bone marrow as it has been believed.

B-cells represent about 5-15\% of circulating blood lymphocytes and are responsible for the humoral immune response, as a critical component of adaptive immune system. Their roles are not limited only to the production of antigen-specific antibodies after antigen binding with high affinity via their membrane Ig but also to antigen presentation. This allows them to interact with cells involved in cellmediated immunity and to produce cytokines [3] within immunological synapses (IS) $[4,5]$ that they create with both $\mathrm{CD}^{+} \mathrm{T}$-cells [6] and CD8 ${ }^{+} \mathrm{T}$-cells [7] (for review, see [8-10]).

The current chapter presents a brief overview on Igs and phases of B-cell ontogeny and B-lymphoid lineage markers. The end of the chapter summarizes the main types of diseases related to B-cell abnormalities.

\section{Immunoglobulins: transmembrane and secreted B-cell receptors}

\subsection{Structure of Igs}

\subsubsection{Ig chains}

The most common form of Igs in the blood has a heterodimeric structure, about approximately $150 \mathrm{kDa}$ [11], with two antibody sites-paratopes-that bind to the epitope of a specific antigen, located in the fragment antigen-binding $[\mathrm{F}(\mathrm{ab})]$. This structure is composed of two identical heavy $(\mathrm{H})$ and two identical light $(\mathrm{L})$ chains, these being either kappa ( $\mathrm{L} \kappa)$ or lambda $(\mathrm{L} \lambda)$. The $\mathrm{H}$ and $\mathrm{L}$ chains are associated with each other by disulfide bridges (Figure 1).

\subsubsection{Ig domains}

Each chain of Igs is composed functionally of constant $\left(\mathrm{H} ; \mathrm{C}_{\mathrm{H}}, \mathrm{L} ; \mathrm{C}_{\mathrm{L}}\right)$ and variable $\left(\mathrm{H} ; \mathrm{V}_{\mathrm{H}}, \mathrm{L} ; \mathrm{V}_{\mathrm{L}}\right)$ domains. The constant region of $\mathrm{H}$ chain is composed of three (for $\operatorname{IgG}, \operatorname{IgA}, \operatorname{IgD}$ ) or four (for IgM and IgE) constant domains, designated, respectively, $\mathrm{C}_{\mathrm{H}} 1, \mathrm{C}_{\mathrm{H}} 2, \mathrm{C}_{\mathrm{H}} 3$, and $\mathrm{C}_{\mathrm{H}} 4$. Except for IgM and $\mathrm{IgE}$, the region between $\mathrm{C}_{\mathrm{H}} 1$ and $\mathrm{C}_{\mathrm{H}} 2$ domains is called the hinge " $\mathrm{H}$ " region, permitting flexibility in the chain [12], which is longer and more flexible in IgG3 than the other IgG subclasses [13]. Ig L chains are composed of two separate domains, each having an approximate molecular weight of $12 \mathrm{kDa}$ [14]. The association of the variable domains of the $\mathrm{H}$ and $\mathrm{L}$ chains defines the site of attachment to the antigen (Figure 1). 


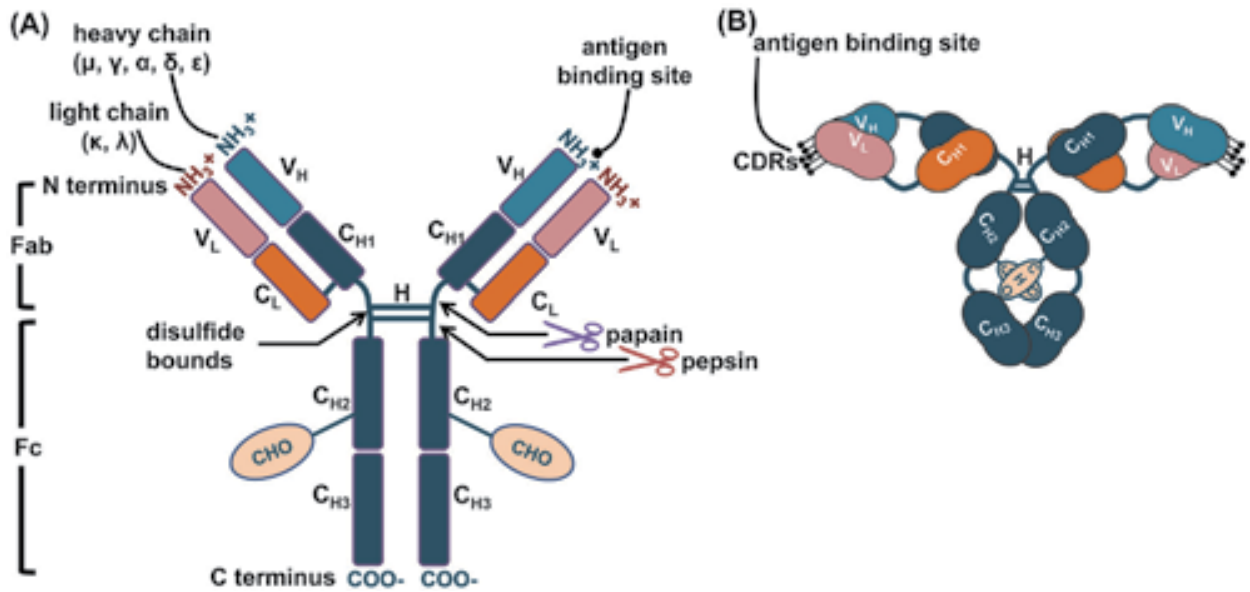

Figure 1.

Molecular structure of a typical Ig molecule. Ig molecules have a symmetric structure that is stabilized by interchain disulfide bonds. The heavy chain determines the isotypes, i.e., the classes (IgM, $\operatorname{Ig} G, \operatorname{Ig} A, \operatorname{IgD}, \operatorname{IgE}$ ) and subclasses (IgG1, IgG2, IgG3, IgG4, IgA1, IgA2) of Igs. Panel (A) shows a simplified schematic representation of an antibody molecule. Panel $(B)$ illustrates a schematic representation of the four-chain composition and the separate domains comprising each chain. This representation is based on the X-ray crystallography of an IgG antibody. Three globular regions form a $Y$. The two antigen-binding sites are at the tip of the arms, which are attached to the trunk of the $Y$ by a flexible hinge region [16]. Incubation of Igs with papain (papaya proteinase I), in the presence of a reducing agent, results in the production of two monovalent fab fragments ( $50 \mathrm{kDa}$ each) and one intact fc fragment (about 50-70 kDa). Igs digestion by pepsin leads to the production of one $F\left(a b^{\prime}\right)_{2}$ fragment and numerous smaller peptide fragments of the $f c$ portion. CDRs, complementarity-determining regions; $C_{H}$, heavy chain constant domain; $\mathrm{CHO}$, carbohydrate; $C_{L}$, light chain constant domain; fab, fragment antigen binding; $f c$, fragment crystallizable; $H$, hinge region; Ig, immunoglobulin; $V_{H}$, heavy chain variable domain; $V_{L}$, light chain variable domain.

Constant domains have specify effector functions such as activation of complement or binding to FcRs [15].

Each Ig domain contains roughly 100-110 amino acids long $[14,17]$ and consists of a two-layer sandwich of seven to nine antiparallel beta-strands arranged in two beta-sheets/-barrels with a Greek topology [18].

Ig domains play well-defined roles, which depend on the location of each one. So the $\mathrm{C}_{\mathrm{H}} 1$ domain, located within the $\mathrm{F}(\mathrm{ab})$ region, interacts with the constant domain of $\mathrm{L}$ chains. The remaining $\mathrm{C}_{\mathrm{H}}$ domains $\left(\mathrm{C}_{\mathrm{H}} 2-\mathrm{C}_{\mathrm{H}} 3\right.$ or $\left.\mathrm{C}_{\mathrm{H}} 2-\mathrm{C}_{\mathrm{H}} 4\right)$ comprise the $\mathrm{Fc}$ region, which defines the isotype, classes, and subclasses of the Ig. The $\mathrm{C}_{\mathrm{H}} 2\left(\mathrm{C}_{\mathrm{H}} 3\right.$ for IgM and $\operatorname{IgE}$ ) domain allows an important role in mediating the effector functions, including interaction with FcRs and antibody stability thanks to the presence of N-linked glycan, which is conserved in mammalian IgGs at Asn297 as well as in homologous regions of other antibody isotypes [19]. The importance of N-glycosylation is well-known for IgGs, but little is known for other isotypes [20]. The $\mathrm{C}_{\mathrm{H}} 3$ domain allows dimerization and participates in the stabilization of the binding of the heavy chains to one another through interactions between the $\mathrm{C}_{\mathrm{H}} 3$ domains. For both $\operatorname{IgM}$ and $\operatorname{Ig} \mathrm{A}$, the $\mathrm{C}_{\mathrm{H}} 3$ domains have short tailpieces to which the J-chain binds via disulfide bonds, whereas the secretory component is disulfide bonded to one of the $\mathrm{C}_{\mathrm{H}} 2$ domains of the dimer. $\mathrm{C}_{\mathrm{H}} 3$ domain of $\operatorname{IgG}$ binds to Fc $\gamma \mathrm{R}$ and of IgE to FceRI and CD23 [15].

\subsubsection{Framework and complementarity determining regions}

Each Ig V domain contains three hypervariable regions, corresponding to the site of recognition of the antigen, thus forming the paratope (complementarity determining regions, CDR1, CDR2, and CDR3). CDRs separate four highly conserved segments with less variability, termed the framework regions and designated FR1, FR2, FR3, and FR4 [16] (Figure 2). As for the T-cell antigen receptor (TCR), the 

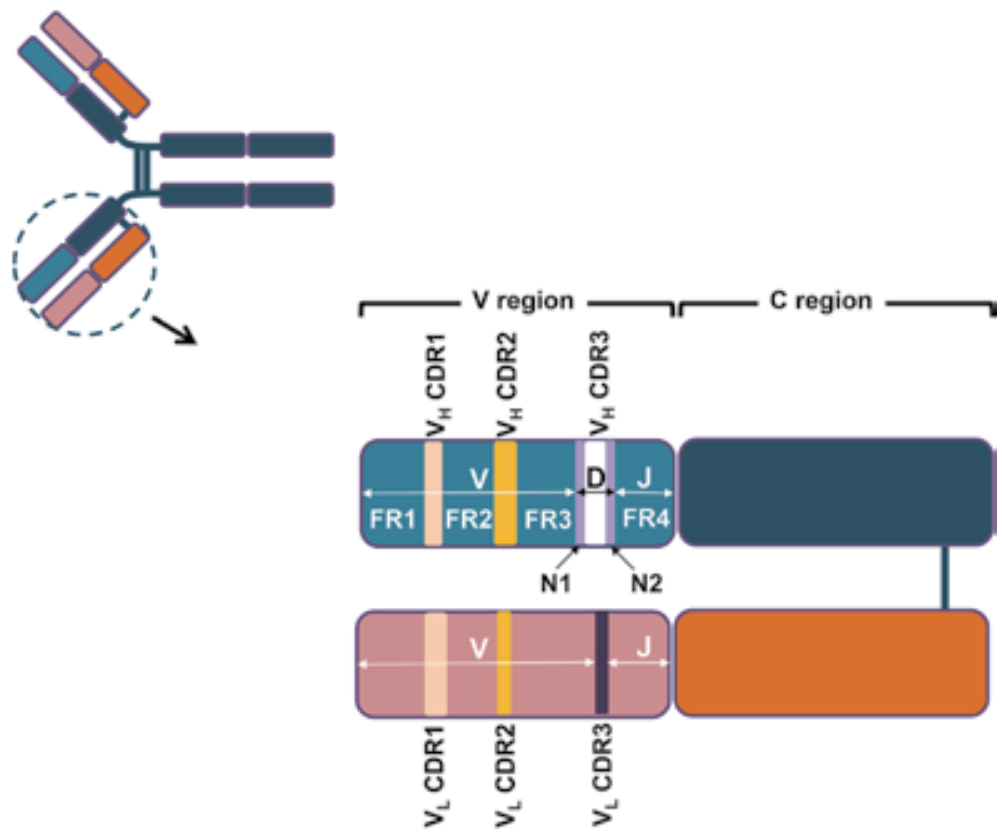

Figure 2.

Subdivision of the variable region of the $I g$ molecule. The $I g V$ region contains seven amino acid regions, four of which are FRs and three of which are CDRs. The FRs are located on the tips of the Y-shaped molecule and act as a scaffold for the CDRs. Of note, this representation shows the physical location of the $V_{H}$ region and the $V_{L}$ region. $N$ region between the $V$ and $D$ regions is called $N 1$, and that between the $D$ and heavy J regions is called $N 2$. CDR, complementarity determining region; FR, framework region; $C$, invariant constant domain; $V$, variable domain; $D$, diversity domain; J, joining domain.

binding specificity of the antigen is therefore determined by the loops present at one end of $\mathrm{V}_{\mathrm{L}}$ and $\mathrm{V}_{\mathrm{H}}$ domains of Ig chains; the difference in specificity between antibodies is therefore related to these loops [21].

\subsubsection{Isotypes and subisotypes of Igs}

There are five isotypes (classes) of Igs that are structurally and functionally distinct, $\operatorname{IgM}$, IgD, IgG, IgA, and IgE. The difference between the classes of Igs lies in the constant portion of the $\mathrm{H}$ chains: $\mathrm{mu}(\mu)$ determines the IgM class, gamma $(\gamma)$ determines the IgG class, alpha $(\alpha)$ determines the IgA class, delta $(\delta)$ determines the IgD class, and epsilon $(\varepsilon)$ determines the IgE class. So the DNA encoding the constant part of an $\mathrm{H}$ chain contains several constant sequences. Thus, there are four subclasses of $\operatorname{IgG}$ in both humans (IgG1, IgG2, IgG3, IgG4) and mice (IgG1, IgG2a, IgG2b, and IgG3) and two subclasses of IgA (IgA1 and IgA2) in humans, which are unequally distributed in the body fluids [22].

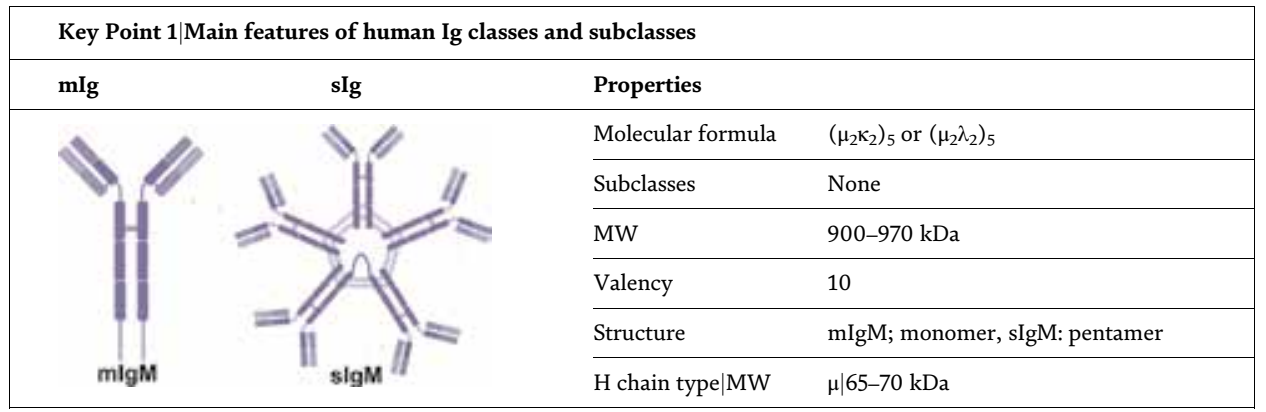


Normal and Malignant B-cell

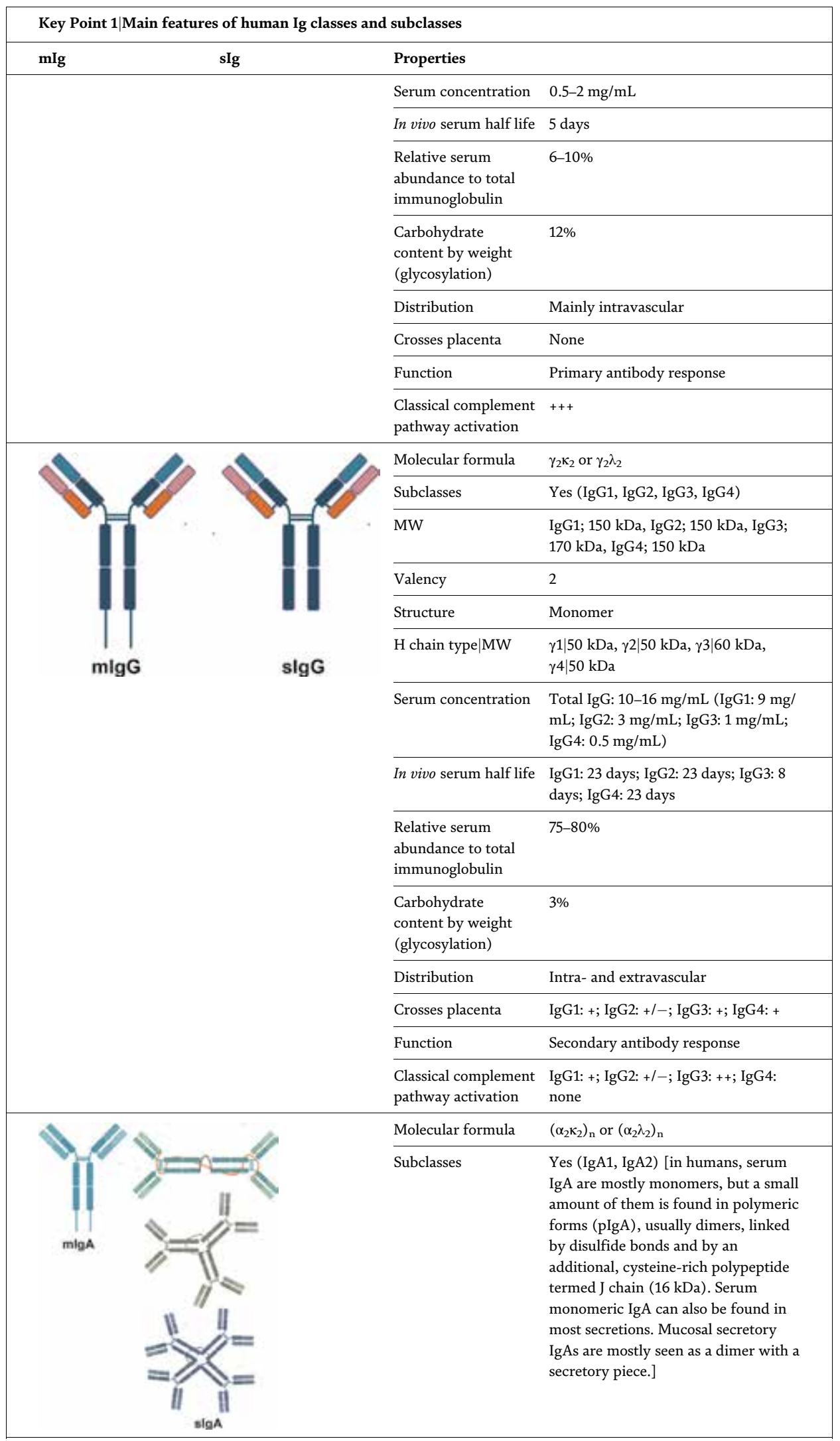


Introductory Chapter: B-Cells

DOI: http://dx.doi.org/10.5772/intechopen.90636

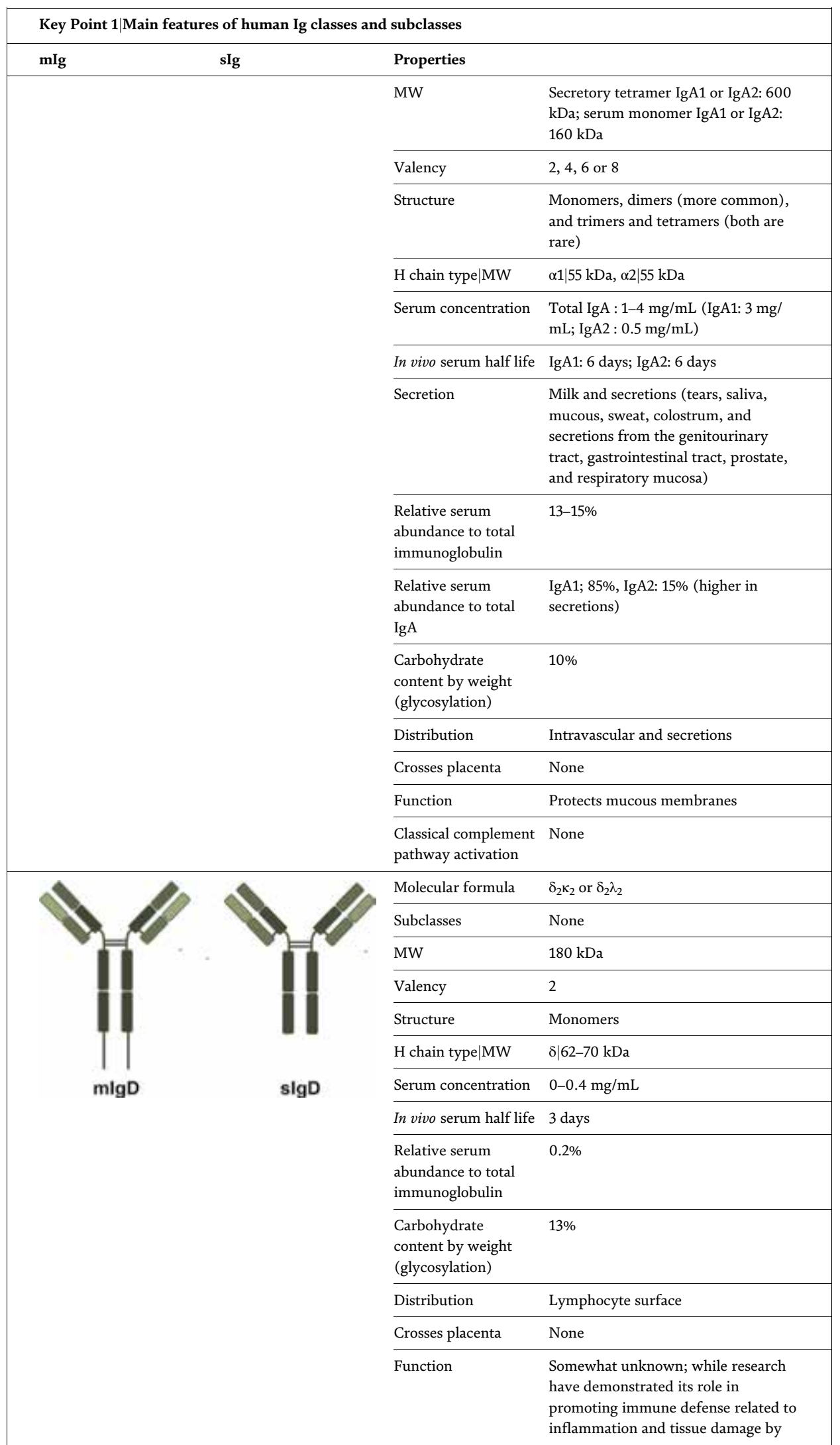




\begin{tabular}{|c|c|c|c|}
\hline \multicolumn{4}{|c|}{ Key Point $1 \mid$ Main features of human Ig classes and subclasses } \\
\hline \multirow[t]{3}{*}{$\mathrm{mIg}$} & \multirow[t]{3}{*}{$\operatorname{sig}$} & \multicolumn{2}{|l|}{ Properties } \\
\hline & & & $\begin{array}{l}\text { inducing the activation and } \\
\text { infiltration of immune cells }\end{array}$ \\
\hline & & $\begin{array}{l}\text { Classical complement } \\
\text { pathway activation }\end{array}$ & None \\
\hline \multirow{14}{*}{$\mathrm{mlg} E$} & \multirow{14}{*}{$\operatorname{slg} E$} & Molecular formula & $\varepsilon_{2} \kappa_{2}$ or $\varepsilon_{2} \lambda_{2}$ \\
\hline & & Subclasses & None \\
\hline & & MW & $190-200 \mathrm{kDa}$ \\
\hline & & Valency & 2 \\
\hline & & Structure & Monomers \\
\hline & & $\mathrm{H}$ chain type $\mid \mathrm{MW}$ & $\varepsilon \mid 70-73 \mathrm{kDa}$ \\
\hline & & Serum concentration: & $10-400 \mathrm{ng} / \mathrm{mL}$ \\
\hline & & In vivo serum half life & 2.5 days \\
\hline & & $\begin{array}{l}\text { Relative serum } \\
\text { abundance to total } \\
\text { immunoglobulin }\end{array}$ & $0.002 \%$ \\
\hline & & $\begin{array}{l}\text { Carbohydrate } \\
\text { content by weight } \\
\text { (glycosylation) }\end{array}$ & $12 \%$ \\
\hline & & Distribution & $\begin{array}{l}\text { Basophils and mast cells in saliva and } \\
\text { nasal secretions }\end{array}$ \\
\hline & & Crosses placenta & None \\
\hline & & Function & Protects against parasites \\
\hline & & $\begin{array}{l}\text { Classical complement } \\
\text { pathway activation }\end{array}$ & None \\
\hline
\end{tabular}

\subsection{Transmembrane B-cell receptor}

B-cells are defined by the presence of membrane-bound Igs (mIg) that act as specific receptors for the appropriate antigen in mature B-cell but, also as an excellent marker of the B-cell line. The mIg constitutes, with other glycoprotein chains, the B-cell antigen receptor complex (BCR). These correspond to non-covalently associated transmembrane disulfide-linked heterodimer phosphoprotein $\operatorname{Ig} \alpha / \operatorname{Ig} \beta$ (CD79a and CD79b), which are encoded by $m b-1$ and $B 29$ genes, and are structurally similar to $\mathrm{CD} 3 \gamma, \delta$, and $\varepsilon$ chains on T-cells and therefore involved in signal transduction of B-cell [23] (Figure 3). The intracytosolic portion size of the heterodimer allows it to initiate signal transduction, following the binding of the specific antigen to the $\mathrm{mIg}$.

\subsection{Mobility of mIgs, capping, and antigenic modulation}

Igs are very mobile on the surface of B-cells. In addition, various specific ligands cause what is called capping, i.e., a rapid redistribution of complexes on the surface of the cell, followed by internalization of the complexes or their release into the surrounding environment. This transient disappearance of the mIg receptor via its binding to specific ligands, like anti-immunoglobulin antibodies or antigens, is called antigenic modulation, which constitutes the initial signal for B-cell activation. The modulated membrane receptor may also be synthesized by the cell and returned to the surface when the B-cell is metabolically active $[24,25]$. 


\subsection{Transmembrane $v s$. secreted B-cell receptor}

The only structural difference between transmembrane and secreted B-cell receptors (soluble immunoglobulins, sIgs) is that the C-terminal region of the heavy

\section{B-CELL ANTIGEN RECEPTOR COMPLEX}

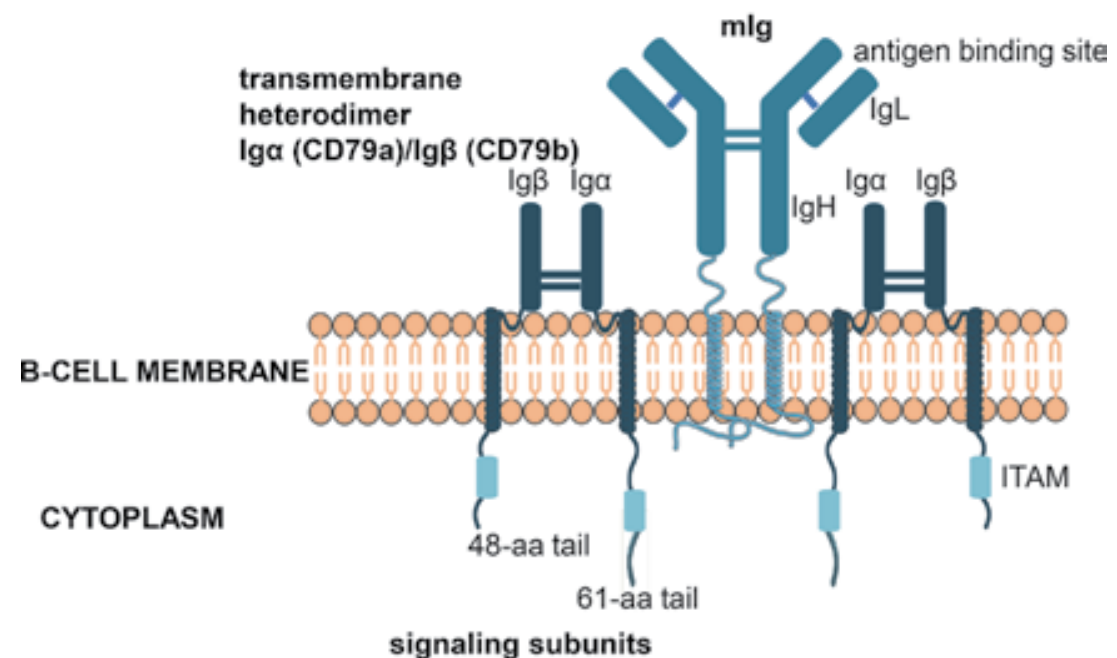

Figure 3.

$B C R$ complex structure. The BCR complex is composed of a mIg non-covalently bonded to a transmembrane disulfide-linked heterodimer phosphoprotein composed of $C D 79 a(\operatorname{Ig} \alpha) / C D 79 b(\operatorname{Ig} \beta)$. CD, cluster of differentiation; mIg, membrane-bound immunoglobulin.

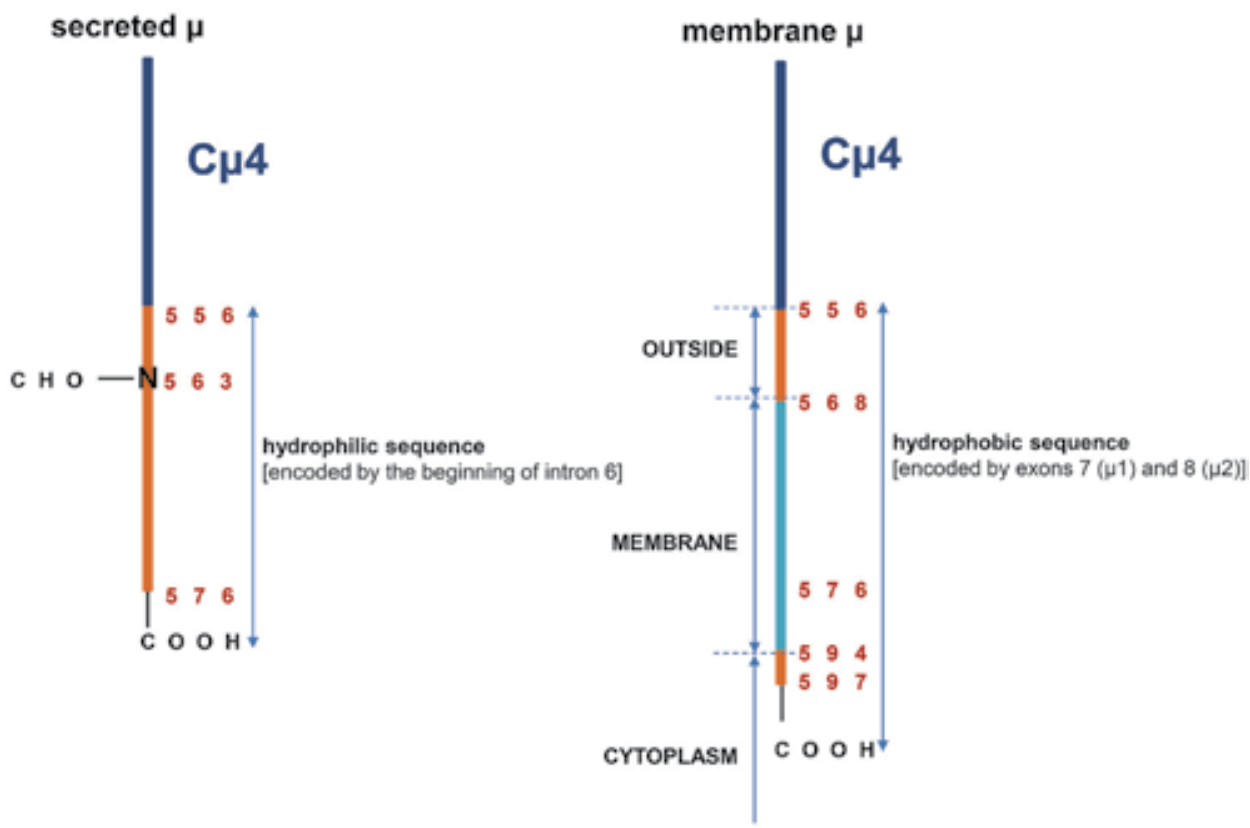

Figure 4.

Structural difference between the C-terminus of the H chain constant region of mIgM and sIgM. mIgM and sIgM differ simply by the $\mathrm{COOH}$ ends of the $\mu$ chain and therefore by mRNAs that differ at their $3^{\prime}$ ends. Membrane-bound IgM (membrane $\mu$ ) is slightly larger than that of secreted IgM (secreted $\mu$ ) [27]. The numbers indicate the position of amino acids. $\mathrm{N}$-CHO represents the position of glycosylation of asparagine ( $N$, Asn) (N-glycosylation site). mIgM, membrane immunoglobulin M; sIgM, secreted immunoglobulin $M$. 
chains contains a short hydrophobic stretch which spans the lipid bilayer of the membrane [26] (Figure 4).

sIgs play a complementary role to that of T-cells. It needs to use other mechanisms for antigen removal. This implies that they bind other molecules, like complement molecules, or specialized receptors, called Fc receptors (FcRs, receptors of fragment crystallizable region), on the surface of effector cells that they activate, including phagocyte cells (Figure 5).

Antibodies allow B-cells to provide systemic protection of the host and immune surveillance through pathogen recognition and organization of immune reactions. Their expression varies according to the state of differentiation of B-cells. After activation, B-cells transform into plasma cells that secrete antibodies of the same specificity as their membrane BCR. Secreted antibodies are transported rapidly throughout the body by blood or lymph or secreted through the epithelia to protect the interface between the body and its environment. IgG antibodies also provide a mechanism by which acquired immunity can be transmitted from the mother to the fetus or infant, thus providing acquired immune protection during the critical period of early life. Nevertheless, some antibodies can bind to self-structures, referred to as autoreactive antibodies, and induce, under certain conditions, aberrant immune responses and tissue damage [28].

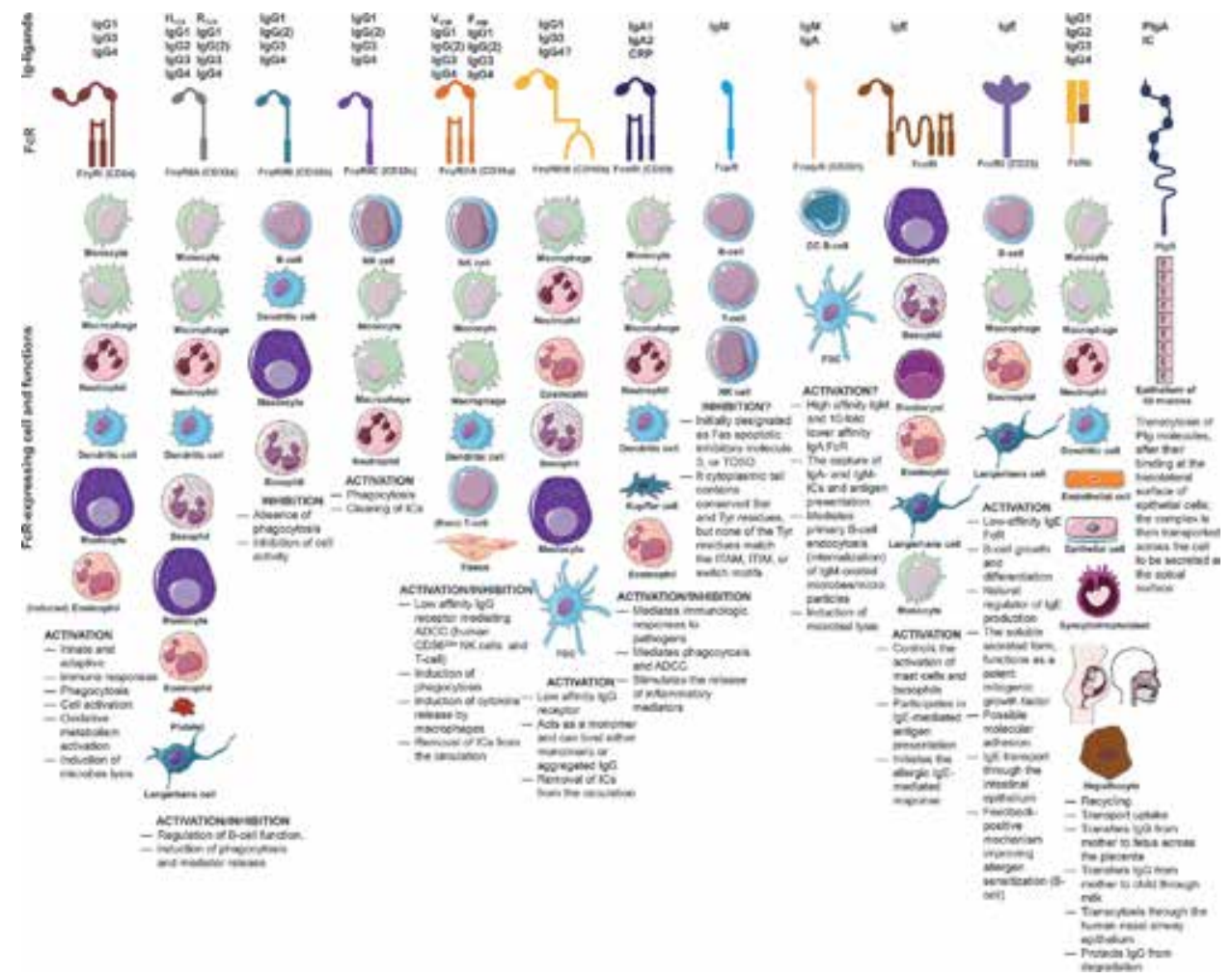

Figure 5.

Human FcRs and their cell localization and immune functions. DCs, dendritic cells; FcRn, neonatal fc receptor; $F c R s$, receptors of fragment crystallizable region; FDCs, follicular dendritic cells; $F_{l_{5} 8}$, phenylalanine at position 158; GC, germinal center; $H_{131}$, histidine at position 131; ICs, antigen-antibody immune complexes; PIgR, polymeric immunoglobulin receptor; $R_{131}$, arginine at position $131 ; V_{158}$, valine at position 158. 


\section{B-cell ontogeny}

The differentiation of B-cells from hematopoietic stem cells into pro-B, then pre-B, then immature B-cells, and finally into mature B-cells is characterized by several events, including (i) modification of membrane differentiation markers; (ii) Ig gene rearrangement, which takes place at the pro-B and pre-B stages, allowing the expression of BCR; and (iii) negative clonal selection.

\subsection{B-cell ontogenesis and maturation}

B-cell ontogenesis occurs in the fetal liver, then in the bone marrow, and continues throughout life. It starts from a hematopoietic stem cell and leads to the development of a so-called "immature" B-cell with the same and unique antigenic specificity. The immature B-cell migrates to the peripheral lymphoid organs, where the different stages of maturation will take place, leading to the Ig-producing plasma cells and memory B-cells [24]. Ultra-complex regulatory mechanisms are involved during all stages of B-cell development and lead to the generation of B-cell repertoire with a vast diversity of antigen recognition capacity.

\subsubsection{Lymphoid progenitor cells and cell fate decisions}

Knowing that B-cells, T-cells, and natural killer (NK) cells all develop from the early lymphoid progenitors that originate from totipotent hematopoietic stem cells, cell fate results from several lineage choices. The B-cell progenitors continue to develop in the bone marrow [21].

\subsubsection{Positive and negative selection and B-cell receptor reformatting}

During their development, B-cell and T-cell undergo a dual process of positive and negative selection in which cells that react with high affinity against selfantigens are eliminated because they constitute a significant danger of triggering autoimmune responses.

In the case of B-cells, outside the negative selection mechanisms, cell survival depends essentially on their ability to compete for survival factors such as the B-cell activating factor (BAFF, also known as B lymphocyte stimulator (BLyS), a subset of the tumor necrosis factor (TNF) tumor necrosis factor ligand superfamily member 13B), which is present in the circulation and produced by resident cells within secondary lymphoid organs [24]. Positive selection mainly corresponds to BCR functionality test and depends on a moderate response to the self-antigen, which stimulates cell maturation and survival. When self-reactivity exceeds a certain level, a process so-called receptor reformatting is triggered by inducing a new cycle of gene rearrangements, principally in the IG L chain loci (see Chapter 2). If the receptor reformatting fails, or if the developing B-cell leaves the bone marrow and encounters the self-antigen soon after it arrives in the spleen, this cell will be eliminated [21].

\subsubsection{Immature B-cell generation}

The differentiation of hematopoietic stem cell (HSC) into immature B-cell passes through four successive steps, which could be identified by the presence of certain markers, corresponding to the different stages of rearrangement of Ig genes: 
a. Early pro-B-cell. These cells appear before the start of rearrangements. They are identified by CD45R, major histocompatibility complex class II (MHC II), and CDI9 and CD38 markers.

b. Late pro-B-cell. Variable (V), diversity (D), and joining (J) recombinations for Ig $\mathrm{H}$ chain gene segments and receptor expression for interleukin-7 (IL7R) are induced at this stage.

c. Pre-B-cell. There is contact between adhesion molecules and, in particular, vascular cell adhesion molecule 1 (VCAM-1/CD106), on the surface of the stromal cells and its ligand, very late antigen-4 (VLA-4 or $\alpha 4 \beta 1$ integrin, a dimer composed of CD49d ( $\alpha 4)$ and CD29 ( $\beta 1)$ ), on the surface of the pre-Bcells. At this point, intact $\mu \mathrm{H}$ chains are produced and exported to the cell surface in association with proteins that simulate light chains: $\lambda 5$, which is similar to a C $\lambda$ domain, and VpreB (CD179a), which has an Ig V domain-like structure. The $\mu$ chains associated to $\lambda 5$ and $V$ preB form a complex which, together with $\operatorname{Ig} \alpha$ and $\operatorname{Ig} \beta$ proteins, can be expressed at the cell surface and transduce signals that inhibit other rearrangements of genes encoding the $\mathrm{H}$ chains but stimulate the genes encoding $\mathrm{L}$ chains and cell proliferation. Moreover, expression of the CD20 marker can be detected at this stage.

d. Immature B-cell. Thanks to a productive Ig L chain genes' rearrangement, these cells express IgM on their surface, which triggers a phenomenon termed feedback inhibition, which blocks any new rearrangement of the genes encoding the $\mathrm{L}$ chains, thus allowing the expression of a single and unique Ig specificity by each B-cell clone. At this point, the cells express the CD21 marker.

These stages are strictly dependent on the presence, in the fetal liver and bone marrow, of nonlymphoid stromal cells that come into contact with the B-cell precursors and provide the input of soluble factors in the cell microenvironment that are essential for differentiation, such as stem tell factor (SCF) and interleukin 7 (IL-7). It should be noted, moreover, that the probability of reaching productive/ efficient rearrangements of $\mathrm{Ig}$ genes encoding the $\mathrm{H}$ and $\mathrm{L}$ chains and obtaining an intact Ig expressed on the cell surface (mIg/BCR) is low. So most of the time there are nonproductive rearrangements, which leads to the deletion of the resulting $\mathrm{B}-$ cells. In addition, the differentiation of B-cells also depends, according on the cell development stage, on the presence of intracellular enzymes. Thus, the enzymes encoded by the recombination-activating genes (RAGs), RAG-1 and RAG-2, are active in early and late pro-B-cells and in pre-B-cells. Finally, the activity of the enzyme terminal deoxynucleotidyl transferase (TdT), which is involved in the addition of $\mathrm{N}$-nucleotides, stops at the pre-B-cell stage.

Key Point 2|Stromal cells

- Stromal cells constitute a support tissue of an organ, i.e., a connective tissue cell that allows the multiplication of hematopoietic stem cells (HSCs) and their differentiation by creating a microenvironment adapted to the growth and differentiation of HSCs. They are also able to differentiate into many cell types.

- It has recently been suggested that stromal cells play a major role, not only in the functional regulation of many tissues and organs, but also more particularly in the immune responses. Of note, non-hematopoietic stromal cells play a key role in the development and function of the immune 
system, but, paradoxically, they can also promote the persistence of many cancers and various immune-mediated diseases. The main non-hematopoietic stromal cells involved in immunity include fibroblasts, myofibroblasts, endothelial cells, pericytes, smooth muscle cells and mesenchymal stromal cells.

- Bone marrow stromal stem cells (BMSC) are almost all of mesenchymal origin and, therefore, are also known as skeletal or mesenchymal stem cells. They influence the microenvironment surrounding Bcell precursors, and thus exert local effects on their development through cytokines and chemokines.

HSCs are multipotent cells; i.e., they are able to differentiate into each of the types of blood cells. After each division into two cells, one of them maintains the HSCs stock and the other one differentiates into one of three types of blood cell, i.e., leukocyte, red blood cell, or platelet.

\subsubsection{Transition from immature B-cell to mature B-cell}

The immature B-cell leaves the bone marrow parenchyma and passes through an endothelial barrier and enters the blood sinusoids, where they are retained, before finally being released into the peripheral blood [29], which allows them to migrate to the spleen where they complete their development [30]. The transition from the immature B-cell to the mature B-cell takes place in a few days and leads, via alternative splicing of long primary mRNA transcripts from the IG heavy (IGH) locus [31], to the coexpression on naïve mature B-cells of membrane IgM and IgD that share the same antigenic specificity. Only about $5 \%$ of immature B-cells will sustainably give rise to peripheral B-cells; however, most newly formed ones disappear within a few days.

\subsubsection{Tonic BCR signal and notch activation}

A so-called BCR-mediated positive signaling tonic signal and activation of Notch pathway, more precisely of Notch2, which is induced following the interaction with delta-like canonical Notch ligand 1 (DLL-1) expressed on splenic endothelial niches and required for marginal zone (MZ) B-cell development [32], allow the triggering of a first differentiation by a lineage cell choice that does not involve the antigenic specificity.

\subsubsection{Intensity of tonic signal and differentiation of lymphoid follicular B-cells or $M Z$ B-cells}

a. Low tonic signal and Notch2 commitment. These will lead to differentiation into MZ B-cells. The latter forms a ring around the follicle and has a more complex structure in humans, also surrounded by a perifollicular zone [PFZ] that surrounds the red pulp. It is a macrophage-rich area (MZ macrophages [MZMs] and metallophilic macrophages [MMMs]) that will efficiently retain antigens from the bloodstream. In mice, the MZ B-cells are CD21++CD23-CD11

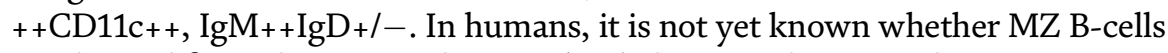
are derived from the germinal center (CG), by an early exit at the IgM stage, or are produced by a lineage choice during early B-cell differentiation.

b. Strong tonic signal, without Notch2 commitment. These lead to differentiation of lymphoid follicular B-cells. Recall that these are structured by specialized stromal cells and follicular dendritic cells (FDCs), which play an important role in immune response by their ability to retain 
antigen-antibody complexes as well as in the selection of memory B-cells during GC reactions (GCRs) [33]. They contain naive B-cells, and adjacent to which are T-cell zones that form the periarteriolar lymphoid sheath (PALS). Phenotypically, they are IgM+/-IgD++, CD21+/-, and CD23+, in mice.

\subsection{Phases of B-cell ontogeny: antigen-dependent and antigen-independent}

B-cell ontogeny can be separated into two main phases: earlier antigenindependent phase and later antigen-dependent phase (Figure 6). It should also be recalled that thymus-independent (TI) antigens have the ability to stimulate B-cells without T-cells' help and are traditionally divided into two categories, TI-1 antigens that can activate B-cells through coengagement of Toll-like receptors (TLR), such as LPS or other bacterial polysaccharides, and TI-2 antigens that lead to extensive cross-linking of the BCR, such as polymeric protein antigens or repeated structural motifs [33]. Some antigens fall outside these and form a third category. Finally, T-cell-independent responses should be discussed, knowing that T-cells could intervene at different levels of B-cell development in response to TI antigens (For review, see [34-36]).

\subsubsection{Earlier antigen-independent phase}

The first phase of B-cell differentiation and maturation would be antigenindependent. It takes place in the bone marrow and results in the generation of immature B-cells expressing pair L chains with $\mu$ chains to form cell surface monomeric $\operatorname{IgM}$ in association with transmembrane $\operatorname{Ig} \alpha$ and $\operatorname{Ig} \beta$ invariant chains, forming the BCR complex, which is able to recognize and capture antigens.

\subsubsection{Later antigen-dependent phase}

The second phase of B-cell activation and final differentiation is dependent on selfantigens, then on non-self-antigens within the secondary lymphoid organs (SLOs). It results in the formation of plasma cells and antigenic specific memory B-cells.

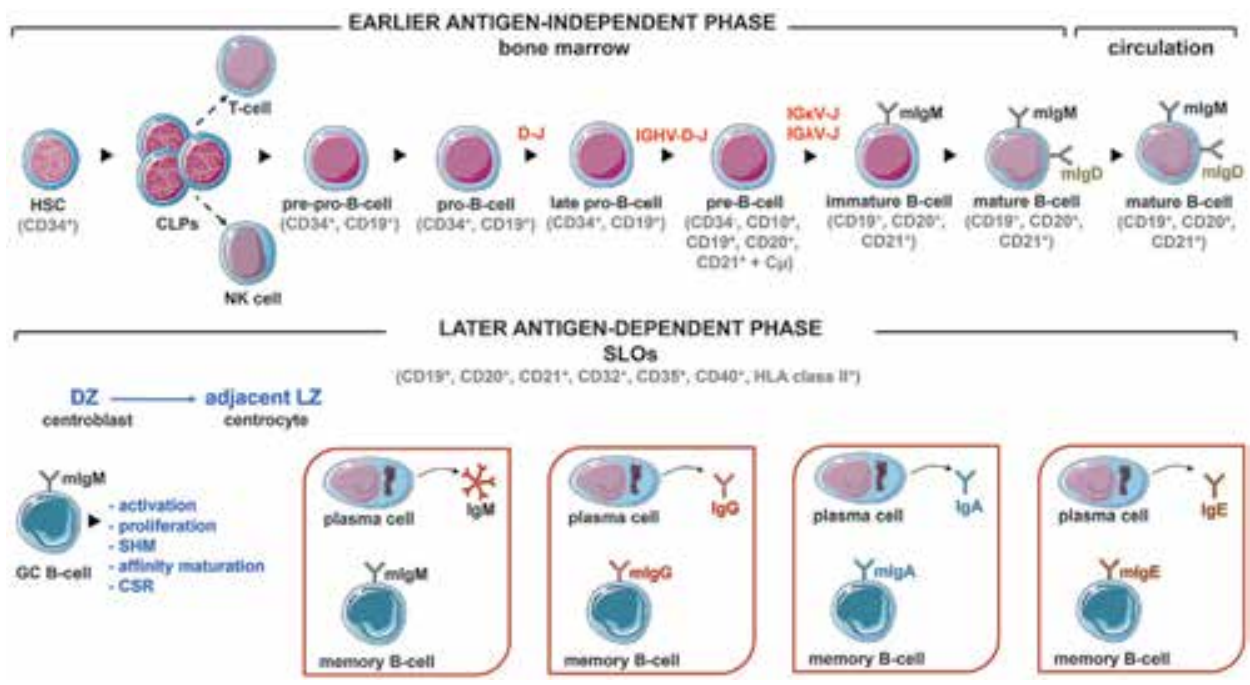

Figure 6.

Phases of B-cell ontogeny. CLPs, common lymphoid progenitors; mIgM, membrane immunoglobulin M; DZ, dark zone; LZ, light zone; HLA, human leucocyte antigen; GC, germinal center; CSR, class switch recombination. 


\section{B-cell markers: the main molecules of the B-lymphoid lineage}

The majority of human peripheral blood B-cells express on their surface IgM and IgD that have the same antigenic specificity. In addition, in humans, a large population of circulating cells expresses membrane $\lg G$ or IgA (but very little IgE). In some tissues, including intestinal mucosa, B-cells selectively express membrane $\operatorname{IgA}$. In addition to the $\operatorname{Ig} \alpha / \operatorname{Ig} \beta$ heterodimer marker, which is part of the BCR complex, there are also other molecules on the B-cell surface that play notable roles in various cellular functions, especially in B-cell regulation, such as human complement receptor type 2 (CR2, C3d), designed as CD21, that regulates B-cell proliferative responses, and serving as a receptor for the $\mathrm{C} 3 \mathrm{~d}, \mathrm{C} 3 \mathrm{dg}$, and $\mathrm{iC} 3 \mathrm{~b}$ proteins of complement. B-cells also express receptor for complement component C3b (CR1, CD35) as well as for Fc fragments (FcR) of certain Ig isotypes, such as IgG (FcyRIIB1, CD32). Of note, only Fc $\gamma$ RIIB1 and Fc $\gamma$ RIIB2 have an immunoreceptor tyrosinebased inhibitory motif (ITIM) sequence among the Fc $\gamma \mathrm{R}$ receptor family and are therefore inhibitory FcRs; they do not induce phagocytosis and represent an important receptor-mediated feedback circuit regulator by circulating antigenspecific $\operatorname{IgG}[24,37]$. CR2/CD21 has also been described as a receptor for the envelope glycoprotein gp350/220 of the Epstein-Barr virus (EBV) [38]. Other molecules are frequently used in routine practice as primary markers for identifying human B-cells, including CD19, CD20, and CD22 markers. CD19 is expressed at all stages of B-cell lineage, including normal plasma cells. CD20, a molecule restricted to the B-cell population, has been shown to be implicated to form calcium channels in cell membrane [39], and as an effective target for immunotherapy in treatment of B-cell lymphoma, as well as in a number of autoimmune diseases, such as type 1 diabetes [40]. It occurs at the early pre-B-cell stage of development and remains throughout all stages of B-cell maturation [41], ranging from pre-B-cells in the bone marrow to short-lived plasmablasts [42]. CD22, a B-cell-restricted surface molecule that regulates BCR signaling in mature B-cells [43], is an early marker and persists at all stages of B-cell differentiation, which has allowed it to be a useful pan marker for all mature B-cell subsets [44]. Recognized as a B-cell-specific sialic acid binding Ig-like lectin 2 (Siglec-2; B-lymphocyte cell adhesion molecule [BL-CAM]), CD22 has been exploited as a therapeutic target for humanized anti-CD22 monoclonal antibody to treat B-cell leukemia [45]. Both immature and mature mouse B-cells as well as subsets of T-cells and NK cells and subset of abnormal T-cells involved in the pathogenesis of systemic autoimmunity in MRL-Fas ${ }^{l p r}$ and MRL-Fas ${ }^{\text {gld }}$ mice express one of the five isoforms of the transmembrane tyrosine phosphatase CD45 (LCA) found on lymphocytes [46], i.e., CD45R (B220, CD45RABC), which has been known to play a major role in lymphocyte signaling and activation. Other B-cell surface molecules allow them to cooperate with T-cells. They include essentially MHC II antigens (DR, DP, and DQ, in humans, and IA and IE, in mice) and CD40 (a member of the TNF receptor superfamily, also expressed on B-cell precursors in the bone marrow), which is capable of transducing extremely potent B-cell activation signals. Mutations in the gene coding for CD40 ligand (CD40L/CD154), predominantly expressed by activated $\mathrm{CD}^{+}{ }^{+} \mathrm{T}$-cells, lead to X-linked hyper-IgM syndrome (HIGM1), a severe primary immune deficiency (PID) in humans, characterized by recurrent infections, associated with very low or absent $\operatorname{IgG}, \operatorname{IgA}$, and IgE levels, but normal or elevated serum levels of IgM [47]. B-cells can also be identified using the inhibitory co-receptor CD72 (Lyb-2 in mice), containing an ITIM in the cytoplasmic. CD72 specifically recognizes the RNA-containing endogenous TLR7 ligand Sm/ribonucleoprotein (RNP) by C-type lectin-like domain (CTLD) located in its extracellular region and specifically inhibits B-cell responses to Sm/RNP by recruiting SH2 domain-containing phosphatase 1 (SHP-1) to the 
phosphorylated ITIM [48]. It has been reported to have a role in the regulation of systemic lupus erythematosus (SLE) development [49]. Its specific ligand is CD5 [50], which is usually expressed on most T-cells, but also on a subset of mature B-cells [51] and $\mathrm{CD}^{+} \mathrm{B} 1$ cells, which emerge early in development and play a major role in autoimmunity [52]. Other markers, including CD10 and CD23, are fond at some stages of B-cell differentiation. CD10, a neutral endopeptidase, also referred to as common acute lymphoid leukemia antigen (CALLA), enkephalinase, and neprilysin, is expressed in early B-cell immature stages in bone marrow, but also in certain stages of immunopoiesis and is also present on antigen-activated cells in GC, in humans [53]. Defined initially as the low-affinity receptor for IgE (FceRII) and as EBV cell surface (EBVCS) activation antigen or BLAST-2, CD23 exists in two distinct protein isoforms, CD23 $\alpha$ (FceRIIa), which is constitutively expressed only in normal B-cells and B-cell lines, and CD23 $\beta$ (FceRIIb), which is an inducible molecule detectable on various cells [54], including most mature B-cells, follicular mantle (FM) B-cells, T-cell subsets (at low levels), NK cells, platelets, FDCs, monocytes, eosinophils, Langerhans cells, etc. CD23, a $45 \mathrm{kD}$ type II transmembrane glycoprotein, can be cleaved and found in plasma as a freely soluble receptor ( $\mathrm{sCD} 23$ ). In contrast to cross-linking of FceRI that leads to degranulation of mast cells to release vasoactive mediators, engagement of membrane-bound CD23 suppresses the production of IgE by B-cells. Moreover, CD23 participates in many regulatory processes, including cytokine release, cell-cell contact, and

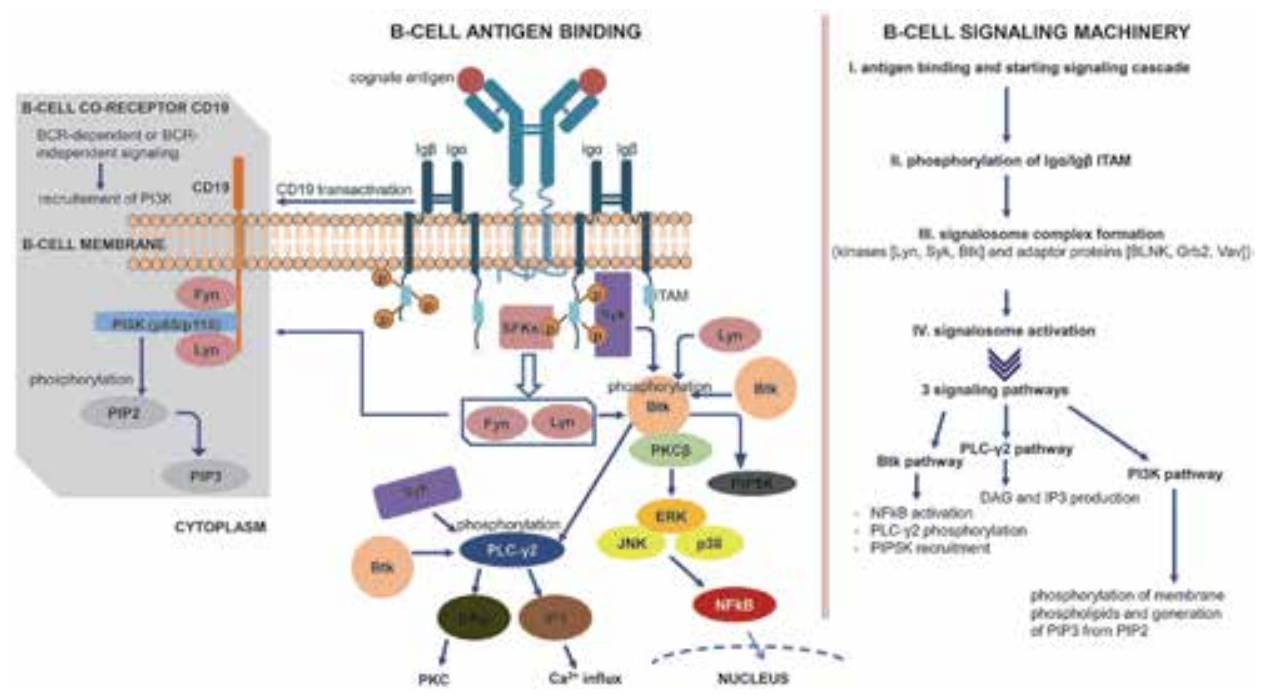

Figure 7.

$B C R$ signaling. As mentioned above, the final activation of mature B-cell occurs in the SLOs, where they migrate through the blood. Within the SLOS, they receive a constant supply of antigen through the circulating lymph. The activation of B-cell is initiated after binding of an appropriate antigen to its BCR, leading to phosphorylation of the non-covalently associated Ig $/$ Ig $\beta$ transmembrane (CD79a and CD79b). The signaling mechanisms triggered during the B-cell activation can be summarized in four main steps: (i) antigen binding and starting signaling cascade, (ii) phosphorylation of Ig $/ \operatorname{Ig} \beta$ ITAM, (iii) signalosome complex formation, and (iii) signalosome activation. Akt, protein kinase $B / P K B ; B C R, B$-cell antigen receptor; $B L N K, B$-cell linker; Btk, Bruton's protein tyrosine kinase/non-receptor kinase; $C D$, cluster of differentiation; ERK, extracellular signal-regulated kinase; Fyn, proto-oncogene tyrosine-protein kinase Fyn/non-receptor Fyn protooncogene; Grb2, growth factor receptor-bound protein 2; ITAM, immunoreceptor tyrosine-based activation motifs; JNK, c-Jun N-terminal kinase; Lyn, Lck/yes novel tyrosine kinase; mIg, membrane-bound immunoglobulin; $N F-\kappa B$, nuclear factor kappa-light-chain-enhancer of activated B-cells; PI3 K, phosphoinositide-3 kinase; PIP2, phosphatidylinositol-4,5-bisphosphate; $P P_{3}$, phosphatidylinositol-3,4,5-trisphosphate; PLCy2, phospholipase $C-\gamma 2$; PKC $\beta$, protein kinase C $\beta$; SLOs, secondary lymphoid organs; SFKs, Src-family kinase/Src-proteintyrosine kinase or Src family tyrosine kinase; Src, proto-oncogene tyrosine-protein kinase c-Src (cellular Src kinase); Syk, spleen tyrosine kinase/non-receptor tyrosine kinases; Vav, proteins acting as guanine nucleotide exchange factors (GEFs) for small $G$ proteins of the rho family. 
receptor-mediated positive and negative feedback circuits, either as a membranebound glycoprotein or as sCD23 [55]. Finally, a new type of immune cell, so-called $\mathrm{X}$ lymphocyte, that is a dual expresser (DE) of TCR and BCR and key lineage markers of both B- and T-cells, has just recently been discovered in patients with type 1 diabetes (For review see [56]).

\section{Normal mature B-cell activation and signaling mechanisms}

Antigen binding to mIg induces the BCR aggregation, which leads to the rapid transmembrane disulfide-linked heterodimer phosphoprotein $\operatorname{Ig} \alpha(\mathrm{CD} 79 \mathrm{a}) / \operatorname{Ig} \beta$ (CD79b) ITAM phosphorylation through recruitment of Syk and SFKs (Fyn, Lyn). This process begins with the formation of a "signalosome" [57]. The signalosome activation leads to three main pathways [58], including Btk, PLC- $\gamma 2$, and PI3K. BCR can transactivate the B-cell co-receptor CD19, which forms, on B-cell surface, a tetrameric co-receptor complex with CD21 and CD81 (target of anti-proliferative antibody 1 (TAPA-1), a tetraspanin family member tetraspanin 1 (Tspan1, NET-1), and Leu13 (CD225)) [59]. CD19 can also be BCR-independently activated but lacks intrinsic or associated tyrosine kinase activity [60]. As CD19 has a long cytoplasmic domain, it binds and amplifies the function of the SFKs and recruits a heterodimer p85/p110 class IA PI3K concurrently, which phosphorylates a membrane phospholipid, PIP2, leading to the production of a second messenger PIP3 [61], as well as promoting Btk and Akt, and a serine/threonine, kinase phosphorylation in B-cell [62] (Figure 7).

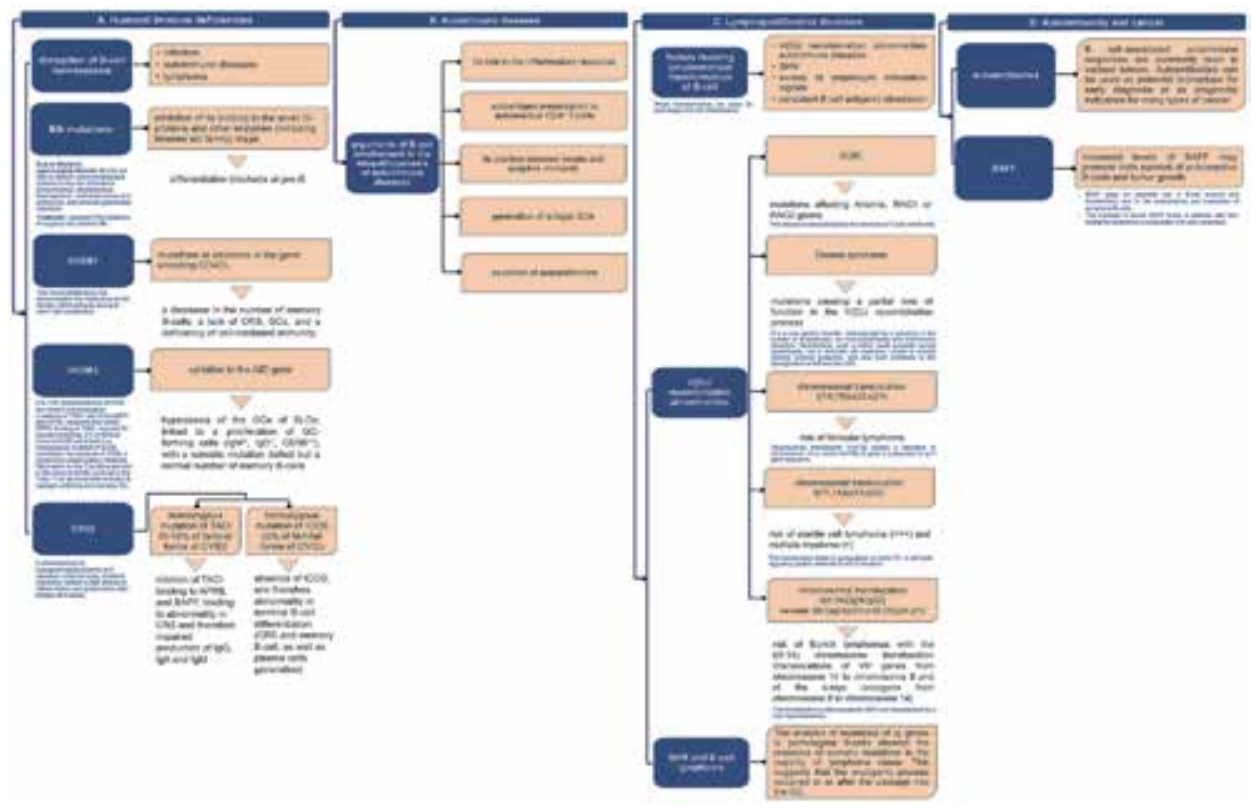

Figure 8.

Main types of diseases related to B-cell abnormalities. AID, activation-induced cytidine deaminase; Btk, Bruton's tyrosine kinase; HIGM1, X-linked hyper-IgM syndrome type 1; CD4oL, CD4o ligand (CD154); CSR, class switch recombination; GCs, germinal centers; Ig H, immunoglobulin heavy chain; BAFF, B-cell activating factor also known as B-lymphocyte stimulator (BLyS) or tumor necrosis factor (TNF) ligand superfamily member 13B (TNF-like molecule BAFF); BCL-2, B-cell lymphoma 2; EBV, Epstein-barr virus; CVID, common variable immunodeficiency; IVIg, intravenous immunoglobulin; SCID, severe combined immunodeficiency; SHM, somatic hypermutation; SLOs, secondary lymphoid organs; TACI, transmembrane activator and calcium modulator and cytophilin ligand interactor; XLA, X-linked agammaglobulinemia (Bruton's agammaglobulinemia); HIGM2, hyper-IgM syndrome type 2 (autosomal recessive). 


\section{B-cell and pathologies}

B-cells are threatened by various pathologies, including (i) immune deficiency, which results from a disruption in their homeostasis due to mutations or deletions, abnormalities in mechanisms of gene repair, Ig class generation, Ig affinity modulation, etc.; (ii) autoimmune disorders, in which potentially dangerous self-reactive clone B-cells escape from mechanisms of tolerance; (iii) cancerous tumors, which result from a disorder in the succession of phases of proliferation and cell death or in the processes of generation of cell diversity; and (iv) allergies that are particularly related to regulatory abnormalities involving $\mathrm{Br} 1\left(\mathrm{IL}-10^{+}\right), \mathrm{Br} 3\left(\mathrm{TGF}-\beta^{+}\right)$, and regulatory B-cells (Breg, Foxp3 ${ }^{+}$) [52]. The main B-cell-associated diseases are illustrated in Figure 8.

\section{Acknowledgements}

Cell schematic illustrations are adapted from free Servier Medical Art (smart. servier.fr/servier-medical-art).

\section{Author details}

\section{Mourad Aribi}

Laboratory of Applied Molecular Biology and Immunology, W0414100, University of Tlemcen, Tlemcen, Algeria

*Address all correspondence to: mourad.aribi@univ-tlemcen.dz

\section{IntechOpen}

(C) 2020 The Author(s). Licensee IntechOpen. This chapter is distributed under the terms of the Creative Commons Attribution License (http://creativecommons.org/licenses/ by/3.0), which permits unrestricted use, distribution, and reproduction in any medium, provided the original work is properly cited. (c) BY 


\section{References}

[1] Cooper MD. The early history of B-cells. Nature Reviews. Immunology. 2015;15:191-197

[2] Ribatti D, Crivellato E, Vacca A. The contribution of Bruce Glick to the definition of the role played by the bursa of Fabricius in the development of the B-cell lineage. Clinical and Experimental Immunology. 2006;145:1-4

[3] Murphy K, Travers P, Walport M, Janeway C. Janeway's immunobiology. (Garland). Science. 2012

[4] Choudhuri K et al. Polarized release of T-cell-receptor-enriched microvesicles at the immunological synapse. Nature. 2014;507:118-123

[5] Dustin ML. What counts in the immunological synapse? Molecular Cell. 2014;54:255-262

[6] Yuseff M-I, Lennon-Duménil AM. B-cells use conserved polarity cues to regulate their antigen processing and presentation functions. Frontiers in Immunology. 2015;6(251)

[7] Bennett SR, Carbone FR, Toy T, Miller JF, Heath WR. B-cells directly tolerize CD8(+) T-cells. The Journal of Experimental Medicine. 1998;188: 1977-1983

[8] Ke Y, Kapp JA. Exogenous antigens gain access to the major histocompatibility complex class I processing pathway in B-cells by receptor-mediated uptake. The Journal of Experimental Medicine. 1996;184: 1179-1184

[9] Yefenof E, Zehavi-Feferman R, Guy R. Control of primary and secondary antibody responses by cytotoxic $\mathrm{T}$ lymphocytes specific for a soluble antigen. European Journal of Immunology. 1990;20:1849-1853
[10] Barnaba V, Franco A, Alberti A, Benvenuto R, Balsano F. Selective killing of hepatitis $B$ envelope antigen-specific B-cells by class I-restricted, exogenous antigen-specific T lymphocytes. Nature. 1990;345:258-260

[11] Porter RR. Structural studies of immunoglobulins. Science. 1973;180: 713-716

[12] Hovenden $\mathrm{M}$ et al. IgG subclass and heavy chain domains contribute to binding and protection by mAbs to the poly $\gamma$-D-glutamic acid capsular antigen of bacillus anthracis. PLoS Pathogens. 2013;9:e1003306

[13] Scharf O et al. Immunoglobulin G3 from polyclonal human immunodeficiency virus (HIV) immune globulin is more potent than other subclasses in neutralizing HIV type 1. Journal of Virology. 2001;75:6558-6565

[14] Chung CM et al. Thermodynamic stability of a kappaI immunoglobulin light chain: Relevance to multiple myeloma. Biophysical Journal. 2005;88: 4232-4242

[15] Schroeder HW, Cavacini L. Structure and function of immunoglobulins. The Journal of Allergy and Clinical Immunology. 2010; 125:S41-S52

[16] Immunobiology: The Immune System in Health and Disease. Garland Publ.; 2001. [animated CD-ROM inside] [u.a.]

[17] Minegishi Y, Hendershot LM, Conley ME. Novel mechanisms control the folding and assembly of lambda5/ 14.1 and VpreB to produce an intact surrogate light chain. Proceedings of the National Academy of Sciences of the United States of America. 1999;96: 3041-3046 
[18] Bork P, Holm L, Sander C. The immunoglobulin fold. Structural classification, sequence patterns and common core. Journal of Molecular Biology. 1994;242:309-320

[19] Prabakaran P et al. Structure of an isolated unglycosylated antibody $\mathrm{C}(\mathrm{H})_{2}$ domain. Acta Crystallographica.

Section D, Biological Crystallography. 2008;64:1062-1067

[20] Göritzer K, Maresch D, Altmann F, Obinger C, Strasser R. Exploring sitespecific N-glycosylation of HEK293 and plant-produced human IgA isotypes. Journal of Proteome Research. 2017;16: 2560-2570

[21] DeFranco AL, Robertson M, Locksley RM. Immunité: la réponse immunitaire dans les maladies infectieuses et inflammatoires. De Boeck; 2009

[22] Pakkanen SH et al. Expression of homing receptors on IgA1 and IgA2 plasmablasts in blood reflects differential distribution of IgA1 and IgA2 in various body fluids. Clinical and Vaccine Immunology. 2010;17:393-401

[23] Minegishi $\mathrm{Y}$ et al. Mutations in Igalpha (CD79a) result in a complete block in B-cell development. The Journal of Clinical Investigation. 1999; 104:1115-1121

[24] Chatenoud L, Bach J-F. Immunologie. Médecine Sciences Publications-Lavoisier; 2012

[25] Chatenoud L, Bach JF. Antigenic modulation-A major mechanism of antibody action. Immunology Today. 1984;5:20-25

[26] Goding JW. Cellular basis of the immune system. In: Monoclonal Antibodies. Elsevier; 1996. pp. 26-49. DOI: 10.1016/B978-012287023-1/ 50051-1
[27] Alt FW et al. Synthesis of secreted and membrane-bound immunoglobulin $\mathrm{mu}$ heavy chains is directed by mRNAs that differ at their $3^{\prime}$ ends. Cell. 1980;20: 293-301

[28] Iype J et al. Differences in selfrecognition between secreted antibody and membrane-bound B-cell antigen receptor. Journal of Immunology (Baltimore, Md). 2019;1950(202): 1417-1427

[29] Allende ML et al. S1P1 receptor directs the release of immature B-cells from bone marrow into blood. The Journal of Experimental Medicine. 2010; 207:1113-1124

[30] Allman D, Pillai S. Peripheral B-cell subsets. Current Opinion in Immunology. 2008;20:149-157

[31] Enders A et al. Zinc-finger protein ZFP318 is essential for expression of $\operatorname{IgD}$, the alternatively spliced Igh product made by mature $B$ lymphocytes. Proceedings of the National Academy of Sciences of the United States of America. 2014;111: 4513-4518

[32] Gamrekelashvili J et al. Regulation of monocyte cell fate by blood vessels mediated by notch signalling. Nature Communications. 2016;7:12597

[33] van Nierop K, de Groot C. Human follicular dendritic cells: Function, origin and development. Seminars in Immunology. 2002;14:251-257

[34] Vinuesa CG, Chang P-P. Innate $\mathrm{B}$-cell helpers reveal novel types of antibody responses. Nature Immunology. 2013;14:119-126

[35] Lentz VM, Manser T. Cutting edge: Germinal centers can be induced in the absence of T-cells. Journal of Immunology (Baltimore, Md). 2001; 1950(167):15-20 
[36] Mongini PK, Stein KE, Paul WE. Tcell regulation of IgG subclass antibody production in response to $\mathrm{T}$ independent antigens. The Journal of Experimental Medicine. 1981;153:1-12

[37] Smith KGC, Clatworthy MR. FcgammaRIIB in autoimmunity and infection: Evolutionary and therapeutic implications. Nature Reviews.

Immunology. 2010;10:328-343

[38] Jabs WJ, Paulsen M, Wagner HJ, Kirchner H, Klüter H. Analysis of Epstein-Barr virus (EBV) receptor CD21 on peripheral B lymphocytes of longterm EBV-adults. Clinical and Experimental Immunology. 1999;116: 468-473

[39] Silverman GJ, Khanna S. B-cell modulation in rheumatology. Current Opinion in Pharmacology. 2007;7: 426-433

[40] Hamouda L, Miliani M, Hadjidj Z, Messali R, Aribi M. Rituximab treatment modulates the release of hydrogen peroxide and the production of proinflammatory cytokines by monocyte at the onset of type 1 diabetes. Endocrine, Metabolic \& Immune Disorders Drug Targets. 2019;19: 643-655

[41] Rehnberg M, Amu S, Tarkowski A, Bokarewa MI, Brisslert M. Short- and long-term effects of anti-CD20 treatment on B-cell ontogeny in bone marrow of patients with rheumatoid arthritis. Arthritis Research \& Therapy. 2009;11:R123

[42] Pröbstel A-K, Hauser SL. Multiple sclerosis: B-cells take center stage.

Journal of Neuro-Ophthalmology. 2018; 38:251-258

[43] Tedder TF, Tuscano J, Sato S, Kehrl JH. CD22, a B lymphocyte-specific adhesion molecule that regulates antigen receptor signaling. Annual
Review of Immunology. 1997;15: 481-504

[44] Erickson LD, Tygrett LT, Bhatia SK, Grabstein KH, Waldschmidt TJ. Differential expression of CD22 (Lyb8) on murine B-cells. International Immunology. 1996;8:1121-1129

[45] Wen $\mathrm{T}$ et al. The pan-B cell marker CD22 is expressed on gastrointestinal eosinophils and negatively regulates tissue eosinophilia. Journal of Immunology (Baltimore, Md). 2012; 1950(188):1075-1082

[46] Benbijja M, Mellouk A, Bobé P. Sensitivity of leukemic T-cell lines to arsenic trioxide cytotoxicity is dependent on the induction of phosphatase B220/CD45R expression at the cell surface. Molecular Cancer. 2014; 13:251

[47] López-Granados E, Cambronero R, Ferreira A, Fontán G, GarcíaRodríguez MC. Three novel mutations reflect the variety of defects causing phenotypically diverse X-linked hyperIgM syndrome. Clinical and Experimental Immunology. 2003;133: 123-131

[48] Akatsu C et al. CD72 negatively regulates $B$ lymphocyte responses to the lupus-related endogenous toll-like receptor 7 ligand Sm/RNP. The Journal of Experimental Medicine. 2016;213: 2691-2706

[49] Tsubata T. CD72 is a negative regulator of $\mathrm{B}$-cell responses to nuclear lupus self-antigens and development of systemic lupus erythematosus. Immune Network. 2019;19:e1

[50] Van de Velde H, von Hoegen I, Luo W, Parnes JR, Thielemans K. The B-cell surface protein CD72/Lyb-2 is the ligand for CD5. Nature. 1991;351: 662-665 
[51] Biancone $L$ et al. Identification of a novel inducible cell-surface ligand of CD5 on activated lymphocytes. The Journal of Experimental Medicine. 1996; 184:811-819

[52] Noh G, Lee JH. Regulatory B-cells and allergic diseases. Allergy, Asthma \& Immunology Research. 2011;3:168-177

[53] Jackson SM, Wilson PC, James JA, Capra JD. Human B-cell subsets. Advances in Immunology. 2008;98: 151-224

[54] Yokota A et al. Two species of human Fc epsilon receptor II (Fc epsilon RII/CD23): Tissue-specific and IL-4specific regulation of gene expression. Cell. 1988;55:611-618

[55] Acharya M et al. CD23/FceRII: Molecular multi-tasking. Clinical and Experimental Immunology. 2010;162: 12-23

[56] Ahmed R et al. A public BCR present in a unique dual-receptorexpressing lymphocyte from type 1 diabetes patients encodes a potent T cell autoantigen. Cell. 2019;177: 1583-1599.e16

[57] Corcos D et al. Pre-B-cell development in the absence of lambda 5 in transgenic mice expressing a heavychain disease protein. Current Biology. 1995;5:1140-1148

[58] Woyach JA, Johnson AJ, Byrd JC. The B-cell receptor signaling pathway as a therapeutic target in CLL. Blood. 2012; 120:1175-1184

[59] Inabe K, Kurosaki T. Tyrosine phosphorylation of B-cell adaptor for phosphoinositide 3-kinase is required for Akt activation in response to CD19 engagement. Blood. 2002;99:584-589

[60] Okkenhaug K, Burger JA. PI3K signaling in normal B-cells and chronic lymphocytic leukemia (CLL). Current
Topics in Microbiology and Immunology. 2016;393:123-142

[61] Jimenez C, Hernandez C, Pimentel B, Carrera AC. The p85 regulatory subunit controls sequential activation of phosphoinositide 3-kinase by Tyr kinases and Ras. The Journal of Biological Chemistry. 2002;277: 41556-41562

[62] Morbach H et al. CD19 controls Toll-like receptor 9 responses in human B-cells. The Journal of Allergy and Clinical Immunology. 2016;137: 889-898.e6 


\title{
Immunogenetic Aspect of B-Cell Antigen Receptor Diversity Generation
}

\author{
Mourad Aribi
}

\begin{abstract}
The generation of antigen receptor diversity, and thus of the B-cell repertoire, is the result of very complex immunogenetic mechanisms. So, this chapter gives a brief overview on immunoglobulin (IG) gene organization and gene rearrangements, as well as the main mechanisms of immunoglobulin repertoire development.
\end{abstract}

Keywords: B-cell antigen receptor diversity, immunoglobulin gene organization, immunogenetic mechanisms

\section{Introduction}

The recognition specificity of different non-self-antigens or defective selfantigens (tumors) by a well-defined B-cell clone does not result from the presence of an extensive number of receptor genes, but rather from immunogenetic mechanisms affecting a limited number of IG genes, including mechanisms of genetic recombination, mutations, deletions or insertions, and gene repair, through very complex regulatory mechanisms that are responsible for a large B-cell repertoire.

This chapter focuses on the molecular description of the immunogenetic mechanisms responsible for the generation of B-cell antigen receptor diversity.

\section{IG gene organization and gene rearrangements}

\subsection{Gene segments and generation of functional IG genes}

In humans, the immunoglobulin heavy (IGH) locus is present at chromosome 14q32.33, and the IG light lambda (IGL) and kappa (IGK) loci are located at 22q11.2 and 2p11.2, respectively [1]. The immunoglobulin heavy chain variable region (IGH V) gene encodes VH framework regions 1-3 (FR1-3), VH complementarity determining region 1 (CDR1), and VH CDR2, while IGH joining (IGH J) gene encodes VH FR4. VH CDR3 is positioned at the IGH V-IGH D-IGH J junction [2]. The constant sequences of heavy $(\mathrm{H})$ chain are arranged in the following order: $\mu \rightarrow \delta \rightarrow \gamma 3 \rightarrow \gamma 1 \rightarrow \alpha 1 \rightarrow \gamma 2 \rightarrow \gamma 4 \rightarrow \varepsilon \rightarrow \alpha 2$ in humans (Figure 1), or $\mu \rightarrow \delta \rightarrow \gamma 3 \rightarrow$ $\gamma 1 \rightarrow \gamma 2 \mathrm{~b} \rightarrow \gamma 2 \mathrm{a} \rightarrow \varepsilon \rightarrow \alpha$ in mice. 
Similar to T-cell receptors (TCRs), functional genes of immunoglobulins (Igs) are the result of somatic recombination of DNA containing the relatively limited germinal genetic information, using the so-called $\mathrm{V}(\mathrm{D}) \mathrm{J}$ recombination process that occurs between individual genes (also referred to as gene segments) of the variable domains of the $\mathrm{H}$ and $\mathrm{L}$ chains (or $\alpha, \beta, \gamma$, and $\delta$ chains of TCRs). Each of these genes is present in multiple copies in most antigen receptor loci. The locus of IGH genes (like TCR $\beta$ and TCR $\delta$ loci) contains variable (V), diversity (D), and joining (J) genes, whereas the IGL and IGK loci (like TCR $\alpha$ and TCR $\gamma$ loci) contain only V and J genes [3]. So, individual V, D, and J genes at the IGH locus, and V and J genes at either the IGL or IGK loci rearrange somatically at the DNA level to generate V-D-J and V-J regions that, after transcription and translation, encode the variable domains of the antibody [4] (for review see [1]).

Key Point 1|Germline.

- Germline DNA is a constitutional DNA because it is related to the DNA of tissues derived from reproductive cells, i.e., egg or sperm that is derived from stem cells, and incorporated into the DNA of each cell of the body of the offspring. Therefore, the mutated parental germline DNA can be passed to the offspring.

- Germline DNA can be extracted from bone marrow or peripheral blood nuclear cells.

Key Point 2|Somatic DNA.

Somatic DNA is found in all cells of the body (tissues, skin, organs, and blood), except germ cells and embryonic cells, which are the source of gametes. Therefore, a mutation in the somatic DNA is not transmitted to the offspring, but it can lead to the genesis of diseases, especially tumors. So, somatic DNA can be extracted from both tumor (or matched normal) tissue and plasma.

\subsection{Diversity of B-cell receptors: primary/preimmune repertoire of Igs: V(D)J/ somatic recombination}

\subsubsection{Ordered rearrangement model}

The ordered model was described by Alt and Baltimore in 1984 [5]. It states that during the $\mathrm{V}(\mathrm{D}) \mathrm{J}$ recombination, rearrangements at the $\mathrm{H}$ chain locus occur before those of the L chains.

\subsubsection{Sequential recombination}

The sequential recombination refers to the order of the stages of rearrangements from $\mathrm{DH}$ to $\mathrm{JH}$ occurring before rearrangements from $\mathrm{VH}$ to $\mathrm{DJH}$ [5]. In contrast, the genes of the TCR $\delta$ locus, in the precursors of T-cells, can recombine in any order. In the case of the IGH locus in B-cell precursors (and TCR $\beta$ locus in T-cell precursors), one of the multiple $\mathrm{DH}$ segments (genes) recombines first with one of

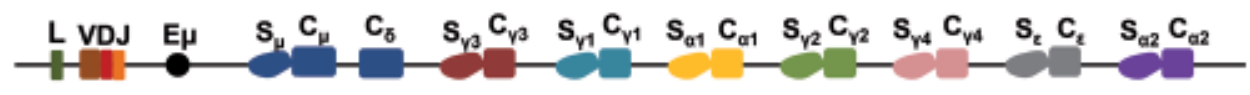

Figure 1.

The organization of the IGH chain C-region genes in humans. E $\mu$ : intronic enhancer, S: switch region, IGH: immunoglobulin heavy chain. 


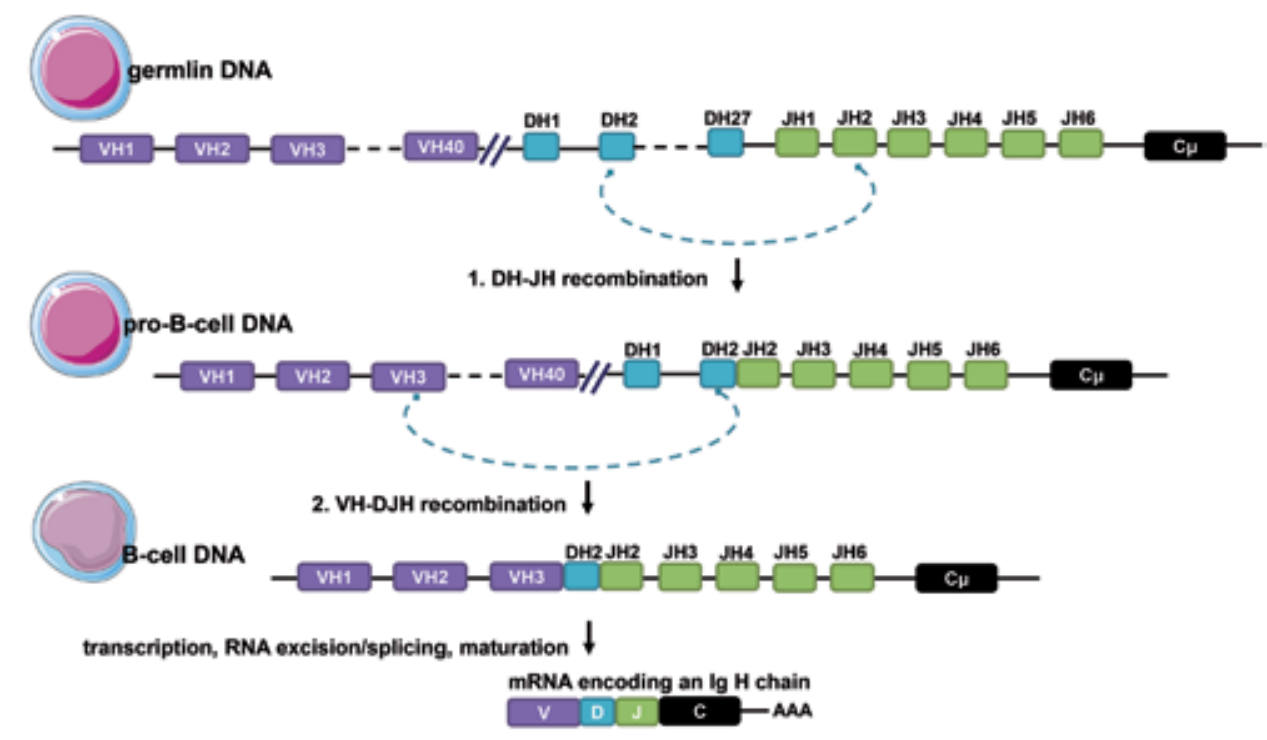

Figure 2.

Ordered rearrangement of gene segments (adapted from [3]). In the ordered rearrangement model, rearrangements of gene segments at the $H$ chain locus precede those at the $L$ chain locus. Sequential rearrangements lead first to the recombination of one of the DH segments with one of the JH segments, and then a VH segment is recombined with the DJH recombination. Although domain D is absent, the principle of IG light chain loci recombination is similar. Ig H chain: immunoglobulin heavy chain, VH: heavy chain variable genes, DH: heavy chain diversity genes, JH: heavy chain joining genes, $\mathrm{CH}$ : heavy chain constant genes

the multiple JH segments, by deletion of the DNA separating them. Then, one of the $\mathrm{VH}$ genes is recombined/juxtaposed with the rearranged $\mathrm{DJ}$ site, again by deletion of the intermediate DNA (Figure 2). After recombination, V, D, and J genes form a single exon [3].

\subsubsection{Combinatorial diversity, " $P$ ” junctional variability, " $N$ ” diversity, and diversity by genetic substitution}

Like the TCR, B-cell receptor (BCR) diversity results from (i) the choice of segments to recombine, (ii) the "P" junctional variability of the nucleotides at the V-D-J or V-J junction sites between gene segments during rearrangements, (iii) the "N" diversity by insertion or deletion of a nucleotide during recombination under the action of terminal deoxynucleotidyl transferase (TdT), but also from (iv) the recombination between $\mathrm{VH}$ genes by substitution of a or part of a second $\mathrm{VH}$ gene to an already recombined VH-D-JH segment. The diversity of the B-cell repertoire is also increased by the process of somatic hypermutation (SHM) of IG variable genes. The $\mathrm{V}(\mathrm{D}) \mathrm{J}$ recombination process generates a much greater diversity at the level of the $\mathrm{H}$ chain loci compared to those of the $\mathrm{L}$ chains, where simply a $\mathrm{V}$ region is joined to a J region. Thus, if the human IGH locus contained only about 40 functional VH segments, $27 \mathrm{DH}$ segments, and $6 \mathrm{JH}$ segments, $\mathrm{V}(\mathrm{D}) \mathrm{J}$ recombination would generate about $6480(40 \times 27 \times 6) \mathrm{H}$ chains, whereas, human IGK, which contains about $40 \mathrm{V \kappa}$ genes and $5 \mathrm{~J} \kappa$ genes, would give rise to approximately $200 \kappa$ chains, following $200(40 \times 5)$ different combinations. On the other hand, the variability of nucleotides/point mutations can occur at the junction sites, and bases can be lost (by deletion) or added (by insertion), giving additional diversity of the hypervariable CDR3 region of the $\mathrm{H}$ and $\mathrm{L}$ chains, which is coded by an additional sequence of DNA created by the junction of V, D, and J segments, for the $\mathrm{H}$ chain, and $\mathrm{V}$ and $\mathrm{J}$ segments, for the $\mathrm{L}$ chain; such a phenomenon is responsible for the junctional 
diversity. In total, molecular mechanisms of genetic recombination could result in a potential repertoire of at least $10^{7}$ antigen-specific recognition sites/receptors. Each clone of such a cell repertoire contains only a few cells that are capable of recognizing only one antigen; exceptionally, a T-cell clone can express two different receptors and can therefore recognize up to two antigens.

\subsubsection{Rearrangements to a nonfunctional allele}

Two-thirds of rearrangements produce a nonfunctional allele for at least three main reasons: (i) the reading frame of $\mathrm{V}$ and $\mathrm{C}$ regions is correctly aligned in only one-third of the cases, (ii) the codons contain three-nucleotide, and (iii) the number of nucleotides inserted or eliminated in the junctions is essentially random.

\subsubsection{Diversity of receptors in the case of loci with a single $V, D$, or J segment}

Some loci include only one $\mathrm{V}, \mathrm{D}$, or J gene segment. In these cases, all diversity is derived from junctional diversity or subsequent mechanisms of diversity, such as somatic mutation in IG loci, or from gene conversion in IG loci of some species.

\subsubsection{D and J segments-CDR3 loop/IgH chain}

$\mathrm{D}$ and $\mathrm{J}$ segments/genes encode amino acid sequences of the third loop of the immunoglobulin domain, which corresponds to the CDR3 region. If they had the same reading frame, recombination can give rise to an $\mathrm{IgH}$ chain.

\subsubsection{Transcription and generation of functional messenger $R N A$}

The transcription of the recombined IG gene gives rise to a functional messenger RNA, after elimination of introns, including any J segment/gene located between that which is joined to $\mathrm{D}$ and $\mathrm{C}$ segments. A similar process takes place in $\mathrm{L}$ chain loci.

\subsubsection{Molecular mechanisms of rearrangements: DNA double strand-breaks and repair}

\subsubsection{Enzymatic mechanisms of recombination: RAG and RSS}

Rearrangements require two major steps: double strand-breaks (DSB) and repair of these breaks.

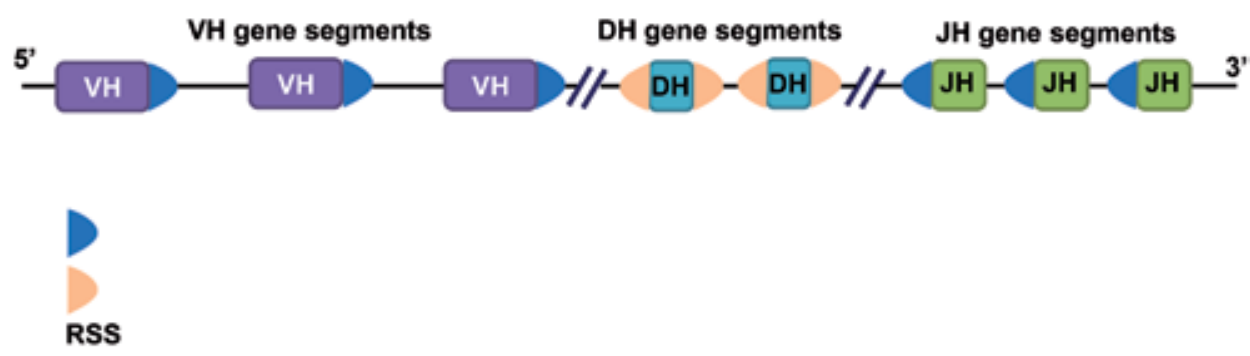

Figure 3.

Cleavage site of RAG proteins at the V,D, and J gene segments of the IGH locus: RSS positions. RAG: recombination-activating gene, RSS: recombination sequence signal, IGH: immunoglobulin heavy chain locus. 


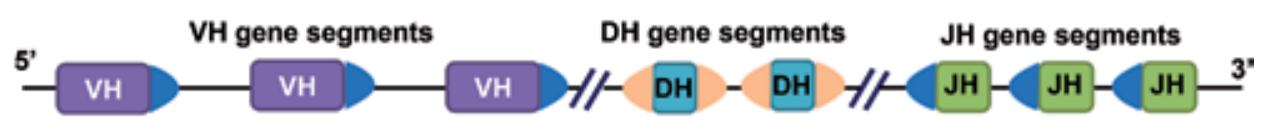

23-RSS

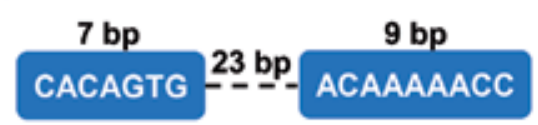

\section{2-RSS

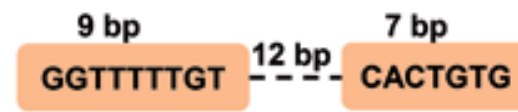

Figure 4.

RSS motifs. There are two types of RSS, one includes a 12-nucleotide spacer (12-RSS), and the other includes a 23-nucleotide spacer (23-RSS). Both 12-RSS and 23-RSS include a highly conserved palindromic heptamer and nonamer sequences. Bp: base pairs, RSS: recombination sequence signal.

Both recombination-activating gene 1 (RAG-1) and RAG-2 recombinase enzymes, expressed exclusively in developing lymphocytes, are required to generate DSBs [6] at the level of recombinant signal sequences (consensus RSS, recombination sequence signal), flanking all functional V, D, and J gene segments, on the side that will be joined, i.e., on the $3^{\prime}$ side of $\mathrm{V}$ segments, on both sides of $\mathrm{D}$ segments $\left(3^{\prime}, 5^{\prime}\right)$, and on the $5^{\prime}$ side of J segments [7] (Figure 3).

\subsubsection{Architecture of RAG-induced DSBs: the 12/23 rule}

The RSS motifs are composed of a conserved palindromic heptamer and conserved nonamer motifs, separated by an intervening variable-sequence spacer of fixed length corresponding to 12 or 23 nucleotides (the resulting signals are referred to as 12-RSS or 23-RSS, respectively). From the architectural point of view of the $\mathrm{H}$ chains, all the $\mathrm{V}$ segments are tracked by a 23-RSS (on the $3^{\prime}$ side), the D segments are "framed" (on the 5' and 3' sides) by 12-RSS, and the J segments are preceded by 23-RSS (on the $5^{\prime}$ side). Regarding the $\mathrm{L}$ chain genes, the $\mathrm{V}$ segments are tracked by 23 -RSS (on the $3^{\prime}$ side), and the J segments are preceded by $12-$ RSS (on the $5^{\prime}$ side) [8]. Only dissimilar RSS associations are efficiently recombined. Thus, each recombination that joins two gene segments occurs between 12-RSS and 23-RSS: this is known as the $12 / 23$ rule. In the $\mathrm{H}$ chain recombination, the fact that the $\mathrm{V}$ and J segments are naturally both flanked by 23 nucleotide spacers (23-RSS), a connection between these two segments is not possible directly, but is done indirectly if they recombine with D elements, which are flanked on both sides by 12-RSS. After 12-RSS recombination with 23-RSS, the intermediate DNA will either be deleted or inverted depending on the orientation of the two signals (Figure 4). RAG-induced DSBs are then resolved by nonhomologous end joining (NHEJ) pathway.

\subsubsection{RAG action and NHEJ repair}

The assembly between the $\mathrm{V}, \mathrm{D}$, and $\mathrm{J}$ segments is done according to the sequential model as reported above. The $\mathrm{V}(\mathrm{D}) \mathrm{J}$ recombination mechanisms can be 
generated experimentally in vitro by mixing DNA (as an enzyme substrate) with the endonuclease RAG-1 and RAG-2 proteins.

The kinetics of main rearrangement events are described according to the following steps (Figure 5):

a. Formation of a synapse. RAG forms synaptic complexes, only with one 12-RSS and one 23-RSS, according to a 12/23 dogma that governs the recombination fidelity, and then the rearrangements are started [9].

b. RAG and RSS binding. A key role is attributed to RAG-1 in DNA binding and catalysis, as well as in interactions with RAG-2, high-mobility group box 1 and 2 (HMG1/2), and itself, given its structure that contains a nonamer binding domain (NBD) required for stable recruitment of RAG proteins into RSS [10]. So, RAG-1 recruit RAG-2 after binding of an RSS and then RAG-2 maintains the RAG-1-RSS complex and binds to a second RSS.

c. DSB generation. The two RAG-RSS complex will generate DSB at the level of the two RSS (between a gene segment and an RSS), by first a DNA strand cleavage, between the $5^{\prime}$ end of the RSS heptamer and the region encoding the antigen receptor and then the other DNA strand, after reaction of the free $3^{\prime}$-hydroxyl (3'-OH) group with a phosphodiester bond of this strand.

d.Formation of hairpin structures. Nucleotides of the cleaved-end coding sequences are covalently bound, thereby forming hairpin structures, and will be maintained within synaptic complexes.

e. Hairpin opening-DNA synthesis and planning of extremities. The hairpin ends are opened and rendered straight by DNA synthesis or nucleolytic cleavage planning using a nuclease, which would appear to be "Artemis." The hairpin cleavage reaction can be done in two points: it can either be cleaved in the middle or a few nucleotides on one side of the center, producing offset cuts.

f. Formation of $N$ regions. During IGH V-IGH D and IGH D-IGH J joining [2], $\mathrm{TdT}$, an important enzyme required for the junctional diversity generation, can intervene, before the juxtaposition of the two coding regions, to generate a higher level of diversity (see above), by catalyzing the elimination of nucleotides and/or the addition of nontemplated nucleotides to the $3^{\prime}$ ends, which will produce the so-called $\mathrm{N}$ regions (nongermline/nontemplated nucleotide) [11]. So N1 and N2 regions are created between the V and D genes and between the $\mathrm{D}$ and $\mathrm{JH}$ genes, respectively.

g.Deletion/insertion of P nucleotides. Deletions or insertions of short complementary palindromic sequences, so-called $P$ nucleotides, are generated through endonuclease activity and repair around the asymmetric opening of hairpin loops that form at the ends of the gene segments to be joined as part of the rearrangement process and produce short, self-complementary single stranded extensions that can be incorporated into junctions, or may alternatively be removed via exonuclease activity [12] (for review, see [13]).

h.NHEJ ligation. The nonhomologous DNA ends of the two coding regions are repaired/ligated using an NHEJ repair system, generating, on the one hand, coding joints, in which the gene segments are joined [14, 15], and, on the other hand, RSS-containing signal joints, resulting from the direct joining of the DSB 


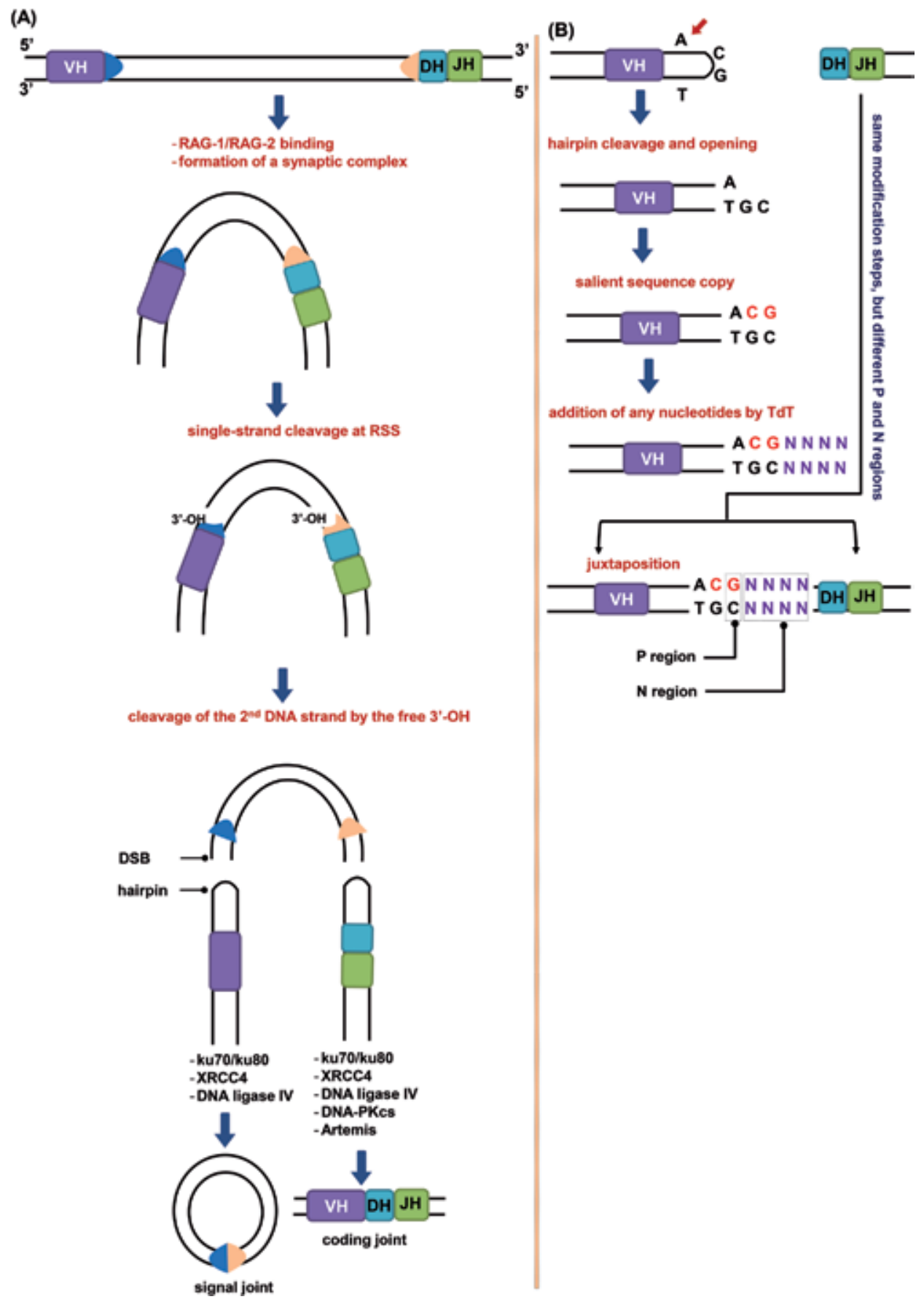

Figure 5.

Molecular mechanisms of $V(D) J$ recombination and junctional diversity generation (adapted from [3]). (A) Main steps of $V(D) J$ recombination. $(B)$ Edge modification of coding regions and junctional diversity. DNA-PKcs: DNAdependent serine/threonine protein kinase complex, DSB: double strand-breaks, $N$ : nongermline/nontemplated nucleotide, P: short complementary palindromic sequences, XRCC4: X-ray cross-complementing gene 4.

bordering the RSS heptamer. When the two gene segments that are joined have the same orientation, which is observed in most cases, the signal joint is excised on a circular DNA segment and generates a circular episome (an extrachromosomal circular DNA) located between the two coding regions, which later disappears from the cell [16-18]. 
The junction system comprises a number of ubiquitous repair proteins (present in both B-cells and T-cells), which would allow rearrangement of IG genes in B-cell precursors, but rarely in T-cell precursors, and TCR gene rearrangements in T-cell precursors, but rarely in B-cell precursors. It includes in particular the catalytic subunit of a nuclear DNA-dependent serine/threonine protein kinase complex (DNA-PKcs), a member of the phosphatidylinositol 3-kinase-related (PIKK) family of protein kinases, composed of a heterodimer of Ku proteins that bind free DNA ends given their strong affinity (Ku70/Ku80 [encoded, respectively, by X-ray cross-complementing gene 5 (XRCC5) and XRCC6 genes in humans, and also called Ku86]) [19], XRCC4, DNA ligase IV and Artemis [3]. TdT is also recruited into the junction system and is involved in the formation of the coding joints, alongside Artemis and DNA-PKcs. Nevertheless, TdT is only rarely recruited into rearrangements that occur during fetal life, so that junctional diversity is limited.

\subsubsection{Molecular mechanisms of regulation of $V(D) J$ rearrangement}

\subsubsection{Transcription-sequential/ordered model-of germinal loci and accessibility by $R A G-1$ and $R A G-2$ proteins}

It should be clearly noted that the $\mathrm{VH}$ segments are not silent before the V-DJH recombination steps or before their physical juxtaposition with the $\mathrm{E} \mu$ enhancer. It has therefore been shown that they undergo active noncoding germline transcription in B-cell precursors. In addition, many other noncoding transcripts appear as rearrangements occur, in order to allow the opening of chromatin, and thus, the targeting and accessibility by RAG-1/RAG-2 complex, as well as the establishment of the three-dimensional structure of the locus considered. From a kinetic point of view, the first noncoding DH transcripts, also referred to as sterile transcripts (to differentiate them from the coding transcripts, which are initiated at the rearranged VDJ segments), are detected before the D-JH rearrangements and are initiated at JH-proximal DH gene (DQ52), which has both promoter and enhancer activities preferentially active in B-cell precursors [20], generating $\mu 0$ transcripts, and at downstream of intronic IGH enhancer $\mathrm{E} \mu$, generating I $\mu$ transcripts. Both $\mu 0$ and transcripts $I \mu$ are getting spliced and polyadenylated [21]. Once the DJH rearrangement is carried out, new noncoding germinal transcripts appear in $\mathrm{VH}$ regions (for review, see [21]).

\subsubsection{Regulation of transcription and epigenetic modifications}

Epigenetic modifications are necessary for the positive or negative regulation of the activities of different loci. Indeed, besides the presence of sites sensitive to DNase activity, other conditions, controlled by the activating elements and the promoters of the loci concerned, are necessary to initiate gene rearrangements and are correlated with the opening of chromatin to transcription, such as histone acetylation, DNA demethylation, and transcription itself.

- Acetylation of histones. It occurs prior to $\mathrm{V}(\mathrm{D}) \mathrm{J}$ recombination. It is associated with the $\mathrm{VH}$ region after IL-7 stimulation and DJ rearrangement before $\mathrm{VH}$ appendage to DJH and is accompanied by increased nuclease sensitivity and reorganization of nucleosome structure [22] (for review, see [23]).

- DNA methylation/demethylation near RSS. DNA methylation/demethylation is involved in regulating $\mathrm{V}(\mathrm{D}) \mathrm{J}$ rearrangement. DNA methylation around the RSS inhibits V(D)J cleavage activity of the RAG-1/RAG-2 complex (depending 
on the position of the $\mathrm{mCpG}$ around the RSS) and induces an inaccessible chromatin configuration. Conversely, $\mathrm{CpG}$ demethylation in the heptamer of broken signal ends derived from the 3' D $\beta 1$ RSS has been shown to allow V(D)J cleavage in mouse [24].

\subsubsection{Establishment of loops-Rosette locus-and contacting segments to recombine}

The establishment of loops is necessary to bring into contact the different segments to recombine giving rise to an image of the so-called rosette locus, which represents one of the prerequisites for $\mathrm{V}(\mathrm{D}) \mathrm{J}$ rearrangements [25]. These loops take place through a number of factors, including transcriptional repressor CCCTCbinding factor (CTCF, also known as 11-zinc finger protein), Yin Yang 1 (YY1), a ubiquitously distributed transcriptional repressor/activator factor of a number of promoters, belonging to the GLI-Kruppel class of zinc finger proteins, and paired box 5 (Pax5), which is important regulators in early development, but not late stages of B-cell differentiation. Such different factors and particularly CTCF, by binding to cohesins, regulate the IG loci reorganization and contraction. This contraction/reorganization allows the juxtaposition of different gene segments (in particular the distal V genes) and thus facilitates rearrangements.

\subsubsection{Regulation of loci position at the nucleus}

The locus nuclear positioning is decisive for the rearrangement. Hence, the IGH locus, anchored via the distal VH genes at the nuclear periphery, migrates, in its extended chromatin state, to the center of the nucleus, which facilitates access of the $\mathrm{V}(\mathrm{D}) \mathrm{J}$ recombinase to proximal IGH domain and thus VH-DJH rearrangements.

\section{Allelic exclusion}

The allelic exclusion of IG of $\mathrm{H}$ and $\mathrm{L}$ chain genes allows the production of antibodies from a single chromosome located on 14q32.3 for the $\mathrm{H}$ chain [26], and one of the two chromosomes located on 2p12 or 22q11.2 for the L chain [27, 28] (respectively, the $\mathrm{L} \kappa$ and $\mathrm{L} \lambda$ chains). This phenomenon constitutes genetic basis of monospecificity of B-cells-a central paradigm in explaining the pathogen-specific production of antibodies (Burnet's clonal selection theory of the adaptive immune system), i.e., each clone of B-cells generates a unique specificity for the appropriate antigen, which is established during the rearrangement of $V(D) J$ gene segments of the variable regions.

During the differentiation of the B-cell, only one fraction of the IG genes, resulting from a first somatic $\mathrm{V}(\mathrm{D}) \mathrm{J}$ recombination on one of the two random chromosomes 14, is functional, i.e., it contains a productive exon $\mathrm{V}(\mathrm{D}) \mathrm{J}$. By cons, if the rearrangement is abortive (nonproductive), a new recombination is attempted on the other chromosome. The success toward a productive rearrangement of the $\mathrm{H}$ chain leads to a temptation to rearrange with the chromosomes encoding the $\mathrm{L}$ chains. The absence of rearrangements leads to the sterility of B-cell.

The mechanism of allelic exclusion uses pre-BCR-mediated signals. The pre$\mathrm{BCR}$ consists of the $\mathrm{H}$ chain resulting from the productive rearrangement of an allele encoding the $\mu \mathrm{H}$ chain associated with a pseudo-L chain (surrogate $\mathrm{L}$ chain). This chain comprises a $\mathrm{V}$ polypeptide (called $\mathrm{V}$ pre-B) and a type $\mathrm{C}$ polypeptide (called $\lambda 5$ in mice and $\lambda$-like in humans) that associate noncovalently. The signals 
mediated by this pre-BCR block the accessibility of the RAG recombinases on the second allele of the nonrecombinant $\mu \mathrm{H}$ chain and redirect them toward the $\mathrm{L} \kappa$ chain locus to initiate the first recombinations. The formation of a complete BCR combining $\mathrm{H}$ and $\mathrm{L}$ chain blocks recombinations on other $\mathrm{L}$ chain alleles.

Importantly, it has been shown, using genetically engineered mice that carry two functional IGH alleles that are completely recombined and different, that the expression of IG loci does not appear to be monoallelic and that B-cells could have the ability to express $\mathrm{H}$ chains by both alleles [29] (for review, see [30]).

\section{Isotypic exclusion}

A single B-cell never expresses both a $\kappa$ string and a $\lambda$ string. The first recombination attempt for the $\mathrm{L}$ chains takes place at one of the two $\kappa$ genes. In case of failure, the $\kappa$ gene of the other chromosome 2 or the $\lambda$ genes is used.

\section{Mature B-cell activation: immunoglobulin class/isotype switching and somatic hypermutation}

\subsection{Isotype switching: a process affecting the constant region of the immunoglobulin $\mathrm{H}$ chain}

The B-cell that initially produced the IgM isotype will subsequently produce other immunoglobulin isotypes (IgG, $\operatorname{IgE}$, and $\operatorname{IgA}$ ), thanks to a process termed $\operatorname{Ig}$ $\mathrm{H}$ chain class switching, isotype switching, or class switch recombination (CSR).

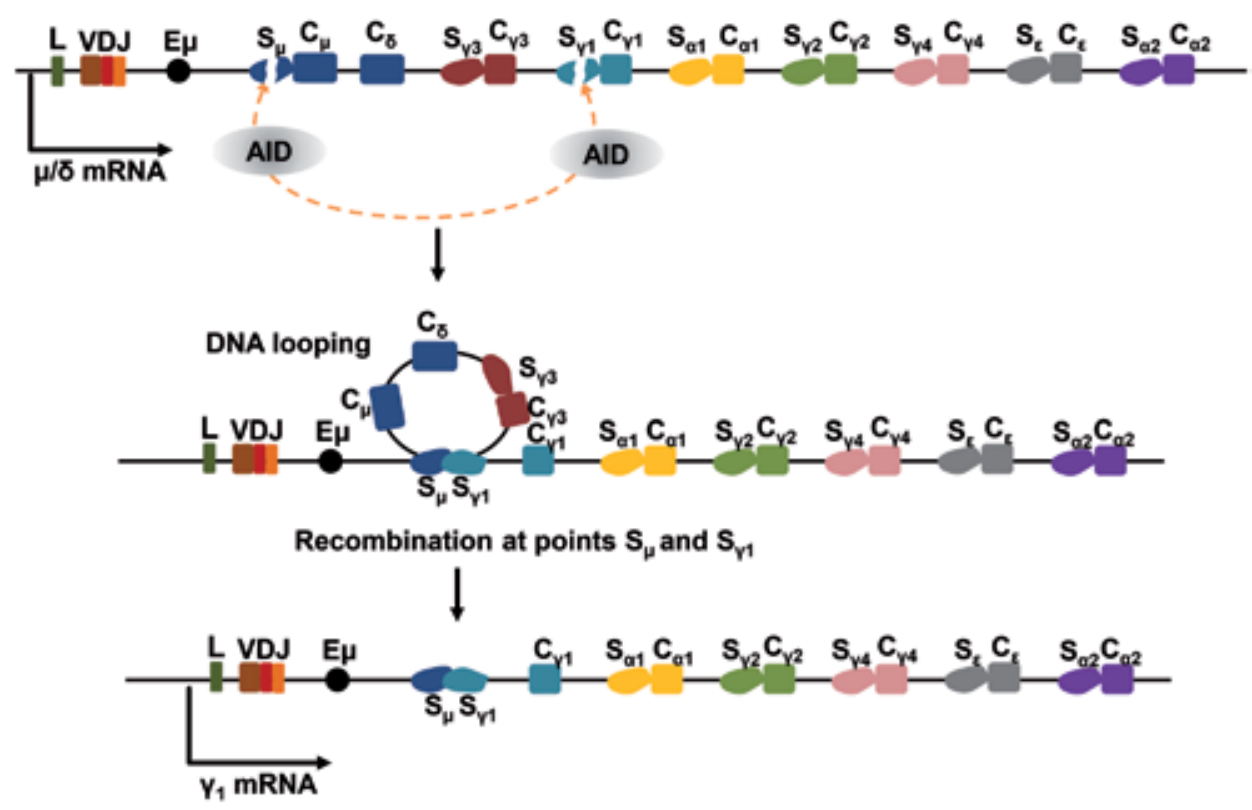

Figure 6.

CSR process. Here is an example of switching to the IgG1 isotype. First, AID induces DSB formation after deamination of $S_{\mu}$ and $S_{\gamma 1}$ regions. Subsequently, these two regions recombine by an intrachromosomal deletional recombination, and the expressed VDJ segment associates with the $C_{r 1}$ gene. AID: activation-induced cytidine deaminase, CSR: class switch recombination (also called immunoglobulin heavy chain class switching/

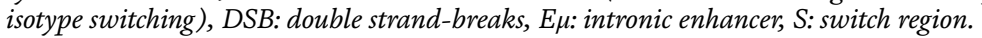


Such a phenomenon occurs after activation of a mature B-cell by an appropriate antigen, thereby generating different antibody isotypes that have the same variable domains as the original antibody generated in the immature B-cell during $\mathrm{V}(\mathrm{D}) \mathrm{J}$ rearrangement, but having distinct constant domains in their $\mathrm{H}$ chains.

CSR is instigated following conversion of deoxycytidines in $S$ regions-a $G$ rich with high density of WGCW (A/T-G-C-A/T) motifs-to deoxyuracil by activationinduced cytidine deaminase (AID) in the IG loci, which is also required for SHM. The presence of deoxyuracil promotes DNA mutagenesis though a subset of DNA repair proteins. Deoxyuracil residues are subsequently removed from DNA by enzymes of the base excision repair (BER) and mismatch repair (MMR) complex $\mathrm{MSH} 2 / 6$ pathways, leading to mutations, single-strand DNA breaks (SSBs), and the DSBs required for CSR. Recall that, in humans, nine functional $\mathrm{CH}$ genes are located downstream of the $V, D$, and J gene segments of antigen receptor loci. The $V(D) J$ segment, initially rearranged in the bone marrow, can be juxtaposed, during B-cell activation, to one of these functional genes coding for another constant domain, depending on antigen and the cytokine milieu, and occurs between DSBs introduced into the donor $\mu \mathrm{S}(\mathrm{S} \mu)$ region and a downstream/acceptor $\mathrm{S}$ region located from $\sim 65$ to $160 \mathrm{~kb}$ downstream, which can subsequently recombine with an $\mathrm{S}$ region farther downstream (for review, see [31-33]). Finally, Igs resulting from the CSR process have the same specificity for the antigen responsible for the B-cell activation. They have also the same $\mathrm{L}$ chains as well as the same variable fragments of the $\mathrm{H}$ chains (Figure 6).

\subsection{Somatic hypermutation: mutations take place on the variable segments of $L$ and $H$ chains}

\subsubsection{Brief anatomo-histological overview of B-cells}

\subsubsection{Primary follicles and interplay between B-cells and FDCs}

Many resting B-cells, agglutinated around follicular dendritic cells (FDCs), harbor primary follicles. Thus, in the adult spleen, about $80 \%$ of B-cells are follicular B-cells.

A major role is attributed to FDCs, as prominent stromal cell constituents of B-cell follicles. These cells do not express major histocompatibility complex class II (MHC II) molecules nor do they have the capacity to phagocytose and process exogenous antigens for MHC I-restricted presentation [34]. Experiments using cryoimmunogold electron microscopy have demonstrated that the presence of MHC II molecules on their surface is passive and originate from microvesicles/ exosomes they are attached to [35]. Additionally, their ontogeny remains controversial. They are not derived from the bone marrow hematopoietic stem cell, but they could originate from local mesenchymal precursors in lymphoid organs [36]. Moreover, FDCs promote the survival and continuous recirculation of naive B-cells and allow for the attraction of activated B-cells, as well as the selective process for affinity maturation within the GC of lymphoid follicles during humoral adaptive/antibody-mediated immune response, allowing activated B-cells to significantly improve the affinity of their BCR. Thus, they have the ability to retain on their $\mathrm{Fc}$ receptor $(\mathrm{FcR})$ antigens in native form combined with antibodies (immune complexes [ICs]), for long periods of time, ranging from months to years, thus making them accessible to the centrocytes (CC) that enter light zone (LZ) and result from the proliferation of blasts in the dark zone (DZ; this zone has been designed because it contains a high cell density) (Figure 7). 


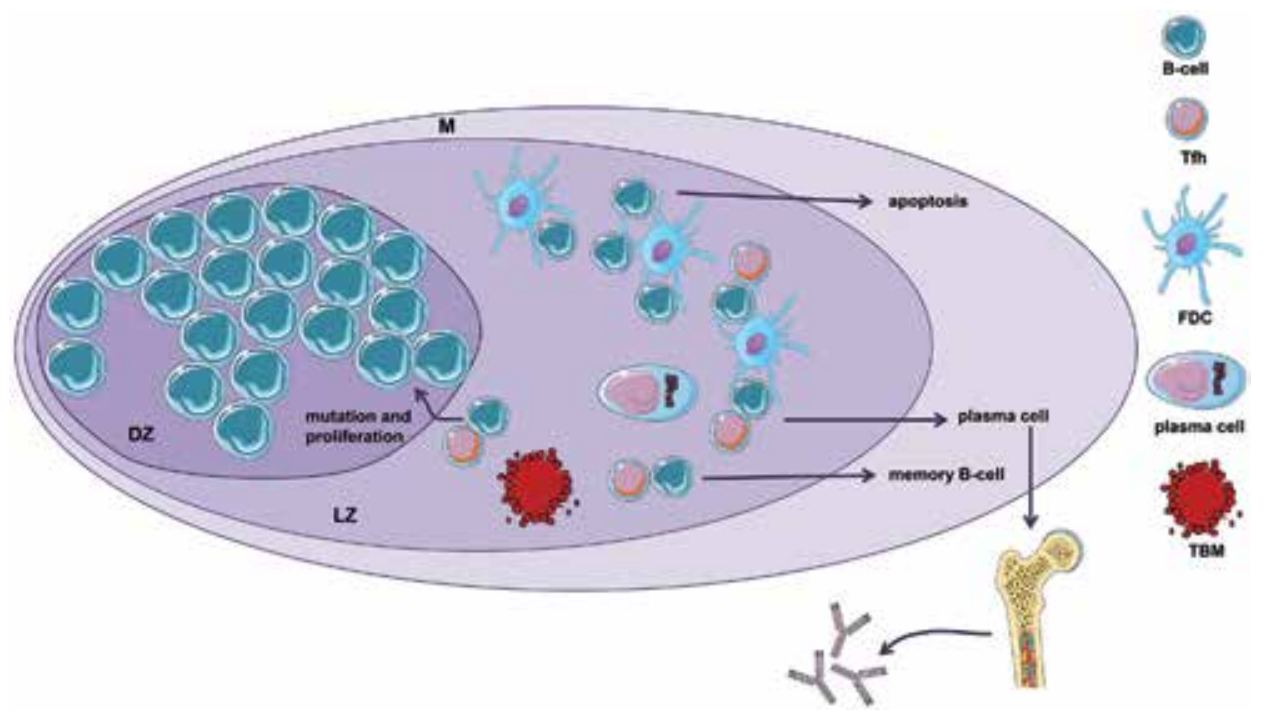

Figure 7 .

Schematic representation of the organization of the germinal center. The dark zone is occupied mainly by proliferating centroblasts. These are cells in which SHM would take place. After proliferation, B-cells, now called centrocytes, are in the adjacent LZ, which also contains Tfh cells and FDCs. Centrocytes that poorly link the antigen will die by apoptosis. Those that can bind the antigen and receive survival signals from the BCR and Tfh cells can either return to the dark zone for another cycle of proliferation, mutation, and selection or become memory B-cells or plasma cells that migrate to bone marrow to ensure prolonged antibody secretion [3]. BCR: B-cell antigen receptor complex, DZ: dark zone, FDC: follicular dendritic cell, LZ: light zone, M: mantle zone, SHM: somatic hypermutation, TBM: tingible body macrophages, Tfh: $\mathrm{CD}_{4}^{+}$T follicular helper cell.

\subsubsection{Immune response, $B$-cell fates, and GC formation}

Most protein antigens induce T-dependent (TD) antigen humoral immune responses (responses to T-independent [TI] antigen are not evoked in this chapter). Such responses require cooperation between the antigen-specific $\mathrm{B}$-cell and the $\mathrm{T}$-cell carrying a specific TCR of the same antigen. Nevertheless, the two cell types have different localizations within ganglion, and the probability for a B-cell to meet a T-cell with the same antigen specificity is extremely low and is about $1 / 10^{8}$ to $1 / 10^{12}$, knowing that the proportion of naive B-cell and T-cell that are specific for a given antigen is about $1 / 10^{4}$ to $1 / 10^{6}$ [37].

The search for the antigen by the appropriate B-cells is done through an immutable path. The blood enables the naive B-cells, i.e., the mature peripheral B-cells (known as follicular B-cells), to be transported to the lymph nodes where they enter through the high endothelial venules (HEV), migrate across the T-cell area, and spend about 24 hours in the follicles before exiting through the efferent lymph and returning to the circulation [38] (for review, see [39]).

When B-cells expressing antigen-specific BCR encounter the appropriate antigen (acquired from FDCs) in secondary lymphoid organs (SLOs), within lymph nodes for the antigen that is carried into them from the tissues, or within spleen for the antigen that reach it from the bloodstream, they increase the expression of the C-C chemokine receptor type 7 (CCR7) on their surface and migrate to the $\mathrm{T} / \mathrm{B}$ border [38] (comment in [40]) in the spleen and in the interfollicular region in lymph nodes, after both T-cells and B-cells have been primed with antigen. The activated B-cells follow one of the following two fates to trigger a TD humoral immune response to protein antigen (for review, see [41-44]):

a. either they migrate to extrafollicular foci (EF) of SLOs, in the medullary cords of lymph nodes or in foci in the red pulp of the spleen [45], and 
differentiate rapidly, as plasmablasts, in short-lived antibody-secreting plasma cells (CLPCs) [ 41], synthesizing IgM and IgG, which makes it possible to have rapidly circulating antigen-specific antibodies. Of note, the development of EFs in TD immune responses requires the help of CD4 ${ }^{+} \mathrm{T}$-cells that share characteristics of $\mathrm{CD}^{+} \mathrm{T}$ follicular helper (Tfh) cells;

b.or they migrate to a primary lymphoid follicle (B-cell follicle) of the lymph nodes or spleen, where they undergo clonal expansion-a strong oligoclonal proliferation-to form, after a few days, the GCs, then undergo somatic mutation to generate high-affinity memory B-cells and long-lived plasma cells (LLPCs). GC formation requires about 7 days during a primary immune response and about $36 \mathrm{~h}$ during a secondary response, which occurs following immunization and activation of memory B-cell with the same $\mathrm{TD}$ antigen. The activated $\mathrm{B}$-cells receive signals from the $\mathrm{CD} 4^{+} \mathrm{Tfh}$ cells, proliferate, and undergo CSR. GCs persist until a few weeks. Of note, similar to naïve B-cells, memory B-cells can also be recruited into $\mathrm{EF}$ and give rise to immune responses that are associated with CSR but, at the most, only low-level SHM [45].

\subsubsection{Immune responses to protein antigens and B-cell cooperation with $C D 4^{+}$ Tfh cells}

Only CCs that express a high affinity receptor for epitopes of the antigen presented in its native form by the FDCs and that can capture it are selected efficiently. These selected CCs process the antigen and present antigen-derived peptides bound to MHC II molecules to antigen-specific $\mathrm{CD}^{+}{ }^{+} \mathrm{Tfh}$ cells, which have been shown to develop immediately from naive $\mathrm{CD} 4{ }^{+} \mathrm{T}$-cells during antigen priming by dendritic cells in T-cell zones [46] (comment in [47]). The Tfh cells then give survival and differentiation signals to B-cells, which can then undergo CSR and mature either in LLPCs or in memory B-cells.

\subsubsection{Blast cell differentiation}

- GCs. The GCs consist essentially of blast cells that divide every $6 \mathrm{~h}$, reaching a number of 60,000 blasts after about $60 \mathrm{~h}$, thus considerably increasing the number of antigen-specific B-cells. They are polarized into two cellular areas:

i. Centroblasts $(D Z)$, which no longer produce surface Igs because their genes undergo SHM.

ii. $C C(L Z)$, which correspond to smaller B-cells, expressing their new surface Ig, no longer proliferating, and are entangled in a large network of FDCs.

- CCs. The few CCs selected after contact with the antigen retained by the FDCs, allowing their affinity maturation, migrate to the apical part of the $\mathrm{LZ}$, then undergo the CSR, and differentiate, as mentioned above, into memory B-cells or in LLPCs, through their cooperation with Tfh cells, which are present specifically within the LZ. DCs can also be selected for apoptosis elimination, if centroblast stage mutations that occur during the SHM process do not modify or even decrease the affinity of their BCR (see below Mechanisms of SHM process and Impacts of mutations on affinity of BCR and secreted Ig). 
- Lymphoid follicles fate. The persistence of lymphoid follicles depends on antigenic stimulation. So they begin to reduce their size from the beginning of the 2 nd week and disappear completely at the 3rd week in the absence of any further stimulation.

- Nonspecific B-cells. Small B cells that are not specific for the antigen are repelled from the primary follicles, as the blast cells divide, and thus form the perifollicular corona.

- Memory B-cells. Memory B-cells have the ability to respond rapidly to antigens that give rise to a primary response and to present it quickly and efficiently to T-cells during a secondary response, and also differentiate into plasma cells. Although they are a minority group of long-lived cells, they are able to persist in the quiescent state from several months to several decades in humans. They are usually $\operatorname{IgD}(-)$ and may have preferential localizations such as mucous membranes for cells that have switched to produce IgA.

\subsubsection{SHM: features and molecular mechanisms}

Following antigenic stimulation, B-cell IG genes undergo SHM and CSR within GCs.

\subsubsection{Genes concerned by SHM}

The process of somatic hypermutation-a process targeting the $\mathrm{V}$ genes of the $\mathrm{H}$ and $\mathrm{L}$ chains-is the basis for the antibody affinity maturation. It is induced during humoral responses of conventional B-follicular cells in response to TD antigen. In contrast to the somatic-V(D)J-recombination that takes place in the bone marrow, the SHM process takes place in the SLOs, in the DZ of the GCs, at a stage where the $\mathrm{B}$-cell is called centroblast.

\subsubsection{Roles and objectives of SHM}

Since the specificity and affinity of the BCR/mIg of the B-cell that left the bone marrow, and subsequently the circulating antibody produced, are determined before the encounter with the antigen (antigenic epitope), the phenomenon of SHM occurs in the activated B-cell clone through mutations in the sequence of genes derived from $\mathrm{V}(\mathrm{D}) \mathrm{J}$ somatic recombination, in order to adjust the hypervariable regions to the epitope and thus to modulate/increase the antibody affinity and the effective and adapted recognition of the antigen triggering the humoral immune response. As mentioned above, such a phenomenon participates in the generation of Igs diversity.

\subsubsection{Mechanisms of SHM process}

\subsection{SHM features}

SHM introduces mutations that replace one or more amino acids in the Ig, producing closely related B-cell clones that differ subtly in terms of antigenic specificity and affinity [48]. Despite recent advances, the molecular mechanisms responsible for them remain little known. Nevertheless, the results of in vitro or in 
vivo studies on mouse models expressing an IG transgene have made it possible to define certain characteristics of this process:

a. It corresponds to an adaptive mutagenesis initiated by the action of the enzyme AID, which is expressed solely by the B-cells of the CG [48].

b.It occurs during an extremely brief stage of differentiation of B-cells at the GCs.

c. It occurs in the peripheral lymphoid organs in the DZ GC B-cells.

d.Numerous point mutations are introduced in the hypervariable regions of the $\mathrm{BCR}$ or $\mathrm{Ig} \mathrm{H}$ and $\mathrm{L}$ chain $\mathrm{V}$ gene following the activation of antigen-specific B-cell clones.

e. The mutations extend over about $1 \mathrm{~kb}$.

f. Purine-purine or pyrimidine-pyrimidine mutations are mainly observed; A and $\mathrm{G}$ are more often mutated than $\mathrm{T}$ and $\mathrm{C}$.

g. Random mutations can enhance the affinity of the antibodies.

h.It relates to TD antigen immune responses.

i. The mutations essentially concern the variable gene and the adjacent $3^{\prime}$ region of the rearranged $\mathrm{V}(\mathrm{D}) \mathrm{J}$ segment.

j. The mutation domain extends in $3^{\prime}$ from the promoter to the intronic J-C region.

k.It also affects the DNA flanking the rearranged $\mathrm{V}$ gene, but does not generally extend to $\mathrm{C}$ region exons.

1. Mutations are mostly nucleotide substitutions, but insertions and deletions are possible.

m. SHMs only occur during the secondary response, but not during the primary responses.

$\mathrm{n}$. The cis sequences of IG locus are indispensable for triggering or regulating the hypermutation process.

o. There is an important involvement of the IG promoter and enhancer sequences of the IG locus, suggesting a link between transcription and SHM [49].

\subsection{AID, adaptive mutagenesis, and erroneous repair of uracil bases}

- Cytosine deamination. AID initiates the SHM process within target sequences by cytosine deamination in the rearranged variable regions and focuses on 3-4 bp SHM motifs that are greatly enriched in S regions and in portions of variable region exons that encode antigen-binding sites (CDR region). SHM of V(D)J exons in GC B-cells require transcription for AID targeting, as during CSR, and begins $\sim 150$ bp downstream of the transcription start site (TSS) and extend 
1-2 kb further downstream [50] (for review, see [51-54]). Hypermutable DNA sequences are found in the regions of IG genes, preferentially in sequences containing mutational "hotspots" corresponding predominantly to RGYW/WRCYmotifs (G: $C$ is a mutable position, $\mathbf{R}=$ purine bases [A/G], $\mathbf{G}=$ guanine, $\mathbf{Y}=$ pyrimidine bases $[\mathrm{C} / \mathrm{T}], \mathbf{W}=\mathrm{A} / \mathrm{T}, \mathbf{C}=$ cytosine) [55].

- Mutagenic repair of $U: G$ mismatches. Uracil (U) generated from cytosine deamination creates $U: G$ lesions/mismatches that will be repaired erroneously by introducing point mutations or, more rarely, insertions and deletions in $\mathrm{V}$ regions at one of $1000 \mathrm{bp}$ per generation. Two possibilities of repair are possible:

a.If the $\mathrm{U}$ is targeted by the enzyme uracil-DNA N-glycosylase (UNG), which is usually followed by components of the base-excision repair (BER) pathway (an essential DNA repair pathway), it will be excised, and an abasic site appears in DNA following the action of apurinic/apyrimidinic endonuclease (APE), an enzyme that identifies damaged apurinic/apyrimidinic sites in DNA, cuts the phosphodiester bond in the backbone of the sites, and has critical roles in the base excision pathway. This site will, in turn, be mutagenically replicated by translesion DNA synthesis (TLS) polymerases, leading to a very high error rates.

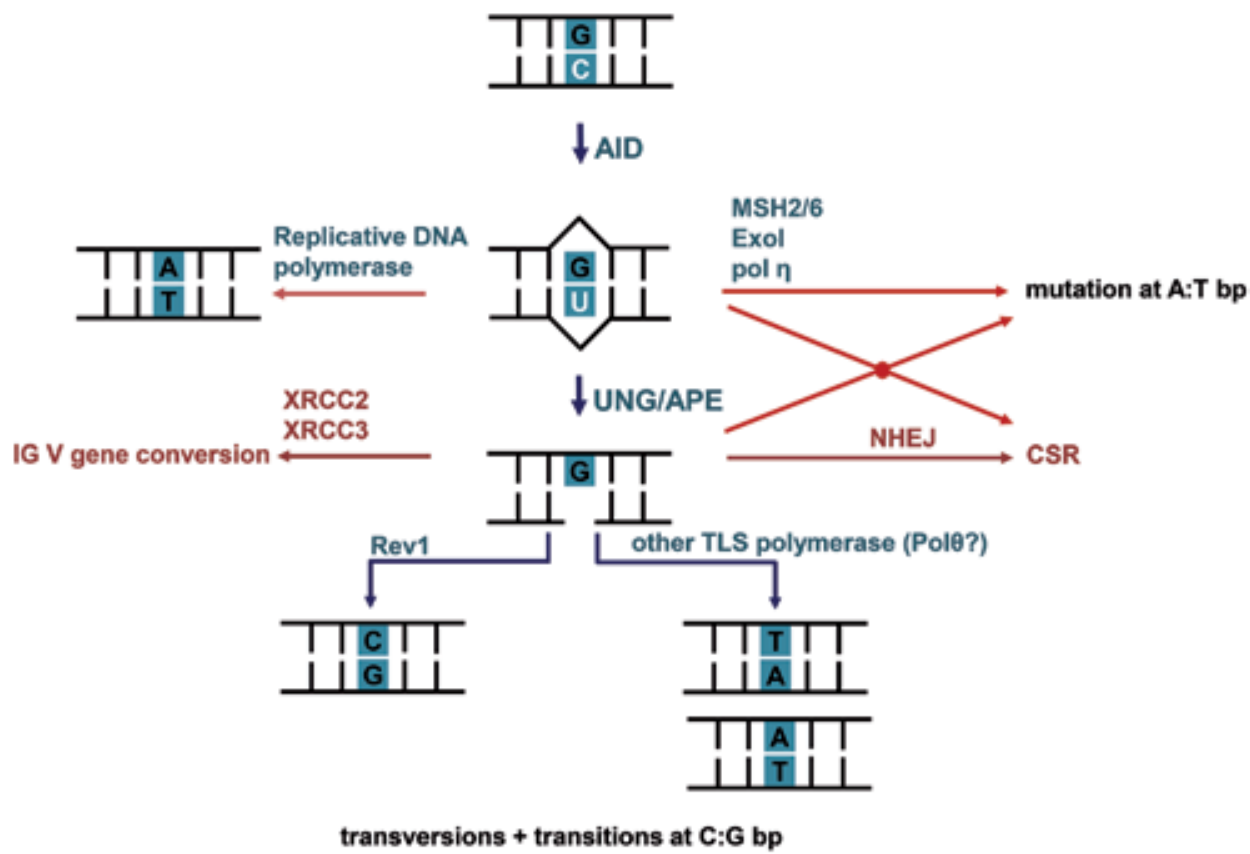

Figure 8.

DNA deamination model of IG gene diversification by AID during SHM (adapted from [51]). AID creates mutations in DNA by deamination of cytosine base, which turns it into uracil, which is then targeted by BER or MMR mechanisms or simply replicated producing mutations. AID: activation-induced deaminase, APE: apyrimidinic/apurinic endonuclease, BER: base excision repair, bp: base pairs, CSR: class switch recombination, ExoI: mismatch repair exonuclease I, IG: immunoglobulin gene, IgV: immunoglobulin variable region, MMR: DNA mismatch repair, $M S H_{2} / 6:$ mismatch recognition proteins, NHEJ: nonhomologous end joining, pol: polymerase, pol $\eta$ : DNA polymerase eta, Rev1: Y-family DNA polymerase involved in DNA damage tolerance, SHM: somatic hypermutation, TLS: translesion DNA synthesis, UNG: uracil-DNA glycosylase, $X R C C_{2} / X R C C_{3}$ : X-ray cross-complementing gene 2/3. 
b.If the $\mathrm{U}: \mathrm{G}$ mismatch is recognized by the mismatch repair (MMR) protein pathway, the U:G lesion will be excised by Exonuclease I, resulting in degradation of the DNA strand surrounding the U, then the MSH2/MSH6 heterodimer induces the formation of a gap in the DNA. Unfaithful replication of a DNA strand will take place at the level of the gap by the TLS DNA polymerase eta (pol ๆ), a "wrong" TLS repair polymerase [56] (Figure 8).

\subsection{Frequencies of mutations}

The frequency of IG region $\mathrm{V}$ gene mutations corresponds to approximately one bp change per 1000 bp per gene and per cell division/generation, while that affecting the rest of the cell DNA is much lower, and corresponds to about one bp change per $10^{10}$ bp per cell and per division. Of note, there is approximately a $50 \%$ chance during each division of $\mathrm{B}$-cells that a mutation leads to a change in BCR, since it is known that each $V$ region is encoded by approximately $360 \mathrm{bp}$ and that approximately $3 / 4$ basic changes modify the encoded amino acid [48].

\subsection{Impacts of mutations on affinity of BCR and secreted Ig}

The low affinity of antibodies produced during the primary immune response tends to increase as the immune response progresses, thanks to the numerous point mutations in hypervariable regions of the IG V gene of the antigen-specific B-cell clones.

Most mutations have no positive effect on the affinity of BCR or Ig produced, and frequently negatively affect their ability to bind antigen inducing B-cell activation.

Of the four types of possible mutations-silent, neutral, deleterious, and positiveonly deleterious mutations and positive mutations have an effect on the affinity of the antigen for its appropriate BCR:

i. The deleterious mutations are responsible for a decrease in the affinity of the antigen for its BCR, but also for the rapid division of B-cells (the expansion would overwhelm the lymphoid tissues), since they can induce modifications of the framework regions and thus disrupt the basic structure of Ig. The many B-cells that carry such mutations will be a target of apoptotic death by a negative selection process, either because they can no longer produce a functional BCR, or because they cannot efficiently internalize antigens through clonally distributed membrane BCRs. These apoptotic cells will invade GC and then be rapidly ingested by resident macrophages, giving rise to tingible body macrophages (TBM), containing dark nuclear debris in their cytoplasm [48].

ii. Positive mutations are less common than deleterious mutations and are responsible for increasing antigen affinity for its BCR and improving its binding. The small portion of daughter cells with many nucleotide substitutions in the Ig V region encoding gene that are derived from B-cell clones undergoing such mutations will be positively selected and will therefore have an increased survival rate relative to the cells expressing a low BCR affinity. Positive selection would be a consequence of the accumulation and concentration of many amino acid substitutions in CDRs of the Ig V region, as a result of nucleotide changes that alter amino acid sequences and so the protein structure. 
iii. Silent or neutral mutations have no noticeable effect on antigen affinity. They preserve the amino acid sequence and do not alter the structure of proteins and are dispersed throughout the $\mathrm{V}$ region [48].

\section{Acknowledgements}

Cell schematic illustrations are adapted from free Servier Medical Art (smart. servier.fr/servier-medical-art).

\section{Author details}

Mourad Aribi

Laboratory of Applied Molecular Biology and Immunology, W0414100, University of Tlemcen, Tlemcen, Algeria

*Address all correspondence to: mourad.aribi@univ-tlemcen.dz

\section{IntechOpen}

(C) 2020 The Author(s). Licensee IntechOpen. This chapter is distributed under the terms of the Creative Commons Attribution License (http://creativecommons.org/licenses/ by/3.0), which permits unrestricted use, distribution, and reproduction in any medium, provided the original work is properly cited. (cc) BY 


\section{References}

[1] Lefranc M-P, Lefranc G. The Immunoglobulin Factsbook. San Diego: Academic Press; 2001

[2] Karan-Djurasevic T, Pavlovic S. Somatic hypermutational status and gene repertoire of immunoglobulin rearrangements in chronic lymphocytic leukemia. In: Isvoranu $\mathrm{G}$, editor. Lymphocyte Updates-Cancer, Autoimmunity and Infection. Rijeka: IntechOpen; 2017. DOI: $10.5772 /$ intechopen.69110

[3] DeFranco AL, Robertson M, Locksley RM. Immunité: la réponse immunitaire dans les maladies infectieuses et inflammatoires. De Boeck; 2009

[4] Watson CT et al. Sequencing of the human IG light chain loci from a hydatidiform mole BAC library reveals locus-specific signatures of genetic diversity. Genes and Immunity. 2015;16:24-34

[5] Alt FW et al. Ordered rearrangement of immunoglobulin heavy chain variable region segments. The EMBO Journal. 1984;3:1209-1219

[6] Kim M-S, Lapkouski M, Yang W, Gellert M. Crystal structure of the V(D) $\mathrm{J}$ recombinase RAG1-RAG2. Nature. 2015;518:507-511

[7] Stanhope-Baker P, Hudson KM, Shaffer AL, Constantinescu A, Schlissel MS. Pillars article: Cell typespecific chromatin structure determines the targeting of $\mathrm{V}(\mathrm{D}) \mathrm{J}$ recombinase activity in vitro. Cell. 1996;85:887-897. Journal of Immunology (Baltimore, Md.: 1950). 2015;195:5106-5116

[8] Larijani M et al. The recombination difference between mouse kappa and lambda segments is mediated by a pairwise regulation mechanism. Molecular Immunology. 2006;43:870-881
[9] $\mathrm{Ru} \mathrm{H}$ et al. Molecular mechanism of $\mathrm{V}(\mathrm{D}) \mathrm{J}$ recombination from synaptic RAG1-RAG2 complex structures. Cell. 2015;163:1138-1152

[10] Fugmann SD, Schatz DG. Identification of basic residues in RAG2 critical for DNA binding by the RAG1-RAG2 complex. Molecular Cell. 2001;8:899-910

[11] Funck T et al. Nucleotide composition of human Ig nontemplated regions depends on trimming of the flanking gene segments, and terminal deoxynucleotidyl transferase favors adding cytosine, not guanosine, in most VDJ rearrangements. Journal of Immunology (Baltimore, Md.: 1950). 2018;201:1765-1774

[12] Jackson KJL, Gaeta B, Sewell W, Collins AM. Exonuclease activity and $P$ nucleotide addition in the generation of the expressed immunoglobulin repertoire. BMC Immunology. 2004;5:19

[13] Roth DB, Menetski JP, Nakajima PB, Bosma MJ, Gellert M. $\mathrm{V}(\mathrm{D}) \mathrm{J}$ recombination: Broken DNA molecules with covalently sealed (hairpin) coding ends in scid mouse thymocytes. Cell. 1992;70:983-991

[14] Sadofsky MJ. The RAG proteins in $\mathrm{V}(\mathrm{D}) \mathrm{J}$ recombination: More than just a nuclease. Nucleic Acids Research. 2001;29:1399-1409

[15] Tonegawa S. Somatic generation of antibody diversity. Nature.

1983;302:575-581

[16] Fujimoto S, Yamagishi H. Isolation of an excision product of T-cell receptor alpha-chain gene rearrangements. Nature. 1987;327:242-243

[17] Okazaki K, Davis DD, Sakano H. T cell receptor beta gene sequences in the circular DNA of thymocyte nuclei: 
Direct evidence for intramolecular DNA deletion in V-D-J joining. Cell. 1987;49:477-485

[18] Roth DB, Nakajima PB, Menetski JP, Bosma MJ, Gellert M. V(D)J recombination in mouse thymocytes: Double-strand breaks near T cell receptor delta rearrangement signals. Cell. 1992;69:41-53

[19] Goodwin JF, Knudsen KE. Beyond DNA repair: DNA-PK function in cancer. Cancer Discovery. 2014;4:1126-1139

[20] Kottmann AH, Zevnik B, Welte M, Nielsen PJ, Köhler G. A second promoter and enhancer element within the immunoglobulin heavy chain locus. European Journal of Immunology. 1994;24:817-821

[21] Perlot T, Alt FW. Cis-regulatory elements and epigenetic changes control genomic rearrangements of the IgH locus. Advances in Immunology. 2008;99:1-32

[22] Johnson K, Angelin-Duclos C, Park S, Calame KL. Changes in histone acetylation are associated with differences in accessibility of $\mathrm{V}(\mathrm{H})$ gene segments to $\mathrm{V}-\mathrm{DJ}$ recombination during B-cell ontogeny and development. Molecular and Cellular Biology. 2003;23:2438-2450

[23] Maës J et al. Chromatin remodeling at the Ig loci prior to $\mathrm{V}$ (D)J recombination. Journal of Immunology (Baltimore, Md.: 1950). 2001;167:866-874

[24] Nakase H, Takahama Y, Akamatsu Y. Effect of CpG methylation on RAG1/ RAG2 reactivity: Implications of direct and indirect mechanisms for controlling $\mathrm{V}(\mathrm{D}) \mathrm{J}$ cleavage. EMBO Reports. 2003;4:774-780

[25] Jhunjhunwala S, van Zelm MC, Peak MM, Murre C. Chromatin architecture and the generation of antigen receptor diversity. Cell. 2009;138:435-448

[26] Ichihara Y, Matsuoka H, Kurosawa Y. Organization of human immunoglobulin heavy chain diversity gene loci. The EMBO Journal. 1988;7:4141-4150

[27] Frippiat JP et al. Organization of the human immunoglobulin lambda light-chain locus on chromosome 22q11.2. Human Molecular Genetics. 1995;4:983-991

[28] Pandey JP. Immunoglobulin kappa chain locus on chromosome 2p12 and onchocerciasis. Journal of Infectious Diseases. 2009;199:286; author reply 286-287

[29] Vettermann C, Schlissel MS. Allelic exclusion of immunoglobulin genes: Models and mechanisms. Immunological Reviews. 2010;237:22-42

[30] Sonoda E et al. B cell development under the condition of allelic inclusion. Immunity. 1997;6:225-233

[31] Stavnezer J, Schrader CE. IgH chain class switch recombination: Mechanism and regulation. Journal of Immunology (Baltimore, Md.: 1950). 2014;193:5370-5378

[32] Daniel JA, Nussenzweig A. The AID-induced DNA damage response in chromatin. Molecular Cell. 2013;50:309-321

[33] Schroeder HW, Cavacini L. Structure and function of immunoglobulins. The Journal of Allergy and Clinical Immunology. 2010;125:S41-S52

[34] McCloskey ML, Curotto de Lafaille MA, Carroll MC, Erlebacher A. Acquisition and presentation of follicular dendritic cell-bound antigen by lymph node-resident dendritic cells. The 
Journal of Experimental Medicine. 2011;208:135-148

[35] Denzer K et al. Follicular dendritic cells carry MHC class II-expressing microvesicles at their surface. Journal of immunology (Baltimore, Md.: 1950). 2000;165:1259-1265

[36] Kapasi ZF et al. Follicular dendritic cell (FDC) precursors in primary lymphoid tissues. Journal of Immunology (Baltimore, Md.: 1950). 1998;160:1078-1084

[37] Weill B editor. Immunité à médiation humorale [Humoral mediated immunity]. 2019. Available from: http:// lvts.fr/Pages_html/Encyclopedies/ Cours\%20Immuno/chapitre11.htm [Accessed: 09 January 2019]

[38] Pape KA, Catron DM, Itano AA, Jenkins MK. The humoral immune response is initiated in lymph nodes by $B$ cells that acquire soluble antigen directly in the follicles. Immunity. 2007;26:491-502

[39] Goodnow CC. Chance encounters and organized rendezvous.

Immunological Reviews. 1997;156:5-10

[40] Tarlinton D, Lew A. Antigen to the node: $B$ cells go native. Immunity. 2007;26:388-390

[41] Weinstein JS, Hernandez SG, Craft J. T cells that promote B-cell maturation in systemic autoimmunity. Immunological Reviews.

2012;247:160-171

[42] Garside P et al. Visualization of specific $B$ and $T$ lymphocyte interactions in the lymph node. Science. 1998;281:96-99

[43] Okada T et al. Antigen-engaged B cells undergo chemotaxis toward the $\mathrm{T}$ zone and form motile conjugates with helper T cells. PLoS Biology. 2005;3:e150
[44] Reif K et al. Balanced responsiveness to chemoattractants from adjacent zones determines B-cell position. Nature. 2002;416:94-99

[45] MacLennan ICM et al. Extrafollicular antibody responses. Immunological Reviews. 2003;194:8-18

[46] Choi YS et al. ICOS receptor instructs $\mathrm{T}$ follicular helper cell versus effector cell differentiation via induction of the transcriptional repressor Bcl6. Immunity. 2011;34:932-946

[47] King C. A fine romance: $\mathrm{T}$ follicular helper cells and B cells. Immunity. 2011;34:827-829

[48] MurphyK.Janeway'sImmunobiology. New York: Garland Science; 2016. DOI: 10.1201/9781315533247

[49] Yves L. Somatic hypermutation of immunoglobulin genes. Hematologie. 1999;5:469-479

[50] Meng F-L et al. Convergent transcription at intragenic superenhancers targets AID-initiated genomic instability. Cell. 2014;159:1538-1548

[51] Di Noia JM, Neuberger MS. Molecular mechanisms of antibody somatic hypermutation. Annual Review of Biochemistry. 2007;76:1-22

[52] Alt FW, Zhang Y, Meng F-L, Guo C, Schwer B. Mechanisms of programmed DNA lesions and genomic instability in the immune system. Cell. 2013;152:417-429

[53] Storb U. Why does somatic hypermutation by AID require transcription of its target genes? Advances in Immunology. 2014;122:253-277

[54] Liu M, Schatz DG. Balancing AID and DNA repair during somatic hypermutation. Trends in Immunology. 2009;30:173-181 
[55] Rogozin IB, Diaz M. Cutting edge: $\mathrm{DGYW} / \mathrm{WRCH}$ is a better predictor of mutability at $\mathrm{G}: \mathrm{C}$ bases in $\mathrm{Ig}$ hypermutation than the widely accepted RGYW/WRCY motif and probably reflects a two-step activation-induced cytidine deaminase-triggered process. Journal of Immunology (Baltimore, Md.: 1950). 2004;172:3382-3384

[56] Makridakis NM, Reichardt JKV. Translesion DNA polymerases and cancer. Frontiers in Genetics. 2012;3:174 
Section 2

B-Cell Lymphomagenesis 



\title{
Chapter 3
}

\section{B-Cell Lymphomas}

\author{
Subramanian Kalaivani Selvi, B.H. Srinivas \\ and Sadhanandham Shrinuvasan
}

\begin{abstract}
B-cell lymphomas arise from different stages of differentiation of B-cells and constitute a broad spectrum, extending from small- to large-cell types, and from low to high grades of clinical behavior. It has undergone several terminologies and classifications. Because of the diverse terminology that is used in the multiple classifications of lymphomas, there have been attempts to develop uniform pathologic descriptions with clinical usefulness. The current WHO classification uses morphologic, immunophenotypic, genotypic, and clinical features to classify the lymphoid neoplasms into five broad categories as precursor B-cell neoplasms, peripheral B-cell neoplasms, precursor T-cell neoplasms, peripheral T-cell neoplasms and Hodgkin lymphoma. Hodgkin lymphoma though originates from B-cell has distinctive pathologic features and is treated as a separate entity. This chapter discusses about the etiology and pathogenesis, clinical features, recent WHO classification of B-cell lymphoma (2016), the highlights of modifications brought in, the morphology, immunophenotype, staging, treatment and prognosis of various B-cell lymphomas.
\end{abstract}

Keywords: B-cell lymphomas, recent WHO classification, pathogenesis, morphology, immunophenotype, treatment, prognosis

\section{Introduction}

B-cell lymphomas are malignant neoplasms that arise from different stages of differentiation of B-cells and constitute a broad spectrum, extending from small- to large-cell types, and from low to high grades of clinical behavior. It constitutes the major type of non-Hodgkin's lymphoma (NHL) [1-3].

The recognition of lymphoma evolved from Thomas Hodgkin's 1832 paper entitled "On Some Morbid Appearances of the Absorbent Glands and Spleen" [4], followed by various nomenclatures and classifications that classified lymphomas into Hodgkins and non-Hodgkin's lymphomas [5-11]. In 1974, Lennert et al. [12] and Lukes and Collins [13] classified NHL on the basis of the cell of origin as B cell lymphomas and $\mathrm{T}$ cell lymphomas which was later confirmed at the molecular level with the identification of specific Ig gene and T-cell receptor (TCR) gene rearrangements [14-17]. In 1982, a Working Formulation (WF) classified NHL according to histologic grade as low, intermediate, and high [18]. In 1994, a Revised European American Lymphoma (REAL) Classification was proposed which diagnosed lymphomas by identifying clinical features, morphology, immunophenotype, and genetic data [19]. The World Health Organization (WHO) then adopted the diagnostic principles of the REAL Classification, and is used as the schema for the diagnosis of all hematopoietic neoplasms [20, 21]. 
The 2001 and 2008 World Health Organization classification of hematopoietic and lymphoid tumors established guidelines for the diagnosis of malignant lymphomas; however, subsequently, there have been major advances with significant clinical and biologic implications which necessitated further revisions $[22,23]$. Hence further revision was done in 2016 which reflects a consensus among hematopathologists, geneticists, and clinicians regarding both updates to current entities as well as the addition of a limited number of new provisional entities leading to more targeted therapeutic strategies. The current WHO classification uses morphologic, immunophenotypic, genotypic, and clinical features to classify the lymphoid neoplasms into five broad categories as precursor B-cell neoplasms, peripheral B-cell neoplasms, precursor T-cell neoplasms, peripheral T-cell neoplasms and Hodgkin lymphoma. Hodgkin lymphoma though originates from B-cell has distinctive pathologic features and is treated as a separate entity. This chapter discusses about the etiology and pathogenesis, clinical features, recent WHO classification of B-cell lymphomas (2017), the highlights of modifications brought in, the morphology, immunophenotype, staging, treatment and prognosis of various B-cell lymphomas [24-26].

\section{B-cell lymphomas: origin and development}

The differentiation of the B-cell lineage starts from stem cells the common lymphoid precursor to plasma cells that occurs successively in the fetal liver, bone marrow, and lymph nodes. The characteristic marker of B cells is the presence of immunoglobulins, which act as the cell surface antigen receptor. The genes that code for antibody are rearranged in the course of differentiation from stem cell to pre-B cell [20]. Understanding the stages of B-cell maturation has facilitated the recognition of the interrelationships between the various types of B-cell lymphomas and leukemia.

The WHO classification distinguishes two major categories within B-cell lymphomas: precursor and mature. The precursor B-cell lymphomas comprise those lymphoblastic lymphomas and leukemia that derive from progenitor cells that have not yet been activated by antigen and are still in an undifferentiated stage. All other lymphomas representing different stages of differentiation are included in the category of mature B-cell lymphomas. Naïve B-cell can give rise to mantle cell lymphoma, small lymphocytic lymphoma/ chronic lymphocytic lymphoma. Lymphomas originating in the cells of the germinal centres are follicular lymphomas, Burkitt lymphoma and diffuse large B cell lymphoma. Post germinal center cells can give rise to marginal zone lymphoma, small lymphocytic lymphoma/ chronic lymphocytic lymphoma, diffuse large B cell lymphoma, plasma cell myeloma, lymphoplasmacytic lymphoma [1, 20, 22-25].

B-cell lymphomas constitute a broad spectrum, extending from small- to largecell types, and from low to high grades of clinical behavior. The term "grade" is defined by the size and shape of cells and nuclei; density of chromatin; the number of mitoses (proliferation index), which may indicate the aggressiveness of a tumor; and by its clinical behavior. However, aggressiveness and tumor grade cannot be used synonymously because their correlation is not consistent; some lymphomas of highly aggressive behavior, such as mantle cell lymphoma, may exhibit low histologic grades.

Hodgkin lymphoma (HL) encompasses another group of lymphoid neoplasms that are characterized by neoplastic Reed-Sternberg cells derived from the germinal center or post-germinal center B cells and differ from NHL in several respects. Hence it is treated as a separate category though it is derived from B-cells. 


\section{Etiology and pathogenesis}

Chromosomal Translocations and Other Acquired Mutations are present in the majority of lymphomas. Many specific rearrangements are associated with particular neoplasms, suggesting a critical role in their genesis. The mutation can produce a "dominant negative" protein that interferes with a normal function (a loss of function) or inappropriate increase in some normal activity (a gain of function). Oncoproteins created by genomic aberrations often block normal maturation, turn on pro-growth signaling pathways that enhance the self-renewal of tumors cells, or protect cells from apoptotic cell death. Pro-growth signaling mutations produce a constitutively active tyrosine kinase; oncogenic tyrosine kinases activate RAS and its two downstream signaling arms, the phosphoinositide-3-kinase/AKT8 virus oncogene cellular homolog (PI3K/AKT) and mitogen-activated protein kinases (MAPK) pathways and thereby drive cell growth. Oncogenic mutations most frequently occur in germinal center B cells during antibody diversification. B cells that enter germinal centres after antigen stimulation upregulate the expression of activation-induced cytosine deaminase (AID), a specialized DNA-modifying enzyme which is essential for immunoglobulin (Ig) gene modifications: (1) class switching, an intragenic recombination event in which the IgM heavy-chain constant gene segment is replaced with a different constant segment leading to a switch in the class (isotype) of antibody produced; and (2) somatic hypermutation, which creates point mutations within Ig genes that may increase antibody affinity for antigen. Certain protooncogenes, such as myelocytomatosis oncogene cellular homolog (MYC), are activated in germinal center B-cell lymphomas by translocations to the transcriptionally active Ig locus. Other proto-oncogenes, such as BCL6, a transcription factor that has an important role in many B cell malignancies, are frequently activated in germinal center B-cell lymphomas by point mutations that also seem to stem from "mistargeted" DNA breaks induced by AID. A different type of regulated genomic instability is unique to precursor $\mathrm{B}$ cells, which express a $\mathrm{V}$ (D)J recombinase that cuts DNA at specific sites within the Ig [1].

Other factors include immunosuppression; infectious agents like Epstein-Barr virus, Human T-cell lymphotropic virus type 1, Helicobacter pylori, Hepatitis C virus, Human herpesvirus 8 (Kaposi sarcoma), Human herpesvirus 6, Human T-cell lymphotropic virus type 2 are known to be associated with lymphomas [27-31]. Male gender, increasing age, family history of non-Hodgkin's lymphoma, prior cancer history, drug history, immunosuppressive agents like phenytoin, methotrexate; occupational history like exposure to herbicides, pesticides, wood dust, epoxy glue, solvents; jobs in farming, forestry, painting, carpentry, tanning, hair dye use, sunlight exposure, nutritional factors, blood transfusion are the other possible etiologic factors [1, 32-37].

\section{Clinical features}

The clinical presentation of the various lymphoid neoplasms is most often determined by the anatomic distribution of disease. Two-thirds of non-Hodgkin's Lymphomas present as enlarged nontender lymph nodes. The remaining one-third of NHLs present with symptoms related to the involvement of extranodal sites leading to mass effect, obstructive and compressive signs and symptoms. The lymphocytic leukemia most often come to attention because of signs and symptoms related to the suppression of normal hematopoiesis by tumor cells in the bone marrow. Plasma cell neoplasm, multiple myeloma, causes bony destruction of the skeleton and often presents with pain due to pathologic fractures. Other symptoms related to 
lymphoid tumors are frequently caused by proteins secreted from the tumor cells or from immune cells that are responding to the tumor. Specific examples include the plasma cell tumors, in which much of the pathophysiology is related to the secretion of whole antibodies or Ig fragments; Significant cytopenias are rare, unless marrow involvement is extensive, or there are associated immune-mediated cytopenias, hypersplenism, or, rarely, hemophagocytosis. Hepatosplenomegaly is a common feature of advanced low-grade B-cell lymphoma. Bleeding manifestations are common in lymphoblastic lymphomas/leukemia with marrow involvement $[1,2]$.

\section{Investigations}

Complete history and physical examination; inquiry about B symptoms, human immunodeficiency virus risk, infections, autoimmune diseases, immunosuppressive therapy.

Complete blood cell count and peripheral smear examination including hemoglobin, total leukocyte count with differential and platelet count.

Biochemistry profile-lactate dehydrogenase; alkaline phosphatase, uric acid, creatinine, calcium, and albumin.

Imaging — computed tomography of chest, abdomen, pelvis, and neck, Selected radiologic procedures as clinically appropriate (e.g., gallium, positron emission tomography scan, magnetic resonance imaging, ultrasound, bone scan).

Bone marrow aspiration and biopsy-morphology, immunophenotyping, cytogenetics, molecular tests, and gene rearrangement studies.

Lumbar puncture with cytology in patients with CNS involvement.

Gastrointestinal endoscopy for patients with Waldeyer ring involvement or abdominal symptoms.

Cytologic assessment of third space fluids (pleura, peritoneum) in case of effusions.

Other blood evaluations: levels of ß2-microglobulin and cytokines (interleukin-2 receptor, tumor necrosis factor).

\section{2016 WHO classification of B lymphoid neoplasms}

The current WHO classification uses morphologic, immunophenotypic, genotypic, and clinical features to classify the lymphoid neoplasms into five broad categories as precursor B-cell neoplasms, peripheral B-cell neoplasms, precursor T-cell neoplasms, peripheral T-cell neoplasms and Hodgkin lymphoma. Hodgkin lymphoma though originates from B-cell has distinctive pathologic features and is treated as a separate entity (Table 1 ).

The WHO classification distinguishes two major categories within B-cell lymphomas:

a. Precursor B-cell neoplasms

b.Mature B-cell neoplasms

\subsection{Precursor B-cell neoplasms}

Acute lymphoblastic leukemia/lymphoma (ALLs) are neoplasms composed of immature B (pre-B) which are referred to as lymphoblasts. About $85 \%$ are B-ALLs, which typically manifest as childhood acute "leukemia." Many of the chromosomal aberrations seen in ALL dysregulate the expression and function of transcription factors required for normal B development. B-ALLs have loss-of-function mutations 
in genes that are required for B-cell development, such as Paired Box 5 (PAX5), E2-alpha (E2A), and early B-cell factor (EBF), or a balanced t(12;21) involving the genes translocation-Ets-leukemia virus (ETV6) and Runt Related Transcription Factor 1 (RUNX1), two genes that are needed in very early hematopoietic precursors. All of these varied mutations disturb the differentiation of lymphoid precursors and promote maturation arrest, and in doing they induce increased self-renewal, a stem cell-like phenotype. Approximately $90 \%$ of ALLs have numerical or structural chromosomal changes. Most common is hyperploidy ( $>50$ chromosomes), but hypoploidy and a variety of balanced chromosomal translocations are also seen $[1,25,38]$.

Patients present with fatigue due to anemia; fever due to infections secondary to neutropenia; and bleeding due to thrombocytopenia. They can so present with mass effects caused by neoplastic infiltration, including bone pain, generalized lymphadenopathy, splenomegaly, hepatomegaly; testicular enlargement; headache, vomiting, and nerve palsies due to central nervous system involvement $[1,25]$.

\subsubsection{Morphology and immunophenotype}

In leukemic presentations, the marrow is hypercellular and packed with lymphoblasts, which replace the normal marrow elements, lymphoblasts have more condensed chromatin, less conspicuous nucleoli, and smaller amounts of cytoplasm that usually lacks granules. Histochemical stains show periodic acid-Schiff-positive cytoplasmic material. Immunostaining for terminal deoxynucleotidyl transferase (TdT), is positive in more than $95 \%$ of cases in addition to B-cell markers. B-ALLs are arrested at various stages of development. The lymphoblasts usually express the pan B-cell marker CD19/CD22/CD79a and the transcription factor PAX5. CD10 is expressed in common ALL and pre-B ALLs express in addition cytoplasmic IgM heavy chain ( $\mu$ chain) and surface immunoglobulins in mature forms (Figure 1).

\subsubsection{New provisional entities in recent WHO classification}

- B-ALL with intrachromosomal amplification of chromosome 21 [24, 39, 40].

- B-ALL with translocations involving tyrosine kinases or cytokine receptors ("BCR-ABL1-like ALL").

\subsubsection{Treatment and prognosis}

Treatment includes chemotherapy, steroids, radiation therapy and marrow transplantation. About $95 \%$ of children obtain a complete remission, and $75-85 \%$ are cured

\section{WHO classification of B lymphoid neoplasms}

B-lymphoblastic leukemia/lymphoma

B-lymphoblastic leukemia/lymphoma, NOS

B-lymphoblastic leukemia/lymphoma with recurrent genetic abnormalities

B-lymphoblastic leukemia/lymphoma with $\mathrm{t}$ (9;22) (q34.1;q11.2);BCR-ABL1

B-lymphoblastic leukemia/lymphoma with $\mathrm{t}(\mathrm{v} ; 11 \mathrm{q} 23.3)$;KMT2A rearranged

B-lymphoblastic leukemia/lymphoma with t(12;21) (p13.2;q22.1); ETV6-RUNX1 B-lymphoblastic leukemia/

lymphoma with hyperdiploidy B-lymphoblastic leukemia/lymphoma with hypodiploidy

B-lymphoblastic leukemia/lymphoma with $\mathrm{t}(5 ; 14)$ (q31.1;q32.3) IL3-IGH

B-lymphoblastic leukemia/lymphoma with t(1;19) (q23;p13.3);TCF3-PBX1

Provisional entity: B-lymphoblastic leukemia/lymphoma, BCR-ABL1-like

Provisional entity: B-lymphoblastic leukemia/lymphoma with iAMP21

Mature B-cell neoplasms 


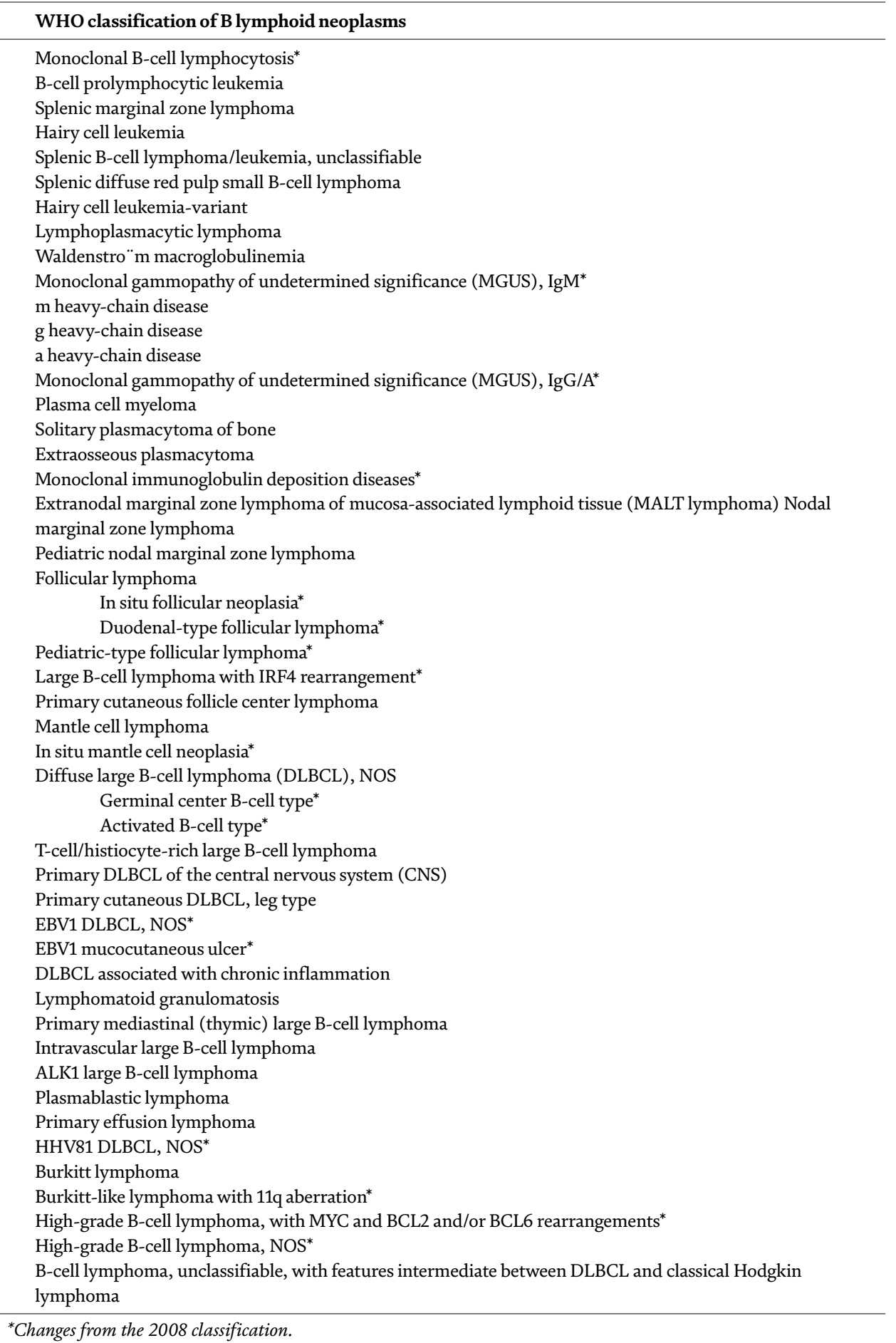

Table 1.

WHO classification of B lymphoid neoplasms

with chemotherapy, whereas only $35-40 \%$ of adults are cured. Treatment of $t(9 ; 22)-$ positive ALLs with BCR-ABL kinase inhibitors in combination with conventional chemotherapy is highly effective and has greatly improved the outcome in children. The outlook for adults with ALL remains more guarded, in part because of differences 


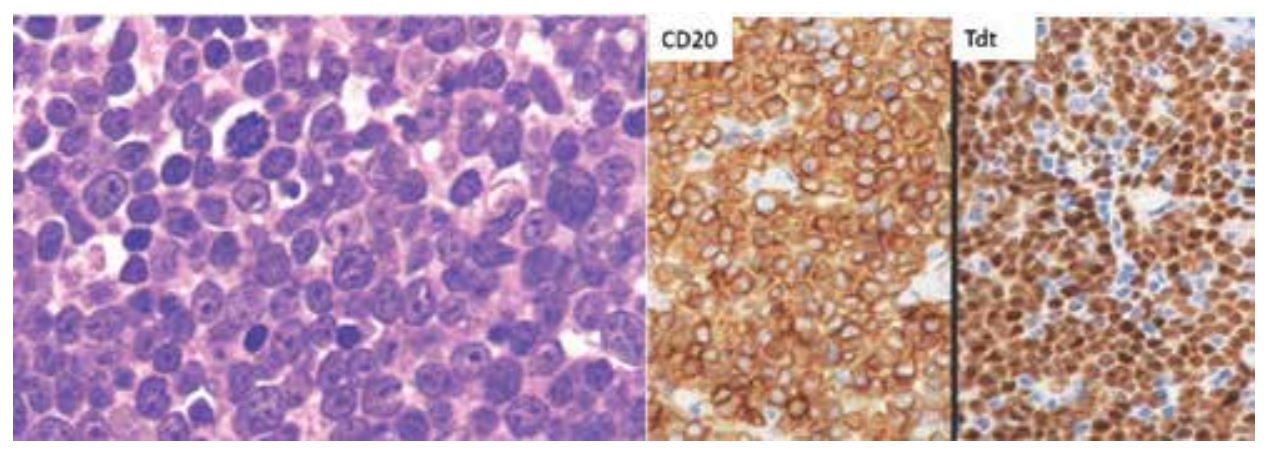

Figure 1.

B-lymphoblastic lymphoma showing CD20, Tdt positivity.

in the molecular pathogenesis of adult and childhood ALL, but also because older adults cannot tolerate the very intensive chemotherapy regimens that are curative in children. Factors associated with worse prognosis includes: (1) age younger than 2 years, (2) presentation in adolescence or adulthood; and (3) peripheral blood blast counts greater than 100,000. Factors associated with favorable prognosis include (1) age between 2 and 10 years, (2) a low white cell count, (3) hyperdiploidy, (4) trisomy of chromosomes 4, 7, and 10, and (5) the presence of a $\mathrm{t}(12 ; 21)[1,25,38]$.

\subsection{Chronic lymphocytic leukemia/small lymphocytic lymphoma}

Chronic lymphocytic leukemia (CLL) and small lymphocytic lymphoma (SLL) are used interchangeably by the degree of peripheral blood lymphocytosis. CLL is the most common leukemia of adults with absolute lymphocyte count $>5000$ per $\mathrm{mm}^{3}$. The median age at diagnosis is 60 years. SLL constitutes only $4 \%$ of NHLs and has lymph node involvement The common genetic anomalies associated are deletions of 13q14.3, 11q, and 17p, and trisomy $12 q[1,25]$. Patients are usually asymptomatic at diagnosis and can present with easy fatigability, weight loss, and anorexia. Generalized lymphadenopathy and hepatosplenomegaly are present in $50-60 \%$ of patients. The leukocyte count is high in most cases; leukopenia can be seen in individuals with SLL and marrow involvement.

\subsubsection{Morphology and immunophenotype}

Peripheral blood contains large numbers of small round lymphocytes with scant cytoplasm. Some of these cells are usually disrupted in the process of making smears, producing smudge cells. Prolymphocytes can also be circulating based on which it is classified as CLL or CLL/PLL or PLL (Prolymphocytic leukemia). The bone marrow is almost always involved by interstitial infiltrates or aggregates of tumor cells. Infiltrates are also virtually always seen in the splenic white and red pulp and the hepatic portal tracts. Lymph nodes are diffusely effaced by predominantly small lymphocytes with mild irregular nucleus, condensed chromatin, and scant cytoplasm along with proliferation centers, which contain aggregates of mitotically active larger activated lymphocytes. (Figure 2).CLL/SLL has a distinctive immunophenotype. The tumor cells express the pan B-cell markers CD19 and CD20, CD23, CD5, LEF1 (Lymphoid Enhancer Binding Factor 1), CD200. Negative for SOX11 (SRY (sex determining region) - Box 11), CD10.

\subsubsection{Highlights in recent WHO classification}

Cytopenias or disease-related symptoms are now insufficient to make a diagnosis of CLL with $<5 \times 10^{9} / \mathrm{L}$ PB CLL cells. 


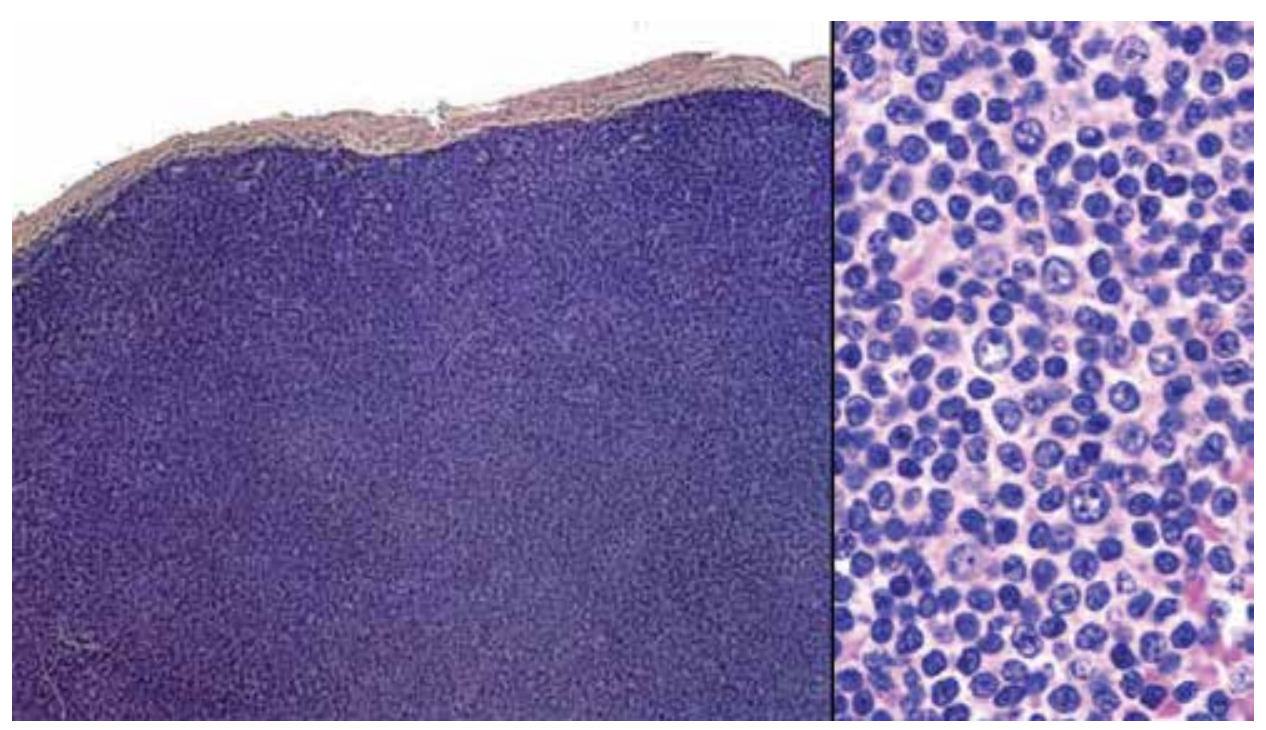

Figure 2.

Small lymphocytic lymphoma showing diffuse effacement by small lymphoid cells.

Large/confluent and/or highly proliferative proliferation centres are adverse prognostic indicators [24, 41-44].

Mutations of potential clinical relevance, such as TP53 (tumor protein 53), NOTCH1 (Notch homolog 1), SF3B1 (Splicing Factor 3b Subunit 1), ATM (Ataxia telangiectasia mutated), and BIRC3 (Baculoviral IAP repeat-containing protein 3), have been recognized

\subsubsection{Treatment and prognosis}

The treatment, course and prognosis depend primarily on the clinical stage. Median survival is 4-6 years but can be more than 10 years in those with minimal tumor burdens. Factors associated with worse outcome include (1) deletions of 11q and 17p, (2) lack of somatic hypermutation, (3) expression of ZAP-70 (z-chainassociated protein kinase), and (4) presence of NOTCH1 mutations. CLL also have the risk of transformation into diffuse large B -cell lymphoma [1, 25]. Symptomatic patients are generally treated with "gentle" chemotherapy and immunotherapy with antibodies against proteins found on the surface of CLL/SLL cells, particularly CD20. Hematopoietic stem cell transplantation is being offered to the relatively young. The most promising new therapy is Bruton's tyrosine kinase (BTK) inhibitors [1, 25].

\subsection{Follicular lymphoma}

Follicular lymphoma (FL) is the most common form of indolent NHL. It usually presents in middle age and afflicts males and females equally. Follicular lymphoma likely arises from germinal center B cells and is strongly associated with chromosomal translocations involving BCL2 (B-cell lymphoma 2). Its hallmark is a $(14 ; 18)$ translocation that juxtaposes the IGH locus on chromosome 14 and the BCL2 locus on chromosome 18 . The $t(14 ; 18)$ is seen in up to $90 \%$ of follicular lymphomas and leads to overexpression of BCL2. Follicular lymphoma tends to present with painless, generalized lymphadenopathy. Involvement of extranodal sites, such as the gastrointestinal tract, central nervous system, or testis, is relatively uncommon [1, $25,45,46]$. 


\subsubsection{Morphology and immunophenotype}

Follicular lymphoma usually shows effacement of nodal architecture by follicular nodules that occupy both cortex and the medulla with two cell types in varying proportions: (1) Centrocytes which are small cells with irregular or cleaved nucleus and scant cytoplasm (2) Centroblasts which are larger cells with open nuclear chromatin, several prominent nucleoli, and modest amounts of cytoplasm. Based on the number of these centroblasts FL is classified into Grade 1, 2, and 3a,b. Grade 1 follicular lymphomas have $0-5$ centroblasts per HPF; 6-15 centroblasts per HPF as grade 2, and greater than 15 per HPF as grade 3 follicular lymphomas. Low-grade (grades 1 and 2) follicular lymphomas are composed of a relatively homogeneous population of small cleaved lymphocytes. Grade 3 follicular lymphomas, which by definition have an increased number of large noncleaved cells and have been provisionally subcategorized into $3 \mathrm{a}$ and $3 \mathrm{~b}$, with the former having a mix of cleaved and large noncleaved cells, and the latter having sheets or large clusters of large noncleaved cells Peripheral blood involvement is seen in about $10 \%$ of cases. Bone marrow involvement occurs in $85 \%$ of cases and characteristically takes the form of paratrabecular lymphoid aggregates. The neoplastic cells express CD19, CD20, CD10, surface Ig, and BCL6 (B-cell lymphoma 6). BCL2 is expressed in more than $90 \%$ of cases. CD5 and cyclin D1 are negative. Ki67 is low [25] (Figure 3).

\subsubsection{Highlights in recent WHO classification}

- Mutational landscape better understood but the clinical impact remains to be determined [24, 47-51].

In situ follicular neoplasia.

- New name for in situ follicular lymphoma reflects low risk of progression to lymphoma.

\subsubsection{Pediatric-type FL}

- A localized clonal proliferation with excellent prognosis; a conservative therapeutic approach may be sufficient.

- Occurs in children and young adults, rarely in older individuals.

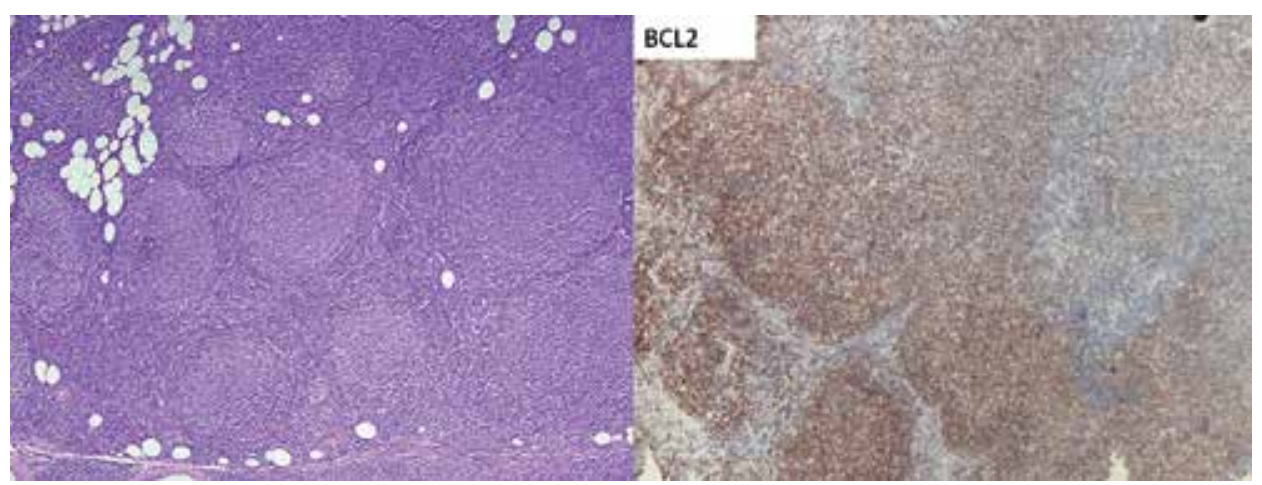

Figure 3.

Follicular lymphoma showing nodular pattern with neoplastic follicles occupying cortex and medulla and showing BCL2 positivity. 


\subsubsection{Duodenal-type FL}

- Localized process with low risk for dissemination. Predominantly diffuse FL with 1 p36 deletion.

- Accounts for some cases of diffuse FL lacks BCL2 rearrangement; presents as a localized mass, often inguinal.

\subsubsection{Treatment and prognosis}

Histological grade correlates with prognosis with grade 1-2 follicular lymphoma cases being indolent and usually not curable by aggressive therapy; and needs to palliate patients with low-dose chemotherapy or immunotherapy (e.g., anti-CD20 antibody). Median survival is 7-9 years. Histologic transformation occurs in 30-50\% of follicular lymphomas, most commonly to diffuse large B-cell lymphoma $[1,25]$.

\subsection{Mantle cell lymphoma}

Mantle cell lymphoma (MCL) is an uncommon lymphoid neoplasm. It usually presents in the fifth to sixth decades of life and shows a male predominance. Virtually all mantle cell lymphomas have an $(11 ; 14)$ translocation involving the IgH locus on chromosome 14 and the cyclin D1 locus on chromosome 11 that leads to overexpression of cyclin D1. The most common presentation is painless lymphadenopathy. Symptoms related to the involvement of the spleen (present in $~ 50 \%$ of cases) and extranodal sites are also common. In GIT present as lymphomatous polyposis of the lower gastrointestinal tract $[1,25,52]$.

\subsubsection{Morphology and immunophenotype}

MCL consists of a homogeneous population of small lymphocytes with irregular to occasionally deeply clefted (cleaved) nuclear contours. In most cases the nuclear chromatin is condensed, nucleoli are inconspicuous, and the cytoplasm is scant. It usually has a diffuse growth pattern or surrounds reactive germinal centers in a mantle zone pattern. Extension of the lymphoma into the capsule and perinodal fat is common Occasionally, tumors composed of intermediate-sized cells with more open chromatin and a brisk mitotic rate are observed; immunophenotyping is necessary to distinguish these "blastoid" variants.

Mantle cell lymphomas express high levels of cyclin D1. Most tumors are also express CD19, CD20. It is usually CD5+, SOX11 +, FMC7+ (Flinders Medical Centre), BCL1+ and CD23-, CD10-, CD200-, LEF1-, which help to distinguish it from CLL/SLL. The IgH genes lack somatic hypermutation, supporting an origin from a naive B cell [25] (Figure 4).

\subsubsection{Highlights in recent WHO classification}

- Two MCL subtypes recognized with different clinicopathological manifestations and molecular pathogenetic pathways [24, 52-54]

1.unmutated/minimally mutated immunoglobulin heavy chain gene (IGHV) and mostly SOX11 positive

2. mutated IGHV and mostly SOX11 negative (indolent leukemic non-nodal MCL with $\mathrm{PB}$ ), bone marrow (BM), (splenic involvement, may become 


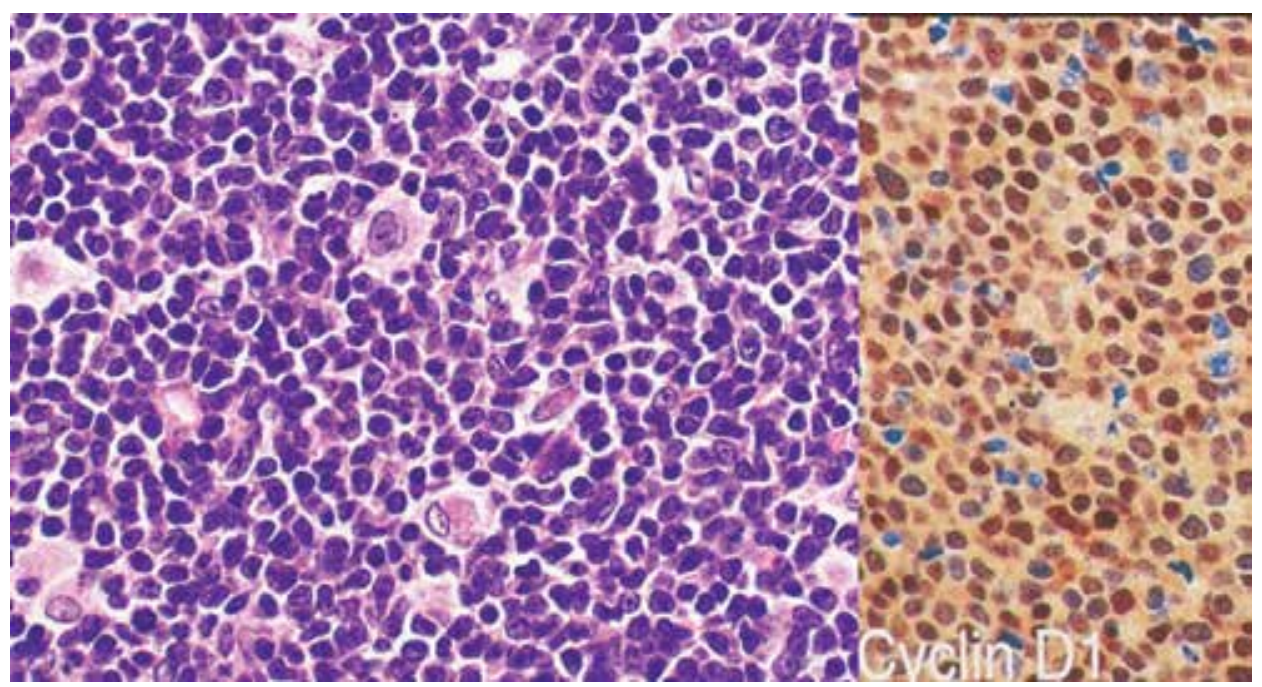

Figure 4.

Mantle cell lymphoma showing cyclin D1 positivity.

more aggressive).Mutations of potential clinical importance, such as TP53, NOTCH 1/2, recognized in a small proportion of cases.

- CCND2 (Cyclin D2) rearrangements in approximately half of cyclin D1 negative MCL.

In situ mantle cell neoplasia-New name for in situ MCL, reflecting low clinical risk.

\subsubsection{Treatment and prognosis}

MCL is usually not curable with conventional chemotherapy, and most patients succumb to organ dysfunction caused by tumor infiltration. The prognosis is poor with median survival of only 3-4 years. The blastoid variant is associated with even shorter survivals. Hematopoietic stem cell transplantation and proteasome inhibitors are newer therapeutic approaches that show some promise [1, 25].

\subsection{Marginal zone lymphomas}

Marginal zone lymphoma (MZL) is a group of B-cell tumors that arise from lymph nodes, spleen, or extranodal tissues. In most cases, there is evidence of somatic hypermutation of memory B-cell origin. The disease begins as a polyclonal immune reaction. With time, however, tumors may acquire additional mutations that render their growth and survival antigen-independent, such as the $(11 ; 18)$, $(14 ; 18)$, or $(1 ; 14)$ chromosomal translocations, which are relatively specific for extranodal marginal zone lymphomas [1,25].

\subsubsection{Nodal marginal zone B-cell lymphoma}

Nodal marginal zone B-cell lymphomas are uncommon lymphomas in which the tumor cells resemble the cytology of those in splenic and extranodal marginal zone B-cell lymphomas of MALT, but there is no evidence for splenic or extranodal disease. Clinically, these lymphomas appear more extensive at presentation than 
MALT lymphomas. They have a tendency to early relapse, and a small minority transform to large cell lymphoma.

\subsubsection{Splenic marginal zone B-cell lymphoma}

Splenic marginal zone B-cell lymphoma (SMZL) is a small B-cell lymphoma of the white pulp of the spleen that often involves the splenic hilar lymph nodes, bone marrow, and peripheral blood. Patients with splenic marginal zone B-cell lymphoma characteristically present with splenomegaly and many have B-symptoms (fever, weight loss, and night sweats). Peripheral blood shows circulating neoplastic lymphocytes that have a villous appearance. These cases were previously termed 'splenic lymphoma with villous lymphocytes'.

\subsubsection{Extranodal marginal zone B-cell lymphoma of mucosa-associated lymphoid tissue}

Extranodal marginal zone B-cell lymphomas arises in normal sites for mucosal immunity (MALT), such as intestinal Peyer patches, or in sites of inflammation triggered by autoimmune disorders, such as Hashimoto thyroiditis or Sjögren syndrome, or by infection (Helicobacter pylori-associated chronic gastritis. They may regress if the inciting agent (e.g., Helicobacter pylori) is eradicated suggesting that extranodal marginal zone lymphomas arise in chronically inflamed tissues that lie on a continuum between reactive lymphoid hyperplasia and full-blown lymphoma. Transformation to large cell lymphoma may occur. The $t(11 ; 18)$ chromosomal abnormality is more specific and involves fusion of the API2 gene (an apoptosis inhibitor) on chromosome 11q21 and the MLT1 gene (a caspase-like protease) on chromosome 18q21. It is found in $40 \%$ of patients with MALT lymphomas. Two, less common, translocations are $\mathrm{t}(1 ; 14)(\mathrm{p} 22 ; \mathrm{q} 32)$ and $\mathrm{t}(14 ; 18)(\mathrm{q} 32 ; 21)$. These three translocations are not found in marginal zone B-cell lymphomas of spleen and lymph node.

\subsubsection{Morphology and immunophenotype}

These lymphomas are composed of small- to medium-sized lymphocytes that exhibit variable cytological features. In some cases, lymphocytes with irregular nuclear contours resembling follicular small cleaved cells or centrocytes may predominate. Other cases may be composed primarily of cells with abundant pale cytoplasm resembling monocytoid B cells. Cases with an abundance of small lymphocytes or plasma cells also may be seen. Regardless of the neoplastic cells' appearance, they produce a diffuse infiltrate that invades epithelial structures, producing lymphoepithelial lesions (Figure 5).

The lymphoid component expresses B-cell markers such as CD20, CD19 and CD43 and monotypic surface Ig (usually IgM without IgD). Negative for CD5, CD10, CYCLIN D1, and CD23.

\subsubsection{Treatment and prognosis}

Management of gastric MALToma with antibiotic therapy for $H$. pylori resulted in regression of lymphoma. Cases with the $t(11 ; 18)(\mathrm{q} 21 ; \mathrm{q} 21)$ appear to be resistant to $H$. pylori eradication therapy, Radiation therapy or single-agent chemotherapy is also effective in low-grade MALToma. MALT lymphomas have an indolent natural course and are slow to disseminate. Recurrences that can occur after many years. Median survival has been variable. SMZL tends to respond favorably to splenectomy alone in contrast to its poor response to chemotherapy $[1,25]$. 


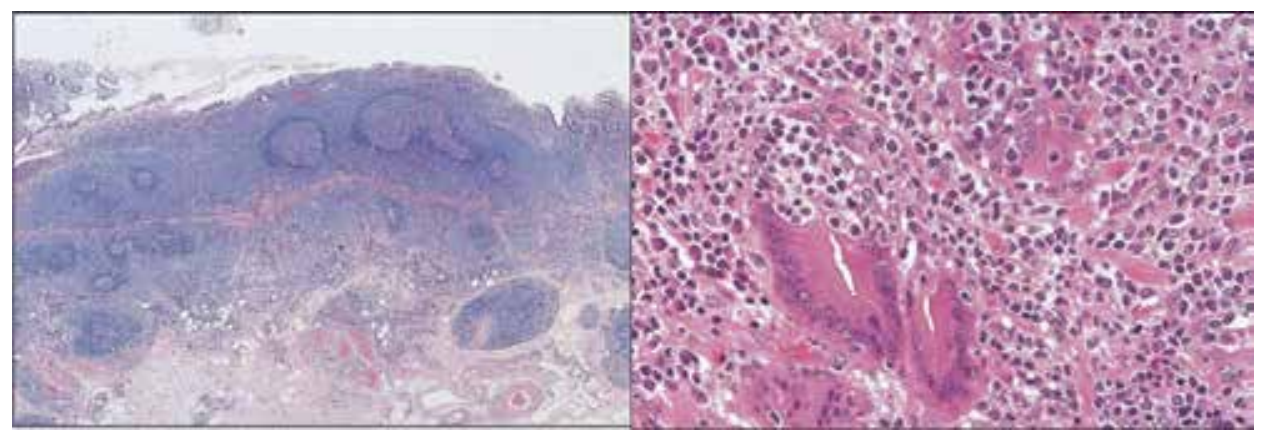

Figure 5.

Extranodal marginal zone lymphoma of stomach showing lymphoepithelial lesions.

\subsection{Lymphoplasmacytic lymphoma}

Lymphoplasmacytic lymphoma is a B-cell neoplasm of older adults that usually presents in the sixth or seventh decade of life and is characterized by tumor cells that undergo terminal differentiation to plasma cells. Most commonly, the plasma cell component secretes monoclonal IgM, often in amounts sufficient to cause a hyperviscosity syndrome known as Waldenström macroglobulinemia. Unlike multiple myeloma, complications stemming from the secretion of free light chains (e.g., renal failure and amyloidosis) are relatively rare and bone destruction does not occur. About $90 \%$ of Lymphoplasmacytic lymphoma are associated with acquired mutations in Myeloid differentiation factor 88 (MYD88) [55, 56]. The dominant presenting complaints are nonspecific and include weakness, fatigue, and weight loss. Approximately half the patients have lymphadenopathy, hepatomegaly, and splenomegaly. Anemia caused by marrow infiltration is common. About $10 \%$ of patients have autoimmune hemolysis caused by cold agglutinins. Cryoglobulinemia resulting from the precipitation of macroglobulins at low temperatures, which produces symptoms such as Raynaud phenomenon and cold urticaria [1, 25].

\subsubsection{Morphology and immunophenotype}

The neoplasm is composed of infiltration of lymphocytes, plasma cells, and plasmacytoid lymphocytes in varying proportions, often accompanied by mast cell hyperplasia. The lymphoid cells expresses CD20 and surface Ig, the plasma cells secretes the same Ig that is expressed on the surface of the lymphoid cells. This is usually IgM but can also be IgG or IgA (Figure 6).

\subsubsection{Highlights in recent WHO classification}

MYD88 L265P mutation in the vast majority of cases impacting diagnostic criteria even though finding is not specific for LPL $[24,55,56]$.

IgM monoclonal gammopathy of undetermined significance (MGUS) is more closely related to LPL and other B-cell lymphomas than to myeloma.

\subsubsection{Treatment and prognosis}

LPL is an incurable progressive disease, however the tumor growth can be controlled with low doses of chemotherapy and immunotherapy with anti-CD20 antibody. Symptoms caused by the high IgM levels like hyperviscosity and hemolysis can be alleviated by plasmapheresis. The clinical course is typically indolent, 


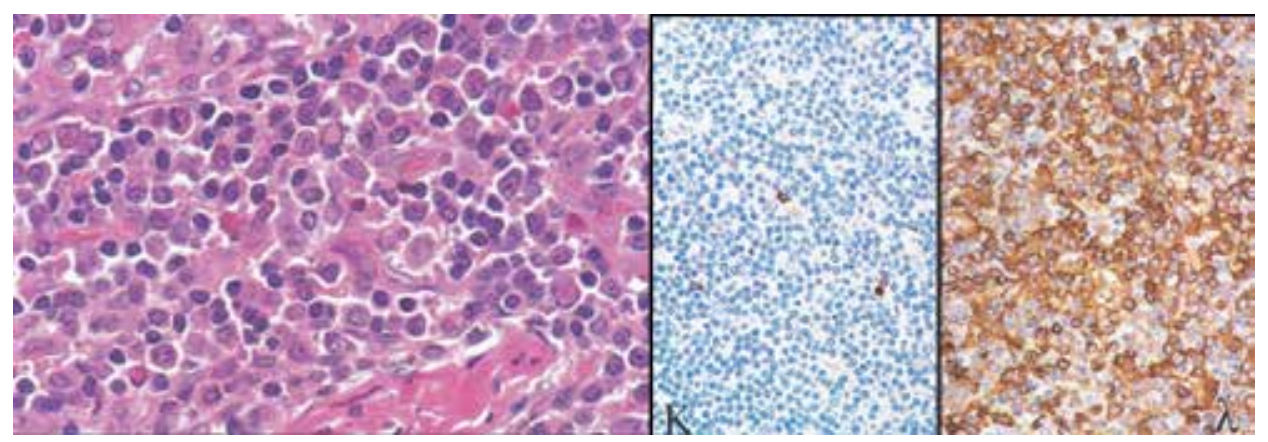

Figure 6.

Lymphoplasmacytic lymphoma showing lambda restriction.

with median survivals of 5-10 years. Transformation to large-cell lymphoma is uncommon $[1,25]$.

\subsection{Burkitt lymphoma}

Burkitt Lymphoma is a high-grade B-cell lymphoma composed of medium-sized, rapidly dividing lymphocytes. Less commonly, they have a leukemic phase. It is classified into (1) African (endemic) Burkitt lymphoma, (2) sporadic (nonendemic) Burkitt lymphoma, and (3) a subset of aggressive lymphomas occurring in individuals infected with HIV. Translocations of the MYC gene on chromosome 8 lead to increased MYC protein levels. The translocation partner for MYC is usually the IgH locus [ $\mathrm{t}(8$; 14)] but may also be the $\operatorname{Ig} \kappa[t(2 ; 8)]$ or $\lambda[t(8 ; 22)]$ light chain loci. The translocated MYC allele often harbors additional point mutations. Endemic Burkitt lymphomas are seen to be latently infected with Epstein bar virus (EBV) (100\%) and 20 to 40\% in sporadic and immunodeficiency-associated Burkitt lymphomas. Both endemic and sporadic Burkitt lymphomas are found mainly in children or young adults. Most tumors involve extranodal sites. Endemic Burkitt lymphoma usually presents as mandibular mass and unusually involves abdominal viscera. In contrast, sporadic Burkitt lymphoma often involves the ileocecum and peritoneum [1, 25, 57-59].

\subsubsection{Morphology and immunophenotype}

Burkitt Lymphoma shows diffuse infiltrate of intermediate-sized lymphoid cells with round or oval nuclei, coarse chromatin, several nucleoli, and a moderate amount of cytoplasm with high mitotic index and numerous apoptotic, cells the nuclear remnants of which are phagocytosed by interspersed benign macrophages. These phagocytes have abundant clear cytoplasm, creating a characteristic "starry sky" pattern. These are tumors of mature B cells that express surface IgM, CD19, CD20, CD10, and BCL6, and negative for BCL2 and Tdt. Ki 67 approaches nearly 100\% [1, 25] (Figure 7).

\subsubsection{Highlights in recent WHO classification}

- TCF3 (Transcription Factor 3) or ID3 (Inhibitor of DNA Binding 3), mutations in up to; $70 \%$ of cases $[24,57-61]$.

\subsubsection{Burkitt-like lymphoma with 11q aberration}

- A new provisional entity that closely resembles Burkitt lymphoma but lacks MYC rearrangement and has some other distinctive features. 


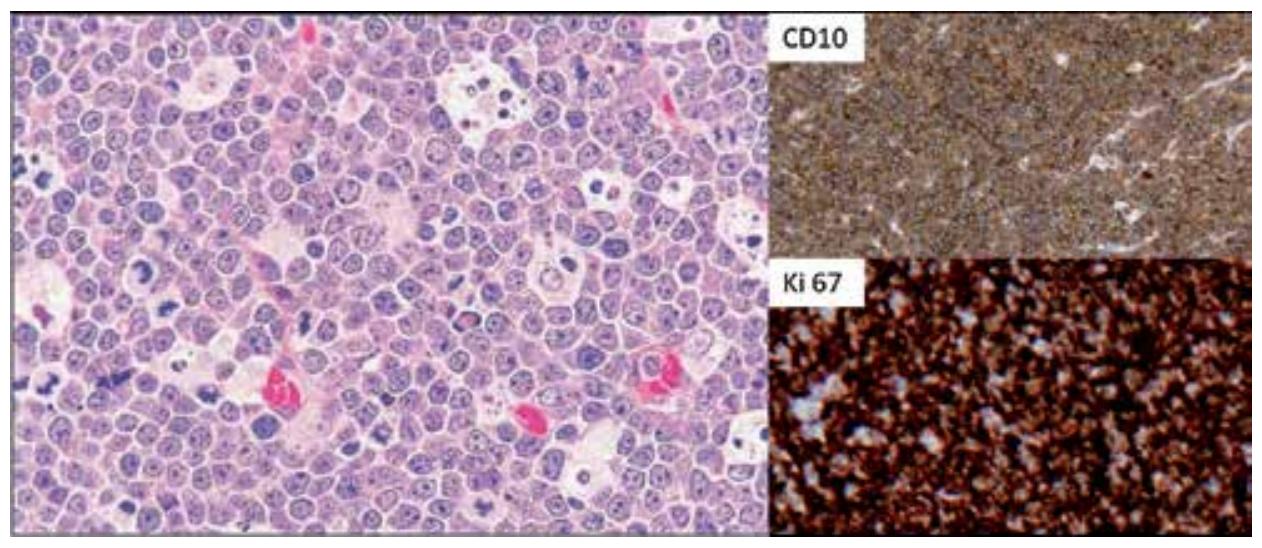

Figure 7.

Burkitt lymphoma showing starry sky pattern with CD10 positivity and high Ki67.

\subsubsection{Treatment and prognosis}

Burkitt lymphoma is very aggressive but responds well to intensive chemotherapy. Most children and young adults can be cured. The outcome is more guarded in older adults.

\subsection{Diffuse large B-cell lymphoma}

Diffuse large B-cell lymphoma (DLBCL) is the most common form of NHL. There is a slight male predominance. The median patient age is about 60 years, but can also occur in young adults and children.

DLBCL is molecularly heterogeneous. One frequent pathogenic event is dysregulation of BCL6. About 30\% of DLBCLs contain various translocations that have in common a breakpoint in BCL6 at chromosome 3q27. Mutations are also seen in multiple other oncogenes including MYC and overexpression of the antiapoptotic protein BCL2. Tumors with BCL2 rearrangements usually lack BCL6 rearrangements. Co-expression of MYC with BCL2 and or BCL6 is now considered as double hit or triple hit lymphomas $[1,25,63]$. DLBCL typically presents as a rapidly enlarging mass at a nodal or extranodal site. Extranodal sites include the gastrointestinal tract, skin, bone, brain, and other tissues. Bone marrow involvement is relatively uncommon and usually occurs late in the course. Rarely, a leukemic picture emerges.

\subsubsection{Morphology and immunophenotype}

DLBCL usually shows a diffuse pattern of growth by a monotonous population of large cells that have a round or oval nucleus that appears vesicular due to margination of chromatin to the nuclear membrane, but large multilobated or cleaved nuclei are prominent in some cases. The cytoplasm is usually moderately abundant and may be pale or basophilic (Figure 8). More anaplastic tumors may even contain multinucleated cells with large inclusion-like nucleoli.

DLBCL express CD19 and CD20 and show variable expression of germinal center B-cell markers such as CD10 and BCL6 and for markers IRF4 (interferon regulatory factor4) and MUM1 (melanoma associated antigen (mutated) 1) which classifies DLBCL into germinal center type and non-germinal center type. Cases with CD10 expression by $>30 \%$ of cells are regarded as GC type as well as cases that are CD10-, BCL6+, IRF4/MUM1-. All other cases are regarded as of non-GC type [25, 62]. 


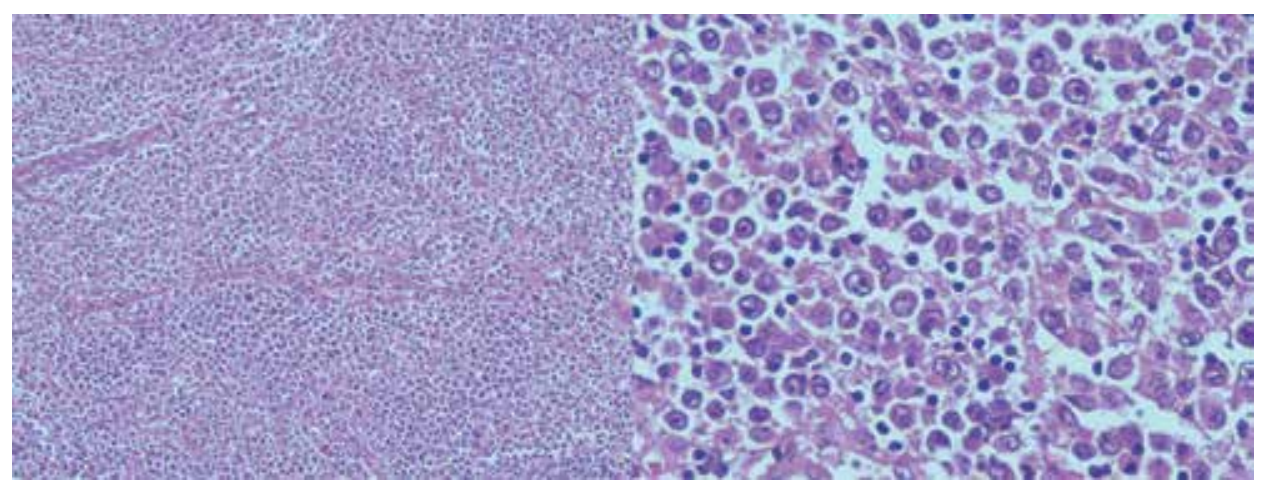

Figure 8

Diffused large cell lymphoma showing diffuse effacement by large cells.

\subsubsection{Highlights in recent WHO classification}

- The distinction of germinal center B-cell-like (GCB) vs. activated B-cell-like $(\mathrm{ABC}) /$ non-GC type required with the use of immunohistochemical algorithm may affect therapy [24, 62-65].

- Coexpression of MYC and BCL2 considered new prognostic marker (doubleexpressor lymphoma).

- Mutational landscape better understood but the clinical impact remains to be determined. EBV + DLBCL, NOS.

- This term replaces EBV + DLBCL of the elderly because it may occur in younger patients.

- Does not include EBV + B-cell lymphomas that can be given a more specific diagnosis.

\subsubsection{Treatment and prognosis}

DLBCLs are aggressive tumors that are rapidly fatal without treatment. With intensive combination chemotherapy, $60-80 \%$ of patients achieve a complete remission, and 40-50\% are cured. Adjuvant therapy with antiCD20 antibody improves both the initial response and the overall outcome. DLBCLs with MYC translocations have a worse prognosis than those without and may be better treated with chemotherapy regimens for Burkitt lymphoma $[1,25]$.

\subsection{Hairy cell leukemia (HCL)}

Hairy cell leukemia (HCL) is a rare but distinctive B-cell neoplasm constitutes about $2 \%$ of all leukemia. It is predominantly a disease of middle-aged white males, with a median age of 55 and a male-to-female ratio of 5:1. Hairy cell leukemia are associated in more than $90 \%$ of cases with activating point mutations in the serine/ threonine kinase BRAF (B-Raf) [66]. Patients usually presents with massive splenomegaly. Hepatomegaly is less common and lymphadenopathy is rare. Pancytopenia is seen in more than half the cases $[1,25]$. 


\subsubsection{Morphology and immunophenotype}

On routine peripheral blood smears, the cells have round, oblong, or reniform nuclei and moderate amounts of pale blue cytoplasm with thread-like or bleb-like extensions. On bone marrow aspiration the cells cannot be aspirated and gives "dry tap", Bone marrow biopsy shows diffuse interstitial infiltrate of tumor cells enmeshed in an extracellular matrix composed of reticulin fibrils giving fried egg appearance. Spleen appears beefy red on gross appearance. Microscopy shows heavily infiltrated splenic red pulp leading to obliteration of white pulp.

The classic immunophenotypic profile of HCL consists of bright monotypic surface immunoglobulin, bright coexpression of CD20, CD22 and CD11c, and expression of CD103, CD25, CD123, T-bet, Annexin A1 (ANXA1), DBA.44 (CD72), FMC-7 and cyclin D1 (usually weak) [1, 25].

\subsubsection{Treatment and prognosis}

Hairy cell leukemia follows an indolent course and is sensitive to "gentle" chemotherapeutic regimens, which produce longlasting remissions. BRAF inhibitors appear to produce excellent responses in tumors that have failed conventional chemotherapy. The overall prognosis is excellent $[1,25]$.

\subsection{Plasma cell neoplasms and related disorders}

These B-cell proliferations contain neoplastic plasma cells that virtually always secrete a monoclonal Ig or Ig fragment. These plasma cell neoplasms are also termed as plasma cell dyscrasias. Multiple myeloma is associated with frequent rearrangements involving the IgH locus and various proto-oncogenes. Included among the loci that are recurrently involved in translocations with the Ig heavy-chain gene on chromosome 14q32 are the cell cycle-regulatory genes cyclin D1 on chromosome 11q13 and cyclin D3 on chromosome 6p21. Deletions of chromosome 17p that involve the TP53 tumor suppressor locus also occur and are associated with a poor outcome. Late-stage, highly aggressive forms of the disease such as plasma cell leukemia are associated with the acquisition of rearrangements involving MYC. More recent deep sequencing of myeloma genomes has identified frequent mutations involving components of the nuclear factor $\kappa \mathrm{B}(\mathrm{NF}-\kappa \mathrm{B})$ pathway, which supports B-cell survival. Based on these studies, it is evident that myeloma is molecularly heterogeneous $[1,67]$.

The various spectrum of plasma cell dyscrasias are [68]:

Non-IgM monoclonal gammopathy of undetermined significance

Serum monoclonal protein (non-IgM type) $<30 \mathrm{~g} / \mathrm{dl}$.

Clonal bone marrow plasma cells $<10 \%$.

The absence of end-organ damage such as hypercalcemia, renal insufficiency, anemia, and bone lesions (CRAB) or amyloidosis that can be attributed to the plasma cell proliferative disorder.

IgM monoclonal gammopathy of undetermined significance

Serum IgM monoclonal protein $<30 \mathrm{~g} / \mathrm{dl}$.

Bone marrow lymphoplasmacytic infiltration $<10 \%$.

No evidence of anemia, constitutional symptoms, hyperviscosity, lymphadenopathy, hepatosplenomegaly, or other end-organ damage that can be attributed to the underlying lymphoproliferative disorder. 


\section{Light-chain monoclonal gammopathy of undetermined significance}

Abnormal free light chain (FLC) ratio $(<0.26$ or $>1.65)$.

Increased level of the appropriate involved light chain (increased $\kappa$ FLC in patients with a ratio $>1.65$ and increased $\lambda$ FLC in patients with a ratio).

No immunoglobulin heavy chain expression on immunofixation.

The absence of end-organ damage such as hypercalcemia, renal insufficiency, anemia, and bone lesions $(\mathrm{CRAB})$ or amyloidosis that can be attributed to the plasma cell proliferative disorder Clonal bone marrow plasma cells $<10 \%$.

Urinary monoclonal protein $<500 \mathrm{mg} / 24 \mathrm{~h}$.

\section{Solitary plasmacytoma}

Biopsy-proven solitary lesion of bone or soft tissue with evidence of clonal plasma cells.

Normal bone marrow with no evidence of clonal plasma cells.

Normal skeletal survey and magnetic resonance imaging (MRI) or Computed tomography (CT) of spine and pelvis (except for the primary solitary lesion) Absence of end-organ damage such as hypercalcaemia, renal insufficiency, anemia, or bone lesions (CRAB) that can be attributed to a lymphoplasma cell proliferative disorder.

\section{Solitary plasmacy toma with minimal marrow involvement}

Biopsy-proven solitary lesion of bone or soft tissue with evidence of clonal plasma cells.

Clonal bone marrow plasma cells $<10 \%$.

Normal skeletal survey and MRI (or CT) of spine and pelvis (except for the primary solitary lesion) Absence of end-organ damage such as hypercalcemia, renal insufficiency, anemia, or bone lesions that can be attributed to a lymphoplasma cell proliferative disorder.

Heavy-chain disease is a rare monoclonal gammopathy characterized by synthesis and secretion of free heavy-chain fragments and is seen associated with diseases including lymphoplasmacytic lymphoma and an unusual small bowel marginal zone lymphoma that occurs in malnourished populations (so-called Mediterranean lymphoma).

Smoldering multiple myeloma-both criteria must be met.

- Serum monoclonal protein (IgG or IgA) $\geq 30 \mathrm{~g} / \mathrm{L}$ or urinary monoclonal protein $\geq 500 \mathrm{mg}$ per $24 \mathrm{~h}$ and/or clonal bone marrow plasma cells $10-60 \%$.

- Absence of myeloma defining events or amyloidosis.

Multiple myeloma is a plasma cell neoplasm commonly associated increased plasma cells in the marrow with accompanying features like lytic bone lesions, hypercalcemia, renal failure, and acquired immune abnormalities. It is commonly seen in older adults, with a peak age of incidence of 65-70 years.

Revised International Myeloma Working Group diagnostic criteria for multiple myeloma and smoldering multiple myeloma [68].

Definition of multiple myeloma

- Clonal bone marrow plasma cells $\geq 10 \%$ or biopsy-proven bony or extramedullary plasmacytoma* and any one or more of the following myeloma defining events: 
Myeloma defining events:

- Evidence of end-organ damage that can be attributed to the underlying plasma cell proliferative disorder, specifically:

- Hypercalcaemia: serum calcium $>0.25 \mathrm{mmol} / \mathrm{L}(>1 \mathrm{mg} / \mathrm{dL})$ higher than the upper limit of normal or $>2.75 \mathrm{mmol} / \mathrm{L}(>11 \mathrm{mg} / \mathrm{dL})$

- Renal insufficiency: creatinine clearance $177 \mu \mathrm{mol} / \mathrm{L}(>2 \mathrm{mg} / \mathrm{dL}$ )

- Anemia: hemoglobin value of $>20 \mathrm{~g} / \mathrm{L}$ below the lower limit of normal, or a hemoglobin value $<100 \mathrm{~g} / \mathrm{l}$

- Bone lesions: one or more osteolytic lesions on skeletal radiography, CT, or positron emission tomography-computed tomography (PET-CT)

Anyone or more of the following biomarkers of malignancy

- Clonal bone marrow plasma cell percentage* $\geq 60 \%$

- Involved: uninvolved serum free light chain ratio $₫ \geq 100$

- 1 focal lesion on MRI studies

\subsubsection{Morphology and immunophenotype.}

Multiple myeloma is characterized by infiltration of marrow by plasma cells in the interstitium, nodules or in diffuse sheets that completely replace normal elements (Figure 9). Plasma cells can be relatively normal-appearing plasma cells, plasmablasts or binucleated and multinucleated cells. Other cytologic

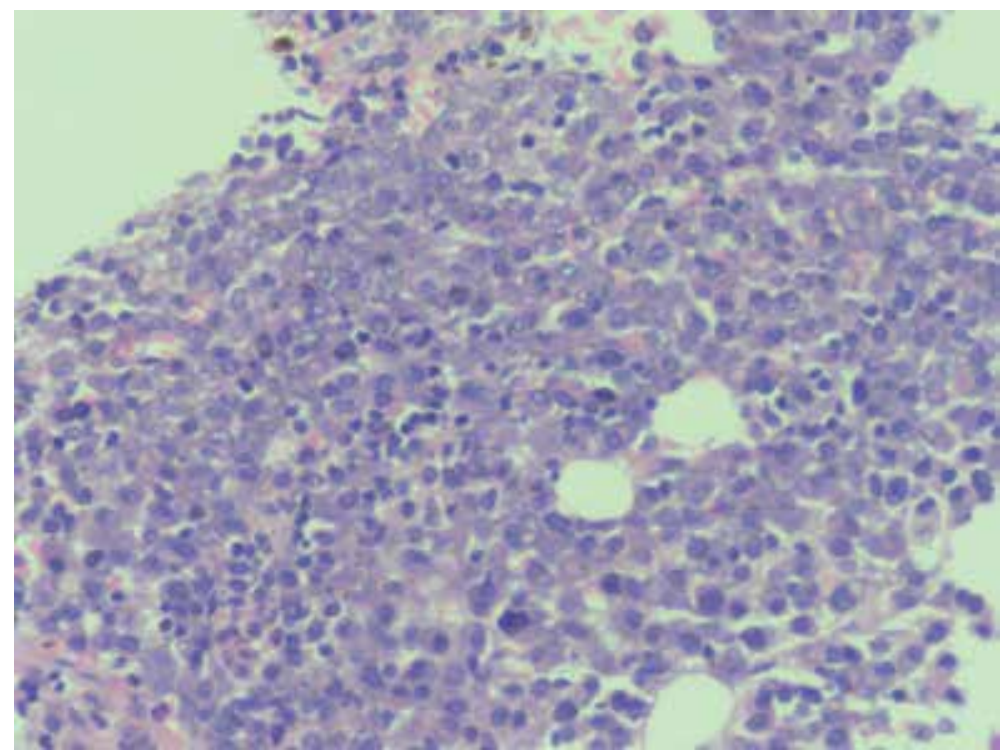

Figure 9.

Bone marrow biopsy showing sheets of plasma cells replacing normal hematopoietic elements. 
variants include flame cells with fiery red cytoplasm, Mott cells with multiple grapelike cytoplasmic droplets, and cells containing a variety of other inclusions-Russell bodies (cytoplasmic) or Dutcher bodies (nuclear), including fibrils, crystalline rods, and globules. Peripheral blood smears shows rouleaux formation. Rarely, tumor cells enters the peripheral blood, giving rise to plasma cell leukemia. Plasma cell tumors are positive for CD 38, CD138, and often express CD56, a feature that can be helpful in identifying small populations of neoplastic cells.

\subsubsection{Treatment and prognosis}

The prognosis is variable but has improved in recent years with new therapeutic approaches. The median survival is 4-7 years. Translocations involving cyclin D1 are associated with a good outcome, whereas deletions of 13q, deletions of $17 p$, and the $t(4 ; 14)$ are associated with more aggressive course. Hematopoietic stem cell transplantation prolongs life but has not yet proven to be curative. Solitary osseous plasmacytoma almost inevitably progresses to multiple myeloma but can take 10-20 years or longer. In contrast, extraosseous plasmacytomas, particularly those involving the upper respiratory tract, are frequently cured by local resection. About $75 \%$ of patients of smoldering myeloma progress to multiple myeloma over a 15 -year period. Approximately $1 \%$ of patients with MGUS develop asymptomatic plasma cell neoplasm, usually multiple myeloma, per year, a rate of conversion that remains roughly constant over time $[1,25,68]$.

\section{Staging, prognosis, and treatment}

The Ann Arbor staging classification (Table 2) which was developed for HD in 1971, has been the standard scheme for NHL [69, 70]; however, it does not account for tumor burden and does not correlate well with prognosis. The Prognosis and

\begin{tabular}{ll}
\hline Stage I & Involvement in a single lymph node region or single extralymphatic site \\
\hline Stage II & $\begin{array}{l}\text { Involvement of two or more lymph node regions on the same side of the diaphragm; localized } \\
\text { contiguous involvement of only one extralymphatic site and lymph node region (stage IIE) }\end{array}$ \\
\hline Stage III & Involvement of lymph node regions on both sides of the diaphragm; may include spleen \\
\hline Stage IV & $\begin{array}{l}\text { Disseminated involvement of one or more extralymphatic organs with or without lymph node } \\
\text { involvement }\end{array}$ \\
\hline
\end{tabular}

Table 2.

The Ann Arbor staging classification.

\begin{tabular}{cccc}
\hline $\begin{array}{l}\text { International Prognostic } \\
\text { Index }\end{array}$ & Adverse factors & Risk group & $\begin{array}{c}\text { No. of } \\
\text { factors }\end{array}$ \\
\hline & Performance status $=2$ & Low & 0,1 \\
\hline Lactate dehydrogenase $>$ normal & Low-intermediate & 2 \\
\hline Extranodal sites $=2$ & High-intermediate & 3 \\
\hline Stage III and IV disease & High & 4,5 \\
\hline Age $>60$ years & & \\
\hline
\end{tabular}

Table 3.

International Prognostic Index. 
treatment depends not only on the stage but also on a variety of clinical parameters that reflect tumor bulk and kinetics including the size of the mass, lactate dehydrogenase (LDH) level, number of extranodal sites, etc.

The international prognostic index (IPI) (Table 3) was developed to correlate clinical parameters with prognosis and appears to be more useful than the Ann Arbor staging system in predicting survival. Studies have indicated that the IPI correlates with prognosis for all histologies [71-73]. Additional biologic and genetic parameters, particularly genomic profiling, further subdivide prognostic groups in NHL.

Therapy follows the assessment of the patient, the pathology, and the stage of the disease. The ability of the patient to tolerate therapy is dependent on age, performance status, and, if present, immunodeficiency due to a prelymphomatous condition. Various treatment modalities include observation, radiotherapy for localized disease, chemotherapy, immunotherapy, and stem cell transplantations.

\section{Conclusion}

B-cells though plays a major role in humoral immunity can also lead to various pathologic diseases. B-cell lymphomas are malignant neoplasms that arise from various stages of differentiation of B-cells which are classified based on the cell of origin and behavior. Historically, there has been much controversy in the classification of lymphoid neoplasms, but consensus has been reached through the use of objective molecular diagnostic tools. The current WHO classification uses morphologic, immunophenotypic, genotypic, and clinical features to classify the lymphoid neoplasms into five broad categories as precursor B-cell neoplasms, peripheral B-cell neoplasms, precursor T-cell neoplasms, peripheral T-cell neoplasms and Hodgkin lymphoma. B-cell lymphomas include precursor B-cell neoplasms and peripheral B-cell neoplasms. Hodgkin lymphoma though originates from B-cell has distinctive pathologic features and is treated as a separate entity. B-cell lymphomas range in their clinical behavior from low grade to high grade and also have histological or clinical progression during a patient's clinical course. For these reasons, the WHO classification does not attempt to stratify lymphoid malignancies in terms of grade. Also both morphology and immunophenotype often change over time with the acquisition of additional genetic changes. Hence B-Cell lymphomas are expanding with emerging new entities due to its wide molecular/genetic landscape and are being revised frequently for better understanding and diagnosis which helps in managing with targeted therapies.

\section{Conflict of interest}

Authors declare no conflict of interest. 


\section{Author details}

Subramanian Kalaivani Selvi ${ }^{1 *}$, B.H. Srinivas ${ }^{2}$ and Sadhanandham Shrinuvasan ${ }^{3}$

1 Department of Pathology, Sri Manakula Vinayagar Medical College and Hospital, Puducherry, India

2 Department of Pathology, Jawaharlal Institute of Postgraduate Medical Education and Research (JIPMER), Puducherry, India

3 Department of Radiology, Indira Gandhi Medical College and Research Institute, Puducherry, India

*Address all correspondence to: klvnselvi@yahoo.co.in

\section{IntechOpen}

(C) 2019 The Author(s). Licensee IntechOpen. This chapter is distributed under the terms of the Creative Commons Attribution License (http://creativecommons.org/licenses/ by/3.0), which permits unrestricted use, distribution, and reproduction in any medium, provided the original work is properly cited. (cc) BY 


\section{References}

[1] Kumar V, Abbas AK, Aster

Robbins JC. Diseases of white blood cells, lymph nodes, spleen, and thymus. In: Robbins and Cotran Pathologic Basis of Disease. 9th ed. Philadelphia: Elsevier; 2015. pp. 579-628

[2] McCurley TL, Macon WR. Diagnosis and classification of non-Hodgkin lymphomas. In: Greer JP, Foerster J, Lukens JN, editors. Wintrobe's Clinical Hematology. 11th ed. Lippincott Williams \& Wilkins Publishers; 2003. pp. $1861-1878$

[3] Baris D, Zahm SH. Epidemiology of lymphomas. Current Opinion in Oncology. 2000;12:383-394

[4] Hodgkin T. On some morbid appearances of the absorbent glands and spleen. Transactions on the Royal Medico-Chirurgical Society of Glasgow. 1832;17:68-114

[5] Kundrat H. Ueber LymphoSarkomatosis. Wiener Klinische Wochenschrift. 1893;6:211-234

[6] Sternberg C. Uber eine eigenartige unter dem Bilde der Pseudoleukamic verlaufende Tuberculose des lymphateschen Apparates. Ztschr f Heilkd. 1898;19:21-90

[7] Reed DM. On the pathological changes in Hodgkin's disease, with especial reference to its relation to tuberculosis. The Johns Hopkins Medical Journal. 1902;10:133-196

[8] Gall EA, Mallory TB. Malignant lymphoma: A clinico-pathological survey of 618 cases. The American Journal of Pathology. 1942;18: 381-429

[9] Hicks EB, Rappaport H, Winter WJ. Follicular lymphoma: A re-evaluation of its position in the scheme of malignant lymphoma, based on a survey of 253 cases. Cancer. 1956;9:792-821

[10] Aisenberg AC, Bloch KJ.

Immunoglobulins on the surface of neoplastic lymphocytes. The New England Journal of Medicine. 1972;287:272-276

[11] Preud'homme JL, Seligmann M. Surface bound immunoglobulins as a cell marker in human lymphoproliferative diseases. Blood. 1972;40:777-794

[12] Lennert K, Stein H, Kaiserling E. Cytological and functional criteria for the classification of malignant lymphomata. British Journal of Cancer. 1975;31(Suppl. 2):29-43

[13] Lukes RJ, Collins RD. Immunologic characterization of human malignant lymphomas. Cancer. 1974;34(Suppl):1488-1503

[14] Aisenberg AC, Krontiris TG, Mak TW, et al. Rearrangement of the gene for the beta chain of the T-cell receptor in T-cell chronic lymphocytic leukemia and related disorders. The New England Journal of Medicine. 1985;313:529-533

[15] Korsmeyer SJ, Hieter PA, Ravetch JV, et al. Developmental hierarchy of immunoglobulin gene rearrangements in human leukemic pre-B-cells. Proceedings of the National Academy of Sciences of the United States of America. 1981;78:7096-7100

[16] Reis MD, Griesser H, Mak TW. T cell receptor and immunoglobulin gene rearrangements in lymphoproliferative disorders. Advances in Cancer Research. 1989;52:45-80

[17] Waldmann TA, Davis MM, Bongiovanni KF, et al. Rearrangements of genes for the antigen receptor on 
$\mathrm{T}$ cells as markers of lineage and clonality in human lymphoid neoplasms. The New England Journal of Medicine. 1985;313:776-783

[18] National Cancer Institute Sponsored Study of Classifications of nonHodgkin's Lymphomas. Summary and description of a working formulation for clinical usage. The non-Hodgkin's Lymphoma Pathologic Classification Project. Cancer. 1982;49:2112-2135

[19] Mason DY, Harris NL. Human Lymphoma: Clinical Implications of the REAL Classification. London: Springer Verlag; 1999

[20] Jaffe ES, Harris NL, Stein H, et al. Pathology \& Genetics: Tumours of Haematopoietic and Lymphoid Tissues. Lyon: IARC Press; 2001

[21] Harris NL, Jaffe ES, Diebold J, et al. World Health Organization classification of neoplastic diseases of the hematopoietic and lymphoid tissues: Report of the Clinical Advisory Committee Meeting-Airlie House, Virginia, November 1997. Journal of Clinical Oncology. 1999;17:3835-3849

[22] Jaffe ES, Harris NL, Stein H, Vardiman JW. Pathology and Genetics of Tumours of the Haematopoietic and Lymphoid Tissues. 3rd ed. Lyon: IARC Press; 2001

[23] Swerdlow SH, Campo E, Harris NL, et al. WHO Classification of Tumours of Haematopoietic and Lymphoid Tissues. 4th ed. Lyon, France: IARC; 2008. pp. 157-267

[24] Swerdlow SH, Campo E, Pileri SA, et al. The 2016 revision of the World Health Organization classification of lymphoid neoplasms. Blood. 2016;127:2375-2390. DOI: 10.1182/ blood-2016-01-643569

[25] Swerdlow SH, Campo E, Harris NL, et al. WHO Classification of Tumours of
Haematopoietic and Lymphoid Tissues. 5th ed. Lyon, France: IARC; 2017. pp. $189-342$

[26] Daniel A, Arber DA, Orazi A, Hasserjian R, et al. The 2016 revision to the World Health Organization classification of myeloid neoplasms and acute leukemia. Blood. 2016;127:2391-2405. DOI: 10.1182/ blood-2016-03-643544

[27] Louie S, Daoust PR, Schwartz RS. Immunodeficiency and the pathogenesis of non-Hodgkin's lymphoma. Seminars in Oncology. 1980;7:267-284

[28] Paya CV, Fung JJ, Nalesnik MA, et al. Epstein-Barr virus-induced post-transplant lymphoproliferative disorders. ASTS/ASTP EBV-PTLD task force and the Mayo Clinic Organized International Consensus Development Meeting. Transplantation. 1999;68:1517-1525

[29] Oksenhendler E, Boulanger E, Galicier L, et al. High incidence of Kaposi sarcoma-associated herpesvirusrelated non-Hodgkin lymphoma in patients with HIV infection and multicentric Castleman disease. Blood. 2002;99:2331-2336

[30] Pozzato G, Mazzaro C, Crovatto M, et al. Low-grade malignant lymphoma, hepatitis $C$ virus infection, and mixed cryoglobulinemia. Blood. 1994;84:3047-3053

[31] Parsonnet J, Hansen S, Rodriguez L, et al. Helicobacter pylori infection and gastric lymphoma. The New England Journal of Medicine. 1994;330:1267-1271

[32] Paltiel O, Schmit T, Adler B, et al. The incidence of lymphoma in first-degree relatives of patients with Hodgkin's disease and non-Hodgkin's lymphoma: Results and limitations of a registry-linked study. Cancer. 2000;88:2357-2366 
[33] Scherr PA, Hutchison GB, Neiman RS. Non-Hodgkin's lymphoma and occupational exposure. Cancer Research. 1992;52:5503s-5509s

[34] Vineis P, Faggiano F, Tedeschi M, et al. Incidence rates of lymphomas and soft-tissue sarcomas and environmental measurements of phenoxy herbicides. Journal of the National Cancer Institute. 1991;83:362-363

[35] Zahm SH, Blair A. Pesticides and non-Hodgkin's lymphoma. Cancer Research. 1992;52:5485s-5488s

[36] Correa A, Jackson L, Mohan A, et al. Use of hair dyes, hematopoietic neoplasms, and lymphomas: A literature review. II. Lymphomas and multiple myeloma. Cancer Investigation. 2000;18:467-479

[37] Davis S. Nutritional factors and the development of non-Hodgkin's lymphoma: A review of the evidence. Cancer Research. 1992;52:5492s-5495s

[38] Pui CH, Mullighan CG, Evans WE, et al. Pediatric acute lymphoblastic leukemia: Where are we going and how do we get there. Blood. 2012;120:1165

[39] Harrison CJ, Moorman AV, Schwab C, et al. Ponte di Legno International Workshop in Childhood Acute Lymphoblastic Leukemia. An international study of intrachromosomal amplification of chromosome 21 (iAMP21): Cytogenetic characterization and outcome. Leukemia. 2014;28(5):1015-1021

[40] Boer JM, Marchante JR, Evans WE, et al. BCRABL1-like cases in pediatric acute lymphoblastic leukemia: A comparison between DCOG/ Erasmus $\mathrm{MC}$ and COG/St. Jude signatures. Haematologica. 2015;100(9): e354-e357

[41] Rawstron AC, Shanafelt T, Lanasa MC, et al. Different biology and clinical outcome according to the absolute numbers of clonal B-cells in monoclonal B-cell lymphocytosis (MBL). Cytometry. Part B, Clinical Cytometry. 2010;78(Suppl 1):S19-S23

[42] Giné E, Martinez A, Villamor N, et al. Expanded and highly active proliferation centers identify a histological subtype of chronic lymphocytic leukemia ("accelerated" chronic lymphocytic leukemia) with aggressive clinical behavior. Haematologica. 2010;95(9):1526-1533

[43] Ciccone M, Agostinelli C, Rigolin GM, et al. Proliferation centers in chronic lymphocytic leukemia: Correlation with cytogenetic and clinicobiological features in consecutive patients analyzed on tissue microarrays. Leukemia. 2012;26(3):499-508

[44] Jeromin S, Weissmann S, Haferlach C, et al. SF3B1 mutations correlated to cytogenetics and mutations in NOTCH1, FBXW7, MYD88, XPO1 and TP53 in 1160 untreated $\mathrm{C}$

[45] Kridel R, Sehn LH, Gascoyne RD. Pathogenesis of follicular lymphoma. The Journal of Clinical Investigation. 2012;122:3424

[46] Roulland S, Kelly RS, Morgado E, et al. $\mathrm{t}(14 ; 18)$ translocation: A predictive blood biomarker for follicular lymphoma. Journal of Clinical Oncology. 2014;32(13):1347-1355

[47] Jegalian AG, Eberle FC, Pack SD, et al. Follicular lymphoma in situ: Clinical implications and comparisons with partial involvement by follicular lymphoma. Blood. 2011;118(11):2976-2984

[48] Pillai RK, Surti U, Swerdlow SH. Follicular lymphoma-like B cells of uncertain significance (in situ follicular lymphoma) may infrequently progress, but precedes follicular lymphoma, is 
associated with other overt lymphomas and mimics follicular lymphoma in flow cytometric studies. Haematologica. 2013;98(10):1571-1580

[49] Mamessier E, Song JY, Eberle FC, et al. Early lesions of follicular lymphoma: A genetic perspective. Haematologica. 2014;99(3):481-488

[50] Louissaint A Jr, Ackerman AM, Dias-Santagata D, et al. Pediatric-type nodal follicular lymphoma: An indolent clonal proliferation in children and adults with high proliferation index and no BCL2 rearrangement. Blood. 2012;120(12):2395-2404

[51] Schmatz AI, Streubel B, Kretschmer-Chott E, et al. Primary follicular lymphoma of the duodenum is a distinct mucosal/submucosal variant of follicular lymphoma: A retrospective study of 63 cases. Journal of Clinical Oncology. 2011;29(11):1445-1451

[52] Jares P, Colomer D, Campo E. Molecular pathogenesis of mantle cell lymphoma. The Journal of Clinical Investigation. 2012;122(10):3416-3423

[53] Carvajal-Cuenca A, Sua LF, Silva NM, et al. In situ mantle cell lymphoma: Clinical implications of an incidental finding with indolent clinical behavior. Haematologica. 2012;97(2):270-278

[54] Salaverria I, Royo C, Carvajal-Cuenca A, et al. CCND2 rearrangements are the most frequent genetic events in cyclin D1(-) mantle cell lymphoma. Blood. 2013;121(8):1394-1402

[55] Swerdlow SH, Kuzu I, Dogan A, et al. The many faces of small $B$ cell lymphomas with plasmacytic differentiation and the contribution of MYD88 testing. Virchows Archiv. 2016;468(3):259-275
[56] Hamadeh F, MacNamara SP, Aguilera NS, Swerdlow SH, Cook JR. MYD88 L265P mutation analysis helps define nodal lymphoplasmacytic lymphoma. Modern Pathology. 2015;28(4):564-574

[57] Molyneux EM, Rochford R, Griffin B, et al. Burkitt's lymphoma. Lancet. 2012;379:1234

[58] Love C, Sun Z, Jima D, et al. The genetic landscape of mutations in Burkitt lymphoma. Nature Genetics. 2012;44(12):1321-1325

[59] Dave SS, Fu K, Wright GW, et al. Lymphoma/Leukemia Molecular Profiling Project. Molecular diagnosis of Burkitt's lymphoma. The New England Journal of Medicine. 2006;354(23):2431-2442

[60] Richter J, Schlesner M, Hoffmann S, et al. ICGC MMML-Seq Project. Recurrent mutation of the ID3 gene in Burkitt lymphoma identified by integrated genome, exome and transcriptome sequencing. Nature Genetics. 2012;44(12):1316-1320

[61] Ferreiro JF, Morscio J, Dierickx D, et al. Post-transplant molecularly defined Burkitt lymphomas are frequently MYCnegative and characterized by the 11q-gain/loss pattern. Haematologica. 2015;100(7):e275-e279

[62] Mareschal S, Ruminy P, Bagacean C, et al. Accurate classification of germinal center B-celllike/activated B-cell-like diffuse large B-cell lymphoma using a simple and rapid reverse transcriptasemultiplex ligation-dependent probe amplification assay: A CALYM Study. The Journal of Molecular Diagnostics. 2015;17(3):273-283

[63] Swerdlow SH. Diagnosis of 'double hit' diffuse large B-cell lymphoma and B-cell lymphoma, unclassifiable, with 
features intermediate between DLBCL and Burkitt lymphoma: When and how, FISH versus IHC. Hematology. American Society of Hematology. Education Program. 2014;2014(1):90-99

[64] Nicolae A, Pittaluga S,

Abdullah S, et al. EBV-positive large B-cell lymphomas in young patients: A nodal lymphoma with evidence for a tolerogenic immune environment. Blood. 2015;126(7):863-872

[65] Said J. The expanding spectrum of EBV1 lymphomas. Blood. 2015;126(7):827-828

[66] Tiacci E, Trifonov V, Schiavoni G, et al. BRAF mutations in hairy-cell leukemia. The New England Journal of Medicine. 2011;364(24):2305-2315

[67] Palumbo A, Anderson KC. Multiple myeloma. The New England Journal of Medicine. 2011;364:1046

[68] Rajkumar V, Dimopoulos MA, Palumbo A, et al. International Myeloma Working Group updated criteria for the diagnosis of multiple myeloma. The Lancet Oncology. 2014;15:e538-e548

[69] Carbone PP, Kaplan HS, Musshoff K, et al. Report of the committee on Hodgkin's Disease Staging Classification. Cancer Research. 1971;31:1860-1861

[70] Moormeier JA, Williams SF, Golomb HM. The staging of nonHodgkin's lymphomas. Seminars in Oncology. 1990;17:43-50

[71] Coiffier B, Gisselbrecht C, Vose JM, et al. Prognostic factors in aggressive malignant lymphomas: Description and validation of a prognostic index that could identify patients requiring a more intensive therapy. The Groupe d'Etudes des Lymphomes Agressifs. Journal of Clinical Oncology. 1991;9:211-219
[72] A predictive model for aggressive non-Hodgkin's lymphoma. The international non-Hodgkin's lymphoma prognostic factors project. The New England Journal of Medicine. 1993;329:987-994

[73] Lopez-Guillermo A, Montserrat E, Bosch F, et al. Applicability of the international index for aggressive lymphomas to patients with lowgrade lymphoma. Journal of Clinical Oncology. 1994;12:1343-1348 



\title{
B Cell Lymphomagenesis
}

Željka Škunca

\begin{abstract}
Lymphoid neoplasms are a heterogeneous group of malignancies whose diagnosis depends on a very good analysis of hematopathology and morphology, immunophenotype, cytogenetic, molecular, and clinical characteristics. B-cell lymphomas begin from different developmental stages of B cells in germinal centers of secondary lymphoid tissue. The evolution of B-cell lymphomagenesis depends on different numbers of signal pathways. Proteins that play key point of signaling networks are changed by aberrant chromosomal expression, translocation, and/or accumulation, and those events determine the fate of the affected B cells. Many chemokines and cytokines have been implicated in providing the line for the cellular surviving and interaction in lymphoid organogenesis. Specific chromosomal alterations were associated with significant changes in gene-expression signatures that reflect various aspects of lymphoma cell biology as well as the host response to the lymphoma. The goal of this study was to find out a correlation between tumor markers and survival in patients with subgroups of DLBCL. The goal is to find out chronic autoimmune or pathogen-induced immune reactions resulting in lymphoid neogenesis. So we address (i) chemokines and adhesion molecules involved in lymphoid neogenesis, (ii) the autoimmune diseases and pathogens which are associated with the development of B-cell lymphomas, and (iii) the molecular mechanisms involved in the initiation and progression of DLBCL.
\end{abstract}

Keywords: DLBCL, lymphomagenesis, GCB, ABC

\section{Germinal center B-cell dynamics}

Characteristic chromosome translocation is associated with certain entities of the disease that is known to play a key role in the development of lymphoma. Chromosomal translocation alone, however, is not sufficient for the appearance of a tumor. Various factors, including microenvironment, epigenetic, and genetic changes, play a role in the development of lymphomas. Follicular dendritic cells (FDC) produce high-affinity antibody needed for the development of B-cell memory. These cells can be detected in B-cell non-Hodgkin lymphomas (NHL). Gene-expression profiling revealed that the FDC network could affect the clinical outcome in DLBCL [1-3].

Transgenic mouse model with different genes linked to chromosomal translocations has shown that chromosomal translocation alone is not sufficient for the development of lymphoma [1]. Transgenic mice with the c-MYC (myelomatosis viral oncogene homolog) genome develop lymphoma after a long time. The $c-M Y C$ gene is located at $8 \mathrm{q} 24$ and is associated with the translocation $\mathrm{t}(8 ; 14)$ (q24; q32). This was the first recurring chromosome abnormality ever reported in lymphoproliferative disorders. $C-M Y C$ in place next to immunoglobulin heavy locus (IGH) results in the expression of c-Myc protein, which is a key transcriptional factor that promotes cell cycle and 
tumor proliferation. 8q24/c-MYC restenosis is found in 7-15\% of the activated B-celllike (ABC) subgroup of diffuse large B-cell lymphoma (DLBCL), and the reports are predominantly associated with extranodal localization [4-8]. B-cell lymphomas include follicular lymphoma (FL), mantle cell lymphoma (MCL), and marginal zone lymphoma (MZL). Tumor cells show a strict topographical and functional relationship with FDCs, included with reactive lymphoid and stromal cells $[3,9]$. The FDC patterns, described for FL and MCL, are reminiscent of the distribution pattern of FCD meshwork seen in the GC or the mantle zone of the secondary lymphoid follicle, respectively $[3,9]$. T cells migrate to B-cell-enriched follicles and germinal centers within secondary lymphoid organs to provide help to B cells. Correlation T and B cells within germinal centers are essential for B-cell differentiation into germinal center B cells and selection of mutated cells into memory B cells or memory plasma cells. Different stages of maturation lead to $\mathrm{B}$ cell becoming a helper T cells and $\mathrm{B}$ follicular helper $\mathrm{T}\left(\mathrm{T}_{\mathrm{FH}}\right)$ cells [10].

$C-M Y C$ translocation is characteristic of Burkitt's lymphoma, where it is found in $80-90 \%$ of cases. In B-cell lymphoma 2 (BCL2) transgenic mice, it has been shown that polyclonal B-cell proliferation causes the growth of lymphoid follicles, but only $20 \%$ of mice develop monoclonal diffuse lymphomas after long latency. Long-term exposure to oncogene, progression from polyclonal to monoclonal disease, and appearance of the BCL2 transgenic mouse model suggests that lymphoma development depends on the secondary genetic events [8].

$C-M Y C$ is a strong transcription factor and promotes cell proliferation and growth, DNA replication, and protein biosynthesis [11]. Dysregulation of c-MYC is essential in the pathogenesis of a number of B-cell lymphomas but is rarely reported in T-cell lymphomas. C-MYC rearrangement is found in multiple B-cell lymphomas including Burkitt lymphoma, diffuse large B-cell lymphoma (DLBCL), and B-cell lymphoma unclassifiable, with features intermedia between DLBCL and Burkitt lymphoma (BCLU). In normal cells $c-M Y C$ is a highly regulated transcription factor that is involved in cell cycle regulation, cell metabolism, mitochondrial biogenesis, nucleic acid synthesis, and apoptosis [12] . C-MYC expression is detected in a much higher proportion of DLBCL (30-50\%) and is associated with concomitant expression of BCL2 in 20 to $35 \%$ of cases [8]. Most of these tumors do not carry $c-M Y C / B C L 2$ chromosomal alterations and have been named "double-hit lymphoma." Most studies use a cutoff of $40 \%$ $c$-MYC-expressing cells to define these cases; the cutoff for BCL2 expression has varied considerably in the literature, but a figure of $50 \%$ is recommended [8, 13-16].

Germinal centers (GCs) form in the center of the B-cell follicles of secondary lymphoid organs, interspersed within a network of stromal cells known as follicular dendritic cells (FDCs) [17, 18]. In follicles that do not contain GCs (primary follicles), FDCs play an important role, helping B cells to cluster into compact, well-defined follicle [18-20]. FDC has a long-term retention of antigen within complement immune complexes in a form that can support affinity-dependent "testing" of immunoglobulin somatic hypermutation (SHM)-modified B-cell Ag receptors (BCRs) that occurs during GC selection [21, 22]. Adaptive immunity involves the development of antibodies in GCs through SHM in GC dark zones (DZs) and clonal selection in light zones (LZs) [22, 23].

The spleen, lymph nodes, and mucosal-associated lymphoid tissues constitute secondary lymphoid tissues that are located strategically to efficiently trap foreign antigens entering peripheral tissues and mucosal sites. In secondary lymphoid tissues, activation of $\mathrm{B}$ cells and $\mathrm{T}$ cells by native and processed antigenic determinants represents the beginning of the GC reaction [24]. The B cells bind membrane-bound immunoglobulins (B-cell receptors (BCR)) and express Ag-derived peptides in major histocompatibility complex (MHC-II) molecules on their surface [6] Secondary lymphoid tissues facilitate interactions between antigen-bearing dendritic cells (DCs), B cells, and T cells to initiate adaptive immune responses. B cells express 
B-cell receptors (BCRs) on their cell membrane, and BCRs allow the cell to bind to a specific antigen and initiate an antibody response $[18,23,25]$. Despite these common features, differences in routes of antigen transport, lymphocyte trafficking, and unique cell populations determine the role of a specific secondary lymphoid tissue in immune responses to various foreign antigens. In the GCs, naive B cells can have clonal expansion, somatic hypermutation, and maturation [26, 27].

Germinal centers (GCs) are organized into two major zones: dark and light zones. The dark zone contains large centroblasts that are rapidly proliferating and undergoing somatic mutation. These cells grow to small nonproliferating centrocytes in the light zone, and binding antigen on follicular dendritic cells (FDCs) and development further depend on receiving signals from helper T cells [18, 22, 23, 28].

The activated B cells have two possibilities: (1) turnover into extrafollicular areas followed by proliferation and terminal differentiation into short-lived plasma cells that secrete antibody and (2) turnover into B-cell follicles followed by proliferation of GCs [27]. The mechanisms responsible for this remain poorly understood, although various studies suggest that the affinity of the BCR for the foreign antigen, the amount of antigen-receptor engagement, and the costimulatory signals received from $T$ cells may all be involved. These observations suggest that the affinity maturation of the antibody response occurs in GCs, through the processes of clonal proliferation, somatic hypermutation, and selection [27].

$\mathrm{T}$ cells play a key role to induce B-cell proliferation and somatic hypermutation and to limit GC reactions. T cells in the germinal center activate helper $\mathrm{T}$ cells (CD4+CD57+CD25-) migrating in the germinal center to activate the B-cell zone-homing C-X-C chemokine receptor type 5 (CXCR5) [29, 30]. B cells primarily excrete interleukin 4 (IL-4). They begin in the paracortical T-cell area of IgD follicle expression, but T-cell maturation results in a characteristic follicular CD10 + immunophenotype that has been acquired. Although the germinal center formation is intact in the presence of the FDC network, FDC plays a key role in the formation of memory $\mathrm{B}$ cell, and interaction is dependent on the expression of the tumor necrosis factor (TNF) family. The germinal center is not only created from different stages of B-cell maturation but also through the division of immunophenotypically different and functionally specialized T cells, dendritic cells, and subpopulations of stromal cells and their interactions. The antigen-stimulated B cells with the germinal center are highly mobile within the zone as well as between the dark and light zone [18, 23, 31].

In general, naive $B$ cells in the central lymphatic system mature through the transformation and proliferation of B cells toward plasma cells and B cells that produce antibodies. Malignant diseases may develop during such processes, and B-cellular neoplasms tend to imitate different stages of normal B-cell differentiation [1].

In the primary phase of differentiation, the progenitor of the B cell passes through renaming, and further development is followed by immunoglobulin genes (Ig) and occurs at naive B cells in peripheral lymphoid tissue or passes through apoptosis. Naive B cells can enter the primary follicle, forming a germinal center (GC), where mature CD10 - and B-cell lymphoma 6 (BCL6) centroblasts expression mature [2]. Centroblasts continue maturing in centrocytes, which later co-express $B C L 2$ gene. Naive B cells can be directly developed in plasma cells. The germinal center is partially monitored by Bcl6 protein, which in humans is encoded by the BCL6 [32] and IRF4/MUM1 proteins, which is essential for further lymphocyte differentiation into plasma cells or memory B cell. On the other hand, antigen stimulation of lymphocyte can go toward apoptosis [2]. MUM1 is a lymphocyte-specific transcriptional factor of the interferon regulatory factor (IRF) family, included in the regulation of gene expression in response to interferon and other cytokines. MUM1 provides immunoglobulin gene expression in the final step of B-cell differentiation within germinal center light zones. At this stage Bcl-6 is downregulated [2]. 
Secondary follicles are important for B-cell differentiation and maturation. B-cell differentiation begins via gene resection for the DJ region of the IgH gene. Each immunoglobulin molecule consists of two identical heavy chains and two identical light chains. This region represents the organization of heavy-chain locus. The locus includes variable $(\mathrm{V})$, diversity $(\mathrm{D})$, joining $(\mathrm{J})$, and constant $(\mathrm{C})$ segments. Within B-cell development, DNA recombination level joins a single D segment with a J segment; the fused DJ segment of a DNA molecule containing information coding for a protein or peptide sequence of this partially rearranged $\mathrm{DJ}$ region is then joined to the $\mathrm{V}$ segment. The introduction of region V into DJ results in VDJ coupling, and then the conversion successfully generates IGH protein chain. After the successful generation of the IgH gene, Ig light chains (IgL) are formed. The removal of IgL starts with light chain kappa. When the IgH and IgL genes are productive, B cells are called naive B cells because they are not exposed to the appropriate antigens and reside in the marginal zone of the secondary follicle [4]. The cells that have not been exposed to antigens are known as naïve or virgin B cells and remain at the mantle zone until they are exposed to antigens [22]. According to the B-cell differentiation stage, B-cell precursor includes B lymphoblastic leukemia/lymphoma, while pre-GC neoplasms include cell lymphoma. GC B-cell tumors are follicular lymphoma, Burkitt's lymphoma, Hodgkin's lymphoma, and diffuse large B-cell lymphoma (DLBCL). In the last stage of B-cell differentiation, post-GC neoplasms, including marginal zone lymphoma, mucosa-associated lymphoma tissue (MALT), lymphoplasmic lymphoma, chronic lymphocytic leukemia (CLL), plasma cell myeloma, and some cases of DLBCL, are developed [1,22] (Figure 1).

The majority of B-cell lymphomas appear from germinal center (GC) B cells, but it is unclear to what extent $B$ cells in lymphoma keep the functional dynamics of GC B cells or are blocked at a special stage of the GC reaction [20].

The germinal center is probably the source of many lymphomas. The germinal center reaction begins when antigens, with T-cell signals, activate centroblasts that migrate from the dark zone to the light zone and begin to express their antibodies

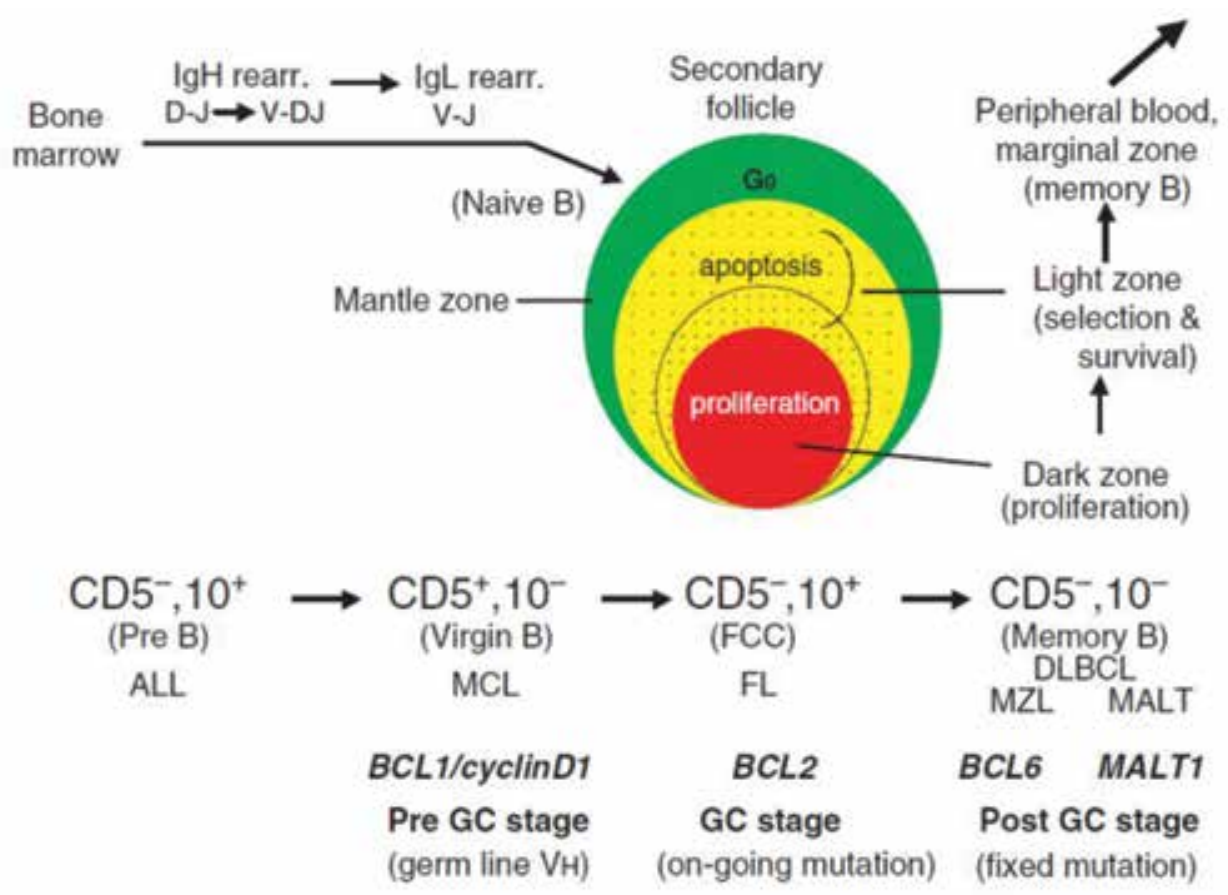

Figure 1.

$B$-cell differentiation and association of B-cell neoplasms [1]. 
on the cell surface known as centrocytes. Then apoptosis begins and competes for survival signals derived from FDCs and $\mathrm{T}_{\mathrm{FH}}$ cells. Germinal center selection is dependent on the tendency of their surface antibody to the antigen and can enter into the light zone of germinal centers, which are morphologically centrocytes and which are indivisible B cells with a notched core. The action or process of reentering into the dark zone as centroblasts gives a chance for nonselected B- cell mutants to gain more mutations in order to improve affinity toward antigen. Interactions with $\mathrm{T}$ cells are to prevent the generation of autoreactive germinal center $B$ cells $[18,23,33]$.

During the germinal center reaction, two different modifications of the B-cell DNA change B-cell receptor: somatic hypermutation and switch-off recombination. Both require activation-induced cytidine deaminase (AID). $\operatorname{IgM}, \operatorname{Ig} A$, or $\operatorname{IgE}$ recurrence of IgM, IgG heavy-chain recombination changes occur, while somatic hypermutations imply mutations in the immunoglobulin-variable region, region that produces a population of $\mathrm{B}$ cells with an increase (or decrease) affinity for a particular antigen. These genetic modifications are essential for normal immune response but also a source of DNA damage that can become pathological with lymphoma [8].

Mature B-cell neoplasms involve about 30 different entities, while DLBCL is the most common type of non-Hodgkin's lymphoma (NHL), which accounts for about $40 \%$ of all non-Hodgkin's lymphomas (NHLs). B-cell lymphomas are identified by a combination of morphological features and recognizable immunophenotype [20]. A list of transcription factors that modulate the B-cell germinal center phenotype and where cell selectively express BCL6, and includes interferon-regulatory factor 4 (IRF4). IRF4 co-bound with the transcription factors PU.1 (plays a critical role in the development of white cells), and B-cell-activating transcription factor (BATF) to Ets or activator protein 1 (AP-1) composite motifs, united with genes involved in $B$ cell activation and the GC response [18, 20, 23].

CD5 is a transmembrane glycoprotein with expression on the surface of T cells and a subset of B cells. The absence of CD5 performs thymocytes hyperresponsive to stimulation through the T-cell antigen receptor (TCR) in vitro. CD5 can influence the developing thymocytes by acting as a negative regulator of TCR-mediated signal transduction [34]. The CD5 signature included downregulated extracellular matrix genes such as POSTN, SPARC, COL1A1, COL3A1, CTSK, MMP9, and LAMB3 and comprised upregulated genes including TRPM4 [35-38] (Figure 2).

Bcl6 protein suppresses many genes involved in plasma cell differentiation, cell cycle progression, and responses to DNA damage and cell death. One of these genes is the transcription factor Blimp-1, the main regulator of plasma cell differentiation that reduces gene expression of mature B cells. The transcription factors Blimp-1 and IRF4 are essential for plasma cell generation. However, their function in mature plasma cells has remained elusive. B cells germinate center begins to differentiate plasma cells, monitored by interferon regulatory factor 4 (IRF4)/MUM1, whose transcription factor is needed for conversion to plasma cells. IRF4 increases the expression of Blimp-1 [39], and this growth is suppressed by BCL6, so differentiation takes place in favor of plasma cells $[25,39]$.

The transcriptional repressor Blimp-1 originally cloned as a silencer of type I interferon (IFN)- $\beta$ gene expression controls cell fate decisions in multiple tissue contexts. Blimp-1 functional loss in 3D cultures of mammary epithelial cells (MECs) results in the accumulation of dsRNA and expression of type III IFN- $\lambda$ [39] (Figure 3).

Chromosomal translocation in B-cell neoplasms is divided into three functional categories: proliferation, inhibition of differentiation, and antiapoptotic activity. These three categories are essential for understanding the mechanism of lymphomagenesis. For DLBCL with BCL6 gene translocation, Bcl6 protein expression is a side for post-GC staging cells, but it is not yet clear what signal is needed. It is clear that the antiapoptotic function must be present for $B C L 2$, which is expressed at the post-GC 


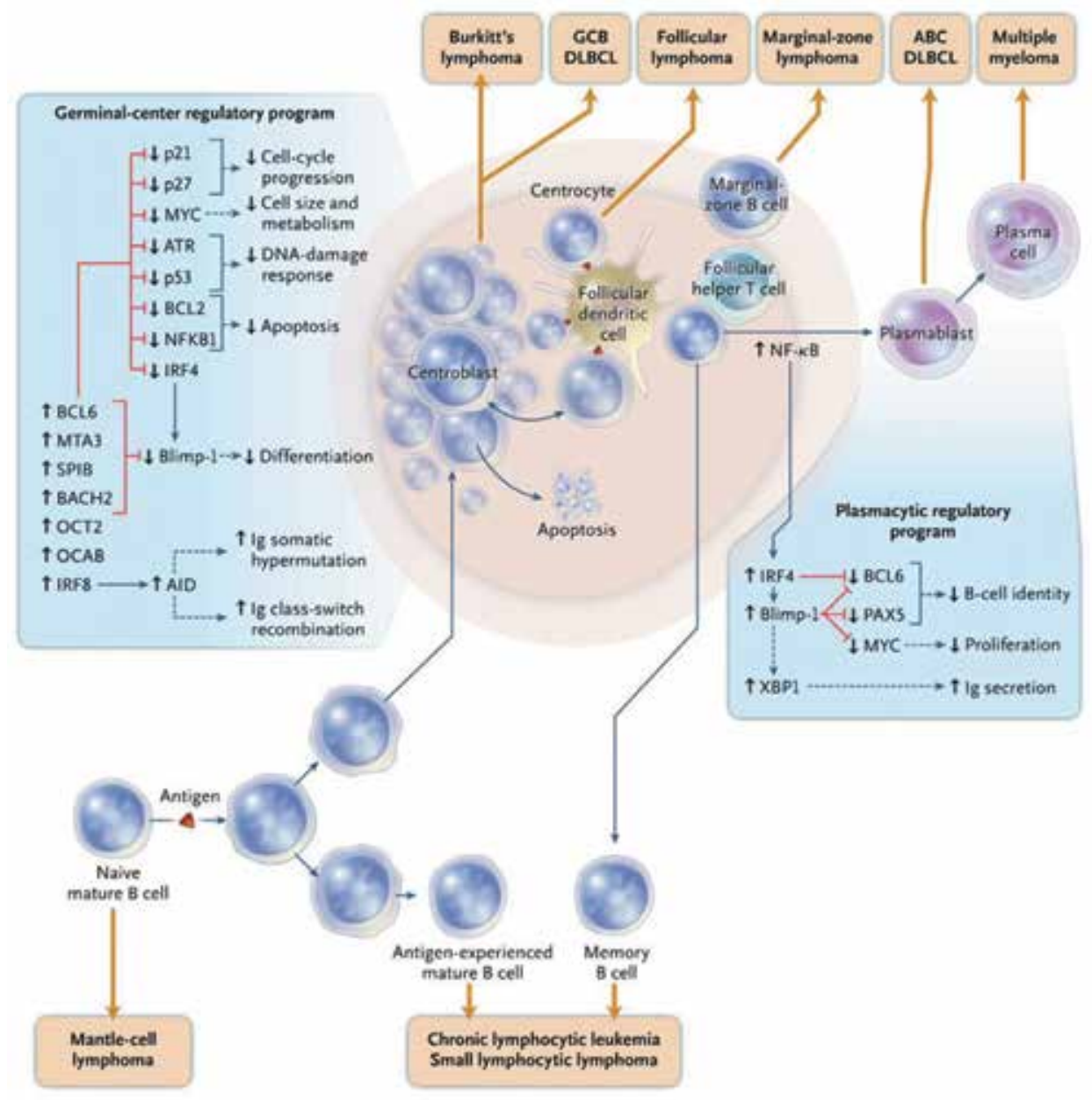

Figure 2.

B-cellular differentiation and lymphomagenesis ([25], p. 1418).

centers. There are indications that $B C L 6$ has the function of protecting cells from terminal differentiation and shows epigenetic changes that are conserved from human hematopoietic stem/progenitor cells (HSPCs) to mature B cells. These results suggest that BCL6 may function in a "hit-and-run" role in lymphomagenesis [8].

Lymphomagenesis is a complex process that takes place in many steps, in which lymphocyte signal distortion, transcriptional regulation, and apoptosis lead to transformation. Experiments suggest that distorted expression of casein kinase II subunit alpha (CK2alpha) creates predispositions for lymphoma development. Further experiments suggest that CK2alpha lymphomas monitor the panel of lymphocyte transcription factors such as, for example, activator protein 1 (AP-1) and nuclear factor-kappaB (NF-kB) [40, 41]. NF-kB represents a group of related homodimeric and heterodimeric transcription factors that can activate different target genes involved in proliferation, differentiation, immune response, cell growth, and survival. Among the molecules induced by NF-kB are the cytokines, chemokines, and effectors of the immune response. NF- $\mathrm{kB}$ participates in response to inflammatory signals through T receptors, TNF receptors, and IL-1 receptors [40-42]. CREB is one of the best understood phosphorylation-dependent transcription factors (CREB) [16]. In effector $\mathrm{T}$ and $\mathrm{B}$ cells, immune receptor signals induce within minutes a rise of intracellular $\mathrm{Ca}++$, the activation of the phosphatase calcineurin, and the 


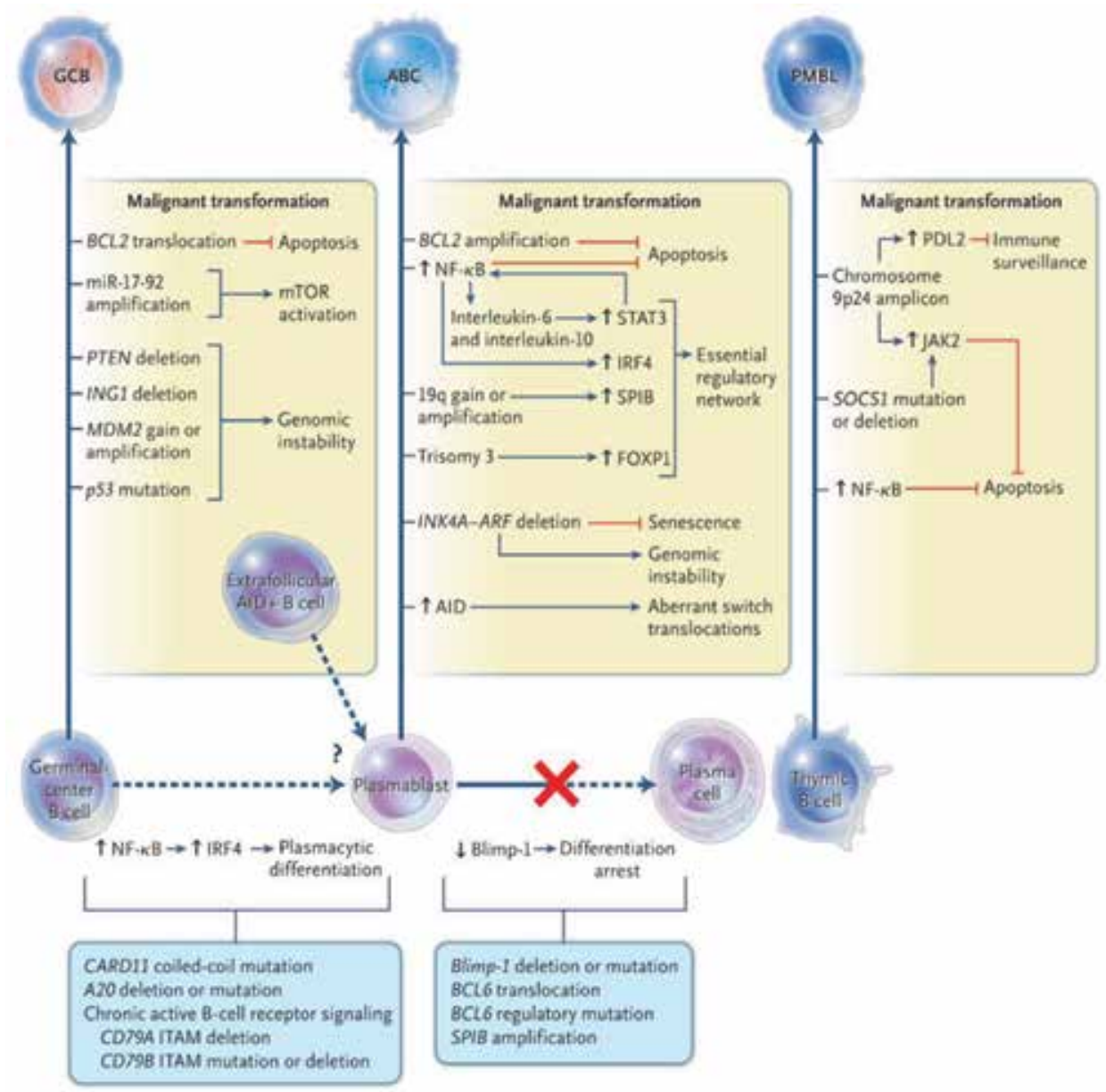

Figure 3.

Oncogene path for three subtypes of DLBCL ([25], p. 1421).

translocation of NFAT transcription factors from cytosol to nucleus; the induction of NFATc1/ $\alpha$ A takes place during the $\mathrm{G} 1$ phase of cell cycle $[43,44]$. The NFAT signaling pathway oversees different aspects of cellular functions; NFAT has a function like calcium sensor, including calcium signaling with other pathways involved in development and growth, immune response, and inflammatory response. The NFAT family of transcription factors regulates different cellular functions such as cell survival, proliferation, migration, invasion, and angiogenesis [44, 45].

TCF/LEFs are multifunctional proteins that use their sequence-specific DNAbinding and context-dependent interactions to specify which genes will be regulated by Wnts. The TCF/LEF families have been shown to regulate the expression of specific genes, such as c-Myc and Cyclin D1 [46]. These transcription factors are interdependent and closely linked with each other to form a network in the above signaling pathways, which regulate the entire process of osteoblast proliferation and differentiation [14]. Normally, these factors appear to be involved in the physiological activation response of lymphocytes before controlling the growth of malignant cells $[47,48]$.

Proliferation, differentiation, and apoptosis are associated with different types of lymphoma and chromosomal translocations. Each lymphoma has a separate proliferation of the site, which is most clearly described in the follicular lymphoma that proliferates in the follicle. Special chromosomal translocations are associated with 
each type of lymphoma. BCL1 translocation results in disturbed cell cycle regulation. BCL2 and API2-MALT1 have an antiapoptotic function [49]. API2-apoptosis inhibitor 2-MALT1 (mucosa-associated lymphoid tissue lymphoma translocation gene 1)-induced NF-kappaB activation may contribute to antiapoptotic action probably through NF-kappaB-mediated upregulation of apoptotic inhibitor genes [49].

\section{Classification and pathogenesis of DLBCL}

Non-Hodgkin's lymphoma (NHL) classification is based on pathohistological findings. The history of classification of lymphoid neoplasms begins in the 1940s. Based on the advancement in knowledge, the work classification and Kiel have replaced the revised European-American Classification of Lymphomas, and it is a step ahead of the classification given by the WHO [8].

Classifications are an essential part of modern medicine, offering a consensus on the terminology and disease definitions to be used interdisciplinary both in research and clinical practice. Evolution of lymphoma classification includes numerous attempts from descriptive schemes, relying on morphology to strictly clinically oriented stratifications proposed by hematologists, usually without significant international acceptance. The classification of the WHO (Swerdlow et al. 2008) differs from the previous classifications in defining the real entities of the disease through multiple divisions. The new entities defined in this release include extended immunophenotypes and some gene information relevant to the classification. Panel antibody was selected based on morphological differential diagnosis and tumor location. DLBCL is a diffuse proliferation of large neoplastic B lymphoid cells of the same size or up to two times than the normal lymphocyte or extremely large as in macrophages. The origin of these cells are B cells of the germinating center and postgerminant cells [8]. DLBCL can occur in the form of nodal and extranodal diseases. Approximately $40 \%$ of patients are present with extranodal disease. Any tissue organ can be the primary site of DLBCL, but the gastrointestinal tract is the most common site [33].

Tumor cells are B large transformed lymphocytes, but the morphological picture of DLBCL is varied, and the predominant morphological cell type can distinguish six subtypes of DLBCL: centroblastic, immunoblastic, T lymphocyte/histiocyte rich, anaplastic, plasmablastic, and DLBCL with cells similar to Reed-Sternberg cells and expression of anaplastic lymphoma kinase (ALK) protein. Tumor cells are positive, as defined by the disease, on pan-B markers CD19, CD20, CD22, and CD79a, and the positivity of intracytoplasmic or surface immunoglobulin (Ig) markers is distinctly expressed as CD5, CD10, CD30, and CD45 markers. Numerous chromosomal abnormalities have been detected with DLBCL, but no specific diagnostic changes have been isolated. The most frequent changes are breaks of regions 14q32, 3p21, 3q27, 22q12, 1q25, and 18q21 and additional chromosomes 7,9,12 and 4q31-35,13p13-14 and $17 \mathrm{p} 11-13,8,9$. In $11-23 \%$ of cases, DLBCL with advanced clinical stage of the disease revealed nine regions of chromosomal amplification and isolated amplified genes with a potential role in the formation of lymphoma. The clinical significance of each individual change has not been established, but some changes are associated with advanced clinical stage or poorer response to therapy. The abovementioned chromosomal abnormalities are generally not found as individual changes. The accumulation of a greater number of abnormalities indicates the progression of genetic changes, which play an important role in the pathogenesis of DLBCL $[8,33]$.

\section{The WHO classification which was revised in 2016}

See Table 1. 


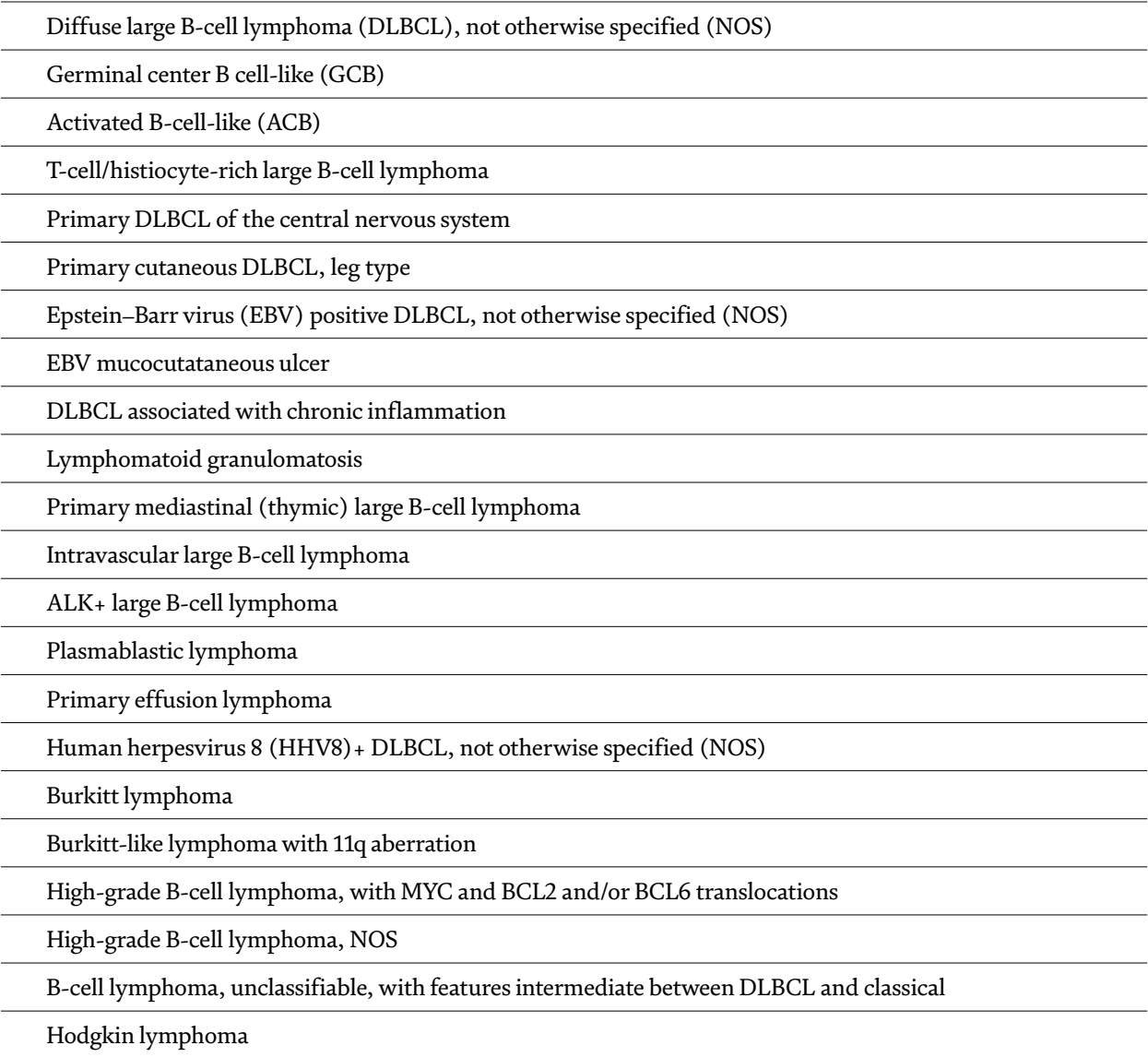

Table 1.

The 2016 update of WHO classification of DLBCL: subtypes and related entities [8].

\section{Prognostic markers in DLBCL}

\subsection{Gene expression profile (GEP)}

Clinical and morphological differences in DLBCL suggest the biological significance of subtypes, which may help in adapting the therapy to be defined. The development of DNA microarray techniques provided the ability to identify gene expression of the tumor with a new molecular entity and a molecular predictor essential for survival. DNA microarray can analyze thousands of sites of previously identified genes. DLBCL has been identified by several tumor markers associated with unfavorable outcome after therapy and which can be linked to tumor cells and normal B lymphocytes. Phenotypic cells resemble normal B lymphocytes, but the clinical course is completely different [50-52].

Gene expression profile has shown that DLBCL can be divided into two molecular entities that differ in the gene expression profile. Hans et al. have identified two subgroups of DLBCL $[34,52]$. One subgroup was called germinal center B-cell-like (GCB) and has a characteristic gene expression of normal GC B cells, in about $50 \%$ of cases, and the second group was called activated B-cell-like (ABC). Type-3 group is defined as nonclassified cases. According to the GEP classification, the observed prognosis distinguishes two major subtypes after the chemotherapy. Patients with GCB lymphoma have a more favorable outcome in 5-year survival than patients in the ABC group (68\% vs. 24\%) [52]. The distinction between GCB and ABC 
subgroups and their effect on survival are independent of any clinical features of the disease, and these findings are further confirmed in other retrospective series with patients treated with chemotherapy [34, 42, 45-49].

In DLBCL, the ratio of BCL2-positive cases is highly variable, ranging from 24 to $80 \%$ among the study population in the previous studies that used immunohistochemistry (IHC); therefore, its prognostic relevance is controversial [16, 53-55].

Overexpression of the BCL2 is associated with poor prognosis [55]. ABC-DLBCL subgroup is characterized by transcription expression of the BCL2 gene [55], trisomy 3, and 18q21-q22 and loss of 6q21-q22 [56]. Activation of the antiapoptotic NF-kB signal pathway occurs at ABC but not at GCB DLBCL [56].

GCB DLBCL is characterized by frequent REL amplifications, BCL2 translocations, and ongoing somatic hypermutation of the immunoglobulin genes [56].

Immunohistochemistry studies have a significant role, although complexity in the expression and performance of the interpretation of findings is very complex. They are used in the prognosis of DLBCL and in the therapeutic advantage of using rituximab [52].

DLBCL is a common type of aggressive non-Hodgkin's lymphoma with clear biological and clinical characteristics. Many studies have focused on the significance of internal tumor characteristics, such as the presence of proteins or the presence of gene expression and chromosomal translocation. Significant component of cell biology is inherited from non-transformed stem cells. Each of the B-cellular lymphoma inherits the traces of B-cell differentiation, although the extent to which this malignancy is maintained and the maintenance of molecular and physiological properties of normal $B$ cells are not yet clear. Redistribution of immunoglobulin genes in DLBCL and other lymphomas carries mutations having somatic hypermutation characteristics, and the diversity of antibodies normally occurs only with the germinal center of the secondary lymphoid organ. This data suggest that DLBCL is generated from each of the germinal centers of the $B$ cell or from the $B$ cell at a later stage of differentiation $[1,25,50,52,56]$.

\subsubsection{Germinal center B-cell-like (GCB)}

CB DLBCL appears to be generated from the normal germinal B cell, the translocation $\mathrm{t}(14,18)$ involving $B C L 2$ [54], and the amplification of $c-R E L$ on the chromosome $2 \mathrm{p}$ was detected in $45 \%$ GCB DLBCL, whereas it was never detected at ABC subtype [56]. This finding suggests that different subgroups represent different diseases and the consequence is a different mechanism of malignant transformation and significantly different survival after chemotherapy. CD10 and BCL-6 are considered as germinal center markers, while IRF4/MUM1 is expressed on plasma cells in atypical light zones of the germinal center. By morphological characteristics, the center is uniform form monomorphic. Expressions CD10, BCL-6, and MUM1 are used to classify GCB and ABC lymphoma subtype [1, 25, 46, 50, 56].

Many factors of B-cell differentiation in the germinal center affect the expression of transcription factors. The key B-cell transcription factor is PAX5 (PAX5 is a nuclear protein that has the ability to bind to wild-type PAX5 target loci) [53] and is required for regulating many B-cell-specific transcription factors and for B-cellular development from the B stage to mature B cells. The transcription factor PU.1 is an E26 transformation-specific family transcription factor that is required for the development of the immune system. PU.1 functions at both early and late stages of lymphoid and myeloid differentiation [57], and the IRF involved with Blim1/ PRDM1 was isolated from the family in further regulation of the transcriptional factor $B C L 6$, which is essential for the formation and maintenance of the germinal center. Translocation t (3q27) is included in BCL6 gene and is found in $20-40 \%$ diffuse lymphomas. IRF4/MUM1 expression is required for activation-induced cytidine deaminase (AID) expression, which is important for two significant functions 
of the germinal center, namely, somatic hypermutation (SHM) and AID-mediated class switch recombination (CSR) [58]. They depend on hierarchical expression and the common regulation of transcription factors. For example, BCL6 and IRF4/ MUM1 are expressed mutually exclusively in germinal center cells, but with DLBCL BCL6 and IRF4 / MUM1, they have co-expression [8, 59].

The Epstein-Barr virus (EBV) is the second factor associated with disturbed GCB regulation. EBV is associated with numerous lymphoid neoplasms including Burkitt's lymphoma and classical Hodgkin's lymphoma and posttransplant lymphoproliferative disease. The transformation that leads through EBV is capable of major negative selection in the germinal center. EBV/LMP2A induces escape of the defective B cells of the germinal center of the apoptosis and does not only offer an intriguing model of lymphomagenesis but also confirms the significant role of exogenous factors such as viruses involved in forming the response of the germinal center [60]. EBV latent membrane protein 2A (LMP2A) is expressed on the membranes of B lymphocytes and blocks B-cell receptor (BCR) signaling in EBV-transformed $B$ lymphocytes in vitro. In vivo studies indicate that LMP2A allows B-cell survival in the absence of normal BCR signals [60].

CD10 expression is associated with a more favorable prognosis, and MUM1 is normally found on plasma cells and in a small part of the atypical spot zone in the germinal center and represents a marker for a non-germinal center [61].

Patients in this group have significantly better 5-year overall survival and survival without signs of disease activity after chemotherapy with combined drugs (68\% for GCB vs. $24.7 \%$ for non-GCB with use of gene-expression profiling) $[8,52,56]$.

\subsubsection{Activated B-cell-like (ABC)}

$\mathrm{ABC}-\mathrm{DLBCL}$ is generated from the postgerminal center of $\mathrm{B}$ cells during plasmacytic differentiation. $A B C$ is characterized by frequent changes in chromosome arm 3p but not 3q [62]. ABC lymphoma has a subtype gene expression that has the properties of normal B cells that are activated over B-cell receptors.

Trisomy 3 is a common chromosomal aberration and is found in $26 \%$ of respondents. The forkhead transcription factor (FOXP1) is the third most potentially monitored gene in trisomy 3. High FOXP1 expression can contribute to B-cell lymphomagenesis by promoting B-cell survival inhibiting plasma cell differentiation. The small FOXP1 isoform (FOXP1-iso) is predominantly expressed in ABCDLBCL, and studying its oncogenic potential and transcriptional activity is directly compared to FOXP1-FL in DLBCL cell lines and primary human B cells [61-64].

$\mathrm{ABC}$ lymphomas have expression of the plasma cell genome, including transcriptional factor XBP1, which is the regulator of immunoglobulin secretion. XPB1 is a protein which in humans is encoded by the XPB1 gene located on chromosome 22. The XBP1 protein is a transcription factor that regulates the expression of genes important of the immune system and in the cellular stress response. C-MYC is necessary and sufficient for activation of the IRE1/XBP1 pathway $[65,66]$.

The constituent part of the NF- $\mathrm{kB}$ activation causes ABC lymphoma with expressing the IRF4 transcription factor, and this may push them toward differentiation in the plasma cells [42].

$\mathrm{ABC}$ lymphomas can obtain genetic changes that interfere with Blimp-1, thereby blocking full differentiation into plasma cells. The block in differentiation represents an early step in the pathogenesis of ABC subtypes, but the nature of the cell precursor is unclear. These lymphomas contain high activation-induced cytidine deaminase (AID) values, and their IgH genes have severe mutations. However, most $\mathrm{ABC}$ lymphomas did not undergo a recombinant trigger, and they have IgM expression, unlike most of the normal $B$ cells of the germinal center and other GCB lymphomas [39]. 
$\mathrm{NF}-\mathrm{kB}$ is present as a latent, inactive, IkB-bound complex in the cytoplasm. When a cell accepts any of a large number of extracellular signals, NF-kB quickly enters the nucleus and activates gene expression. Key step for controlling NF-kB activity is the regulation of the I kappa B kinase (IKK) [42, 55, 62].

Various genetic abnormalities activate CARD11 in ABC subtype lymphoma. In normal B cells, antigen-receptor-induced NF-kB activation requires CARD11, a cytoplasmic scaffolding protein. To determine whether CARD11 contributes to tumorigenesis, we sequenced the CARD11 gene in human DLBCL tumors [67]. In about 10\% of patients, CARD11 is an oncogene with acquired mutations that activate NF- $\mathrm{KB}$ and can prolong cell survival. Mutant CARD11 generates large protein aggregates in the cytoplasm, which represent possible NF- $\mathrm{kB}$ activation sites. The survival of lymphoma ABC with the wild-type CARD11 depends on B-cell receptors and kinases [67].

$\mathrm{ABC}$ lymphomas have expression of the plasma cell genome, including transcriptional factor XBP1, which is the main regulator of immunoglobulin secretion. $A B C$ lymphoma has presented expression of genes characteristic of mitogen-activated $B$ cells in the blood and is associated with a worse prognosis [66]. ABC-DLBCL is characterized by gain of 3q, 18q, and 19q and loss of $6 q$ and $9 p 21$, and GCB DLBCL is characterized by gain of 1q, 2p, 7q, and 12q; the genomic imbalances characteristic of the CD5(+) and CD5(-)CD10 (+) groups were similar to those of the ABC and GCB types [68].

Lymphoma $\mathrm{ABC}$ does not have one expression of the germinal center gene, but has gene expression that is normally present in B cells after B-cell receptor stimulation. MUM1 is found on plasma cells at later stage B-cellular differentiation and is associated with the gene profile of activated B-cellular DLBCL. The presence of $B C L 2$ and Cyklin D2 is adverse prognostic parameters. Polymorphic centroblasts and immunoblasts are more commonly present in activated B-cell DLBCL. This group is characterized by a group of genes that are characteristic of plasma cells, in part, added to the endoplasmic reticulum and Golgi's proteins involved in secretion. There is a significantly higher percentage of patients in this group [69].

\section{Conclusion}

The contribution of GC selection to phenomena such as immunodominance and original antigenic guilt has also not been established and is likely to be of considerable interest. Answering these questions will be crucial to our quest to produce more broad and new medications and will undoubtedly bring novel insights into the general functioning of GC, as well as of the immune system in general.

\section{Author details}

Željka Škunca

Psychiatric Hospital, Ugljan, Croatia

*Address all correspondence to: skunca.zeljka@gmail.com

\section{IntechOpen}

(C) 2019 The Author(s). Licensee IntechOpen. This chapter is distributed under the terms of the Creative Commons Attribution License (http://creativecommons.org/licenses/ by/3.0), which permits unrestricted use, distribution, and reproduction in any medium, provided the original work is properly cited. (cc) BY 


\section{References}

[1] Seto M, Honma K, Nakagawa

M. Diversity of genome profiles in malignant lymphoma. Cancer Science. 2010;101(3):573-557

[2] Jin MK, Hoster E, Dreyling M, Unterhalt M, Hiddemann W, Klapper W. Follicular dendritic cells in follicular lymphoma and types of non-Hodgkin lymphoma show reduced expression of CD23, CD3J5 and CD54 but no association with clinical outcome. Histopathology. 2011;58:586-592

[3] Carbone A, Gloghini A. Follicular dendritic cell in lymphomas of follicular origin. Atlas of Genetics and Cytogenetics in Oncology and Hematology. 2018;6

[4] Ma X, Zhong Y, Yan Zheng Y, Jiang J, Wang Y. Coexpression of CD5 and CD43 predicts worse prognosis in diffuse large B cell lymphoma. Cancer Medicine. 2018;7(9):4284-4295

[5] Thakral B, Medeiros LJ, Desai P, Lin P, Yin CC, Tang G, et al. Prognostic impact of CD5 expression in diffuse large B-cell lymphoma in patients treated with rituximabEPOCH. European Journal of Hematology. 2017;98(4):415-421

[6] Bende RJ, van Maldegem F, van Noesel CJM. Chronic inflammatory disease, lymphoid tissue neogenesis and extranodal marginal zone B-cell lymphomas. Haematologica. 2009;94(8):1109-1123

[7] Niitsu N, Okamoto M, Miura I, Hirano M. Clinical significance of $8 q 24 / c-M y c$ translocation in diffuse large B-cell lymphoma. Cancer Science. 2009;100(2):233-237

[8] Swerdlow SH, Campo E, Pileri SA, Harris NL, Jaffe ES, Stein H. The 2016 revision of the World Health Organization classification of lymphoid neoplasms. Blood. 2016;127:2375-2390
[9] Carbone A, Gloghini

A. Follicular dendritic cell in early lymphomas involving follicles. Advances in Anatomic Pathology. 2014;21(4):260-269

[10] Ramiscal RR, Vinuesa

CG. T-cell subsets in the germinal center. Immunological Reviews. 2013;252(1):146-155

[11] McPhail E, Maurer MJ, Macon WR, Feldman AL, Kurtin PJ, Ketterling RP, et al. Inferior survival in high-grade B-cell lymphoma with MYC and BCL2 and/or BCL6 rearrangements is not associated with MYC/IG gene rearrangements. Haematologica. 2018;103:1-36

[12] Li S, Weiss VL, Wang XJ, Desai PA, $\mathrm{Hu}$ S, Yin CC, et al. High-grade B-cell lymphoma with MYC rearrangement and without BCL2 and BCL6 rearrangements is associated with high P53 expression and a poor prognosis. The American Journal of Surgical Pathology. 2016;40(2):253-261

[13] Visco C, Tzankov A, Xu-Monette $\mathrm{ZY}$, et al. Patients with diffuse large B-cell lymphoma of germinal center origin with BCL2 translocations have poor outcome, irrespective of MYC status: a report from an International DLBCL rituximab CHOP Consortium Program Study. Haematologica. 2013;98(2):255-263

[14] Lin P, Medeiros LJ. Highgrade B-cell lymphoma/leukemia associated with $\mathrm{t}(14 ; 18)$ and $8 q 24 /$ $M Y C$ rearrangement: A neoplasm of germinal center immunophenotype with poor prognosis. Haematologica. 2007;92(10):1297-1301

[15] Nguyen L, Papenhausen P, Shao $\mathrm{H}$. The Role of c-MYC in B-cell lymphomas: Diagnostic and molecular aspects. Genes (Basel). 2017;8(4):116 
[16] Hachem A, Gartenhaus

RB. Oncogenes as molecular targets in lymphoma. Blood. 2005;106(6):1911-1923

[17] Heesters BA, Myers RC, Carroll MC. Follicular dendritic cells: Dynamic antigen libraries. Nature Reviews. Immunology. 2014;14:495-504

[18] Basso K, Dalla-Favera R. Germinal centres and B cell lymphomagenesis. Nature Reviews Immunology. 2015;15:172-184

[19] Wang X, Cho B, Suzuki K, Xu Y, Green JA, An J, et al. Follicular dendritic cells help establish follicle identity and promote $B$ cell retention in germinal centers. The Journal of Experimental Medicine. 2011;208:2497-2510

[20] Kovalchuk AL, Qi CF, Torrey TA, Taddesse-Heath L, Feigenbaum L, Park SS, et al. Burkitt Lymphoma in the Mouse. The Journal of Experimental Medicine. 2000;192(8):1183-1190

[21] Milpied P, Cervera-Marzal I, Mollichella ML, Tesson B, Brison G, Traverse-Glehen A, et al. Human germinal center transcriptional programs are de-synchronized in B cell lymphoma. Nature Immunology. 2018;19:1013-1024

\section{[22] Mesin L, Ersching J, Victora} GD. Germinal center B cell dynamics. Immunity. 2016;45(3):471-482

[23] Stewart I, Radtke D, Phillips B, McGowan SJ, Bannard O. Germinal center $B$ cells replace their antigen receptors in dark zones and fail light zone entry when immunoglobulin gene mutations are damaging. Immunity. 2018;49(3):477-489

[24] Mebius RE, Kraal G. Structure and function of the spleen. Nature Reviews. Immunology. 2005;5:606-616
[25] Lenz G, Staudt M. Aggressive lymphomas. The New England Journal of Medicine. 2010;362(15):1417-1429

[26] Jacobson KL, Shlomchik MJ. Plasticity and heterogeneity in the generation of memory B cells and long-lived plasma cells: The influence of germinal center interactions and dynamics. Journal of Immunology. 2010;185:3117-3125

[27] Allen CDC, Okada T, Cyster JG. Germinal center organization and cellular dynamics. Immunity. 2007;27(2):190-202

[28] Zhang Y. Gene Expression During the Activation of Human B cells. 2018. pp. 165-189. Chapter 9

[29] Vaccari M, Franchini G. Cell subsets in the germinal center: Lessons from the Macaque model. Frontiers in Immunology. 2018;9:348

[30] Ng Y-H, Chalasani G. Role of secondary lymphoid tissues in primary and memory $\mathrm{T}$-cell responses to a transplanted organ. Transplantation Reviews (Orlando, Fla.). 2010;24(1):32-41

[31] Crotty S. T follicular helper cell differentiation, function, and roles in disease. Immunity. 2014;41(4):529-542

[32] Duen CV, Camarero IR, Liu CL, Dai B, Gonzalez-Herrero I, Ramırez IG, et al. Transient expression of Bcl6 is sufficient for oncogenic function and induction of mature B-cell lymphoma. Nature Communications. 2014;5:3904

[33] Li S, Young KH, Jefferey Medeiros L. Diffuse large B-cell lymphoma. Pathology. 2018;50(1):74-87

[34] Tarakhovsky A, Kanner SB, Hombach J, Ledbetter JA, Muller W, Killeen N, et al. A role for CD5 in TCR-mediated signal transduction and thymocyte selection. Science. 1995;269(5223):535-537 
[35] Suguro M, Tagawa H, Kagami Y, Okamoto M, Ohshima K, Hiroshi Shiku H, et al. Expression profiling analysis of the $\mathrm{CD}^{+}$diffuse large $\mathrm{B}$ cell lymphoma subgroup: Development of a CD5 signature. Cancer Science. 2006;97(9):868-874

[36] Ennishi D, Takeuchi K, Yokoyama M, Asai H, Mishima Y, Terui Y, et al. CD5 expression is potentially predictive of poor outcome among biomarkers in patients with diffuse large B-cell lymphoma receiving rituximab plus CHOP therapy. Annals of Oncology. 2008;19:1921-1926

[37] Hyo R, Tomita N, Takeuchi K, Aoshima T, Fujita A, Kuwabara H, et al. The therapeutic effect of rituximab on CD5-positive and CD5-negative diffuse large B-cell lymphoma. Hematological Oncology. 2009;28(1):27-32

[38] Murase T, Yamaguchi M, Suzuki R, Okamoto M, Sato Y, Tamaru J, et al. Intravascular large B-cell lymphoma (IVLBCL): A clinicopathologic study of 96 cases with special reference to the immunophenotypic heterogeneity of CD5. Blood. 2007;109(2):479-485

[39] Elias S, Robertson EJ, Bikoff EK, Moud AW. Blimp-1/PRDM1 is a critical regulator of Type III Interferon responses in mammary epithelial cells. Scientific Reports. 2018;8237

[40] Gerondakis S, Siebenlist U. Roles of the NF-kappaB pathway in lymphocyte development and function. Cold Spring Harbor Perspectives in Biology. 2010;2(5):1-29

[41] Harper CV, Woodcock DJ, Lam C, Garcia-Albormaz M, Adamson A, Ashall L, et al. Temperature regulates $\mathrm{NF}-\kappa \mathrm{B}$ dynamics and function through timing of A20 transcription. PNAS. 2018;115(22)

[42] Espinosa I, Briones J, Bordes R, Brunet S, Martino R, Sureda
A. Activation of the NF-kappaB signalling pathway in diffuse large B-cell lymphoma: clinical implications. Histopathology. 2008;53:441-449

[43] Wen AY, Sakamoto KM, Miller LSL. The role of the transcription factor CREB in immune function. Journal of Immunology. 2010;185(11):6413-6419

[44] Oin JJ, Nag S, Wang W, Zhou J, Zhang WD, Wang $\mathrm{H}$, et al. NFAT as cancer target: Mission possible? Biochimica et Biophysica Acta. 2014;1846(2):297-311

[45] Serfling E, Andris Avots A, Klein-Hessling S, Rudolf R, Vaeth $M$, Berberich-Siebelt F. NFATc1/ $\alpha A$ : The other face of NFAT factors in lymphocytes. Cell Communication and Signaling: CCS. 2012;10:16

[46] Lossos IS. Molecular pathogenesis of diffuse large B-cell lymphoma. Journal of Clinical Oncology. 2005;23(26):6351-6357

[47] Cadigan KM, Waterman ML. TCF/ LEFs and Wnt signaling in the nucleus. Cold Spring Harbor Perspectives in Biology. 2012;4(11):1-22

[48] Li Z, Xu Z, Duan C, Liu W, Jingchun S, Han B. Role of TCF/LEF transcription factors in bone development and osteogenesis. International Journal of Medical Sciences. 2018;15(12):1415-1422

[49] Hosokawa Y. Anti-apoptotic action of API2-MALT1 fusion protein involved in $\mathrm{t}(11 ; 18)$ (q21;q21) MALT lymphoma. Apoptosis. 2005;10(1):25-34

[50] Alizadeh AA, Eisen MB, Davis RE, Ma C, Lossos IS, Rosenwald A, et al. Distinct types of diffuse large B-cell lymphoma identified by gene expression profiling. Nature. 2000;403:503-511

[51] Kuper-Hommel MJ, van de Schans SA, Vreugdenhil G, van Krieken JH, Coebergh JW. Undertreatment of 
patients with localized extranodal compared with nodal diffuse large B-cell lymphoma. Leukemia \& Lymphoma. 2013;54(8):1698-1705

[52] Haarer CF, Chadwick

F. Immunohistochemical classification of de novo transformed, and relapsed diffuse large B-cell lymphoma into germinal center B-cell and nongerminal center B-cell subtypes correlates with gene expression profile and patient survival. Archives of Pathology \& Laboratory Medicine. 2006;30:1819-1824

[53] Schinnerl D, Fortschegger K, Kauer M, João RM, Marchante JRM, Kofler $\mathrm{R}$, et al. The role of the Janus-faced transcription factor PAX5-JAK2 in acute lymphoblastic leukemia. Blood. 2014;04

[54] Kusumoto S, Kobayashi Y, Sekiguchi N. Diffuse large B-cell lymphoma with extra BCL2 gene signals detected by FISH analysis is associated with a non-germinal center phenotype. The American Journal of Surgical Pathology. 2005;29:1067-1073

[55] Tsuyama N, Sakata S, Satoko Baba S, Mishima Y, Nishimura N, Ueda $\mathrm{K}$, et al. BCL2 expression in DLBCL: Reappraisal of immunohistochemistry with new criteria for therapeutic biomarker evaluation. Blood. 2017;130(4):489-500

[56] Bea S, Zettl A, Wright G, Salaverria I, Jehn P, Moreno V. Diffuse large B-cell lymphoma subgroups have distinct genetic profiles that influence tumor biology and improve gene-expressionbased survival prediction. Blood. 2005;106(9):3183-3190

[57] Turkistany SA, DeKoter RP. The transcription factor PU.1 is a critical regulator of cellular communication in the immune system. Archivum Immunologiae et Therapiae Experimentalis (Warsz). 2011;59(6):431-440
[58] Schneider C, Pasqualucci L, DallaFavera R. Molecular pathogenesis of diffuse large B-cell lymphoma. Seminars in Diagnostic Pathology. 2011;28(2):167-177

[59] Moskowitz CH, Zelenetz AD, Kewalramani T, Hamlin P, LessacChenen S, Houldsworth J. Cell of origin, germinal center versus nongerminal center, determined by immunohistochemistry on tissue microarray, does not correlate with outcome in patients with relapsed and refractory DLBCL. Blood. 2005;106(10):3383-3385

[60] Swart R, Ruf IK, Sample J, Longnecker R. Latent membrane protein 2A-mediated effects on the phosphatidylinositol 3-kinase/ Akt pathway. Journal of Virology. 2000;74(22):10838-11084

[61] Lu TX, Miao Y, Wu JZ, Gong QX, Liang JH, Wang Z, et al.

The distinct clinical features and prognosis of the CD $10^{+} \mathrm{MUM}^{+}$and $\mathrm{CD}^{-}{ }^{-} \mathrm{Bcl6}^{-} \mathrm{MUM}^{-}$diffuse large B-cell lymphoma. Scientific Reports. 2016;6:20465

[62] Lenz G, Wright GW, Emre NCT, Kohlhammer H, Dave SS, Davis E. Molecular subtypes of diffuse large B-cell lymphoma arise distinct genetic pathways. PNAS. 2008;105(36):13520-13525

[63] Dekker JD, Park D, Shaffer AL III, Holger Kohlhammer H, Wei Deng W, Lee BK, et al. Subtypespecific addiction of the activated B-cell subset of diffuse large B-cell lymphoma to FOXP1. Proceedings of the National Academy of Sciences of the United States of America. 2016;113(5):E577-E586

[64] Gascoyne DM, Banham AH. The significance of FOXP1 in diffuse large B-cell lymphoma. Leukemia \& Lymphoma. 2017;58(5):1037-1051 
[65] Keimpema M, Grüneberg LJ, Schilder-Tol EJM, Oud MECM, Beuling EA, Hensbergen PJ. The small FOXP1 isoform predominantly expressed in activated B cell-like diffuse large B-cell lymphoma and full-length FOXP1 exert similar oncogenic and transcriptional activity in human B cells.

Haematologica. 2017;102(3):573-583

[66] Zhao N, Cao J, Xu L, Qianzi T, Dobrolecki LE, Xiangdong LV, et al. Pharmacological targeting of MYC-regulated IRE1/XBP1 pathway suppresses MYC driven breast cancer. The Journal of Clinical Investigation. 2018;128(4):183-199

[67] Lenz G, Davis RE, Ngo VN, Lam L, George TC, Wright GW, et al. Oncogenic CARD11 mutations in human diffuse large B cell lymphoma. Science. 2008;319(5870):1676-1679

[68] Tagawa H, Suguro M, Tsuzuki S, Matsuo K, Karman S, Ohsima K, et al. Comparison of genome profiles for identification of distinct subgroups of diffuse large B-cell lymphoma. Blood. 2005;106(5):1770-1777

[69] Salles G, Barrett M, Foà R, Maurer J, O’Brien S, Valent N, et al. Rituximab in B-Cell hematologic malignancies: A review of 20 years of clinical experience. Advances in Therapy. 2017;34:2232-2273 



\title{
Diffuse Large B-Cell Lymphoma
}

\author{
Patrascu Ana Maria, Ionela Rotaru, Valeriu Surlin \\ and Stefan Patrascu
}

\begin{abstract}
Diffuse large B-cell lymphoma (DLBCL) is a heterogenous class of aggressive lymphoma and is considered as the most common subtype of non-Hodgkin lymphomas (NHL). Several genetic anomalies such as point mutations, numerical alterations, and, more rarely, translocations and gene amplifications play a role in the pathogenesis of this class of B-cell lymphoma and have been related to specific histological and immunophenotypic subtypes. On the other hand, the treatment protocol in DLBCL did not witness significant changes during the last two decades. The widespread adoption of rituximab as an important adjuvant to standard chemotherapy protocol in CD20 + cases was a notable exception, which provided significant improvement in disease-free survival and overall survival, with limited toxicity. However, no less than $20 \%$ of patients diagnosed with DLBCL exhibit relapse after the initial response to $\mathrm{R}-\mathrm{CHOP}$ regimen, while more than $15 \%$ of the patients exhibit primary refractory disease. This is the reason why a review of all the morphological, clinical, and therapeutic particularities of DLBCL is required.
\end{abstract}

Keywords: diffuse large B-cell lymphoma, immunohistochemistry, lymphoma, molecular diagnostics, rituximab-CHOP

\section{Introduction}

Non-Hodgkin lymphomas (NHL) are the most common type of lymphoma, accounting for roughly $85 \%$ of this category of lymphoid neoplasia. NHL are most commonly classified as B-cell, T-cell, and natural killer (NK) cell lymphomas, according to their cell of origin. Diffuse large B-cell lymphoma (DLBCL) is a heterogenous class of aggressive lymphoma and is considered as the most common subtype of NHL. Several genetic anomalies such as point mutations, numerical alterations, and, more rarely, translocations and gene amplifications play a role in the pathogenesis of this class of B-cell lymphoma and have been related to specific histological and immunophenotypic subtypes [1].

\section{Etiopathogeny of diffuse large B-cell lymphoma}

\subsection{Epidemiology}

The incidence of diffuse large B-cell lymphoma (DLBCL) is increasing with age, from 0.3 cases/100,000/year in those between the ages of 35 and 39 years and 
$26.6 / 100,000 / y e a r$ for the 80- to 84-year-old age group [2, 3]. Mean age of diagnosis is 65 years for DLBCL and between 20 and 30 years of age for primary mediastinal subtype [4].

This type of lymphoma is more common in Caucasians than African and Asian populations, while the extranodal involvement is more frequent in European and the Far East population than the American patients. The sex ratio ranges from 1.5 to $3.5 / 1$ in favor of men [5].

\subsection{Pathogeny}

DLBCL originates in mature B cells in certain stages of differentiation. Various changes occur in the B cell toward its malignant transformation, which are induced by genetic mutations. During their ontogenesis, the B cells are passing in the secondary lymphoid tissues where the antigen-dependent activation occurs. The activation and amassment of B cells in the secondary lymphoid tissue lead to the creation of the germinal center, which is critically dependent on BCL-6. If certain genetic alterations occur during lymphocyte development, then the determinatives of the neoplastic changes are settled. The type of lymphoma is determined by the stage of maturation of the $\mathrm{B}$ cell and by the type of anomalies that are interfering with their development and differentiation [6]. More specifically, the upregulation of B-cell lymphoma-2 (Bcl-2) protein expression and the inactivation of BCL6 which in turn blocks the apoptosis have both been observed in DLBCL.

Moreover, the elevation of the nuclear factor kappa-light-chain-enhancer of activated $\mathrm{B}$ cells $(\mathrm{NFkB})$ and the upregulation of the avian myelocytomatosis virus oncogene cellular homolog (c-Myc) expression, leading to an increase in B cell proliferation, have also been cited [7]. The signal pathways for the B-cell receptor (BCR) and the activation of NFkB and downregulation of the B-cell lymphoma-6 (Bcl-6) pathways have a special pathogenic significance in DLBCL [7].

\section{Classification and standardization}

\subsection{Classification}

DLBCL can originate from three types of cells and can be classified accordingly as germinal center DLBCL (GCB DLBCL), from the centroblasts of the germinal center; activated B-cell DLBCL (ABC-DLBCL), from the plasmablasts that are involved in the terminal differentiation of the $\mathrm{B}$ cells; and primary mediastinal large B-cell lymphoma (PMBCL), which derives from thymic B cells. This classification has a prognostic utility, as the activated B-cell subtype has an unfavorable evolution [8].

Apart from the cell-of-origin classification, several other classifications for nonHodgkin lymphomas have been suggested during the last half-century, each with its own advantages and drawbacks: Rappaport, Kiel, International Working Formulation (IWF), and the Revised European-American Lymphoma classification (REAL). The last classification that is currently in use has been offered by the World Health Organization (WHO) in 2001 and was last revised in 2016. According to the maturation stage in which the $\mathrm{B}$ cell is in, and to the type of anomalies that occur during differentiation and maturation, DLBCL presents several variants and subtypes.

The World Health Organization classification of the lymphoid neoplasms has systemized DLBCL into several subtypes, each with its own morphological, clinical, and immunohistochemical particularities. The 2016 revision of the WHO classification brought several updates concerning diagnostic and prognostic factors 
Diffuse Large B-Cell Lymphoma

DOI: 10.5772/intechopen.85489

for DLBCL, such as the acknowledgment of the prognostic role of double-hit DLBCL-NOS, which involves the double expression of MYC and BCL2, or the newly introduced designation of DLBCL EBV + (NOS) which is replacing the old term of "DLBCL EBV + of the elderly" (Table 1) [9].

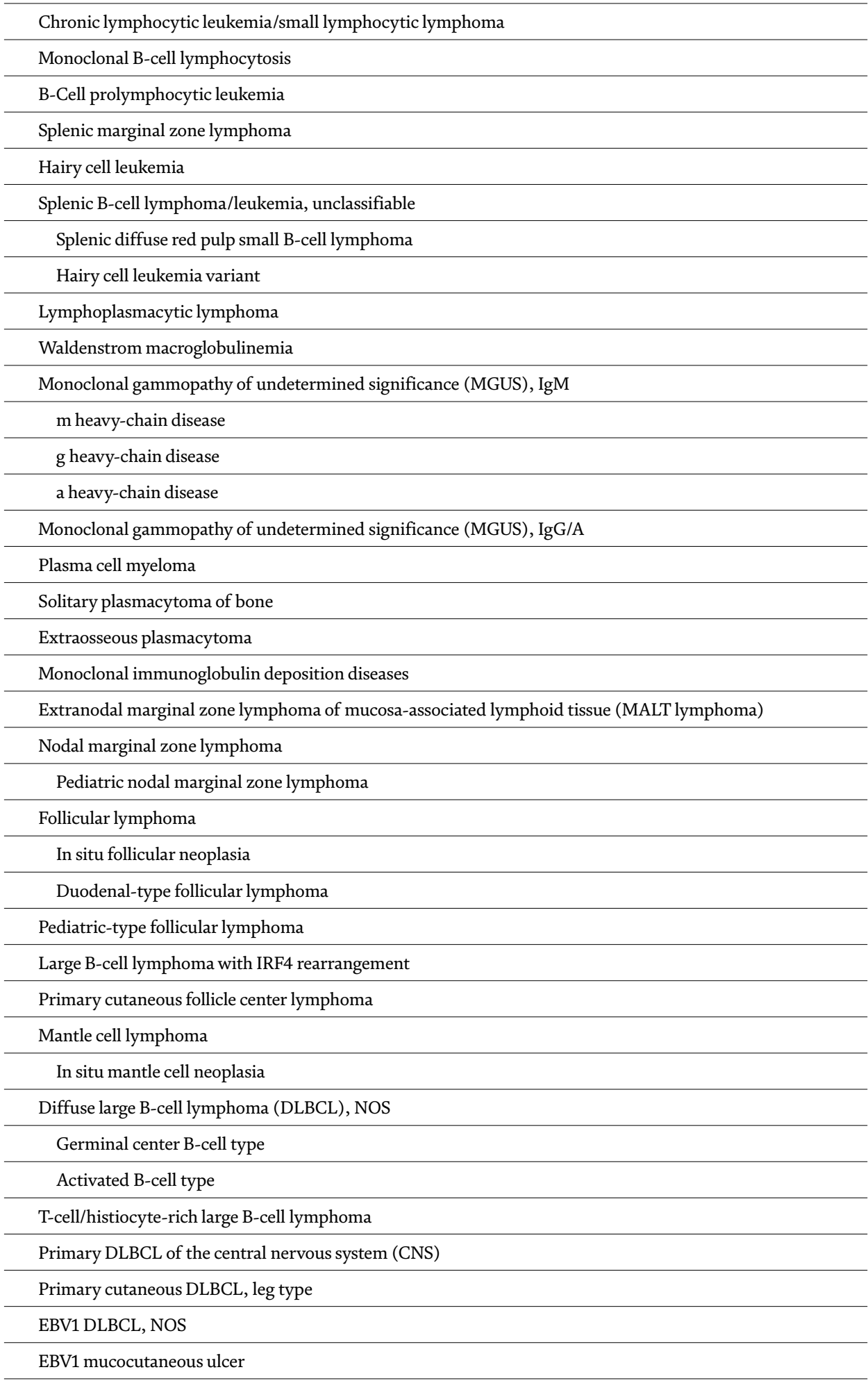


DLBCL associated with chronic inflammation

Lymphomatoid granulomatosis

Primary mediastinal (thymic) large B-cell lymphoma

Intravascular large B-cell lymphoma

ALK1 large B-cell lymphoma

Plasmablastic lymphoma

Primary effusion lymphoma

HHV81 DLBCL, NOS

Burkitt lymphoma

Burkitt-like lymphoma with 11q aberration

High-grade B-cell lymphoma, with MYC and BCL2 and/or BCL6 rearrangements

High-grade B-cell lymphoma, NOS

B-cell lymphoma, unclassifiable, with features intermediate between DLBCL and classical Hodgkin lymphoma

Table 1.

2016 WHO classification of mature B-cell neoplasms [9].

\subsection{Variants of DLBCL and related pathologic entities}

Over time, several variants and subtypes of DLBCL have been identified, according to their clinical features, localization, and morphology, which are all included in the recent REAL and WHO classifications. Extranodal DLBCL are relatively rare, accounting for $1-5 \%$ of NHL [10]. Less than $40 \%$ of DLBCL cases are originating in extranodal sites, especially in the gastrointestinal tract but also the mediastinum, bones, central nervous system (CNS), testes, and breast [11].

\subsubsection{Primary mediastinal large B-cell lymphoma (PMBCL)}

Roughly $10 \%$ of the total number of DLBCL is represented by PMBCL, a subtype which originates in medullary thymic $B$ cells and affects young women, around the age of 30 and 40 years. They clinically appear as large mediastinal tumors sometimes involving the lungs and pericardium, which can lead to local compression with superior vena cava syndrome and airway obstruction. PMBCL is positive for pan-B markers, CD23 and CD30, and is negative to CD15 and sIg. BCL6, CD10, and interferon regulatory factor 4 (IRF4) can sometimes be positive [12]. Several chromosomal abnormalities can be found, such as gains in chromosomal arm $9 p$ and $2 p$ corresponding to JAK2 and cREL loci $[13,14]$. Because of the diagnosis confusions between PMBCL and DLBCL with secondary mediastinal involvement, the reports concerning the survival rates of the two pathologic entities have been similar [15].

More recently the improvements in diagnosis of PMBCL have allowed to observe a higher survival rate of this type of lymphoma compared to DLBCL [16]. Some variants of PMBCL, which own morphologic, immunophenotypical, and molecular resemblance with the nodular sclerosis subtype of Hodgkin lymphoma, are included in the category of B-cell lymphoma, unclassifiable, with features intermediate between DLBCL and classical Hodgkin lymphoma [9, 10, 17].

\subsubsection{Primary DLBCL of the central nervous system (CNS)}

Only a limited number of cases (2-3\%) of cerebral neoplasms are lymphomas, the most frequent of which is DLBCL. Primary DLBCL of CNS can be both 
germinal center and non-germinal center, while some genetic anomalies suggest the implication of the microenvironment as a pathogenic factor [18].

The clinical manifestations usually range from neurological deficits to psychiatric symptoms, but ocular involvement, seizures, and symptoms of increased intracranial pressure can also be found [18].

\subsubsection{Primary testicular lymphomas (PTL)}

PTL are usually DLBCL ( $>80 \%$ ) but can also classified as follicular, plasmablastic, Burkitt, mantle cell, or plasmablastic lymphomas in a minority of cases. Usually this type of lymphoma is diagnosed in stages $1-2$, while in advanced stages, it can also affect the central nervous system, the liver, the skin, the Waldeyer ring, and the lungs [19]. PTL displays a modified expression of adhesion molecules that can be correlated with extranodal involvement. In most cases (60-96\%) the cell of origin analysis indicates the activated B-cell (ABC) pattern. Several mutations have been observed, such as MYD88 mutations in 70\% of cases, rearrangements of forkhead box protein P1 (FOXP1), programmed death-ligand 1 (PDL 1), and class II MHC transactivator (CIITA), as well as inactivation mutations of beta-2 microglobulin (B2M) gene [10].

\subsubsection{Primary breast lymphoma}

Primary breast lymphoma is a rare form of breast cancer, with cell of origin studies usually indicating an activated B-cell pattern. The cytogenetic analysis shows multiple chromosomal anomalies, such as trisomies 3 and 18 and translocations of chromosome 18 involving IGH/MALT1 [20].

\subsubsection{Primary bone lymphoma (PBoL)}

PBoL is a rare type of lymphoma that is confined to the bone tissue, preponderantly affecting the middle-aged male patients. It should be differentiated from primary medullar lymphoma which, unlike $\mathrm{PBoL}$, does not display cortical involvement [21]. The germinal center subtype is more common, frequently displaying BCL2, BCL6, and MYC rearrangements [10].

\section{Clinical, morphologic, and cytogenetic characteristics}

\subsection{Clinical aspects}

DLBCL patients have a wide spectrum of clinical manifestations, a frequent nodal involvement, but also, in up to $40 \%$ of cases, extranodal symptoms (skin, digestive and central nervous system, etc.). All these clinical manifestations, together with the general signs and symptoms (such as fever, weight loss, sweating) usually indicate a more aggressive phenotype. On rare occasions, the diagnosis is incidentally established when the clinical examination detects enlarged lymph nodes with no other signs or symptoms. Medullary involvement is uncommon in the early phases of the disease, as it is only found in less than $30 \%$ of cases [22].

As for the paraclinical investigations, usual blood tests consist in complete blood count, lactate dehydrogenase and uric acid determination, serology, osteomedular biopsy, and cytologic exam of the cerebrospinal fluid. Computed tomography (CT) scan or, even better, positron emission tomography-computed tomography (PET-CT) is considered mandatory to assess the extension of the disease. 
PET-CT is of great diagnostic and prognostic importance, but it is also necessary for the post-chemotherapy assessment, such that in case of negative scans at the end of chemotherapy regimen, the overall prognosis is favorable $[23,24]$. The drawbacks of this technique consist of the possibility of false-positive results due to reversible thymic hyperplasia, infections, and sarcoidosis or as a consequence of hematopoietic growth factor therapy [23].

\subsection{Morphologic and cytogenetic characteristics}

The search for an exclusively cytologic classification of DLBCL is mostly abandoned, due to the wide observer-dependent variations in morphologic analysis and nosologic framing. The cytologic exam usually differentiates between centroblastic, immunoblastic, anaplastic, and T-cell/histiocyte-rich B-cell lymphoma.

The subtype of DLBCL is decided by the genetic anomalies that occur during B-cell differentiation and maturation process $[6,25]$.

Even though gene expression profiling has the best accuracy for the identification of the cell of origin in DLBCL, its numerous drawbacks - such as the diverse cellular regulating pathways, some financial limitations, etc.-make its widespread clinical use still impractical. Consequently, several surface molecules have been evaluated for the differentiation between GCB and ABC DLBCL, which prove to be consistent with gene expression profiling.

The Hans algorithm has structured DLBCL in these two main subtypes, by analyzing three essential markers: multiple myeloma 1 protein (MUM1), CD10, and bcl-6 (Figure 1). The same classification can be achieved by using the germinal center B cell-expressed transcript 1 (GCET1), CD10, BCL-6, MUM1, and FOXP1 biomarkers (the Tally and Choi algorithms) with a slightly better accuracy (Figure 2). All these algorithms are important, as the cell of origin classification tends to display a prognostic role, due to the fact that DLBCL-GCB subtype usually has a favorable prognosis compared to non-GCB subtype. To further add to the complexity of this classification, GC and ABC DLBCL subtypes also express several particularities in cell marker expression, activation pathways, and outcomes [26].

However, the detection of other cell marker expression has become a fundamental component both in establishing an accurate prognosis and in the development of an optimal therapeutic algorithm.

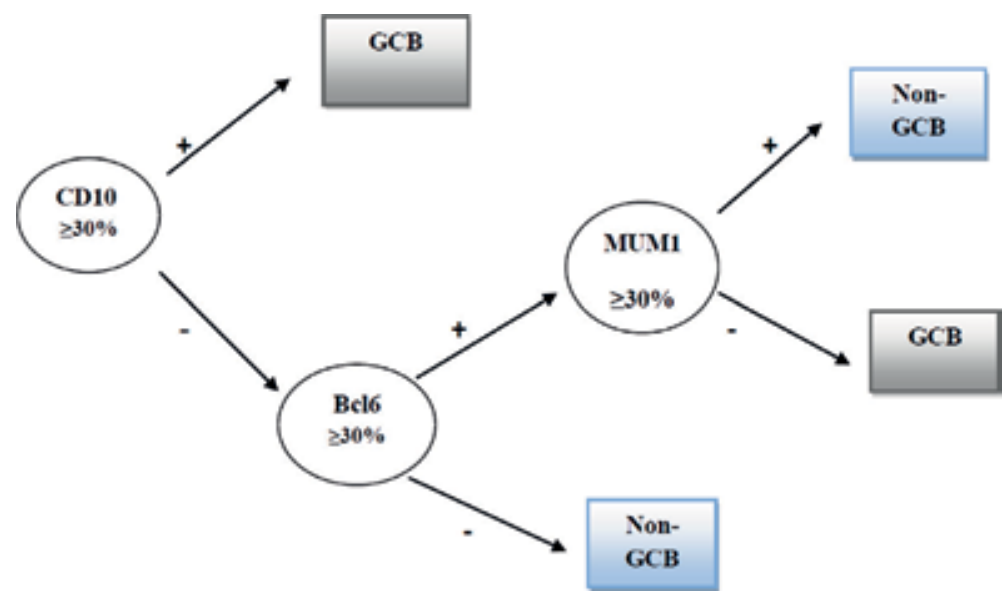

Figure 1.

Hans algorithm for DLBCL subtyping. 


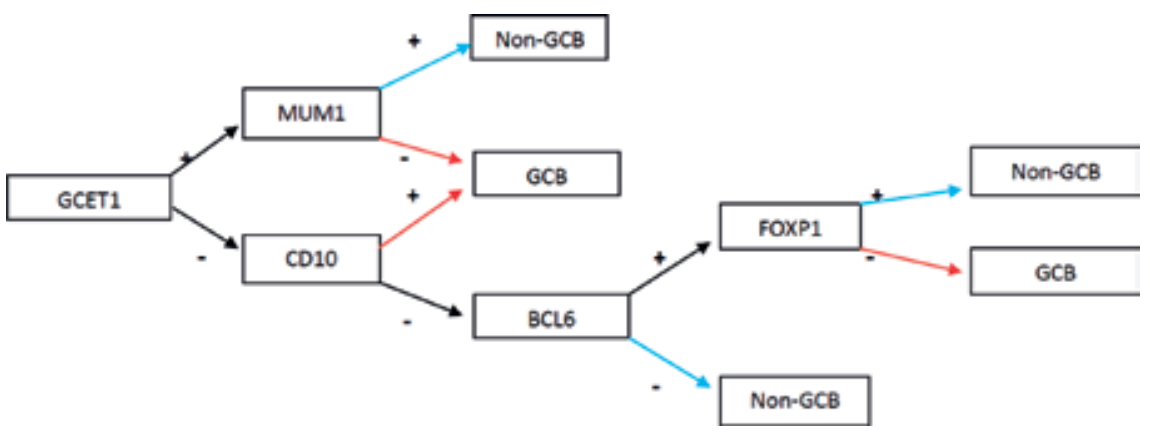

Figure 2.

Choi algorithm for DLBCL subtyping.

\section{Treatment of diffuse large B-cell lymphoma}

The treatment protocol in DLBCL did not witness significant changes during the last two decades. The widespread adoption of rituximab as an important adjuvant to standard chemotherapy protocol in CD20+ cases was a notable exception, which provided significant improvement in disease-free survival, overall survival, and complete remission rates, with limited toxicity. However, no less than $20 \%$ of patients diagnosed with DLBCL exhibit relapse after the initial response to R-CHOP (rituximab, cyclophosphamide, doxorubicin, vincristine, and prednisone) regimen, while more than $15 \%$ of the patients exhibit primary refractory disease [27]. All these factors required the search for alternative therapeutic regimens, such as R-CHOEP (rituximab, cyclophosphamide, doxorubicin, vincristine, etoposide, and prednisone), R-miniCHOP (adjusted short-term R-CHOP therapy), R-ACVBP (adriamycin-cytoxan-vindesine-bleomycin-prednisonerituximab), etc., that are strictly codified by several therapeutic protocols, such as the 2015 ESMO guidelines [10].

The choice for any of these regimens should be adapted to the specific clinical status of each patient, as the exact therapy depends on a number of factors, such as the stage of the disease, age, and biological status. However, despite numerous attempts, no clear recommendation has been published thus far.

The association of radiation therapy to chemotherapy offered conflicting results. While some studies showed some benefits for the combined therapy, most of the authors did not find any real advantages, especially in the case of localized disease without bulky mass [28]. There were some suggestions of a combined therapeutic algorithm, involving four R-CHOP cycles followed by either local radiation therapy or two more cycles of R-CHOP, in the case of complete remission. Armitage et al. pleaded for mandatory radiation therapy after six cycles of R-CHOP in the case of bulky disease [29]. More recently MInT (MabThera International Trial) study recommended the same therapeutic algorithm for localized bulky disease [30].

In the case of localized disease, the therapeutic protocol varies with the specific organ involvement. For primary DLBCL of the testis, R-CHOP should be associated with radiotherapy and methotrexate or intrathecal cytarabine, due to the potential risk of CNS involvement. In case of documented CNS involvement before the onset of therapy, then high-dose intravenous and intrathecal methotrexate is advised. Conversely, cytarabine should be used instead of methotrexate for lymphomatous meningitis [31]. R-CEOP can be advised for patients with an altered cardiac function.

In the case of advanced stage DLBCL, the therapeutic options varied greatly since the early 1980s. The third-generation regimens, ProMACE/CytaBOM 
(cyclophosphamide, doxorubicin, etoposid, Cytosar, bleomycin, vincristine, methotrexate, prednisone) and M-BACOD (methotrexate, bleomycin, doxorubicin, cyclophosphamide, vincristine, and dexamethasone), showed no benefits for complete remission or disease-free survival when compared to CHOP. However, a lower toxicity for CHOP was observed [32].

The R-ACVBP regimen, consisting of rituximab, doxorubicin, cyclophosphamide, vindesine, bleomycin, and prednisone, for induction of remission, and consolidation with methotrexate, doxorubicin, and cyclophosphamide, was tested by the GELA (Groupe d'Etude des Lymphomes de l'Adulte) study on 379 patients. This regimen showed some advantages over the R-CHOP-21 but at the price of significantly higher toxicity [33].

Given these circumstances, there is a growing need for new therapeutic alternatives, fitted for the morphologic, immunohistochemical, and genetic profile of each patient selected for individualized treatment protocol.

The role of immunophenotype variability for the therapeutic outcome has long been the cornerstone for DLBCL management strategy, largely because the treatment of lymphomas evolves toward new therapies (immunotherapy, targeted therapy), which is made possible by analyzing the biology and the signaling pathways of this disease [34, 35]. Furthermore, a growing number of biological agents are available, varying from interferon to rituximab or radiolabeled antibodies, but also the more recent acquisitions in targeted therapy, such as ibrutinib, acalabrutinib, and daratumumab [36-38].

\section{Conclusions}

Despite the numerous advances and better understanding of the clinical, immunophenotypic, and genetic characteristics of DLBCL, but also in face of several breakthroughs in its treatment, the prognosis of this type of NHL has witnessed only modest improvements. The search for new biomarkers and efficient therapeutic agents in the context of future individualized treatment will be crucial in our quest for improved results.

\section{Acknowledgements}

All authors shared equal contribution to this chapter.

\section{Conflict of interest}

None.

\section{Abbreviations}

$\begin{array}{ll}\text { ABC DLBCL } & \text { activated B-cell DLBCL } \\ \text { B2M } & \text { beta-2 microglobulin } \\ \text { Bcl-2 } & \text { B-cell receptor } 2 \\ \text { Bcl-6 } & \text { B-cell receptor } 6 \\ \text { CIITA } & \text { class II MHC transactivator } \\ \text { c-Myc } & \text { avian myelocytomatosis virus oncogene cellular homolog } \\ \text { CNS } & \text { central nervous system }\end{array}$


DLBCL diffuse large B-cell lymphomas

FOXP1 forkhead box protein P1

GCB DLBCL germinal center DLBCL

GCET1 germinal center B cell-expressed transcript 1

IRF4

MUM1 interferon regulatory factor 4

NFkB

NHL multiple myeloma 1 protein nuclear factor kappa-light-chain-enhancer of activated B cells

PDL 1 non-Hodgkin lymphoma

PET-CT programmed death-ligand 1

PMBCL

PTL

R-ACVBP adriamycin-cytoxan-vindesine-bleomycin-prednisone-rituximab

$\mathrm{R}-\mathrm{CHOP}$ rituximab, cyclophosphamide, doxorubicin, vincristine,

R-CHOEP rituximab, cyclophosphamide, doxorubicin, vincristine, etoposide, and prednisone

WHO World Health Organization

\section{Author details}

Patrascu Ana Maria ${ }^{1}$, Ionela Rotaru ${ }^{1}$, Valeriu Surlin ${ }^{2}$ and Stefan Patrascu ${ }^{2 *}$

1 Department of Hematology, University of Medicine and Pharmacy of Craiova, Craiova, Romania

2 Department of Surgery, University of Medicine and Pharmacy of Craiova, Craiova, Romania

*Address all correspondence to: stef.patrascu@gmail.com

\section{IntechOpen}

(C) 2019 The Author(s). Licensee IntechOpen. This chapter is distributed under the terms of the Creative Commons Attribution License (http://creativecommons.org/licenses/ by/3.0), which permits unrestricted use, distribution, and reproduction in any medium, provided the original work is properly cited. (cc) BY 


\section{References}

[1] Bea S, Colomo L, Guillermo AL, Salaverria I, Puig X, Pinyol M, et al. Clinicopathologic significance and prognostic value of chromosomal imbalances in diffuse large B-cell lymphomas. Journal of Clinical Oncology. 2004;22(17):3498-3506

[2] Tilly H, Vitolo U, Walewski J, da Silva MG, Shpilberg O, André M, et al. Diffuse large B-cell lymphoma (DLBCL): ESMO clinical practice guidelines for diagnosis, treatment and follow-up. Annals of Oncology. 2012;23(7):78-82

[3] Morgan G, Vornanen M, Puitinen J, et al. Changing trends in the incidence of non-Hodgkin's lymphoma in Europe. Biomed Study Group. Annals of Oncology. 1997;8(Suppl 2):49-54

[4] Siegel R, Naishadham D, Jemal A. Cancer statistics, 2013. CA: A Cancer Journal for Clinicians. 2013;63(1):11-30

[5] Jemal A, Siegel R, Xu J, Ward E. Cancer statistics, 2010. CA: A Cancer Journal for Clinicians. 2010;60(5):277-300

[6] Kuppers R, Dalla-Favera R. Mechanisms of chromosomal translocations in B cell lymphomas. Oncogene. 2001;20:5580-5594

[7] Pasqualucci L et al. Hypermutation of multiple proto-oncogenes in B-cell diffuse large-cell lymphomas. Nature. 2001;412:341-346

[8] Ng AK. Diffuse large B-cell lymphoma. Seminars in Radiation Oncology. 2007 Jul;17(3):169-175. DOI: 10.1016/j.semradonc.2007.02.002

[9] Swerdlow SH, Campo E, Pileri SA, Harris NL, Stein H, Siebert R, et al. The 2016 revision of the World Health Organization classification of lymphoid neoplasms. Blood. 2016;127(20):2375-2390

[10] Vitolo U, Seymour JF, Martelli M, Illerhaus G, Illidge T, Zucca E, et al. Extranodal diffuse large B-cell lymphoma (DLBCL) and primary mediastinal B-cell lymphoma: ESMO clinical practice guidelines for diagnosis, treatment and follow-up. Annals of Oncology. 2016;27:91-102

[11] Møller MB, Pedersen NT, Christensen BE. Diffuse large B-cell lymphoma: Clinical implications of extranodal versus nodal presentation-A population-based study of 1575 cases. British Journal of Haematology. 2004;124:151-159. DOI: 10.1046/j.1365-2141.2003.04749.x

[12] Savage KJ, Al-Rajhi N, Voss N, Paltiel C, Klasa R, Gascoyne RD, et al. Favorable outcome of primary mediastinal large B-cell lymphoma in a single institution: The British Columbia experience. Annals of Oncology. 2006;1:123-130

[13] Bentz M, Barth TF, Bruderlein S, Bock D, Schwerer MJ, Baudis M, et al. Gain of chromosome arm $9 \mathrm{p}$ is characteristic of primary mediastinal B-cell lymphoma (MBL): Comprehensive molecular cytogenetic analysis and presentation of a novel MBL cell line. Genes, Chromosomes \& Cancer. 2001;30:393-401. DOI: 10.1002/1098-2264(2001)9999: 9999<::AID-GCC1105>3.0.CO;2-I

[14] Joos S, Otano-Joos MI, Ziegler S, Brüderlein S, du Manoir S, Bentz M, et al. Primary mediastinal (thymic) $\mathrm{B}$-cell lymphoma is characterized by gains of chromosomal material including 9p and amplification of the REL gene. Blood. 1996;87:1571-1578

[15] Lazzarino M, Orlandi E, Paulli M, et al. Treatment outcome 
and prognostic factors for primary mediastinal (thymic) B-cell lymphoma: A multicenter study of 106 patients. Journal of Clinical Oncology. 1997;15:1646-1653

[16] Todeschini G, Secchi S, Morra E, et al. Primary mediastinal large B-cell lymphoma (PMLBCL): Long-term results from a retrospective multicentre Italian experience in 138 patients treated with CHOP or MACOP-B/ VACOP-B. British Journal of Cancer. 2004;90:372-376

[17] Rosenwald A, Wright G, Leroy K, Yu X, Gaulard P, Gascoyne RD, et al. Molecular diagnosis of primary mediastinal B cell lymphoma identifies a clinically favorable subgroup of diffuse large B cell lymphoma related to Hodgkin lymphoma. The Journal of Experimental Medicine. 2003;198(6):851

[18] Ferreri AJ, Blay JY, Reni M, et al. Prognostic scoring system for primary CNS lymphomas: The International Extranodal Lymphoma Study Group experience. Journal of Clinical Oncology. 2003;21:266-272

[19] Kuper-Hommel MJ, Janssen-Heijnen MLG, Vreugdenhil G, et al. Clinical and pathological features of testicular diffuse large B-cell lymphoma: A heterogeneous disease. Leukemia \& Lymphoma. 2012;53:242-246

[20] Cheah CY, Campbell BA, Seymour JF. Primary breast lymphoma. Cancer Treatment Reviews. 2014;40:900-908

[21] Martinez A, Ponzoni M, Agostinelli C, et al. Primary bone marrow lymphoma: An uncommon extranodal presentation of aggressive non-Hodgkin lymphomas. The American Journal of Surgical Pathology. 2012;36:296-304

[22] NCCN Guidelines for Treatment of Non-Hodgkin Lymphoma. http://www. nccn.org [Accessed: December 31, 2018]
[23] Cheson BD, Pfistner B, Juweid ME, et al. Revised response criteria for malignant lymphoma. Journal of Clinical Oncology. 2007;25:579-586

[24] Juweid ME, Cheson BD. Role of positron emission tomography in lymphoma. Journal of Clinical Oncology. 2005;23(21):4577-4580

[25] Pătraşcu AM, Rotaru I, Olar L, Pătraşcu Ş, Ghiluşi MC, Neamtu SD, et al. The prognostic role of $\mathrm{Bcl}-2$, Ki67, c-MYC and p53 in diffuse large B-cell lymphoma. Romanian Journal of Morphology and Embryology. 2017;58(3):837-843

[26] Martelli M, Ferreri AJ, Agostinelli C, Di Rocco A, Pfreundschuh M, Pileri S. Diffuse large B-cell lymphoma. Journal of Hematology \& Oncology. 2013;87(2):146-171

[27] Laursen MB, Reinholdt L, Schönherz AA, Due H, Jespersen DS, Grubach L, et al. High CXCR4 expression impairs rituximab response and the prognosis of R-CHOP-treated diffuse large B-cell lymphoma patients. Oncotarget. 2019;10(7):717-731. DOI: 10.18632/oncotarget. 26588

[28] Miller TP, Dahlberg S, Cassady JR, Adelstein DJ, Spier CM, Grogan TM, et al. Chemotherapy alone compared with chemotherapy plus radiotherapy for localized intermediate- and highgrade non-Hodgkin's lymphoma. The New England Journal of Medicine. 1998;339(1):21-26

[29] Armitage JO. How I treat patients with diffuse large B-cell lymphoma. Blood. 2007;110(1):29-36

[30] Pfreundschuh M, Kuhnt E, Trümper L, Osterborg A, Trneny M, Shepherd L, et al. CHOP-like chemotherapy with or without rituximab in young patients with good-prognosis diffuse large-B-cell lymphoma: 6-year results of an 
open-label randomised study of the MabThera International Trial (MInT) Group. The Lancet Oncology. 2011;12(11):1013-1022

[31] Fletcher CD, Kahl BS. Central nervous system involvement in diffuse large B-cell lymphoma: An analysis of risks and prevention strategies in the post-rituximab era. Leukemia \& Lymphoma. 2014;55(10):2228-2240

[32] Fisher RI, Gaynor ER, Dahlberg S, Oken MM, Grogan TM, Mize EM, et al. Comparison of a standard regimen (CHOP) with three intensive chemotherapy regimens for advanced non-Hodgkin's lymphoma. The New England Journal of Medicine. 1993;328(14):1002-1006

[33] Recher C, Coiffier B, Haioun C, Molina TJ, Fermé C, Casasnovas O, et al. Intensified chemotherapy with ACVBP plus rituximab versus standard $\mathrm{CHOP}$ plus rituximab for the treatment of diffuse large B-cell lymphoma (LNH03-2B): An openlabel randomised phase 3 trial. Lancet. 2011;378(9806):1858-1867

[34] He Y, Li J, Ding N, Wang X, Deng L, $\mathrm{Xie} Y$, et al. Combination of enzastaurin and ibrutinib synergistically induces anti-tumor effects in diffuse large B cell lymphoma. Journal of Experimental \& Clinical Cancer Research. 2019;38(1):86. DOI: 10.1186/s13046-019-1076-4

[35] Afonso J, Pinto T, Simões-Sousa S, Schmitt F, Longatto-Filho A, Pinheiro C, et al. Clinical significance of metabolism-related biomarkers in non-Hodgkin lymphoma-MCT1 as potential target in diffuse large $B$ cell lymphoma. Cellular Oncology (Dordrecht). 2019. DOI: 10.1007/ s13402-019-00426-2 [Epub ahead of print]

[36] Wu J, Zhang M, Liu D.

Acalabrutinib (ACP-196): A selective second-generation BTK inhibitor. Journal of Hematology \& Oncology. 2016;9:21. DOI: 10.1186/ s13045-016-0250-9

[37] Maffei R, Fiorcari S, Martinelli S, Potenza L, Luppi M, Marasca R. Targeting neoplastic $\mathrm{B}$ cells and harnessing microenvironment: The "double face" of ibrutinib and idelalisib. Journal of Hematology \& Oncology. 2015;8:60. DOI: 10.1186/ s13045-015-0157-x

[38] Salles G, Gopal AK, Minnema MC, Wakamiya K, Feng H, Schecter JM, et al. Phase 2 study of daratumumab in relapsed/refractory mantle-cell lymphoma, diffuse large B-cell lymphoma, and follicular lymphoma. Clinical Lymphoma, Myeloma \& Leukemia. 2019;pii: S2152-2650 (18):31284-31289. DOI: 10.1016/j. clml.2018.12.013 [Epub ahead of print] 
Section 3

Minimal Residual Disease and Acute Leukemia 



\title{
B-Cell Precursors:
}

\section{Immunophenotypic Features in the Detection of Minimal Residual Disease in Acute Leukemia}

\author{
Olga Chernysheva, Lyudmila Yuryevna Grivtsova, \\ Alexander Popa and Nikolay Nikolayevich Tupitsyn
}

\begin{abstract}
Minimal residual disease (MRD) as a tool to monitor response to therapy is both a criterion for detailed risk stratification and an independent prognostic factor in childhood acute lymphoblastic leukemia (ALL). Immunological assays particularly flow cytometry (FC) are priority methods in MRD monitoring. Multicolor flow cytometry makes it possible to most fully characterize the immunophenotype of tumor B lymphoblasts and reveal leukemia-associated immunophenotypes not only according to the CD58 and CD38 antigens but also as an additional criterion of aberrancy. This allows you to identify and select individual criteria for further monitoring of minimal residual disease for each patient with ALL. The aim of this chapter is to compare immunophenotyping features of normal B-cell precursors and B-lymphoblasts in acute leukemia and to show possibilities of use of a leukemiaassociated immunophenotype in monitoring of the MRD.
\end{abstract}

Keywords: bone marrow, B-cell precursors, acute leukemia, leukemia-associated immunophenotype, flow cytometry, minimal residual disease

\section{Introduction}

Control of response to chemotherapy is an intrinsic part of current treatment protocols [1-5]. Assessment of response in key points of chemotherapy programs helps both to stratify patients by risk groups more accurately and to avoid serious chronic side effects and patient overtreatment [6-12]. In case of acute leukemia, the number of tumor blasts undetectable in bone marrow (BM) morphologically at different therapy stages or minimal residual disease (MRD) is a criterion for such assessment.

In adult patients, problems of most significant points of immunological detection and the role of MRD levels are a matter of discussion [2]. The MRD significance is demonstrated in full in pediatric oncology. The MRD is of importance both in prognosis of acute lymphoblastic leukemia (ALL) and in prediction of recurrence [13]. Key points for MRD assessment are determined as well as their clinical significance and MRD levels that help in detailed risk stratification of patients [1]. 
Immunological quantification of MRD cells solves different problems depending on chemotherapy stages. In the middle of induction therapy (day 15), it evaluates primary response [14]. While at the end of induction therapy (day 33), the purpose is final risk stratification of patients with respect to clinical and immunological prognostic factors $[1,14,15]$. MRD assessment at the end of induction consolidation (day 78) identifies a patient group with so called slow response. These patients remain MRD-positive by days 15 and 33 and reach MRD-negativity by day 78 only. This group is characterized by good prognosis [3].

Many international research groups have developed flow cytometry (FC) protocols for MRD diagnosis; however, there is not a common approach yet. The St Jude Children's Research Hospital (Memphis, USA) has proposed a simplified 3-color FC assay to detect MRD cells on day 15 of induction therapy [16] that is based on elimination of normal B-cell precursors (BCP) under the effect of corticosteroids [17] that are a basis for therapy at the given stage. The BFM international study group has developed an MRD monitoring protocol basing on the detection of B-LP with aberrant (leukemia-associated) immunophenotype (LAIP). Antigens CD58 and CD38 are most common markers to characterize the aberrant immunophenotype $[18,19]$. However, tumor lymphoblasts show no aberrance by these antigens [20]. There are no clearly identified alternative combinations of aberrant markers.

In ALL from T-cell precursors (T-ALL), there are no clearly cut criteria for MRD assessment [21] and research in this field is ongoing.

The aim of this chapter is to compare immunophenotyping features of normal B-cell precursors and B-lymphoblasts in acute leukemia and to show possibilities of use of a leukemia-associated immunophenotype in monitoring of the MRD.

\section{Materials and methods}

The study involved 191 ALL cases (160 B-ALL [142—primary diagnosis, 18diagnosis in relapse] and 31 T-ALL). The diagnosis was made basing on a combination of morphocytochemical and immunophenotyping assays of BM puncture biopsies.

In most cases ( $88.8 \%$ of B-ALL and $87.1 \%$ of T-ALL), the immunophenotyping at diagnosis was performed by 3-color FC (at least 20 markers was analyzed). The immunophenotyping using EuroFlow 8-color standardized panels was made in $11.2 \%$ of B-ALL and $12.9 \%$ of T-ALL cases. Lineage of blasts was determined using ALOT (acute leukemia orientation tube) (Table 1).

A more accurate B-ALL (Table 2) or T-ALL (Table 3) 8-color standardized panel was used depending upon the identified blast lineage. The BCP aberrance was assessed basing on expression of the following antigens: CD58, CD38, CD81, CD9, CD123, CD66c, CD13, CD33, CD20, CD21, and CD24; T-cell precursors (TCP) were characterized with respect to CD99, CD56 expression.

MRD quantification was made in $397 \mathrm{BM}$ specimens from ALL patients at different therapy stages (days 15, 33, and 78, Table 4).

\begin{tabular}{lcccccccc}
\hline \multirow{2}{*}{$\begin{array}{l}\text { No./ } \\
\text { fluorochrome }\end{array}$} & \multicolumn{7}{c}{ Markers } \\
\cline { 2 - 9 } & FITC & PE & PerCP-cy5.5 & PE-cy7 & APC & APC-117 & V450 & V500 \\
\hline 1 & cy & cy & CD34 & CD19 & CD7 & sm & cy & CD45 \\
& MPO & CD79a & & & & CD3 & CD3 & \\
\hline
\end{tabular}

Table 1.

Acute leukemia orientation tube. 
B-Cell Precursors: Immunophenotypic Features in the Detection of Minimal Residual Disease... DOI: http://dx.doi.org/10.5772/intechopen.84223

\begin{tabular}{|c|c|c|c|c|c|c|c|c|}
\hline \multirow{2}{*}{$\begin{array}{l}\text { No./ } \\
\text { fluorochrome }\end{array}$} & \multicolumn{8}{|c|}{ Markers } \\
\hline & FITC & PE & PerCP-cy5.5 & PE-cy7 & APC & APC-117 & V450 & V500 \\
\hline 1 & CD58 & CD66c & CD34 & CD19 & CD10 & $\mathrm{CD} 38$ & CD20 & CD45 \\
\hline 2 & cyIgM & CD33 & CD34 & CD19 & CD117 + sIgM & $\operatorname{sIg}-\lambda$ & sIg-K & CD45 \\
\hline 3 & nuTdT & CD13 & CD34 & CD19 & CD22 & $\mathrm{CD} 24$ & CD9 & CD45 \\
\hline 4 & $\mathrm{CD} 15+\mathrm{CD} 65$ & NG2 & CD34 & CD19 & CD123 & CD81 & $\mathrm{CD} 21$ & CD45 \\
\hline
\end{tabular}

Table 2.

EuroFlow consortium 8-color standardized panel for B-ALL diagnosis.

\begin{tabular}{lcccccccc}
\hline \multirow{2}{*}{ No./fluorochrome } & \multicolumn{7}{c}{ Markers } \\
\cline { 2 - 9 } & FITC & PE & PerCP-cy5.5 & PE-cy7 & APC & APC-117 & V450 & V500 \\
\hline 1 & nuTdT & CD99 & CD5 & CD10 & CD1a & smCD3 & cyCD3 & CD45 \\
\hline 2 & CD2 & CD117 & CD4 & CD8 & CD7 & smCD3 & cyCD3 & CD45 \\
\hline 3 & TCR $\gamma \delta$ & TCR $\alpha \beta$ & CD33 & CD56 & cyTCR $\alpha \beta$ & smCD3 & cyCD3 & CD45 \\
\hline 4 & CD44 & CD13 & HLA-DR & CD45RA & CD123 & smCD3 & cyCD3 & CD45 \\
\hline
\end{tabular}

Table 3.

EuroFlow consortium 8-color standardized panel for T-ALL diagnosis.

\begin{tabular}{|c|c|c|c|c|c|c|c|c|c|c|}
\hline \multirow{2}{*}{\multicolumn{2}{|c|}{$\begin{array}{l}\text { ALL immuno-subtype } \\
\text { FC color number }\end{array}$}} & \multicolumn{9}{|c|}{ MRD monitoring points } \\
\hline & & \multicolumn{3}{|c|}{ Day 15} & \multicolumn{3}{|c|}{ Day 33} & \multicolumn{3}{|c|}{ Day 78} \\
\hline & & $3 \mathrm{col}$. & 4-6 col. & $8 \mathrm{col}$. & 3 col. & 4-6 col. & $8 \mathrm{col}$. & 3 col. & 4-6 col. & $8 \mathrm{col}$. \\
\hline \multirow[t]{3}{*}{ B-ALL } & Total & & 139 & & & 148 & & & 54 & \\
\hline & No. & 59 & 68 & 12 & 51 & 79 & 18 & 3 & 38 & 13 \\
\hline & Percentage & 42.4 & 49.0 & 8.6 & 34.4 & 53.4 & 12.2 & 5.6 & 70.4 & 24.0 \\
\hline \multirow[t]{3}{*}{ T-ALL } & Total & & 30 & & & 26 & & & - & \\
\hline & No. & 9 & 19 & 2 & 6 & 18 & 2 & - & - & - \\
\hline & Percentage & 30.0 & 63.3 & 6.7 & 23.1 & 69.2 & 7.7 & - & - & - \\
\hline
\end{tabular}

Table 4.

The number of analyses at each MRD monitoring point.

At diagnosis, every BM specimen was characterized both morphologically and immunologically. Myelogram count was made by two morphologists (250 cells each) on Giemsa stained BM smears. The following M-types were identified basing on standard morphological criteria for the number of blasts: M1-specimens with $\leq 5 \%$ of blasts, M2-specimens with $5.0-25.0 \%$ of blasts, and M3-specimens with $\geq 25 \%$ of blasts. After that, a more detailed analysis was made, and the morphological criteria were compared with immunological findings. Detailed analysis of MRD levels was made in M1, M2, and M3 specimens. Subgroups of specimens within each group were identified with respect to the number of MRD cells. The subgroups were identified according to the BFM protocol for MRD assessment on induction chemotherapy as follows: standard risk $<0.1 \%$ (including negative cases), medium risk $0.1-10.0 \%$, and high risk $\geq 10 \%$ /the level of $0.01 \%$ of tumor cells in a specimen was taken as a standard threshold for MRD negativity. 
Statistical analysis was made using IBM-SPSS Statistics v.17 software. Parametric data were analyzed by comparison of means using Student's t-test. Comparison of nonparametric data was made by Pearson's $\chi 2$-test.

\section{Results}

\subsection{General patient characteristics}

A total of 186 patients with ALL (five patients were treated in debut and in relapse of the disease) managed at the N.N. Blokhin Cancer Research Center during 2006 through 2017 were entered in the study.

The B-ALL group included 155 patients 1-18 years of age: 78 boys (48.7\%) and 82 girls $(51.3 \%)$ (Table 5$)$. In 142 cases $(88.8 \%)$, the diagnosis was made at the disease onset. In 18 cases (11.2\%), the diagnosis was made in recurrence stage. Five patients were followed up both in the debut and recurrences stages.

The T-ALL group consisted of 31 patients aged 2-17 years including 26 boys (83.9\%) and 5 girls (16.1\%) (Table 6).

Treatment was given according to the ALL IC BFM 2002 and 2009 protocols. Data on risk stratification are shown for 79 patients with B-ALL receiving treatment by the ALL IC BFM 2009 protocol (data for 63 patients with B-ALL onset are not available). The majority of patients $(67.1 \%)$ were classified into an intermediate risk group. Only $5.1 \%$ of patients were a high risk group. And $27.8 \%$ of patients were assigned to a standard risk group.

$71.0 \%$ of T-ALL patients received treatment by ALL IC BFM 2009 protocol. The majority of patients $(72.7 \%)$ were classified into an intermediate risk group. Other patients $(27.3 \%)$ were assigned to a high risk group.

\begin{tabular}{lccc}
\hline Characteristic & & Number & Percentage \\
\hline Gender & $\mathrm{M}$ & 78 & 48.4 \\
\cline { 2 - 4 } & $\mathrm{F}$ & 83 & 51.6 \\
\hline Age & & $1-18$ years (mean $5.9 \pm 0.3$ years) & \\
\hline Time of diagnosis & Debut & 142 & 88.8 \\
\cline { 2 - 4 } & Recurrence & 18 & 11.2 \\
\hline Immunosubtype & Pre-pre-B & 150 & 93.8 \\
\cline { 2 - 4 } & Pro-B & 10 & 6.2 \\
\hline
\end{tabular}

Table 5.

Patient characteristics in the B-ALL group.

\begin{tabular}{|c|c|c|c|}
\hline Characteristic & & Number & Percentage \\
\hline \multirow[t]{2}{*}{ Gender } & M & 29 & 83.9 \\
\hline & $\mathrm{F}$ & 7 & 16.1 \\
\hline Age & \multicolumn{3}{|c|}{$1-17$ years (mean $7.3 \pm 4.7$ years) } \\
\hline \multirow[t]{3}{*}{ Time of diagnosis } & Debut & 31 & 100 \\
\hline & Pre-T-cell & 12 & 38.7 \\
\hline & Cortico-thymocytic & 19 & 61.3 \\
\hline
\end{tabular}

Table 6.

Patient characteristics in the T-ALL group. 
B-Cell Precursors: Immunophenotypic Features in the Detection of Minimal Residual Disease... DOI: http://dx.doi.org/10.5772/intechopen.84223

MRD monitoring was made on days 15, 33, and 78 of chemotherapy according to the treatment protocols used at the Research Institute of Pediatric Oncology and Hematology of the FBI N.N. Blokhin NMRCO and international recommendations.

\subsection{ALL from B-cell precursors}

\subsubsection{Immunological characterization of blasts at primary diagnosis}

Table 7 shows B-lymphoblast immunophenotype characteristics at primary diagnosis. These immunological characteristics were used further in MRD monitoring.

CD58 and CD38 are currently most commonly used antigens as main criteria of tumor B-lymphoblast aberrance. Blasts are considered aberrant if they are characterized by overexpression of CD58 in combination with low or no expression of $\mathrm{CD} 38$ (immunophenotype $\mathrm{CD} 58^{++} \mathrm{CD} 38^{\text {low/- }}$, Figure 1).

Analysis for this antigen combination demonstrated that blasts do not always have the $\mathrm{CD} 58^{++} \mathrm{CD} 38^{\text {lowl- }}$ immunophenotype, that is, aberrance by both antigens is found in $54.3 \%$ of cases only (Table 8 ). Figure 2 shows an example of no aberrance by CD58 and CD38 antigens.

The following markers were studied as additional criteria of aberrance: CD123 (Figure 3), CD66c, CD81 (Figure 4), CD9, CD21, CD24 with their expression presented in Table 9. Figures 3 and $\mathbf{4}$ show an example of aberrant expression of CD123 and CD81 in B-lymphoblasts at primary diagnosis.

\subsubsection{Immunophenotypic characterization of blasts at relapse}

A total of 18 patients were examined at relapse of the disease. Five patients were examined at both disease onset and relapse. Blast characterization was made using a

\begin{tabular}{lcc}
\hline Antigen & $\begin{array}{c}\text { No. of cases } \\
\text { analyzed }\end{array}$ & Frequency of Ag-positive cases (\%) \\
\hline CD10 & 142 & 93.0 \\
\hline CD34 & 139 & 74.1 \\
\hline nuTdT & 24 & 100.0 \\
\hline smCD22 & 137 & 50.3 \\
\hline CD20 & 129 & 14.7 \\
\hline Pan-myeloid (CD13, CD33) & 137 & 46.0 \\
\hline CD58 ${ }^{++}$CD38 ${ }^{\text {low/- }}$ & 50 & 54.0 \\
\hline CD38 ${ }^{+++}$ & 93 & 54.8 \\
\hline Additional criteria of aberrance & & 100.0 \\
\hline CD123 & 8 & 75.0 \\
\hline CD66c & 8 & 14.3 \\
\hline CD81 & 7 & 87.5 \\
\hline CD9 & 8 & 0.0 \\
\hline CD21 & 7 & 100.0 \\
\hline CD24 & 7 & \\
\hline
\end{tabular}

Table 7.

Tumor blast immunophenotype characteristics at primary diagnosis at disease onset. 

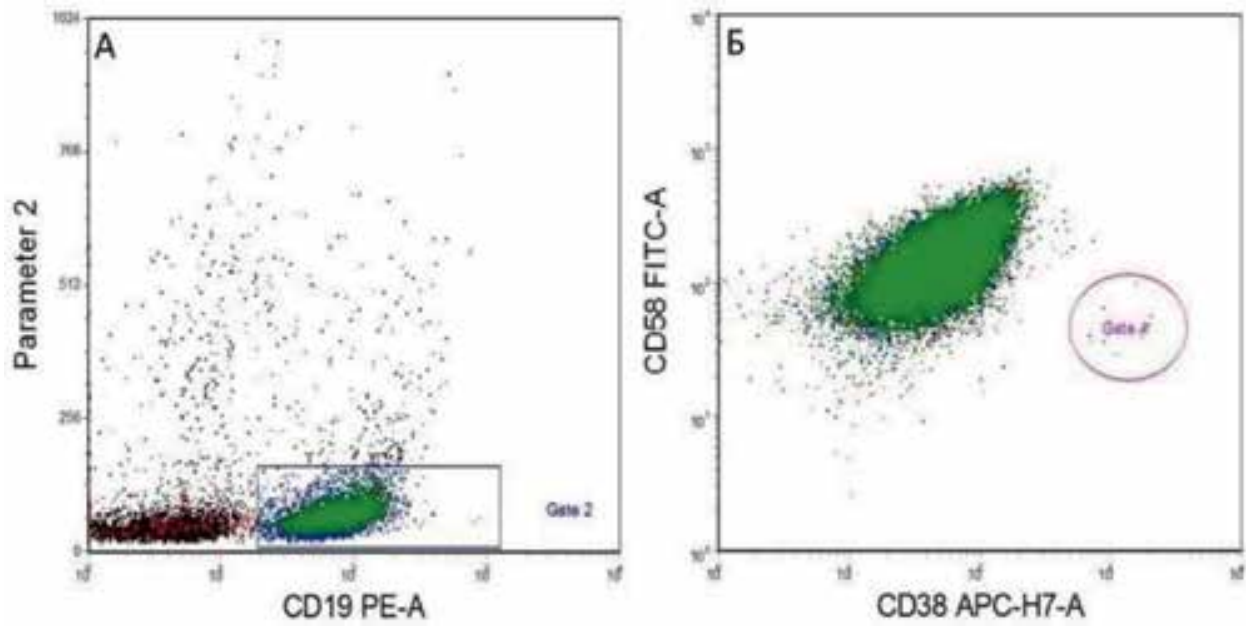

Figure 1.

Blasts with aberrant immunophenotype $C D 58^{++} / C D 38^{\text {low }}$. Cytogram A: blasts (gate 2, green) demonstrate bright CD19 expression (X-axis) against side scattering parameters (SSC, Y-axis). Cytogram B: B-lymphoblasts demonstrate bright $C D 58$ expression ( $Y$-axis) in combination with low $C D 38$ expression ( $X$-axis) as compared to normal $B C P\left(C D 58^{+} C D_{3} 8^{+}\right.$, gate 4$)$.

\begin{tabular}{lcc}
\hline CD58/CD38 expression & Number & Percentage \\
\hline $\mathrm{CD} 58^{++} / \mathrm{CD} 38^{\text {low } /-}$ & 25 & 54.3 \\
\hline $\mathrm{CD} 58^{+} / \mathrm{CD} 38^{\text {low } /-}$ & 2 & 4.3 \\
\hline $\mathrm{CD} 58^{++} / \mathrm{CD} 38^{+}$ & 8 & 17.4 \\
\hline $\mathrm{CD} 58^{+} / \mathrm{CD} 38^{+}$ & 11 & 24.0 \\
\hline Total & 46 & 100.0 \\
\hline
\end{tabular}

Table 8.

Blast immunophenotypes with respect to $C D 58$ and $C D 38$ expression at primary diagnosis.
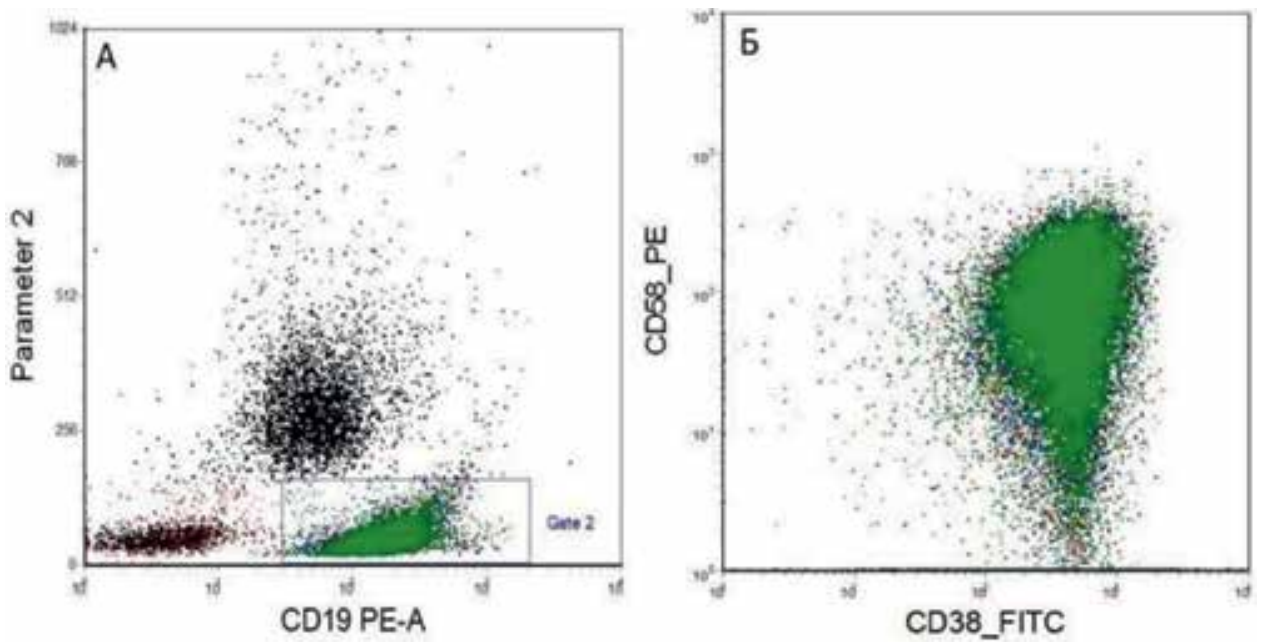

Figure 2.

Tumor B-lymphoblasts with immunophenotype $C D 58^{+} / C D 38^{+}$. Cytogram A: tumor B-lymphoblasts are identified basing on CD19 expression (X-axis) and low SSC characteristics (Y-axis). Blasts $\left(C D 45^{\text {low }} C D_{19}{ }^{+}\right.$) are characterized by bright $C D_{3} 8$ expression (X-axis) in combination with normal $C D_{5} 8$ expression ( $Y$-axis) (cytogram B). 
B-Cell Precursors: Immunophenotypic Features in the Detection of Minimal Residual Disease... DOI: $h$ ttp://dx.doi.org/10.5772/intechopen.84223
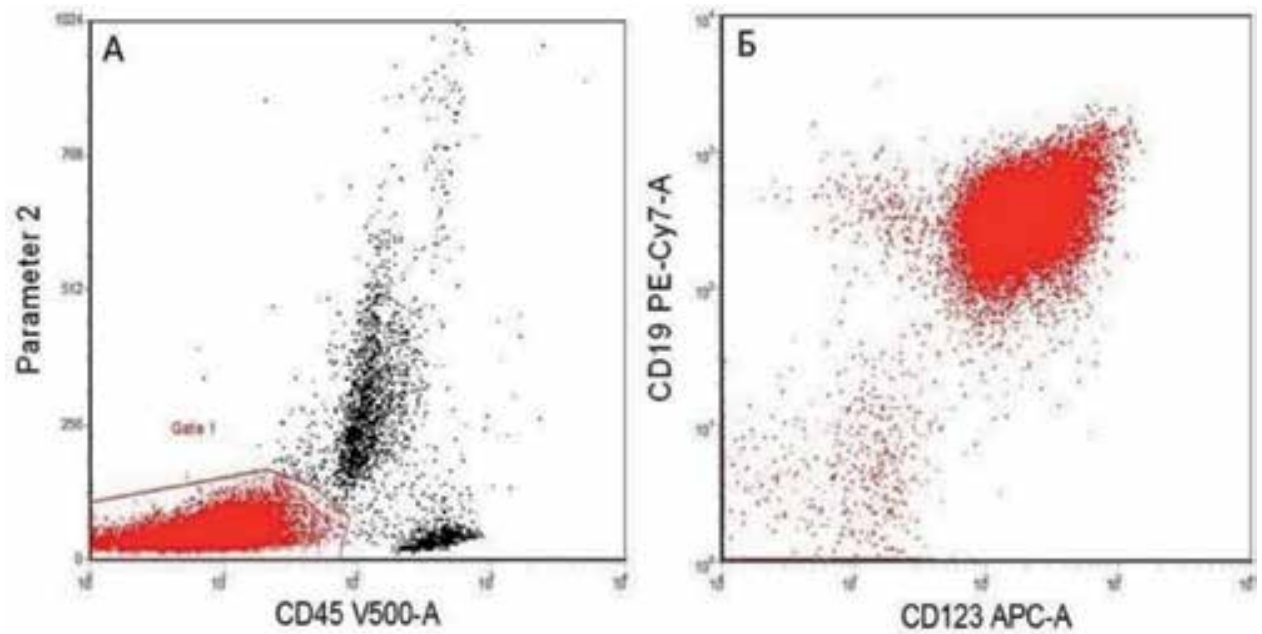

Figure 3.

Tumor B-lymphoblast aberrance by CD123 at primary diagnosis. Cytogram A: blasts (gate 1, red) are detected by low CD45 expression (X-axis) and low SSC characteristics (Y-axis). Cytogram B: tumor lymphoblasts demonstrate bright expression of pan-B-cell antigen $C D 19$ (Y-axis) in combination with bright (aberrant) CD123 expression (X-axis).
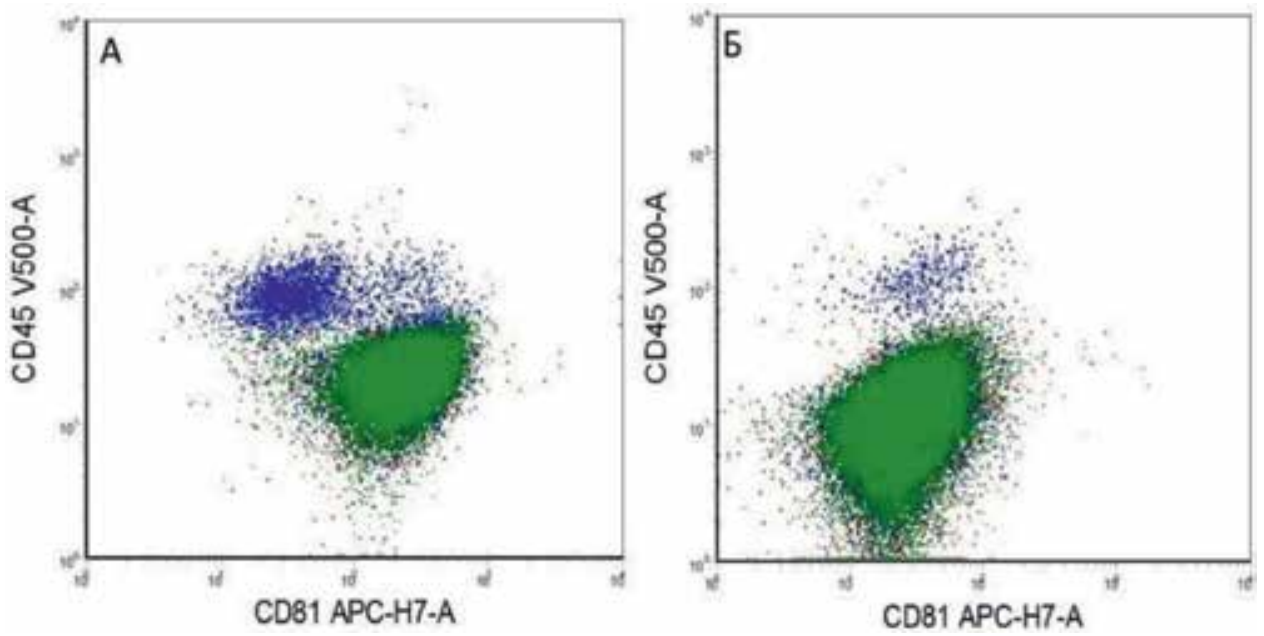

Figure 4.

Normal $(A)$ and aberrant $(B)$ expression of CD81 on B-LP. Cytogram A: normal bright CD81 expression on tumor B-lymphoblasts (green) in X-axis (CD81) against Y-axis (CD45) coordinates. Cytogram B: tumor $B$-lymphoblasts (green) with aberrant (weak) CD81 expression in X-axis (CD81) against Y-axis (CD45).

3-color FC protocol in 66.7\% (12/18) patients. In six patients (33.3\%), immunophenotyping used the EuroFlow consortium 8-color protocol.

Expression of main CD58/CD38 aberrance markers at disease recurrence was assessed in 13 patients.

Blast immunophenotype with respect to CD58 and CD38 expression intensity as compared with the primary diagnosis changed in 2 of 5 cases. In the first case, blasts at primary diagnosis were immunophenotypically close to normal BCP as concerns $\mathrm{CD} 58$ and $\mathrm{CD} 38$ expression $\left(\mathrm{CD} 58^{+} \mathrm{CD} 38^{++}\right)$, while acquiring aberrant $\mathrm{CD} 58$ and $\mathrm{CD} 38$ expression $\left(\mathrm{CD} 58^{++} \mathrm{CD} 38^{+}\right)$at relapse. In the second case, on the opposite, blasts lost aberrant CD38 sign and became close to normal non-tumor B-lymphoblasts by this antigen expression. 


\begin{tabular}{lcc}
\hline Antigen & No. of cases studied & Frequency of Ag-positive cases (\%) \\
\hline nuTdT & 31 & 80.6 \\
\hline CD34 & 31 & 19.4 \\
\hline CD10 & 31 & 38.7 \\
\hline CD4 ${ }^{+} \mathrm{CD}^{+}$ & 31 & 35.5 \\
\hline $\mathrm{CD} 1 \mathrm{a}$ & 31 & 54.8 \\
\hline $\mathrm{CD} 5$ & 31 & 90.3 \\
\hline $\mathrm{CD} 7$ & 31 & 96.8 \\
\hline
\end{tabular}

Table 9.

Detection frequency of antigens associated with various TCP differentiation stages in T-ALL.

\subsubsection{MRD assessment on day 15 of therapy}

We compared morphological and immunological findings from BM analysis on day 15 of therapy. In group M1, morphological and FC data were fully similar (no blasts by morphology and complete MRD negativity [MRD cells $<0.01 \%$ ] by FC) in $11.5 \%$ of cases.

Specimens from the M1 group were characterized by a marked percentage of lymphocytes (mean > 60.0\%). The presence of MRD-positive specimens (FC) in the M1 group (good morphological response) may be explained by blast mimicry, that is, similarity with lymphocytes. This makes difficult accurate morphological verification of residual leukemic blasts.

In group M1, there was no contradiction between morphological and FC data. Most M3 specimens ( $85.7 \%$ ) contained $\geq 10.0 \%$ of MRD-positive cells by FC. The fraction of MRD-positive cells was $5.5 \%$ in one case only; that is, in terms of FC, this patient might be referred to the intermediate risk group and did not require therapy intensification.

Comparison of two FC protocols for MRD monitoring on day 15 (3-color St. Jude [28] based on identification of $\mathrm{CD}_{10}{ }^{+} / \mathrm{CD} 34^{+} \mathrm{BCP}$ among $\mathrm{BM}$ mononuclear fraction, and BFM protocol based on identification of $\mathrm{BCP}$ with aberrant immunophenotype among nucleated cells [NC]) demonstrated that the mononuclear approach was a more strict criterion for risk stratification of patients.

MRD on day 15 of induction therapy in B-ALL is always represented by BCP. Their identification is based on detection of CD10 and CD34 expression or no expression of pan-leukocyte antigen CD45 and combination of the above mentioned markers in B-cells. Quantification of MRD cells on the basis of each of the progenitor markers demonstrated that CD10 was the most reliable criterion for evaluation of BCP cells on day 15 of chemotherapy in children with pre-pre-B ALL. While in pro-B B-ALL, the count of BCLP should be made basing on nuTdT-positive cyCD22-expressing B-cells.

CD58/CD38 expression was assessed on day 15 of induction chemotherapy in 28 patients. All BCP, that is, MRD cells demonstrated aberrant immunophenotype $\mathrm{CD} 58^{++} / \mathrm{CD} 38^{\text {low }}$ only in 15 of 28 patients (54\%) (Figure 5 ).

$\mathrm{CD} 58^{++} / \mathrm{CD} 38^{\text {low/- }} \mathrm{BCP}$ content was analyzed in patients with no aberrance by this antigen combination at primary diagnosis $(n=11)$. The proportion of CD10 $\mathrm{B}$-cells was similar to that of $\mathrm{CD} 58^{++} / \mathrm{CD} 38^{\text {low/- }} \mathrm{BCP}$ in four specimens only. This example is illustrated in Figure 5. In the remaining cases, the number of $\mathrm{CD}^{2} 8^{++} /$ $\mathrm{CD} 38^{\text {tow }} \mathrm{BCP}$ was less than the number of $\mathrm{CD} 10^{+} \mathrm{B}$-cells.

The analysis demonstrated a significant predominance of MRD on day 15 of therapy in pro-B ALL as compared to pre-B $(\mathrm{p}=0.016)$.

Day 15 of induction chemotherapy is characterized by BM hypocellularity and a marked fraction of debris that can interfere with results (Figure 6). To avoid this, 

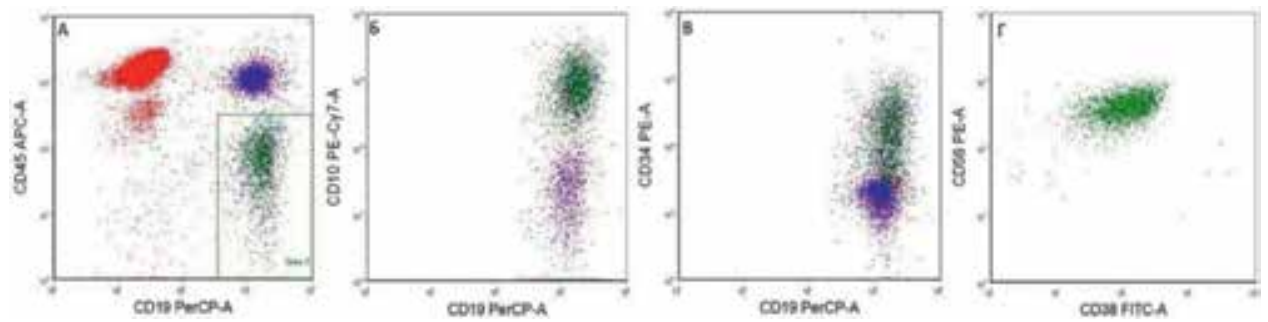

Figure 5.

BCP immunophenotype features on day 15 of induction therapy. Cytogram A: $16.6 \% C D 19^{+} C D 45^{\text {low }} B C P$ (gate 3, green) in CD19 (X-axis) against CD45 (Y-axis) coordinates. The cells demonstrate bright CD10 (cytogram $B$ ), $C D_{19}$ (X-axis) expression against CD10 (Y-axis) and marked CD34 expression (cytogram C), CD19 (X-axis) against $C D_{34}\left(Y\right.$-axis). MRD cells show aberrant immunophenotype $C D_{5} 8^{++} C D_{3} 8^{\text {low }}$ (cytogram $D$, $C D 38$ [X-axis] against $C D 58$ [Y-axis]).
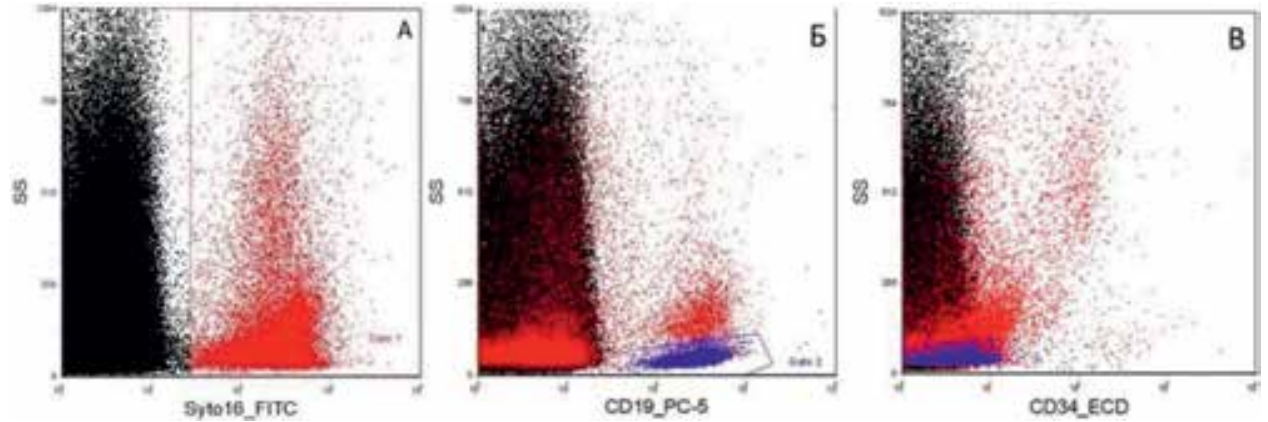

Figure 6.

Day 15 of induction therapy. The specimen has much debris. Cytogram A: NC detection basing on expression of nucleotropic die Syto16 against SSC. The specimen has 3.65\% of NC (gate 1, red). Cytogram B: evaluation of B-cell fraction (gate 2, blue): CD19 (X-axis) against SSC. The B-cell fraction without NC is $0.57 \%$, with recount for NC CD19 ${ }^{+}$cells are $15.6 \%$ in this specimen. $C D 34^{+} B C P$ are $0.0021 \%$ without $N C$, that is, $M R D-$ negativity. Recount with respect to Syto16 results in $C D 34^{+} B C P$ being $0.06 \%$, that is, MRD-positivity.

a nucleotropic Syto die (Sito16 and Sito16 in our study) was included in the MRD detection panel.

In the group, as a whole MRD-negative status was found on day 15 of induction chemotherapy in $11.5 \%$ of patients, which allowed reduction in anthracycline dose to be considered with respect to clinical prognostic factors without the risk of recurrence in this subgroup.

\subsubsection{MRD assessment on day 33 of therapy}

MRD quantification was based on count of $\mathrm{CD} 58^{++} \mathrm{CD} 38^{\text {low/- }}$ BCP. If specimens demonstrated no aberrance by this antigen combination at primary diagnosis, MRD was assessed by $\mathrm{CD} 58^{++} \mathrm{CD} 10^{++}$or $\mathrm{CD} 38^{\text {low }} \mathrm{CD} 10^{++}$combinations.

According to the morphological risk stratification criteria, all specimens contained less than $5.0 \%$ of blasts $(1.2 \% \pm 0.1, \mathrm{n}=80)$ and were included in the M1 group. There were no blasts in $6.25 \%$ of specimens $(5 / 80)$. MRD-positivity by immunology was identified in $40.0 \%$ of cases (32/80). In two patients (2.5\%), MRD cells were $>1.0 \%$. There were no high risk specimens (MRD $\geq 10.0 \%$ ) in our study.

CD58 and CD38 primary tumor aberrance on day 33 of induction chemotherapy was assessed in $50.0 \%$ of patients. CD58 aberrance was found in 28 of 40 cases (70\%), and CD38 aberrance was detected in $60.0 \%$ of cases $(24 / 40) .55 .0 \%$ of cases (22/40) were CD58/CD38 aberrant and 45.0\% (18/40) demonstrated no aberrance. 
Cases without CD58/CD38 aberrance at the primary diagnosis were examined for markers identifying cells of residual tumor by the literature.

We analyzed CD81, CD123, CD9, CD21, CD24 expression in 21 BM specimens. As a result, most informative marker combinations for detection of aberrant B-lymphoblasts were identified: combinations of CD58 or CD38 with CD10 (aberrant immunophenotypes $\mathrm{CD} 58^{++} \mathrm{CD} 10^{+}$or $\mathrm{CD} 38^{+} \mathrm{CD} 10^{++}$) were the most informative in terms of FC. In case of CD20-positive ALL MRD could be detected by asynchronous CD20 and CD34 expression (aberrance characterized by $\mathrm{CD} 34^{+} \mathrm{CD} 20^{+}$phenotype, Figure 7). In most cases, residual tumor may be detected by marked expression of CD123 in combination with weak or no expression of CD81 (aberrant immunophenotype $\mathrm{CD} 123^{++} \mathrm{CD} 81^{\text {low }}$, Figure 8). In some cases, CD9 monomorphic tumor expression especially in combination with one of clear-cut
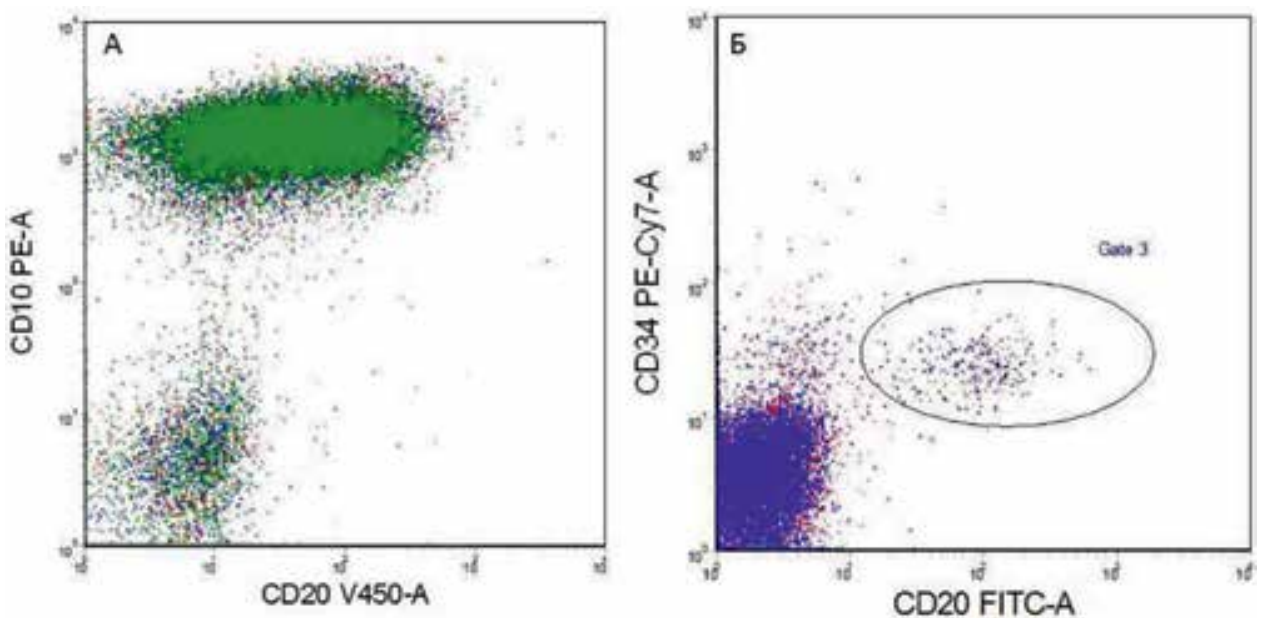

Figure 7.

$M R D$ quantification basing on asynchronous expression of stage-specific Ag CD34/CD20 in a patient with $C D 20^{+}$pre-pre-B B-ALL immunosubtype. Cytogram A: tumor B-lymphoblasts $\left(C D 45^{\text {low }} \mathrm{CD}_{19^{+}}\right)$at primary diagnosis (X-axis $C D_{20}$ against $Y$-axis $C D 10$ ), of which 60.0\% express $C D_{20}$. Cytogram B: MRD detection basing on simultaneous $C D 20$ (X-axis) and $C_{34}$ ( $Y$-axis) expression. MRD cells are $0.027 \%$ of NC specimen, that is, MRD-positivity.
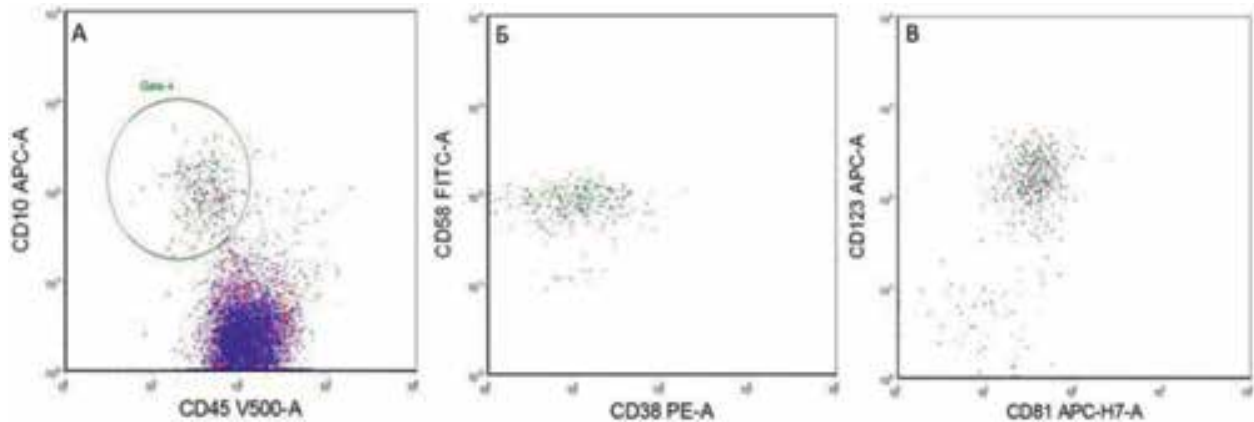

Figure 8.

$M R D$ quantification basing on aberrance by $C D 58 / C D 38$ and $C D 123 / C D 81$. Cytogram A: BCP detection basing on bright $C D 10$ ( $Y$-axis) expression in combination with low $C D 45$ expression ( $X$-axis), gate 4 (o.03\% of NC) within $C D 19^{+} B$-cells. Cytogram B: BCP are characterized CD58 overexpression (Y-axis) in combination with no $C D 38$ expression (X-axis) and demonstrate $C D 123^{++} C D 81^{\text {low }}$ immunophenotype (cytogram C: CD123 [Y-axis] against CD81 [X-axis]). Therefore, B-lymphoblasts are aberrant by all four $\mathrm{Ag}$ analyzed, and there are no normal BCP in this specimen. Aberrant BCP are $0.027 \%$ of NC specimen, that is, $M R D$-positivity. 

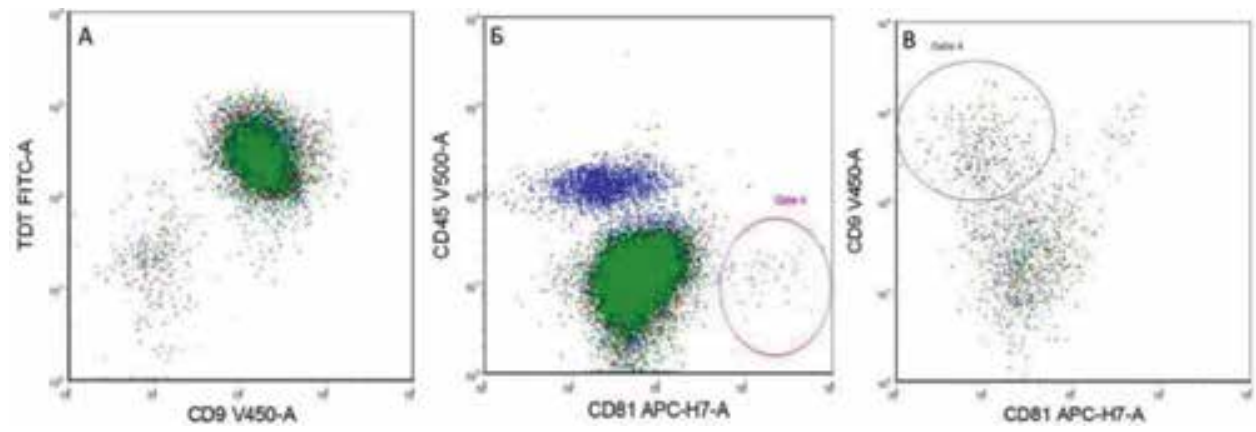

Figure 9.

$M R D$ quantification basing on aberrance by CD9 and CD81. Cytogram A: tumor B-lymphoblasts $\left(C D 45^{\text {low }} \mathrm{CD}_{19^{+}}\right)$at primary diagnosis with bright nuTdT expression (Y-axis) in combination with monomorphous CD9 overexpression (X-axis). Cytogram B: tumor cells are aberrant by CD81 (X-axis CD81 against $Y$-axis $C D 45$ ). As compared to residual normal BCP (gate 4, pink) with bright CD81 expression, tumor B-lymphoblasts demonstrate low (aberrant) Ag expression. Cytogram C: MRD detection basing on bright monomorphous CD9 overexpression (Y-axis) in combination with low CD81 expression (X-axis) (gate 4, dark blue). They are $0.015 \%$ of NC specimen: MRD-positivity.

aberrance criteria $\left(\mathrm{CD} 58^{++}, \mathrm{CD} 123^{++}, \mathrm{CD} 38^{\text {low }}, \mathrm{CD} 81^{\text {low }}\right.$, Figure 9) are a sign of tumor aberrance and criterion for MRD assessment.

In cases with monomorphic co-expression of myeloid antigens (CD66c, CD13 or CD33), MRD assessment may be based on these markers.

Of the whole patients, cohort (80 patients) MRD-negative status was determined by FC in $60.0 \%$ (48 patients), and $40.0 \%$ (32 patients) were found MRDpositive. Comparison of basic morphological and immunological characteristics in these groups identified significant differences in the number of blasts $(p=0.012)$ and CD19 ${ }^{+}$B-cells $(\mathrm{p}=0.044)$.

Basing on FC quantification of MRD, most patients (65.0\%) receiving treatment by ALL IC BFM 2009 protocol were included in the intermediate risk group.

\subsubsection{MRD assessment on day 78 of therapy}

MRD assessment on day 78 of therapy was made in 42 patients and was based on detection of BCP with aberrant immunophenotype (CD58 $\left.{ }^{++} \mathrm{CD} 38^{\text {low/- }}\right)$.

As recommended by BFM protocols, BM specimens were divided into MRDpositive and MRD-negative subgroups. Most BM specimens were MRD-negative $(\mathrm{n}=27)$, and 15 of 42 specimens $(35.7 \%)$ were MRD-positive.

In 14 patients, MRD status was assessed at three points of treatment protocol (days 15, 33 and 78). Seven of them achieved MRD-negativity by day 78 and met the criterion of slow response to therapy.

\subsubsection{MRD assessment after 1 block of anti-relapse therapy (day 35)}

After 1 block of anti-recurrence therapy, MRD was detectable in $15 \mathrm{BM}$ specimens. By FC, $40.0 \%$ of patients $(0.004 \pm 0.0008 \%, n=6)$ were MRD-negative and $60.0 \%$ of patients $(7.3 \pm 4.8 \%, \mathrm{n}=9)$ were MRD-positive with $77.0 \%$ of the MRDpositive specimens $(0.9 \pm 0.6 \%, \mathrm{n}=7)$ containing $<5.0 \%$ of blasts by morphological study.

\subsubsection{MRD monitoring on targeted therapy}

In our study, one patient with early recurrence of ALL (pre-pre-B immunosubtype) received anti-recurrence targeted agent blinatumomab (biospecific 
anti-CD19 monoclonal antibody). Blinatumomab mechanism of action involves specific binding with $\mathrm{CD} 19^{+}$cells and recruitment of effector T-cells to enhance response. According to the literature data, CD19 is not expressed on cells during blinatumomab therapy which makes difficult BCP identification. We chose an alternative $\mathrm{BCP}$ identification procedure to monitor MRD in this patient category: BCP identification and characterization on blinatumomab (anti-CD19) therapy should be based on expression of cyCD22 and nuTdT due to lost of CD19 expression.

\subsection{ALL from T-lineage precursors}

A total of 31 patients with T-ALL were included in our study. About $61.3 \%$ of patients $(n=19)$ presented with cortico-thymocytic immunosubtype (CD1a expression and/or the presence of $\mathrm{CD} 4^{+} \mathrm{CD} 8^{+}$population) as determined by primary immunophenotyping. Table 9 shows characteristics of blast immunophenotype at the stage of primary diagnosis.

Since T-cell ontogenesis is characterized by the absence of T-cell progenitors in normal BM, MRD monitoring by FC at all therapy stages involves detection and count of TCP.

According to BFM protocol, MRD detection in T-ALL is based on identification of T-cells with aberrant immunophenotype within CD7-positive fraction. However, CD7 demonstrates a broad range of expression and is present not only on TCP (NK-cells and myeloid progenitor cells); therefore, a cytometric protocol for TCP detection in BM (MRD cells) was developed that was based on expression of pan-T-cell antigen CD3 in cytoplasm (cyCD3) as the most stable lineage-specific pan-T-cell antigen. Choice of appropriate antigen clone is an important requirement for detection of cytoplasmic CD3 expression. For instance, SK7 clone is used to detect membrane determinant, while UCHT-1 binds to cytoplasmatic determinant. So, only UCHT-1 monoclonal antibody should be used in analysis of cyCD3.

In our study, quantification of TCP in BM was based on detection of subpopulations smCD3 ${ }^{-} \mathrm{CD}^{+}$, smCD3 ${ }^{-} \mathrm{TdT}^{+}, \mathrm{smCD}^{-} \mathrm{CD} 1 \mathrm{a}^{+}$, and $\mathrm{CD} 4^{+} \mathrm{CD} 8^{+}$within cyCD3positive BM T-cells at all time points of MRD monitoring.

To simplify recount and exclusion of debris, the quantification was made within $\mathrm{NC}$ of specimens as identified by Syto dies. The highest values were used as recommended by MRD detection protocols.

\subsubsection{MRD assessment on day 15 of therapy}

Quantification of residual blasts on day 15 of induction chemotherapy was made in $30 \mathrm{BM}$ specimens.

The morphological and immunological findings were as a whole similar. The group M2 was heterogeneous demonstrating variability in blast numbers and MRD levels; however, these specimens belonged to intermediate risk group both by M-subtypes and MRD levels and therefore did not interfere in patient stratification.

BM characteristics on day 15 of treatment were analyzed with respect to T-ALL immunosubtype. The pre-T immunosubtype was characterized by significantly higher MRD level on day 15 as compared to cortico-thymocytic one $(p=0.044)$.

About 76.2\% of patients composed the intermediate risk group (according to ALL-IC-BFM 2009 protocol), and 23.8\% were stratified into the high risk group. There were no patients meeting criteria for standard risk in our study

Basing on MRD level on day 15 of induction chemotherapy, $25.0 \%$ were transferred from the intermediate to the high risk group. 

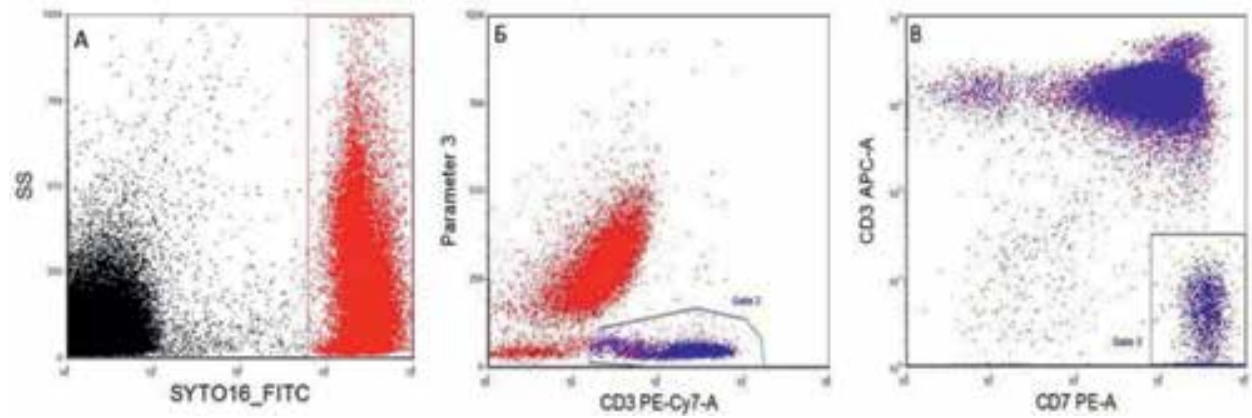

Figure 10.

An example of MRD-positivity with no blasts in the BM specimen by morphology on day 33 of therapy. Cytogram A: shows NC of the specimen (gate 1, red) basing on reactivity with Syto16 (X-axis) against SSC. Cytogram B: cyCD $3^{+}$T-cells within NC (gate 2, blue) with low SSC parameters (cyCD3, X-axis against SSC Y-axis). Cytogram C: $C D 7, X$-axis against $\operatorname{smCD} 3$, Y-axis (gate 2) shows TCP (MRD cells) with $\mathrm{CD}_{3}{ }^{+} \mathrm{CD}^{+}{ }^{+} \mathrm{smCD}_{3}{ }^{-}$immunophenotype that are $2.69 \%$ of myelokaryocytes: $M R D$-positivity.

It is important to note that MRD negativity was not reported on day 15 of induction chemotherapy in any of the patients, that is, none of the patients achieved complete leukemic cytoreduction in the middle of remission induction therapy.

\subsubsection{MRD assessment on day 33 of therapy}

Quantification of residual blasts on day 33 of induction chemotherapy was made in 26 patients.

Most BM specimens (25/26) were included into group M1, while there was only one specimen meeting the M2 criteria. None of the specimens was included in group M3 basing on morphological characteristics.

We compared morphological and immunological findings. Specimens from the standard and intermediate risk groups were analyzed in detail with respect to MRD content.

All BM specimens from group M1 were MRD-positive. Basing on the immunological criteria, $16.0 \%$ of BM specimens $(n=4)$ were included in the standard risk group (MRD $<0.1 \%$ ). The intermediate risk group consisted of 20 of $25 \mathrm{BM}$ specimens $(80.0 \%)$. One BM specimen from this group contained no blast cells by morphology, though FC discovered 2.69\% of MRD cells (Figure 10).

One specimen was included in the high risk group by MRD assessment $(\mathrm{MRD} \geq 10.0 \%)$.

Note that specimens from this sample demonstrated rather high lymphocytosis (more than 28.0\%).

By morphological criteria, only one BM specimen was included in the M2 group (blasts $10.8 \%$ ), while by immunological characteristics, this specimen might be referred to the standard risk group (MRD cells 0.04\%).

CD7 in combination with CD3 are used to assess MRD in T-ALL in the BFM protocol. However, CD7 is commonly found on myelokaryocytes including both lymphoid and myeloid progenitors. Basing on ontogenetic characteristics of expression of T-lineage antigens, we propose to detect TCP (that is MRD cells) by expression of cytoplasmatic CD3 as the earliest lineage-specific T-cell marker.

Comparison of these two approaches to MRD monitoring (the standard BFM protocol basing on MRD cell count within CD7-positive cells and MRD count within cyCD3 ${ }^{+}$cells), both on days 15 and 33 of induction chemotherapy allowed us to make the conclusion that MRD quantification in T-ALL by detection of cyCD3 ${ }^{+}$ smCD3- populations is more accurate. 


\section{Conclusions and discussion}

Successful treatment of patients with acute leukemia is associated with escalation of chemotherapy doses which requires effective monitoring of response. Assessment of response in key points of chemotherapy protocols helps both to stratify patients by risk groups more accurately and to avoid serious long-term side effects or patient overtreatment.

Search for adequate approaches to assessment of response was started since the 1970s. For a long time, response to therapy was assessed basing on the number of blasts in BM specimens as determined by morphological study, and as a result so called M-types were defined as follows: M1: $<5.0 \%$ of blasts, M2: 5-25\% of blasts, and M3: $\geq 25 \%$ of blasts [22].

However, the progress in molecular methods such as polymerase chain reaction (PCR) and flow cytometry (FC) allowed quantification of minimal number of residual blasts at submicroscopic level $(<0.01 \%)$.

In recent years, quantification of residual tumor cells in BM, that is, minimal residual disease (MRD) was a main criterion of response to chemotherapy. Opposite to myeloid leukemias when molecular genetic methods play the leading role in MRD detection, it is immunological approaches involving FC alone that can detect MRD cells in more than $95.0 \%$ of cases [23].

Both PCR and FC have their advantages and disadvantages. Implementation of multiparameter FC able to assess up to 12 parameters of a single cell and development of computer software that allows tens of millions of cells to be examined makes FC close to PCR by sensitivity [24]. FC is currently the most rapid and less costly approach to MRD monitoring.

In adults, problems of the most important detection points are a matter of discussion [2]. The MRD significance is most vivid in pediatrics. MRD is found to play a role both in ALL prognosis and recurrence prediction [1]. Key points of MRD monitoring and their clinical significance have been determined as well as MRD levels that allow detailed risk stratification of patients.

It is in childhood oncology that the MRD effects of the patient faith have been studied $[1,25]$. The current protocols defined three mandatory time points such as the middle and end of remission induction chemotherapy (days 15 and 33) and the end of consolidation induction (day 78).

MRD monitoring plays different roles at different chemotherapy stages. The most important point in terms of the patient faith is the middle of induction chemotherapy when primary tumor response and prognosis are determined.

For a long time, there were multiple attempts to make the earliest possible assessment of response. One of the approaches is count of blasts in peripheral blood on day 8 of treatment. Patients with blast reduction below 1000 cells $/ \mathrm{mcl}$ are a group of good response and good prognosis. However, the blast clearance on day 8 is found to reflect response to steroids only [5], while MRD level on day 15 of induction chemotherapy is the most accurate reflection of leukemic cytoreduction, that is, primary response to treatment $[5,14]$.

The key moment is the selection of good response patients (MRD $<0.01 \%$ ) in whom reduction of anthracycline dose may be considered [11, 26]. In our study, FC discovered MRD-negativity in $11.5 \%$ of patients in whom reduction of anthracycline dose could be considered. These patients did not develop recurrence.

The situation in BM by day 15 of therapy is unique in terms of immunology. Since BCP are highly sensitive to glucocorticoids [17] that are the basis for treatment at the given stage, these cells are fully eliminated from BM [16]. This observation was a basis for a FC protocol developed by the St Jude Children's Research Hospital (Memphis, USA) study group for detection of MRD cells on day 15. This protocol 
involves MRD monitoring within BM mononuclear fraction, while the BFM protocol uses recount for NC in the specimen.

We compared the two approaches to conclude that recount for NC (the St. Jude Hospital protocol) is the most robust criterion for risk stratification of patients. Moreover, analysis of MRD cell immunophenotype with respect to CD58 and CD38 expression demonstrated that the number of $\mathrm{CD} 10^{+} \mathrm{B}$-cells was similar to that of $\mathrm{CD} 58^{++} / \mathrm{CD} 38^{\text {low } /-} \mathrm{BCP}$ in $36.4 \%$ of cases only. While the number of $\mathrm{CD} 58^{++} \mathrm{CD} 38^{\text {low }}$ $\mathrm{BCP}$ was less as compared to $\mathrm{CD} 10^{+} \mathrm{B}$-cells in the remaining specimens of aberrant $\mathrm{BCP}$. We conclude therefore that quantification of MRD should be based on detection of BCP rather than of aberrant blasts.

MRD cells on day 15 are BCP. We used a variety of monoclonal antibodies for their monitoring. In pre-pre-B and pre-B ALL immunosubtypes, it is just enough to count $\mathrm{CD} 34^{+}$and/or $\mathrm{CD} 10^{+} \mathrm{BCP}$. In case of pro-B immunosubtype (CD10 ${ }^{-}$and/or CD34- ${ }^{-}$, MRD detection should involve a combination of nuclear TdT with cytoplasmatic CD22 or CD79 $\alpha$ that show stable expression as demonstrated already in early studies of B-cell ontogenesis [27, 28].

Important properties of BM on day 15 are hypocellularity and a marked proportion of debris, that is, destroyed cells under the effect of systemic chemotherapy $[29,30]$. This requires modification of FC protocols for MRD monitoring, namely use of special dies able to identify viable, not destroyed cells in specimens. Our study showed reasonable to use Syto nucleotropic dies that can clearly select NC and as a consequence help to avoid debris dilution that may result in a considerable underestimation of MRD count and interfere with risk stratification.

By the end of induction chemotherapy, appearance (regeneration) of normal $\mathrm{B}$-lineage progenitors in BM makes MRD detection more difficult. Clear-cut distinguishing between MRD cells and regenerating BCP is possible basing on LAIP or aberrant immunophenotype.

Aberrance is currently defined as follows:

1. Different levels of Ag expressions (overexpression of some molecules [CD58, CD10, CD9], low or no expression of Ag such as CD38, CD81)

2. Expression of $\mathrm{Ag}$ of uncommon differentiation lineages (e.g., co-expression of myeloid Ag such as CD13, CD33, CD66c, CD123 on tumor blasts)

3. Asynchronous expression of lineage-specific $\mathrm{Ag}$ (expression of $\mathrm{Ag}$ of mature B-cells, e.g., CD20 on CD34 ${ }^{+} \mathrm{BCP}$ )

A combination of CD58 and CD38 is the most frequently used Ag combination for assessment of B-lymphoblast immunophenotype aberrance in the AIEOP-BFM and COG FC protocols.

Normal BCP are characterized by CD $58^{+/ \text {low }} / \mathrm{CD} 38^{+/++}$immunophenotype, while aberrant immunophenotypes demonstrate CD58 overexpression and no or low CD38 expression.

As shown by the I-BFM-ALL-MRD Study group, CD58 overexpression is present on overwhelming majority of tumor B-lymphoblasts and is found in $93.5 \%$ of cases $[31,32,19]$.

CD38 molecule with receptor and enzymatic activities that is involved in B- and $\mathrm{T}$-cell ontogenesis is brightly expressed on normal BM progenitor cells. Low CD38 expression in BCP is considered aberrant $[19,41]$ and is found in $61.2 \%$ of B-ALL according to Min Xia et al.

In our study, CD58 was overexpressed in $71.7 \%$ of B-ALL cases, that is, less frequently that by literature data. An explanation may be that the boundary between 
Ag normal and overexpression may be unclear. To make a more accurate evaluation of aberrant immunophenotype in primary diagnosis, Ag tumor expression should be compared with the number of residual normal BCP that is not always large. To make visualization more determinant, one has to select a considerable amount of cells ( $\geq 1$ million), which was not possible in early studies.

There were only $58.6 \%$ of ALL with aberrant (low) CD38 expression which was in accord with foreign data.

If one of two $\mathrm{Ag}$ is not aberrant, MRD may be assessed basing on alternative combinations such as CD58/CD10, CD58/CD34, CD38/CD10, and CD38/CD34.

Of note, in our study, about one fourth of all cases (24.0\%) had tumor B-lymphoblasts with no aberrance by this Ag combination. Therefore, additional criteria to identify aberrant immunophenotype are needed.

This requires MRD criteria to be used at time of diagnosis and most informative MRD markers to be selected in every specific case at the stage of ALL primary diagnosis.

Multicolor FC that simultaneously evaluates up to 12 various cell characteristics makes the most complete characterization of LAIP. This approach may be implemented by use of the EuroFlow consortium 8-color panels with optimal combination of stable markers and fluorochromes [33-35].

The panel for more accurate B-ALL diagnosis includes 3 basic (repeated in all specimens) $\mathrm{Ag}$ and 20 specific $\mathrm{Ag}$. This helps to make multiple aberrance evaluation by expression of nonlineage-specific CD45, CD58, CD38, CD9, CD123, and CD81; by expression of noncommon differentiation lineages such as pan-myeloid CD13, CD33, CD66c, CD15, CD65; and by asynchronous expression of Ag of different stages of B-cell differentiation CD10, CD34, CD, CD22, CD20, CD21, CD24. It is of much importance that expression of all above-mentioned markers may be assessed within a single cell population, that is, $\mathrm{CD} 19^{+} \mathrm{CD} 34^{+} \mathrm{CD} 45^{\text {low }} \mathrm{BCP}$.

The protocol makes possible indirect prediction of clinically significant abnormalities basing on a proper immunophenotype [36]. For instance, immunophenotypes of cells with mutations BCR-ABL, MLL, Tel-AML-1, and E2APBX1 are described.

When analyzing capacities of EuroFlow 8-color protocols with respect to MRD monitoring, we paid attention to CD81 [35]. The CD81 molecule belongs to the tetraspanin family and is directly associated with CD19, thus forming a signal complex CD19-CD21-CD81 that realizes its functional activity in normal B-cell ontogenesis. By the literature [37], aberrant (weak) CD81 expression is found in $82 \%$ of B-ALL cases. Our evaluation of CD81 expression in primary diagnosis coincided with international study data. For instance, aberrant expression was found in $85.7 \%$ of primarily diagnosed ALL.

Another molecule from the tetraspanin family is of interest as a criterion for MRD detection, that is, CD9 [38-40]. Its expression is evaluated both in 4- and 6-color FC protocols of the COG study group (M. Borowitz). CD9 is brightly expressed on early $\mathrm{BCP}$, disappears at the pre-B stage, and appears again on mature B-cells. Its monomorphic overexpression on BCP is considered aberrant. In our study, $87.5 \%$ of B-ALL cases demonstrated CD9 aberrant expression on tumor B-lymphoblasts.

In case of monomorphous co-expression of myeloid Ag such as CD13, CD33 and CD66c [31, 41] and also CD123 [42], they may be used as LAIP of tumor B-lymphoblasts. Prognostic significance of myeloid Ag co-expression on tumor cells is disputable, though CD66c (KORSA) is shown to be associated with BCR/ ABL1 reconstructions [43, 44]. N. Guillaume et al. analyzed immunophenotype of ALL from BCP to discover CD66c co-expression to be the most frequent (40.0\%), while pan-myeloid Ag CD13 and CD33 were detected in $15.0 \%$ of cases only. 
In our evaluation of primary immunophenotype of tumor B-lymphoblasts, CD66c co-expression was found in $75.0 \%$ of cases, while CD13 and CD33 were present in $46.0 \%$, which is similar to international study data.

As concerns interleukin-3 receptor $\alpha$-chain (CD123), all B-ALL were aberrant (i.e., the Ag was expressed on tumor cells), which is in accord with L. Munoz et al. [45].

Asynchronous expression of $\mathrm{Ag}$ of noncharacteristic differentiation lineages is an additional criterion for tumor B-lymphocyte LAIP. CD20 is such a marker in CD20-positive B-ALL whose expression is characteristic of mature B-cells only. However, CD20 co-expression on tumor B-lymphoblasts is found in $6.4-15.3 \%$ of B-ALL $[29,30]$. CD20 is included in most FC panels for MRD diagnosis though it is appropriate rather for more clear-cut identification of $\mathrm{CD} 20^{-} \mathrm{BCP}$ than for evaluation of its aberrant expression. This finding may be explained by a small cohort of B-ALL patients (up to $16.0 \%$ of all B-ALL patients) in whom residual blasts may be identified on the basis of $\mathrm{CD} 34^{+} \mathrm{CD} 20^{-}$immunophenotype. In our study, only $14.7 \%$ of ALL patients demonstrated CD20 co-expression on tumor B-lymphoblasts.

So in terms of FC approaches to evaluation of small populations which may also include MRD determination of LAIP is most effective using a combination of two Ag with aberrance manifesting itself as overexpression or a combination of molecules with over- and low/no expression. We propose the following Ag combinations: $\mathrm{CD} 123^{+} \mathrm{CD} 81^{\text {low }}$, and $\mathrm{CD} 9^{++} \mathrm{CD} 81^{\text {low }}$.

Remission completeness is clinically assessed on day 33 of treatment. In our study, MRD-negative status was detected in $600 \%$ of patients.

Most patients (65.0\%) receiving treatment by ALL IC BFM 2009 schedule were stratified into the intermediate risk group by MRD content.

Day 78 of treatment (end of consolidation induction) is the third time point with undoubted prognostic value for MRD detection. Basing on this evaluation, a group of so called slow response may be identified basing on MRD status. These patients are MRD-positive on days 15 and 33 and reach MRD negativity by day 78 only. This cohort is characterized by good prognosis.

In our study, $64.3 \%$ of patients were MRD negative, with 7 of 14 patients followed-up in all the three points belonging to the slow response group.

Tumor immunophenotyping in disease recurrence is of special interest. Changes in Ag expression during treatment are studied and described rather well. According to international study data, changes as compared to disease onset may occur also in tumor cell immunophenotype in disease recurrence.

We assessed blast immunophenotype both in disease onset and relapse in five patients. Tumor blast immunophenotype was the same by the main diagnostic Ag in disease onset and recurrence in four of the five patients. Of interest is that change in blast phenotype as concerns intensity of CD58/CD38 expression versus the primary diagnosis was found in two of the five patients.

Clinical value of immunophenotype change as concern aberrance markers needs further clarification and may become an additional criterion in the protocol.

Novel targeted therapies that influence disease at molecular level are implemented in clinical practice every year and many are at various stages of clinical trial.

A new stage of progress in targeted therapy is associated with development of biospecific antibodies that are a new class of monoclonal antibodies (MAb) binding with a surface antigen target, on the one hand, and with T-cell receptor, on the other hand, thus recruiting effector T-cells and enhancing tumor response. Blinatumomab (Blinzito) is the first therapy in this class that is approved by FDA for the treatment of Ph-negative refractory/relapse ALL from B-LP [38]. This approval was based on results of phase II clinical trials with $43 \%$ of 189 adults achieving complete response and 82\% achieving MRD-negativity [46]. 
Notwithstanding initial treatment results, some patients fail to respond to blinatumomab or develop progressive disease after initial response. Recurrence rate is $30 \%$.

Characterization of blast immunophenotype in recurrence on blinatumomab therapy discovered no CD19 expression on tumor cells. This interferes with BCP identification and requires new methodological approaches to MRD assessment.

Inclusion of blinatumomab into B-ALL therapy requires an alternative MRD evaluation strategy.

There was one patient receiving blinatumomab in our study [47]. The MRD monitoring and immunophenotyping at second recurrence was difficult due to the absence of $\mathrm{CD} 19^{+} \mathrm{B}$-cells. An algorithm for BCP detection was proposed and tested that was based on alternative B-lineage differentiation markers. Nuclear nuTdT in combination with cytoplasmatic CD22 as most stably expressed Ag were chosen.

So, given the appearance of new targeted therapies, FC algorithms for both MRD diagnosis and monitoring require certain flexibility and timely rational changes.

There is an equivocal situation with T-ALL. On the one hand, search for aberrant immunophenotype for TCP ended in failure. Expression of main Ag studied with respect to LAIP, that is, CD99 and nuTdT is variable [21]. On the other hand, taking into account normal T-cell ontogenesis, MRD assessment may be based on the absence of TCP of the $\mathrm{cyCD}^{++}{ }^{\mathrm{smCD}} 3^{-} \mathrm{nuTdT}^{+} \mathrm{CD}^{+}$level in $\mathrm{BM}$. One has therefore just to assess TCP number in order to quantify MRD at any therapy stage.

Correct choice of antibody CD3 clone is of much importance for TCP identification. For instance, clone UCHT1 should be used to detect CD3 cytoplasmatic expression, while CD7 is needed to detect the membrane determinant.

The AIEOP-BFM protocol suggests that MRD detection in T-ALL should be based on CD7.

We compared the two approaches to TCP identification to find optimal TCP detection with $\mathrm{CD}^{+} /^{++} \mathrm{SmCD}^{+}$immunophenotype within cyCD3 ${ }^{+}$population basing on T-cell ontogenesis.

All T-ALL patients in our study were stratified into the intermediate and high risk groups. According to MRD levels on day 15, most patients remained in the initial stratification group though $25.0 \%$ were transferred from the intermediate into the high risk group.

Of note that all patients demonstrated MRD-positivity on day 15, that is, none of the T-ALL patients achieved complete leukemic cytoreduction on ALL-IC-BFM 2009 therapy.

So, clinical significance of MRD in ALL arises no doubt. It is reasonable to make MRD quantification immunologically using FC assay.

Since there are no normal BCP on day 15 of induction chemotherapy, MRD quantification in case of pre-pre-B and pre-B ALL immunosubtypes should be based on detection of $\mathrm{CD} 10^{+} / \mathrm{CD} 34^{+}$population within $\mathrm{CD} 19^{+} \mathrm{B}$-cells. In case of pro-B (CD10- and/or CD34-), ALL immunosubtype MRD detection should be based on expression of nuclear nuTdT in combination with cyCD22.

During BM regeneration (end of remission induction therapy and long-term treatment stages), MRD quantification is based on identification of $\mathrm{BCP}$ with aberrant immunosubtype. Alongside with the most common CD58/CD38, the following $\mathrm{Ag}$ should be used in LAIP assessment: CD81, CD9, CD13, CD33, CD66c, CD123, and CD20. At the stage of diagnosis, the most informative personalized Ag combinations should be selected for further MRD monitoring to make a more accurate risk stratification of patients at different therapy stages and are an effective tool for its modification.

Tumor immunophenotype in disease recurrence should be compared with that in disease onset taking into account its possible changes.

In case of targeted therapy, for example, anti-recurrence treatment, FC protocol should be changed with respect to treatment features. For instance, BCP evaluation 
B-Cell Precursors: Immunophenotypic Features in the Detection of Minimal Residual Disease... DOI: $h$ ttp://dx.doi.org/10.5772/intechopen.84223

on blinatumomab therapy should be based on expression of nuTdt in combination with cyCD22.

In T-ALL, MRD assessment at any therapy stage may be limited to quantification of $\mathrm{CD}^{+/++}$smCD3 ${ }^{-}$cells within cyCD3 ${ }^{+}$population.

\section{Conflict of interest}

The authors declare no conflict of interests.

\section{Appendixes and nomenclature}

$\begin{array}{ll}\text { Ab } & \text { antibody } \\ \text { Ag } & \text { antigene } \\ \text { ALOT } & \begin{array}{l}\text { acute leukemia orientation tube } \\ \text { acute lymphoblastic leukemia } \\ \text { ALL }\end{array} \\ \text { ALL-IC-BFM } & \begin{array}{l}\text { intercontinental acute lymphoblastic leukemia protocol of Berlin- } \\ \text { Frankfurt-Munster study group }\end{array} \\ \text { B-ALL } & \text { ALL from B-cell precursors } \\ \text { BCP } & \text { B-cell precursors } \\ \text { BFM } & \text { Berlin-Frankfurt-Munster study group } \\ \text { BM } & \text { bone marrow } \\ \text { CD } & \text { cluster of differentiation } \\ \text { cyCD } & \text { cytoplasmic cluster of differentiation } \\ \text { COG } & \text { children oncology group } \\ \text { FC } & \text { flow cytometry } \\ \text { LAIP } & \text { leukemia-associated immunophenotype } \\ \text { MAb } & \text { monoclonal antibodies } \\ \text { MRD } & \text { minimal residual disease } \\ \text { MNC } & \text { mononuclear cells } \\ \text { NC } & \text { nucleated cells } \\ \text { SmCD } & \text { membrane cluster of differentiation } \\ \text { T-ALL } & \text { ALL from T-cell precursors } \\ \text { TCP } & \text { T-cell precursors }\end{array}$

\section{Author details}

Olga Chernysheva*, Lyudmila Yuryevna Grivtsova, Alexander Popa and Nikolay Nikolayevich Tupitsyn

Federal State Budgetary Institution, "N.N. Blokhin National Medical Research

Center of Oncology" of the Ministry of Health of the Russian Federation

(N.N. Blokhin NMRCO), Moscow, Russia

*Address all correspondence to: dr.chernysheva@mail.ru

IntechOpen

(C) 2019 The Author(s). Licensee IntechOpen. This chapter is distributed under the terms of the Creative Commons Attribution License (http://creativecommons.org/licenses/ by/3.0), which permits unrestricted use, distribution, and reproduction in any medium, provided the original work is properly cited. (cc) BY 


\section{References}

[1] Borowitz MJ, Devidas M, Hunger SP. Clinical significance of minimal residual disease in childhood acute lymphoblastic leukemia and its relationship to other prognostic factors: A Children's oncology group study. Blood. 2008;111:5477-5485. DOI: 10.1182/blood-2008-01-132837

[2] Campana D. Role of minimal residual disease monitoring in adult and pediatric acute lymphoblastic leukemia. Hematology-Oncology Clinics of North America. 2009;23(5):1083-1098. DOI: 10.1016/j.hoc.2009.07.010

[3] Conter V, Bartram CR, Valsecchi MG. Molecular response to treatment redefines all prognostic factors in children and adolescents with B-cell precursor acute lymphoblastic leukemia: Results in 3184 patients of the AIEOP-BFM ALL 2000 study. Blood. 2010;15:3206-3214. DOI: 10.1182/ blood-2009-10-248146

[4] Dworzak MN, Froschl G, Printz D, Austrian Berlin-Frankfurt-Munster Study Group. Prognostic significance and modalities of flow cytometric minimal residual disease detection in childhood acute lymphoblastic leukemia. Blood. 2002;99:1952-1958

[5] Ratei R, Basso G, Dworzak M. Monitoring treatment response of childhood precursors B-cell acute lymphoblastic leukemia in the AIEOP-BFM-ALL 2000 protocol with multiparameter flow cytometry: Predictive impact of early blast reduction on the remission status after induction. Leukemia. 2009;23:528-534. DOI: $10.1038 /$ leu.2008.324

[6] Hitchcock-Bryan S, Gelber RD, Cassady JR. The impact of induction anthracycline on long-term failurefree survival in childhood acute lymphoblastic leukemia. Medical and Pediatric Oncology. 1986;14:211-215
[7] Meadows AT, Robison LL, Neglia JP. Potential long-term toxic effects in children treated for acute lymphoblastic leukemia. The New England Journal of Medicine. 1989;321:1830-1831

[8] Ochs JJ. Neurotoxicity due to central nervous system therapy for childhood leukemia. The American Journal of Pediatric Hematology/Oncology. 1989;11:93-105

[9] Pui CH, Behm FG, Raimondi SC. Secondary acute myeloid leukemia in children treated for acute lymphoid leukemia. The New England Journal of Medicine. 1989;321:136-142

[10] Rimm IJ, Li FC, Tarbell NJ. Brain tumors after cranial irradiation for childhood acute lymphoblastic leukemia. Cancer. 1987;59:1506-1508

[11] Schrappe M, Reiter A, Ludwig W-D. Improved outcome in childhood acute lymphoblastic leukemia despite reduced use of anthracyclines and cranial radiotherapy: Results of trial ALL-BFM 90. Blood. 2000;95:3310-3320

[12] Steinherz PG, Gaynon PS, Breneman JC. Cytoreduction and prognosis in acute lymphoblastic leukemia the importance of early marrow response: Report from the Children's cancer group. Journal of Clinical Oncology. 1996;14:389-398

[13] Eckert C, Stackelberg A, KarlSeeger T. Minimal residual disease after induction is the strongest predictor of prognosis in intermediate risk relapsed acute lymphoblastic leukemia-Longterm results of trial ALL-REZ BFM P95/96. European Journal of Cancer. 2013;49:1346-1355. DOI: 10.1016/j. ejca.2012.11.010

[14] Coustan-Smith E, Sancho J, Behm FG. Prognostic importance of measuring early clearance of leukemic 
cells by flow cytometry in childhood acute lymphoblastic leukemia.

Blood. 2002;100:52-58. DOI: 10.1182/ blood-2002-01-0006

[15] Dworzak MJ, Froshl G, Printz D. Prognostic significance and modalities of flow cytometric minimal residual disease in childhood acute lymphoblastic leukemia. Blood. 2002;99:1952-1958

[16] Coustan-Smith E, Ribeiro RC, Stow P. A simplified flow cytometry assay identifies children with acute lymphoblastic leukemia who have a superior clinical outcome. Blood. 2006;108:97-102. DOI: 10.1182/ blood-2006-01-0066

[17] Igarashi H, Medina KL, Yokota T. Early lymphoid progenitors in mouse and man are highly sensitive to glucocorticoids. International Immunology. 2005;17:501-511. DOI: 10.1093/intimm/dxh230

[18] Romero-Ramirez H, MoralesGuadarrama MT, Pelayo R. CD38 expression in early B-cell precursors contributes to extracellular signalregulated kinase-mediated apoptosis. Immunology. 2014;144:271-281. DOI: 10.1111/imm.12370

[19] Veltroni M, De Zen L, Sanzari MC. Expression of CD58 in normal, regenerating and leukemic bone marrow B cells: Implications for the detection of minimal residual disease in acute lymphocytic leukemia. Haematologica. 2003;88:1245-1252

[20] Xia M, Zhang H, Lu Z. Key markers of minimal residual disease in childhood acute lymphoblastic leukemia. Journal of Pediatric Hematology/Oncology. 2016;38:418-422. DOI: $10.1097 /$ MPH.0000000000000624

[21] Roshal M, Fromm JR, Winter S. Immaturity associated antigens are lost during induction for $\mathrm{T}$ cell lymphoblastic leukemia: Implications for minimal residual disease detection. Cytometry Part B: Clinical Cytometry. 2010;78:139-146. DOI: 10.1002/ cyto.b.20511

[22] Szczepanski T, Orfao A, van der Velden VH. Minimal residual disease in leukaemia patients. The Lancet Oncology. 2001;2:409-417

[23] Grivtsova LY, Kupryshina NA, Frenkel MA. Diagnosis and immunophenotypic features of blast cells in acute myeloid leukemia: Panmyeloid and linear-nonrestricted antigens. Medical Alfavit. 2017;4:18-24

[24] van Dongen JJ, van der Velden VH, Bruggemann M. Minimal residual disease diagnostics in acute lymphoblastic leukemia: Need for sensitive, fast, and standardized technologies. Blood. 2015;125:3996-4009. DOI: 10.1182/ blood-2015-03-580027

[25] Basso G, Veltroni M, Valsecchi MG. Risk of relapse of childhood acute lymphoblastic leukaemia is predicted by flow cytometric measurement of residual disease on day 15 bone marrow. Journal of Clinical Oncology. 2009;27:5168-5174. DOI: 10.1200/ JCO.2008.20.8934

[26] Steinherz PG, Gaynon PS, Breneman JC. Cytoreduction and prognosis in acute lymphoblastic leukemiathe importance of early marrow response: Report from the Childrens cancer group. Journal of Clinical Oncology. 1996;14:389-398

[27] Janossy G, Bollum FJ, Bradstock KF. Cellular phenotypes of normal and leukemic hemopoietic cells determined by analysis with selected antibody combinations. Blood. 1980;56:430-431

[28] Janossy G, Coustan-Smith E, Campana D. The reliability of cytoplasmic CD3 and CD22 antigen 
expression in the immunodiagnosis of acute leukemia: A study of 500 cases. Leukemia. 1989;3:170-180

[29] Grivtsova LY, Popa AV, Kupryshina NA. Detection of minimal residual disease in children with B-cell precursor acute lymphoblastic leukemia with simplified protocols. Haematopoiesis Immunology. 2008;2:8-33

[30] Grivtsova LY, Popa AV, Serebryakova IN. To further standartization in detection of residual blasts in bone marrow ofchildren with B-cell acute lymphoblastic leukemia on day 15 of induction therapy. Haematopoiesis Immunology. 2011;1:35-54

[31] Bullens DM, Rafiq K, Charitidou L. Effects of co-stimulation by CD58 on human T cell cytokine production: A selective cytokine pattern with induction of high IL-10 production. International Immunology. 2001;13:181-191

[32] Imai T, Tanaka Y, Fukudome K. Enhanced expression of LFA-3 on human T-cell lines and leukemic cells carrying human T-cell-leukemia virus type 1. International Journal of Cancer. 1993;55:811-816

[33] Kalina T, Flores-Montero J, van der Velden VH. EuroFlow Consortium (EU-FP6, LSHB-CT-2006-018708). EuroFlow standardization of flow cytometer instrument settings and immunophenotyping protocols. Leukemia. 2012;26:1986-2010. DOI: 10.1038/leu.2012.122

[34] Pedreira CE, Costa ES, Lecrevisse Q. EuroFlow Consortium. Overview of clinical flow cytometry data analysis: Recent advances and future challenges. Trends in Biotechnology. 2013;31:415-425. DOI: 10.1016/j.tibtech.2013.04.008

[35] Beznos OA, Grivtsova LY, Popa AV. Evaluation of minimal residual disease in B-lineage acute lymphoblastic leukemia using EuroFlow approaches. Clinical Oncohematology. 2017;10:158-168. DOI: 10.21320/2500-2139-2017-10-2-158-168

[36] van Dongen JJ, Lhermitte L, Bottcher S. EuroFlow consortium (EU-FP6, LSHB-CT-2006-018708). EuroFlow antibody panels for standardized n-dimensional flow cytometricimmunophenotyping of normal, reactive and malignant leukocytes. Leukemia. 2012;26:1908-1975. DOI: $10.1038 /$ leu.2012.120

[37] Muzzafar T, Medeiros LJ, Wang SA. Aberrant underexpression of CD81 in precursor B-cell acute lymphoblastic leukemia utility in detection of minimal residual disease by flow. American Journal of Clinical Pathology... 2009;132:692-698. DOI: 10.1309/ AJCP02RPVOKTNWEC

[38] Gelin C, Aubrit F, Phalipon A. The E2 antigen, a $32 \mathrm{kd}$ glycoprotein involved in T-cell adhesion processes, is the MIC2 gene product. The EMBO Journal. 1989;8:3253-3259

[39] Jen EY, Xu Q, Schetter A. FDA approval: Blinatumomab for patients with B-cell precursor acute lymphoblastic leukemia in morphologic remission with minimal residual disease. Clinical Cancer Research. 2015;21:4035-4039. DOI: 10.1158/10780432.CCR-18-2337

[40] Klinger M, Brandl C, Zuqmaier G. Immunopharmacologic response of patients with B-lineage acute lymphoblastic leukemia to continuous infusion of $\mathrm{T}$ cell-engaging CD19/CD3bispecific BiTE antibody blinatumomab. Blood. 2012;119:6226-6233. DOI: 10.1182/blood-2012-01-400515

[41] Boccuni P, Di Noto R, Lo Pardo C. CD66c antigen expression is myeloid restricted in normal bone marrow but is a common feature of $\mathrm{CD} 10^{+}$early 
B-Cell Precursors: Immunophenotypic Features in the Detection of Minimal Residual Disease...

DOI: $h$ ttp://dx.doi.org/10.5772/intechopen.84223

B-cell malignances. Tissue Antigens.

1998;52:1-8

[42] Jordan CT, Upchurch D, Szilvassy

SJ. The interleukin-3 receptor a chain

is a unique marker for human acute

myelogenous leukemia stem cells.

Leukemia. 2000;14:1777-1784

[43] Kalian T, Vaskova M, Mejstrikova

E. Myeloid antigens in childhood

lymphoblastic leukemia: Clinical

data point to regulation of CD66c

distinct from other myeloid antigens.

BMC Cancer. 2005;5:38. DOI:

10.1186/1471-2407-5-38

[44] Sugita K, Mori T, Yokota S. The

KOR-SA3544 antigen predominantly

expressed on the surface of

Philadelphia chromosome-positive

acute lymphoblastic leukemia

cells is nonspecific cross-reacting

antigen-50/90 (CD66c) and

invariably expressed in cytoplasm

of human leukemia cells. Leukemia.

1999;13:779-785

[45] Munoz L, Nomdedeu JF, Lopez

Sierra O. Interleukin-3 receptor $\alpha$

chain (CD123) is widely expressed

in hematologic malignancies.

Haematologica. 2001;86:1261-1269

[46] Hoffman LM, Gore L.

Blinatumomab, a bi-specific anti-CD19/ CD3 BiTE $^{\circledR}$ antibody for the treatment of acute lymphoblastic leukemia: Perspectives and current pediatric applications. Frontiers in Oncology. 2014;4:1-5. Available from: www. frontiersin.org

[47] Beznos OA, Grivtsova LY, Popa AV. Approaches to the assessment of minimal residual disease in B-cell acute lymphoblastic leukemias in con ditions of target therapy. Russian Journal of Biotherapy. 2017;4:18-24. DOI: 10.17650/1726-9784-2017-16-4-18-24 

Section 4

\section{Splenectomy Associated Changes in B-Cell Subsets}





\title{
Splenectomy in Gastric Cancer: Influence of B Lymphocytes
}

\author{
Chulkova Svetlana Vasilievna, Lyudmila Yuryevna Grivtsova, \\ Ivan Sokratovich Stylidi, Nikolay Nikolayevich Tupitsyn and \\ Zamira Magometovna Galaeva
}

\begin{abstract}
The spleen is the largest peripheral organ of the immune system. The standard volume of lymphodissection in stomach cancer during gastrectomy or proximal resection is D2, which implies splenectomy. Immunity disorders in patients after splenectomy primarily affect the B cell immune response. Peripheral blood B-lymphocytes subpopulations have been studied in patients with gastric cancer. Group 1 - patients with gastrectomy, D2 lymphodissection, group 2 - patients with gastrectomy, D2-lymphodissection, splenectomy. Evaluation of the expression of antigens (CD20, CD21, CD23, CD38, HLA-DR, CD71, CD10, CD95, CD25, CD5, CD56, $\kappa$ - and $\lambda$-light was performed in the gate of CD19+ cells. Among peripheral blood lymphocytes the presence of CD19+CD5+ B cells (B1a cells), some of which express the activation antigens CD38 and CD23 is found; a small part of CD5+ B cells is CD25+CD38-. The number of CD23+ cells ranged from 25 to $40 \%$ in different patients. A significant number of B cells with a low level of CD21+ expression were detected. In group 2 after surgery, the percentage of cells with CD5+ expression significantly increased, the relative amount of CD19+ lymphocytes, CD19+CD21+ B cells decreased. Given data on B1 and BMZ populations, this can lead to a weakening of both general and antitumor immunity.
\end{abstract}

Keywords: B lymphocytes, B1 cell, cells of the marginal zone of the spleen, thymus-independent antigens, humoral immunity, stomach cancer, splenectomy, splenomegaly, D2 lymphodissection, IgM

\section{Introduction}

The spleen is one of the most important peripheral organs of the immune system. The content of lymphocytes in the white pulp of the spleen reaches $85 \%$ of the total number of cells. This amount is almost $25 \%$ of all body's lymphocytes, almost half of them being B cells. Thus, it is the spleen, along with the lymph nodes, which is the organ providing humoral immunity. In the spleen, a red pulp of $70-80 \%$ of the body weight is distinguished and white pulp, which accounts for $6-20 \%$ of the mass. The red pulp of the spleen is represented by venous sinuses and pulpal strands. In the red pulp, destruction of red blood cells 
and their absorption by macrophages occur. Lymphocytes predominate in the white pulp of the spleen. They accumulate around the arterioles in the form of so-called periarteriolar clutches. B cell follicles are located closer to the edge of the clutch [1-3].

Complex processes of activation of B cells occur in the spleen. Immature $\mathrm{B}$ cells come from the bone marrow to the spleen and lymph nodes, where their further maturation, antigen presentation, proliferation, and differentiation occur. Molecules of IgD, CD21, and CD22 appear on their surface.

The process of activation of $\mathrm{B}$ cells can be carried out in response to thymus-dependent antigens or without the involvement of a T lymphocyte [4]. T-independent antigens are generally polyvalent lipopolysaccharides, polysaccharides, or proteins. T-independent antigens are divided into type I and type II antigens, which differently ensure the full development of B cells in cells that synthesize antibodies [5-8].

Immature B cells react to $T$ cell-independent antigens of type 1 , which elicit a rapid antibody response. Most of mature B cells are within the lymphoid follicles of the spleen and lymph nodes, where they collide and react to T-dependent antigens associated with follicular dendritic cells and proliferate and either differentiate into plasma cells [1].

B cells, specific for autologous antigens, do not enter the follicles; they linger in the outer zone of the periarteriolar lymphoid clutches and die [9]. During the immune response to various antigens, the B lymphocyte-specific immunoglobulin receptor is bound after which the movement of all B cells in the outer zone of the periarteriolar lymphoid clutches has significantly slowed down. Activated B lymphocytes die in the event that there is no interaction with the T cells necessary for the realization of an immune response to thymus-dependent antigens. In the presence of cooperation with $\mathrm{T}$ cells, naive $\mathrm{B}$ cells enter mainly into follicles, where they undergo differentiation in the germinal centers during primary immune responses.

In secondary immune responses of memory B cells to thymus-dependent antigens, pronounced B cell proliferation and differentiation into plasma cells within the outer zone of periarteriolar lymphoid clutches are observed; follicular B cell proliferation is somewhat weaker than with primary responses $[10,11]$.

Also in the spleen, there is a special population of cells that delimits white pulp from the red pulp. This area is called the marginal or marginal zone, where both $\mathrm{T}$ and $B$ cells are located with a relative predominance of the latter [12]. The population of the B cells of the marginal zone is not homogeneous: it includes naive B cells, as well as B cells of immunological memory, generated both during T-dependent and T-independent antibody responses of the first type [13].

The spleen is the main place for the synthesis of IgM [14-16]. IgM is a polymer in which multiple immunoglobulins are linked together by covalent bonds known as disulfide bonds. IgM-class antibodies are the earliest in immunogenesis and constitute about $6 \%$ of all immunoglobulins. The time of their half-life is 5-6.5 days. They are produced by activated B cells at a primary immune response in peripheral lymphoid organs, which also includes lymph nodes and lymphoid formations of mucous membranes [17].

At the same time, the spleen cells are capable of producing various cytokines. In the experiment, it was shown that splenocytes produce interleukin-2, interferongamma, and interleukin-7 during antigen stimulation, which in turn stimulate the proliferation of B cells and the production of immunoglobulins [18].

Surgical treatment of patients with gastric cancer involves the implementation of lymphodissection. The standard volume of lymphodissection for stomach cancer 
during gastrectomy or proximal resection is D2, which implies a splenectomy that is performed to completely remove the lymph nodes of the spleen gates. However, the splenectomy leads to an increase in the frequency of postoperative complications and mortality, as confirmed by European randomized trials [19-23].

The spleen is the largest peripheral organ of the immune system. Immunity disorders can be more pronounced and prolonged after splenectomy. Clinical observations indicate that the improvement of health and clinical and laboratory parameters after splenectomy is in some cases replaced by the development state of immunodeficiency. Currently, this is confirmed experimentally and is referred to in the foreign literature as overwhelming postsplenectomy infections (OPSI) [24-26]. An analogue of the name "overwhelming postsplenectomy infections" is the term "postsplenectomy hypersplenism"; the signs of which are decrease in general tone and performance and susceptibility to viral, bacterial, parasitic, and fungal infections [26, 27].

Splenectomy for the purpose of adequate lymphodissection in stomach cancer causes pronounced and long-term dysfunction of various immunity units: the presentation of macrophages by foreign antigens to $\mathrm{T}$ and $\mathrm{B}$ lymphocytes is disrupted, the subpopulation of B lymphocytes changes, and the levels of all classes of immunoglobulins (IgG, IgA, IgM) decrease [28-30]. However, immunity disorders in patients after splenectomy primarily affect the $\mathrm{B}$ cell immune response, including thymus-independent type 2 antigens, which is provided by the population of $\mathrm{B} 1$ lymphocytes [31, 32].

B1 lymphocytes are relatively small group of B cells, found in humans and mice, and are considered to be the most phylogenetically oldest branch of antibodyproducing cells. The population of B1 cells was first described in 1983 by Lee Herzenberg (Hayakawa et al.) as a CD5+ population that differs from normal B (B2) cells by phenotype, anatomical localization, self-healing ability, and the production of natural antibodies. It includes two subpopulations: B1a and B1b [32, 33]. B1 lymphocytes develop in the fetal liver from progenitor cells.

The predecessors of B1a lymphocytes in ontogenesis appear before other subpopulations and migrate from the embryonic hematopoietic tissues (fetal liver and omentum) to the abdominal and pleural cavities as early as the embryonic period. B1b lymphocytes also originate from fetal precursors, but their pool in adults can be partially replenished by the bone marrow and migrate to the serous cavities during the embryonic period where they exist throughout the life of the organism [34, 35].

Thus, during life, the B1 lymphocyte pool is maintained by the activity of progenitor cells through their very slow proliferation. B1 cells are localized mainly in serous cavities - the abdominal and pleural. Some B1 cells migrate (through the omentum) to the intestinal mucosa and mesenteric lymph nodes (up to $50 \%$ of $\operatorname{IgA}$ producers in the lymphoid tissue of the intestinal B1cells). In the lymph nodes of the mouse, they are absent.

B1 cells are characterized by an "activated phenotype," which is manifested in the expression on their surface of costimulatory molecules CD80 and CD86. This property provides the ability of $\mathrm{B} 1$ lymphocytes to function as antigen-presenting cells. Subpopulations of B1 lymphocytes are similar, but subpopulation of B1b is characterized by the absence of CD5 expression [36].

The antibodies produced by B1 lymphocytes are almost exclusively IgM. The response of $\mathrm{B} 1$ cells is predominantly thymus-independent [37]. IgM plays an important role in the induction of apoptosis of tumor cells [38-40]. Approximately half of the serum IgM is secreted by B1 cells. A small number of B1 lymphocytes, mainly cells secreting antibodies, are detected in the spleen, where they account for up to $5 \%$ of the number of B cells. 
To study the peculiarities of the B cell link in patients with gastric cancer after splenectomy, the subpopulation composition of B lymphocytes was analyzed. The study included two groups of patients who underwent surgery. The first group of patients received treatment in the volume of gastrectomy with spleen-protective D2 lymphodissection. In the second group, patients underwent gastrectomy with D2 lymphodissection and splenectomy. The study of subpopulations of B lymphocytes was carried out at the preoperative stage and 3 months after the surgical treatment.

\section{Materials and methods}

We studied the subpopulation composition of B lymphocytes of peripheral blood in patients with gastric cancer. The possible influence of splenectomy on the subpopulation composition of B lymphocytes was investigated. The B cell link of peripheral blood lymphocytes in patients with gastric cancer was studied in dynamics (3 months after the operation).

To assess the effect of the splenectomy on the B cell link, the subpopulation composition of B cells of peripheral blood after surgery was assessed both in patients after gastrectomy with standard D2 lymphodissection (splenectomy) (14 people) and in patients after gastrectomy with spleen-protective D2 lymphodissection (12 people).

The reaction was taken into account on flow cytometers (FACScan, Lysys II and FACSCanto II, FACSDiva program). Data processing: WinMDI 2.8 and FCS 3.0 applications. Evaluation of the expression of membrane antigens was carried out in the gate of CD19+ B cells. Cells were stained at the same time with three monoclonal antibodies labeled with different fluorochromes. In 42 peripheral blood samples before the operation and 23 samples after the operation on the hematological analyzer Micros 60, the hemogram was calculated, which allowed to estimate the absolute number of B cells.

The expression of the following antigens is analyzed: CD20, CD21, CD23, CD38, HLA-DR, CD71, CD10, CD95, CD25, CD5, CD56, IgG- $\lambda$, and IgG- $\kappa$ light chain immunoglobulins (Table 1). Direct conjugates of monoclonal antibodies with fluorochromes were used: FITC, fluorescein; PE, phycoerythrin; PerCP, peridinin

\begin{tabular}{|c|c|c|c|c|}
\hline Antigen & Antibody clone & Antibody isotype & Manufacturer & Fluorochrome \\
\hline CD19 & 4G7, HIB19 & $\operatorname{IgG1-\kappa }$ & BD Biosciences & PerCP \\
\hline CD20 & $2 \mathrm{H} 7$ & $\operatorname{IgG1-\kappa }$ & BD Biosciences & $\mathrm{PE}$ \\
\hline CD23 & LT23 & $\operatorname{IgG1-\kappa }$ & Sorbent, Russia & FITC \\
\hline CD5 & L17F12 & $\operatorname{IgG} 2 \mathrm{a}-\kappa$ & BD Biosciences & $\mathrm{PE}$ \\
\hline $\mathrm{CD} 21$ & BL13 & $\operatorname{IgG1-\kappa }$ & BD Biosciences & FITC \\
\hline CD10 & HL10a & $\operatorname{IgG2a-\kappa }$ & BD Biosciences & $\mathrm{PE}$ \\
\hline CD71 & L01.1 & $\operatorname{IgG} 2 \mathrm{a}-\kappa$ & BD Biosciences & FITC \\
\hline CD95 & DX2 & $\operatorname{IgG1-\kappa }$ & BD Biosciences & $\mathrm{PE}$ \\
\hline $\mathrm{CD} 25$ & $2 \mathrm{~A} 3$ & $\operatorname{IgG1-\kappa }$ & BD Biosciences & FITC \\
\hline CD56 & NCAM 16.2 & $\operatorname{IgG2a-\kappa }$ & BD Biosciences & $\mathrm{PE}$ \\
\hline CD3 & SK7 & $\operatorname{IgG1-\kappa }$ & BD Biosciences & FITC \\
\hline $\operatorname{IgG}-\lambda / \operatorname{IgG}-\kappa$ & - & - & BD Biosciences & PE/FITC \\
\hline
\end{tabular}

Table 1.

Monoclonal antibodies and antigens. 
chlorophyll protein; and PE-Cy5, double (tandem) dye-combining phycoerythrin with cyanine 5 . The expression of the above antigens was detected by monoclonal antibodies directly labeled with various fluorochromes.

\section{The effect of the splenectomy on humoral immunity in patients with gastric cancer}

An analysis of the B cell subpopulation was performed in the gate of CD19+ cells. At the first stage of the analysis, the number of CD19+ B cells within the lymphocytes was cytometrically estimated (Figure 1a). Further, within the limits of only B cells [gate CD19+, Figure 1b], the expression of two antigens associated with B cells was analyzed. In these samples, there is an estimate of CD56 antigens concurrently with CD21 (Figure 1c).

The main indices of peripheral blood samples before and after surgery are given in Table 2. In general, in the group before the surgical intervention in comparison with the physiological norm, the average indices of both the relative quantity and the absolute content of B cells fit within the limits of the norm.

In 33\% of patients with gastric cancer at the preoperative period, a decrease in the relative number of B cells (less than 5\%) were detected. Moreover in $38 \%$ of patients decrease in the absolute number were revealed. Three months after the operation, in $52 \%$ of cases, the relative number of B cells was reduced, in $31 \%$ of the absolute content of B cells.

The average relative number of B cells, as well as their mean absolute content in $1 \mu$ of peripheral blood, was slightly elevated 3 months after surgery in comparison with these parameters in preoperative assessment. The average percentage of $\mathrm{B}$ lymphocytes after the operation was slightly lower than before surgery. However, these differences were statistically unreliable (T-test when comparing two independent variables). This can be explained by a significant spread of the analyzed indicators both in patients before and after surgery.

\section{$3.1 \mathrm{~B} 2$ cells}

Investigation of subpopulations of peripheral blood B lymphocytes in patients with gastric cancer at the preoperative stage established that all B cells had immunophenotype of naïve mature B2 cells: CD19+ CD20 + HLA-DR + CD10-CD21low/+. The data of subpopulation composition of B lymphocytes of peripheral blood of gastric cancer patients are given in Table 3 . B2 cells have a long life, localized mainly

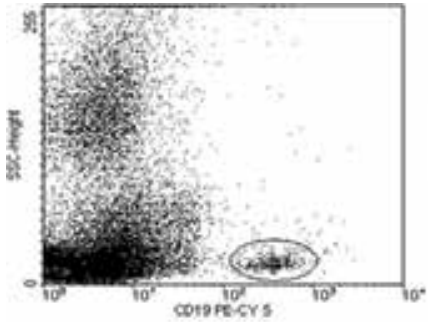

a

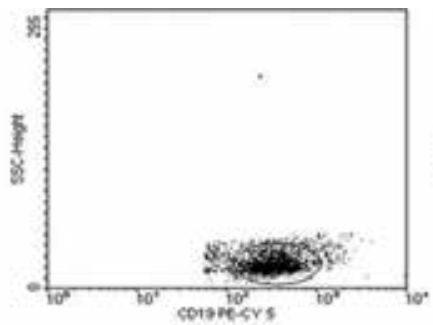

b

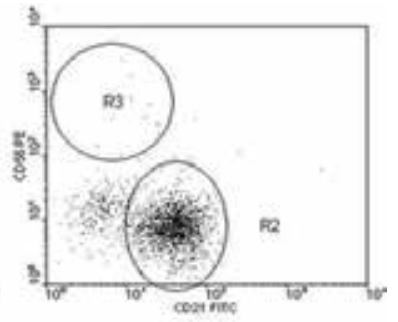

c

Figure 1.

(a) Estimating the total number of CD19+ B cells within the lymphocytes. The abscissa is the expression of pan-B cell antigen CD19+; along the ordinate axis-the parameter of lateral light scattering of the laser beam, reflecting the working cytometric concept - the granularity of the cells. (b) Cells that fall only in the region of CD19+, i.e., B cells accumulated during sample collection. (c) Evaluation of the expression of two antigens associated with $B$ cells in the CD19+CD56 and CD21. 


\begin{tabular}{lcccc}
\hline & Before operation & \multicolumn{3}{c}{ After the operation } \\
\cline { 2 - 5 } & Average & Median & Average & Median \\
\hline Leucocytes $\left(\times 10^{3} / \mu \mathrm{L}\right)$ & $6.3 \pm 0.34 \mathrm{n}=43$ & 5.9 & $6.76 \pm 0.49 \mathrm{n}=24$ & 6.4 \\
\hline Lymphocytes $(\%)$ & $30.1 \pm 1.8 \mathrm{n}=43$ & 30.0 & $36.9 \pm 3.06 \mathrm{n}=24$ & 35.5 \\
\hline B lymphocytes $(\mathrm{CD} 19+) \%$ & $6.44 \pm 0.51 \mathrm{n}=48$ & 5.5 & $6.0 \pm 0.57 \mathrm{n}=28$ & 4.8 \\
\hline B leucocytes $(\mathrm{CD} 19+) \%$ & $2.12 \pm 0.2 \mathrm{n}=42$ & 2.04 & $2.5 \pm 0.4 \mathrm{n}=22$ & 1.86 \\
\hline B cells $(\mathrm{CD} 19+) / \mu \mathrm{L}$ & $122.5 \pm 10.8 \mathrm{n}=42$ & 110.0 & $156.4 \pm 21.5 \mathrm{n}=22$ & 131.0 \\
\hline
\end{tabular}

Table 2.

Parameters of peripheral blood of the general group of patients.

in the spleen, bone marrow, lymph nodes, Peyer's patches, and individual follicles of the lymphoid tissue of the intestine. The histological unit, which is the site of the concentration of B2 cells, is the lymphoid follicle. These cells constitute the vast majority of circulating B lymphocytes. B2 cells undergo selection in the bone marrow and participate in the formation of an adaptive humoral immune response to thymus-dependent antigens.

Some patients noted the presence of transient T2B and T3B cells. They are characterized by pronounced expression of CD23 and CD21. The number of CD23+ cells ranged from 25 to $40 \%$ in different patients. In this case, as a rule, CD23 + B cells had a weaker expression of the antigen of mature B cells of CD20. Figure 2a shows samples of peripheral blood with a pronounced proportion of CD23+ B cells. In $40 \%$ of cases, CD23 coexpression was more than $25 \%$, and in $22.4 \%$ of patients, the number of CD23+ B cells exceeded $40 \%$ of B cells. Some patients have an insignificant number of CD23+ $\mathrm{B}$ cells (6\%) (Figure $2 \mathbf{b})$.

Transient (immature) B cells were first characterized in mice [41]. Immature B cells migrate from the bone marrow to the spleen. Throughout their migration to the spleen and after spleen entry, they are considered T1 B cells; within the spleen, T1 B cells transition to T2 B cells. Under normal conditions, CD19+CD21lowCD23 B cells (T1-transient) pass positive selection in the course of B cell ontogeny: cells receive a signal through the $B$ cell receptor without the participation of any

\begin{tabular}{lll}
\hline & $\mathbf{M} \pm \mathbf{m}$ & Median \\
\hline $\mathrm{CD} 19+\mathrm{CD} 5+$ & $14.2 \pm 1.91$ & $9.8 \mathrm{n}=46$ \\
\hline $\mathrm{CD} 19+\mathrm{CD} 23+$ & $24.5 \pm 2.4$ & $20.5 \mathrm{n}=49$ \\
\hline $\mathrm{CD} 19+\mathrm{CD} 20+$ & $97.2 \pm 0.4$ & $97.5 \mathrm{n}=48$ \\
\hline $\mathrm{CD} 19+\mathrm{CD} 71+$ & $9.6 \pm 1.1$ & $7.7 \mathrm{n}=48$ \\
\hline $\mathrm{CD} 19+\mathrm{CD} 10+$ & $0.48 \pm 0.09$ & $0.2 \mathrm{n}=45$ \\
\hline $\mathrm{CD} 19+\mathrm{CD} 38+$ & $19.8 \pm 2.9$ & $11.1 \mathrm{n}=45$ \\
\hline $\mathrm{CD} 19+\mathrm{HLA}-\mathrm{DR}+$ & $98.6 \pm 0.3$ & $99.1 \mathrm{n}=48$ \\
\hline $\mathrm{CD} 19+\mathrm{CD} 25+$ & $2.1 \pm 0.82$ & $0.5 \mathrm{n}=40$ \\
\hline $\mathrm{CD} 19+\mathrm{CD} 95+$ & $9.6 \pm 1.96$ & $7.8 \mathrm{n}=31$ \\
\hline $\mathrm{CD} 19+\mathrm{CD} 21+$ & $80.6 \pm 1.43$ & $82.1 \mathrm{n}=43$ \\
\hline $\begin{array}{l}\mathrm{CD} 19+\mathrm{CD} 56+ \\
(\mathrm{IgG}-\kappa+/ \mathrm{IgG}-\lambda+)\end{array}$ & $2.7 \pm 2.0$ & $0.15 \mathrm{n}=40,1.5-2.0 \mathrm{n}=29,1.0-1.3 \mathrm{n}=12$ \\
\hline
\end{tabular}

Table 3.

Subpopulations of B lymphocytes of peripheral blood in patients' stomach cancer before surgery. 


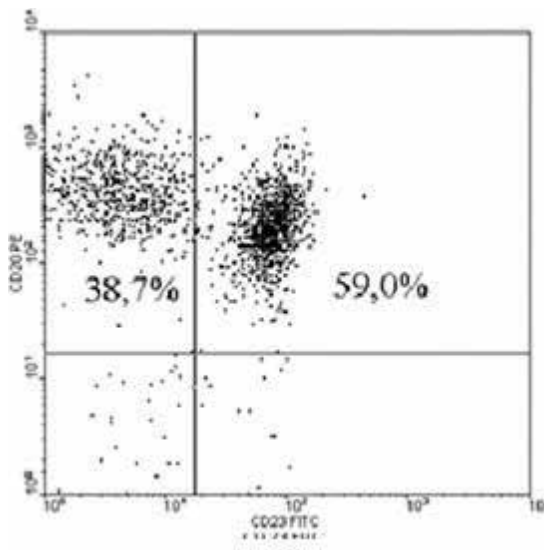

a

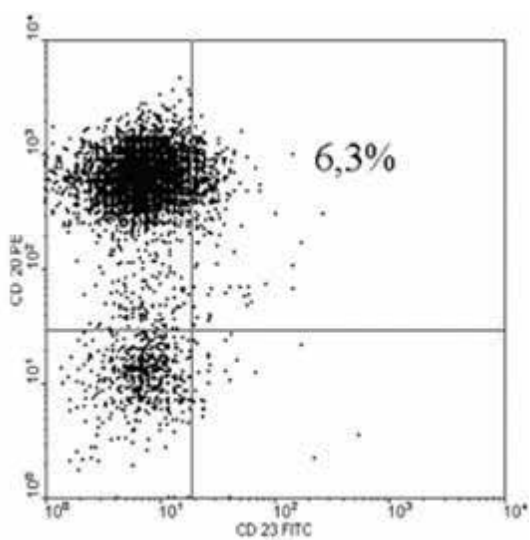

$\mathrm{b}$

Figure 2.

Expression of $C D 23$ antigen on peripheral $B$ cells in cancer patients'stomach. (a) The population of $C D_{20}+C D 23+i$ the majority (59\%) of $B$ cells and represents as a separate discrete population. (b) Insignificant number of $C D 23+B$ cells.

antigens, which ensures their survival. This process can occur both in the bone marrow and in the spleen $[42,43]$. In the evaluation of subpopulations of peripheral blood B cells in patients with gastric cancer before surgery treatment, a significant number of B cells with a low level of CD21+ expression were detected [area R2, Figures 3 and 4]. This phenotype corresponds to the T1 transient stage of B cell development. Expression of CD21 antigen was characteristic of a larger number of B cells and averaged $82 \%$.

The selection of transient T2B and T3B cells, characterized by the expressed expression of CD23 and CD21 antigens, passes in the peripheral lymphoid organs (the spleen, lymph nodes) high levels of IgM, IgD, and CD23 and lower levels of CD21. The expressed expression of CD23 antigen is intrinsic to the B cells of the embryonic center of the follicle. The follicular B cells that make up the majority and $\mathrm{B}$ cells of the marginal zone are lining outside the marginal sinus and bordering the red pulp. Follicular B cells also express high levels of IgM, IgD, and CD23 and lower levels of CD21. These cells are absent in CD1 or CD5, which distinguishes them from $\mathrm{B} 1$ cells and B cells of the marginal zone.

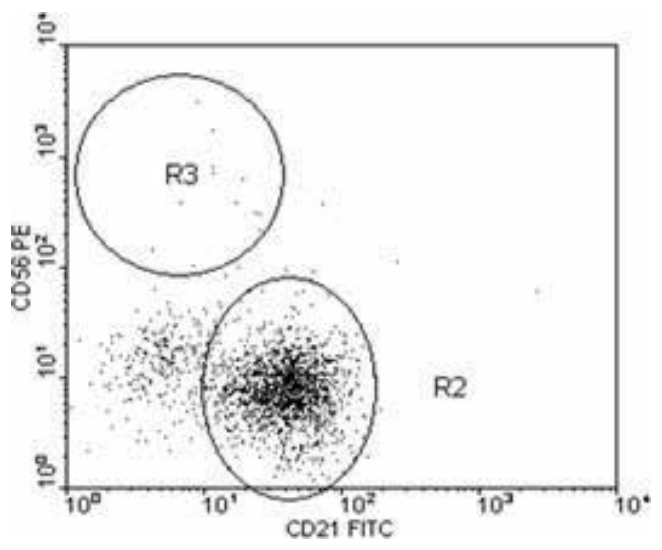

Figure 3.

The population of $C D_{19}+C D_{21}$ low $B$ cells (region $R 2$ ). 


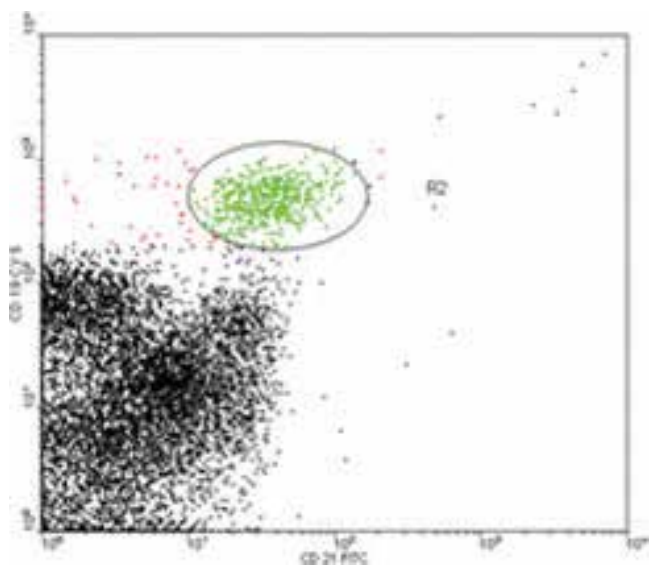

Figure 4.

Expression of CD21 antigen on B cells of blood of patient with stomach cancer. The abscissa axis is the expression of CD21; on the ordinate axis-CD19 expression, in the figure all cells of the sample, including granulocytes. Area R2, CD19+CD21+cells, this region is located above the granulocytes, which indicates a weak expression of CD21 B cells.

Thus, in patients with gastric cancer, a violation of the immunological repertoire of B2 cells was established: the presence of a pronounced proportion of CD21+ B cells with weak expression, a significant number of CD23+ cells, and cases of clonal $B$ cells. In most of the studied samples, $B$ cells were polyclonal with a predominance

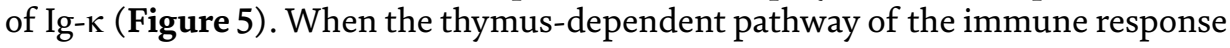
is realized, these patients will have a disruption in the synthesis of antibodies.

It is known that a B cell can be activated without the involvement of a T lymphocyte, which leads to the full development of B lymphocytes to antibody-producing forms. It is a characteristic that in this case the immunoglobulin $M$ is synthesized predominantly [5-7]. The process of activation of B cells without T lymphocyte is provided by thymus-independent antigens of type I and II [4]. They are lipopolysaccharides, polysaccharides, and proteins.

Antibodies of IgM class are the earliest in immunogenesis and make up about $6 \%$ of all immunoglobulins; their half-life is 5-6.5 days. Approximately half of the

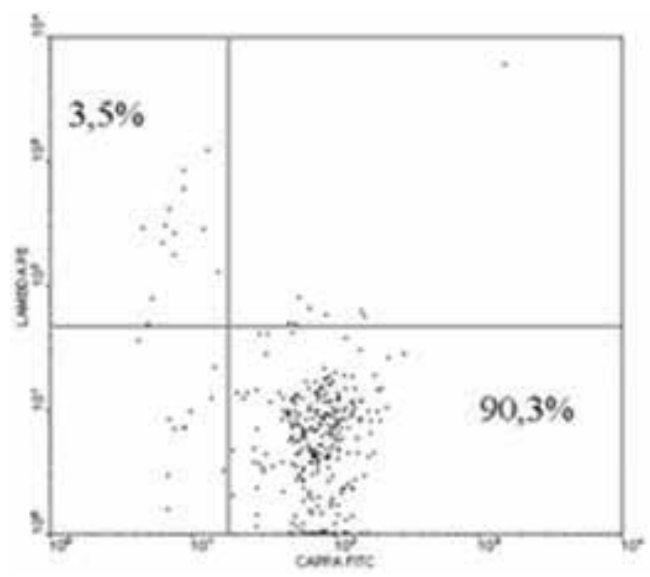

Figure 5.

Polyclonality of B cells with predominance of $I g-\kappa$. 
serum IgM is secreted by a pool of B1 lymphocytes. Many of the antibodies are polyspecific, i.e., are able to interact with several antigens, including autologous ones. These antibodies have a low affinity for antigens, including autoantigens, and are not capable of causing damage to tissues. B1 cells are constantly circulating between the spleen and the abdominal cavity but do not enter the follicles, since they do not express the chemokine receptor. Therefore, the processes of "improving" the humoral immune response in the form of switching isotypes and increasing the affinity for antigens do not affect or minimize B1 cells.

\subsection{B1 cells}

The population of B1 cells is the most phylogenetically ancient branch of antibody producing cells found in humans and mice. B1 lymphocytes develop in the liver of the fetus from progenitor cells. The B1 precursor, which differs from the B-line progenitor that develops primarily in the B2 population, is identified in the murine bone marrow to a lesser degree in the adult bone marrow [34]. B1 cells are considered as key players of the early humoral response against pathogens and considered primary antibody producers in response to T cell-independent type 2 antigens [44]. A specific thymus-independent response is realized by two subpopulations of B1 cells: B1a and B1b.

Both subpopulations of B1 cells are characterized by an "activated phenotype," which is manifested in the expression on their surface of costimulatory molecules CD80 and CD86. This property provides the ability of B1 lymphocytes to function as antigen-presenting cells. B1b cells are phenotypically similar to B1a cells, but they are characterized by the absence of CD5 expression. B1b lymphocytes realize an adaptive immune response, and B1a lymphocytes produce natural antibodies that are specific to microbial agents and opsonize pathogen-mediated innate immunity [45-47].

Such a B1a population of lymphocytes has the phenotype CD19+CD21lowCD23$\mathrm{CD} 5+\mathrm{IgM}++$. A number of experimental studies have revealed that immunity disorders after splenectomy primarily affect the B cell immune response, including thymus-independent (TN) type 2 antigens, which is provided by the population of B1a lymphocytes [31, 32].

Among B lymphocytes of peripheral blood of patients with gastric cancer, expressed subpopulation of CD5+ cells was noted. The number of CD19+CD5+ $\mathrm{B}$ cells averaged $17.7 \%$. In $23 \%$ of patients, CD19+CD5+ lymphocytes were more than $20 \%$, and in three patients, more than $40 \%$ of CD19+CD5+lymphocytes were detected. Normally, the population of CD19+CD5+ B cells is no more than $10 \%$ of the total number of peripheral blood B lymphocytes. Among the B cells of the group with a higher CD19+CD5+ B lymphocyte count (more than 15\%), the percentage of cells expressing CD25+ and CD21+ antigens was significantly higher; differences in the number of CD38 + B cells were found to be significant, but the range of values for one group of samples with respect to this antigen was higher. The data are presented in Table 4.

The presence of CD38 and CD25 antigens on circulating peripheral B cells indicates their activation. It is possible in coexpression of CD23 antigen, which was observed in a group of samples containing more than $25 \%$ of B1a lymphocytes.

A high probability of the presence of the $\mathrm{CD} 19+\mathrm{CD} 23+\mathrm{CD} 38+\mathrm{CD} 5+$ population (the presence of a reliable correlation relationship for $\mathrm{B}$ cells with the expression of CD38 and CD23 antigens, $\mathrm{R}=0.885, \mathrm{p}=0.008$ ) was established. There was also a high probability of the presence of the CD19+CD5+CD25+ population (significant 


\begin{tabular}{lccccc}
\hline Population & Group 1 & Group 2 & Group 1/group 2 & $\boldsymbol{t}$-Test & Relevance \\
\hline CD21 & $85.3 \pm 1.6$ & $79.1 \pm 1.9$ & $13 / 27$ & 2.436 & 0.02 \\
\hline CD25 & $3.9 \pm 2.0$ & $0.7 \pm 0.1$ & $11 / 26$ & 2.435 & 0.02 \\
\hline CD38 & $27.7 \pm 6.5$ & $16.1 \pm 2.9$ & $16 / 38$ & 1.858 & 0.07 \\
\hline
\end{tabular}

Table 4.

Significant populations of $B$ cells in groups of patients with stomach cancer with (CD5+) lymphocytes (group $1 \geq 15 \%$ ) and their normal content (group $2<15 \%$ ).

correlation for $\mathrm{CD} 1+\mathrm{CD} 5+$ and $\mathrm{CD} 19+\mathrm{CD} 25+\mathrm{B}$ cells, $\mathrm{R}=0.879, \mathrm{p}=0.05)$. However, in most samples $(65 \%)$, the number of $\mathrm{CD} 19+\mathrm{CD} 38+\mathrm{B}$ cells was insignificant-less than $15.0 \%$ (Figure $3 \mathbf{b}$ ).

It is interesting to note that the expression levels of the CD5 antigen on B cells proved to be significantly weaker [region R3, (Figure 5d)] as compared to the expression of CD5 antigen on peripheral CD3+ T cells.

Thus, in $17.7 \%$ of patients with gastric cancer in the peripheral blood, there is a pronounced proportion of a special subpopulation that provides a specific response to thymus-independent type II antigens, which is accompanied primarily by the synthesis of immunoglobulin M: B1a lymphocytes, some of which express the activation antigens CD38 and CD23. It is known that the precursors of these cells migrate early from the hematopoietic tissue to their anatomical niche, into the abdominal and pleural cavities, where autonomy from the central organs of the immune system is maintained by the number of its population. Some B1 cells migrate (through the omentum) to the intestinal mucosa and mesenteric lymph nodes (up to $50 \%$ of $\operatorname{IgA}$ producers in the lymphoid tissue of the intestinal B1 cells).

\subsection{Cells of the marginal zone}

Coexpression of CD38 and CD25 can be observed within the B cell population of the marginal zone of the spleen. B cells of the marginal zone (BMZ) originate from a pool of recycled $B$ lymphocytes that have returned to the marginal zone of the spleen. Phenotypically, these cells are more similar to B2 cells than to B1 cells. They come from the same bone marrow precursor cells. Separation of the line of BMZ cells from the general line of B2 cells occurs in the transitional stage of transient cells (T3), when future BMZ cells weaken the expression of non-IgM (like B2 cells) and IgD and lose the CD23 molecule.

These cells have specific morphological features: IgM molecules are expressed on their membrane, but there are no IgD molecules [48]. IgM is expressed more strongly than on B2 cells. For BMZ, high expression of CD21 is characteristic, which allows them to successfully bind T cell-independent type 2 antigens, presented in particular on encapsulated bacteria [49]. The molecules of CD69, CD25, and CD38 in a small amount of CD23 are expressed on BMZ. B lymphocytes with this phenotype are also found in other lymphoid tissues, but only the marginal zone of the spleen accumulates the largest number of these cells in the body. At the BMZ lymphocytes, the chemokine receptor is not expressed, which allows the cells to migrate to the follicles. The cells of the marginal zone are located in the primary blood sine network of the spleen, which allows them to interact with antigens carried by the blood [38, 51]. Information on antigens of BMZ is obtained by "shuttle" migration to lymphoid follicles and back. When answering antigens, the BMZ cells differentiate into short-lived antibodyforming cells. Due to the strong expression of MHC-11 molecules and costimulatory 
molecules, BMZ cells have pronounced an ability to interact with T-helper cells. The period of their life is comparable with the life of an organism.

In the spleen, there are complex processes of differentiation, selection of $\mathrm{B}$ lymphocytes, and replenishment of the pool of recirculating B lymphocytes and the pool of BMZ and B1 cells. To evaluate the features of the B cell link of immunity in patients with gastric cancer after gastrectomy with splenectomy, an investigation of subpopulations of B lymphocytes in the dynamics before and after the operation was carried out. Immunophenotypic profile of B cells was studied in 14 patients with gastric cancer with spleen-protective D2 lymphodissection and gastrectomy and in 16 patients with gastric cancer after gastrectomy and D2 lymphodissection with splenectomy.

In the group of patients with spleen-protective D2 lymphodissection, a significant correlation between the relative values (the proportion of lymphocytes and leukocytes) and the absolute (cells in $1 \mu$ of blood) in the number of CD19+ $\mathrm{B}$ cells was established in a pairwise comparison (T-test for paired variables) ( $\mathrm{p}=0.015, \mathrm{p}=0.04$, and $\mathrm{p}=0.05$, respectively). The number of cells in the $\mathrm{CD} 19+\mathrm{CD} 21+$ population $(\mathrm{p}=0.034)$ also significantly correlated before and after the operation.

In the group of patients who underwent gastrectomy with splenectomy, a significant correlation between the relative number of $B$ lymphocytes $(p=0.018)$ and CD5+ B lymphocytes $(p=0.012)$ and the number of CD19+CD38+ cells was found in a pairwise comparison of mean values before and after surgery $(p=0.035)$.

Three months after surgery in comparison with preoperative parameters in patients with gastric cancer after splenectomy, the percentage of cells with CD5+ expression significantly increased $(t=-6.015 \mathrm{sig}<0.0001, \mathrm{p}=0.013)$, and the relative amount of CD19+ lymphocytes and CD19+CD21+ B cells was decreased (before surgery, their number was $83.6 \%$, and after, $73.9 \%, \mathrm{p}=0.08$ ). The largest number of CD19+CD21+ B cells in the body is accumulated in the marginal zone of the spleen. When comparing the two groups after surgery, a high percentage of CD19+CD5+ B cells was detected (21.7vs. 14.5\%) in the group of patients with splenectomy ( $p=0.049$ ), which are precursors of functionally more advanced and clonally more diverse true B cells.

\section{Discussion}

In the spleen, there are complex processes of differentiation, selection of $\mathrm{B}$ lymphocytes, and replenishment of the pool of recirculating $B$ lymphocytes and the pool of BMZ and B1 cells.

Coexpression of CD38 and CD25 can be observed within the B cell population of the marginal zone of the spleen. B cells of the marginal zone (BMZ) originate from a pool of recycled $B$ lymphocytes that have returned to the marginal zone of the spleen. Phenotypically, these cells are more similar to B2 cells than to B1 cells. They come from the same bone marrow precursor cells.

These cells have specific morphological features: IgM molecules are expressed on their membrane, but there are no IgD molecules [49]. IgM is expressed more strongly than on B2 cells. For BMZ, high expression of CD21 is characteristic, which allows them to successfully bind TH2 antigens (T cell-independent type 2 antigens), presented in particular on encapsulated bacteria [50, 51]. The molecules of CD69, CD25, and CD38 in a small amount of CD23 are expressed on BMZ. B lymphocytes with this phenotype are also found in other lymphoid tissues, but only the marginal zone of the spleen accumulates the largest number of these cells in the body. 
Information on antigens of BMZ is obtained by "shuttle" migration to lymphoid follicles and back. When responding to antigens, the BMZ cells differentiate into short-lived antibody-forming cells. Due to the strong expression of MHC-11 molecules and costimulatory molecules, $\mathrm{BMZ}$ cells have a pronounced ability to interact with T-helper cells.

B1 lymphocytes are small group of B cells, found in humans and mice. CD5+ population differs from B2 cells by their phenotype, anatomical localization, self-healing ability, and the production of natural antibodies, includes two subpopulations: B1a and B1b [32, 33]. B1 lymphocytes develop in the fetal liver from progenitor cells.

The predecessors of B1a lymphocytes in ontogenesis appear before other subpopulations and migrate from the embryonic hematopoietic tissues (fetal liver and omentum) to the abdominal and pleural cavities as early as the embryonic period. B1b lymphocytes also originate from fetal precursors, but their pool in adults can be partially replenished by the bone marrow and migrate to the serous cavities during the embryonic period where they exist throughout the life of the organism $[34,35]$. Thus, during life, the B1 lymphocyte pool is maintained by the activity of progenitor cells through their very slow proliferation. B1 cells are characterized by an "activated phenotype" which is manifested in the expression on their surface of costimulatory molecules CD80 and CD86. This property provides the ability of B1 lymphocytes to function as antigen-presenting cells. Subpopulations of B1 lymphocytes are similar, but subpopulation of B1b is characterized by the absence of CD5 expression [36].

The data obtained show a disruption in the composition of B cell subpopulations. Most peripheral blood B cells showed weak levels of CD21 (low) antigen expression, marked presence of a pronounced amount of CD2+ B cells, and cases of clonal B cells. This probably reduces the function of antibody formation in the case of the realization of the main path of development of antibody producers in response to thymus-dependent antigens.

The antibodies produced by B1 lymphocytes are almost exclusively IgM. The response of B1 cells is predominantly thymus-independent [37]. IgM plays an important role in the induction of apoptosis of tumor cells [38-40]. Approximately half of the serum IgM is secreted by B1 cells. A small number of B1 lymphocytes, mainly cells secreting antibodies, are detected in the spleen, where they account for up to $5 \%$ of the number of B cells.

In the works which were devoted to the study of the function of the spleen and performed on animals, it has been shown that after splenectomy in the serum, the IgM level and the phagocytic activity of neutrophilic granulocytes decreased. However, if the spleen is reimplanted, the concentration of $\operatorname{IgM}$ is increased [52].

In a clinical study conducted at our research center, the levels of the main IgG, IgM, and IgA immunoglobulin classes were studied in patients with gastric cancer who underwent a standard operation in the volume of gastrectomy and lymphadenectomy with splenectomy [53].

The level of immunoglobulins was determined by the method of radial immunodiffusion in Mancini with the use of test systems produced by the SPC Medical Immunology (Russia). The level of immunoglobulins $A, G$, and $M$ in serum in patients without splenectomy, from 14 days after the operation, was slightly elevated and decreased to the initial value by 3 months (Figure 6a).

The level of all investigated immunoglobulins in the blood serum in patients with splenectomy before the operation was within the physiological norm. The content of IgA initially and for the entire monitoring period was within physiological values. The authors found that the levels of immunoglobulins $\mathrm{G}$ and $\mathrm{M}$ in 


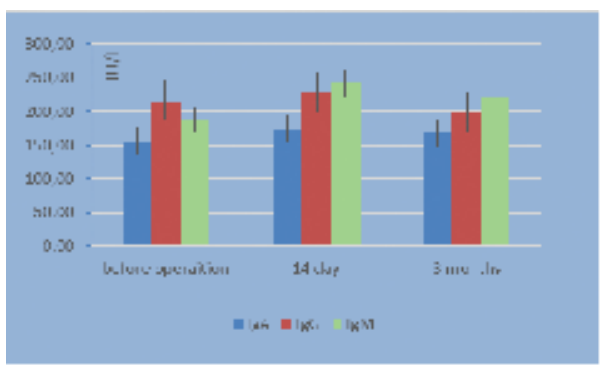

a

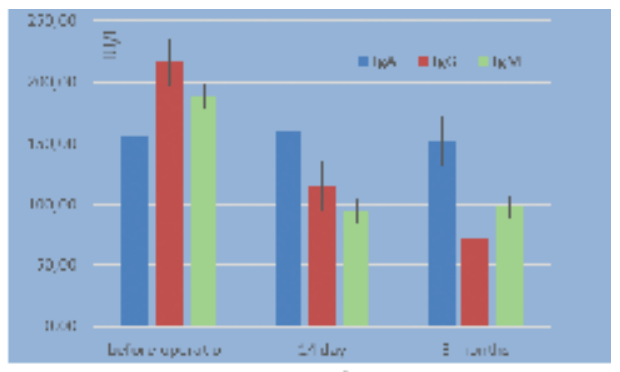

b

Figure 6.

(a) The level of immunoglobulin IgA, IgG, and IgM in the blood serum in patients in the dynamics in the postoperative period without splenectomy and $(b)$ the level of immunoglobulin IgA, IgG, and IgM in the blood serum in patients in the dynamics in the postoperative period with a splenectomy.

patients with gastric cancer who underwent surgical treatment with splenectomy were reduced almost twofold from the baseline, from the 14th day to the 3rd month of Figure 6b.

This fact agrees with the data obtained by our study. Change in the immunological repertoire of B2 cell antigens, weak expression of the CD21 membrane antigen, and a significant amount of CD23+ cells in the case of realization of the main pathway of development of antibody producers in response to thymus-dependent antigens may lead to decrease in antibody production.

Among peripheral blood lymphocytes, the presence of CD19+CD5+ B cells (B1a cells), some of which express the activation antigens CD38 and CD23, is found; a small part of CD5+ B cells is CD25+CD38-. Given the membrane immunophenotype circulating in the peripheral blood of $\mathrm{B}$ cells, patients with gastric cancer probably have an alternative $\mathrm{TH} 2$ response to pathogens.

In the group of patients after surgical intervention in the volume of gastrectomy with standard D2 lymphodissection and splenectomy, the relative total number of CD19+ B lymphocytes and the number of CD19+CD21+ B cells decreased (the differences are close to reliable) compared to preoperative values. In the group of patients with standard D2 lymphodissection and splenectomy, the percentage of CD5+ B lymphocytes significantly increased from 12.9 to $21.8 \%$, after the operation. Given data on B1 and BMZ populations, this can lead to a weakening of both general and antitumor immunity. Since maintaining the population B1 population is very slow, and the renewal of the BMZ pool is possible only in the spleen.

\section{Conclusion}

Immunosuppression in patients who underwent surgery (including splenectomy) develops as a result of a disruption in the composition of B cell link. Disorders of the immune response primarily affect the population of B1a lymphocytes, which provides a response to thymus-independent antigens of the second type. Patients in the experimental group may experience decreased production of antibodies, including IgM, which plays an important role in inducing apoptosis of tumor cells.

\section{Conflict of interest}

We hereby inform you that there is no conflict of interest. 


\section{Author details}

Chulkova Svetlana Vasilievna, ${ }^{1,2 *}$, Lyudmila Yuryevna Grivtsova ${ }^{3}$, Ivan Sokratovich Stylidi ${ }^{1}$, Nikolay Nikolayevich Tupitsyn ${ }^{1}$ and Zamira Magometovna Galaeva ${ }^{2}$

1 Federal State Budgetary Institution «N.N. Blokhin National Medical Research Center of Oncology» of the Ministry of Health of Russia, Moscow, Russia

2 N.I. Pirogov Russian National Research Institute, Ministry of Health of Russia, Moscow, Russia

3 Department of Laboratory Medicine of the IRRC named after A.F. Tsyba - The Branch of the National Medical Research Radiological Center of the Ministry of Health of Russia, Moscow

*Address all correspondence to: chulkova@mail.ru

\section{IntechOpen}

(C) 2018 The Author(s). Licensee IntechOpen. This chapter is distributed under the terms of the Creative Commons Attribution License (http://creativecommons.org/licenses/ by/3.0), which permits unrestricted use, distribution, and reproduction in any medium, provided the original work is properly cited. (cc) BY 


\section{References}

[1] Tupitsyn NN. Structure and function of the human immune system. In: Volkovoy MA, editor. Clinical Oncohematology. Chapter. 2nd ed. Medicine; 2007. pp. 46-65

[2] Sapin MR, Etingen LE. The Human Immune System. Medicine; 1996. p. 302

[3] Abbas AK, Lichtman AH, Pober JS. Cellular and Molecular Immunology. Philadelphia: W.B. Saunders Company; 1996. pp. 28-32

[4] Vos Q, Lees A, Wu Z-Q, Snapper $\mathrm{CM}$, Mond JJ. B-cell activation by T-cell-independent type 2 antigens as an integral part of the humoral immune response to pathogenic microorganisms. Immunological Reviews. 2000;176:154-170

[5] Radbruch A, Muehlinghaus G, Luger EO, et al. Competence and competition: The challenge of becoming a longlived plasma cell. Nature Reviews Immunology. 2006;6:741-750

[6] McHeyzer-Williams LJ, McHeyzerWilliams MG. Antigen-specific memory B cell development. Annual Review of Immunology. 2005;23:487-513

[7] Shapiro-Shelef M, Calame K. Regulation of plasma-cell development. Nature Reviews Immunology. 2005;5:230-242

[8] Zhang J, Liu Y-J, Maclennan ICM, Gray D, Lane PJL. B cell memory to thymus-independent antigens type 1 and type 2: The role of lipopolysaccharide in B memory induction. European Journal of Immunology. 1988;18(9):1417-1424

[9] Cyster JC, Goodnow CC. Antigeninduced exclusion from follicles and anergy are separate and complementary processes that influence peripheral B cell fate. Immunity. 1995;3:691-701
[10] Liu YJ. Sites of B lymphocyte selection, activation, and tolerance in spleen (review). Journal of Experimental Medicine. 1997;186:625-629

[11] Mebius R, Kraal G. Structure and function of the spleen. Nature Reviews Immunology. 2005;5:606-616

[12] Nolte M, Arens R, Kraus M, van Oers M, Kraal G, van Lier R, Mebius R. B cell are crucial for both development and maintenance of the spleen marginal zone. Journal of Immunology. 2004;172(6):3620-3627

[13] Kruschinski C, Zidan M, Debertin A, von Hörsten S, Pabst R. Agedependent development of the splenic marginal zone in human infants is associated with different causes of death. Human Pathology. 2004;35(1):113-121

[14] Roit A, Brostoff J, Mail D. Immunology. Translation with English (Moscow: Mir). 2000. $581 \mathrm{p}$

[15] Kruetzmann S, Rosado MM, Weber $\mathrm{H}$, et al. Human immunoglobulin $\mathrm{M}$ memory B cells controlling Streptococcus pneumoniae infections are generated in the spleen. Journal of Experimental Medicine. 2003;197(7):939-945

[16] Di Sabatino A, Rosado M, Ciccocioppo R, et al. Depletion of immunoglobulin M memory B cells is associated with splenic hypofunction in inflammatory bowel disease. The American Journal of Gastroenterology. 2005;100(8):1788-1795

[17] Mikhaylenko AA, Bazanov GA, Pokrovsky VI, Konenkov VI . Prophylactic Immunology. Tver: Triad; 2004. $448 \mathrm{p}$

[18] Yanagisava K, Kamiyama T. In vitro activation of mouse spleen cells by a lysate of Theileria sergentiinfected bovine red blood cells. Journal of Veterinary Parasitology. 1997;68(3):241-249 
[19] Brady MS, Rogatko A, Dent LL, Shiu MH. Effect of splenectomy on morbidity and survival following curative gastrectomy for carcinoma. Archives of Surgery. 1991;126(3):359-364

[20] Csendes A, Burdiles P, Rojas J, Braghetto I, et al. A prospective randomized study comparing D2 total gastrectomy versus D2 total gastrectomy plus splenectomy in 187 patients with gastric carcinoma. Surgery. 2002;131(4):401-407

[21] Fatouros M, Roukos DH, Lorenz $\mathrm{M}$, et al. Impact of spleen preservation in patients with gastric cancer. 2005;25(4):3023-3030

[22] Griffith JP, Sue-Ling HM, Martin I, et al. Preservation of the spleen improves survival after radical surgery for gastric cancer. Gut. 1995;36(5):684-690

[23] Okuno K, Tanaka A, Shigeoka $\mathrm{H}$, et al. Suppression of T-cell function in gastric cancer patients after total gastrectomy with splenectomy: Implications of splenic autotransplantation. Gastric Cancer. 1999;2(1):20-25

[24] William B, Corazza G. Hyposplenism: A comprehensive review. Part I: Basic concepts and causes. Hematology. 2007;12(1):1-13

[25] William B, Thawani N, Sae-Tia S. Hyposplenism: A comprehensive review. Part II: Clinical manifestations, diagnosis, and management. Hematology. 2007;12(2):89-98

[26] Hansen K, Singer D. Asplenichyposplenic overwhelming sepsis: Postsplenectony sepsis revisited. Pediatric and Developmental Pathology. 2001;4:105-121

[27] Sumaraju V, Smith L, Smith S. Infectious complications in asplenic hosts. Infectious Disease Clinics of North America. 2001;15:551-565
[28] Vorobiev AA, Kiselevsky MV, Titov KS. The concept of adoptive immunotherapy in patients with gastric cancer after radical surgical treatment. Bulletin of the Russian Academy of Medical Sciences. 2003;6:16-19

[29] Pavlova IE, Bubnova LN. Dynamics of cellular and humoral immunity in patients who underwent splenectomy in a remote postoperative period with trauma. Medline Express. 2007;3-4:26-31

[30] Tuguz AR, Gromova EG, Anisimova NY. The production of INF-alpha by neutrophils, mononuclear cells and splenocytes of cancer patients with postoperative complications. Bulletin of Intensive Therapy. 2003;3:48-50

[31] Yanaba K, Bouaziz JD, Haas KM, Poe JC, Fujimoto M, Tedder TF. A regulatory $B$ cell subset with a unique CD1dhiCD5+ phenotype controls T cell-dependent inflammatory responses. Immunity. 2008;28:639-650. PMID:1882568

[32] Hardy RR, Hayakawa K. B cell development pathways. Annual Review of Immunology. 2001;19:595-621

[33] Hayakawa K, Hardy RR, Parks DR, Herzenberg LA. The "Ly-1 B" cell subpopulation in normal immunodefective, and autoimmune mice. Journal of Experimental Medicine. 1983;157:202-218

[34] Montecino-Rodriguez E, Leathers $\mathrm{H}$, Dorshkind K. Identification of a B-1 B cell-specified progenitor. Nature Immunology. 2006;7:293-301

[35] Dorshkind K, Montecino-Rodriguez E. Fetal B-cell lymphopoiesis and the emergence of B-1-cell potential. Nature Reviews Immunology. 2007;7:213-219

[36] Berland R, Wortis HH. Origins and functions of B-1 cells with notes on the role of CD5. Annual Review of Immunology. 2002;20:253-300 
[37] LeBien TW, Tedder TF. B lymphocytes: How they develop and function. Blood. 2008;112: 1570-1580. PMID: 18725575. DOI: 10.1182/blood-2008-02-078071

[38] Brandlein S, Lorenz J, Ruoff N. Human monoclonal IgM antibodies with apoptotic activity isolated from cancer patients. Human Antibodies. 2002;11(4):107-119

[39] Varambally S, Bar-Dayan Y, Bayry J. Natural human polyreactive IgM induce apoptosis of lymphoid cell lines and human peripheral blood mononuclear cells. International Immunology. 2004;16(3)

[40] Piao X, Ozawa T, Hamana H. TRAIL-receptor 1 IgM antibodies strongly induce apoptosis in human cancer cells in vitro and in vivo. Oncoimmunology. 2016;5(5):e1131380

[41] Chung JB, Silverman M, Monroe JG. Transitional B cells: Step by step towards immune competence. Trends in Immunology. 2003;24:343-349

[42] Schmidlin H, Diehl SA, Blom $B$. New insights into the regulation of human B-cell differentiation. Trends in Immunology. 2009;30:277-285

[43] DiLilo DJ, Hamaguchi Y, Ueda Y, Yang K, Uchida J, Haas G, Kelsoe G, Tedder TYF. Maintenance of long-lived plasma cells and serological memory despite mature and memory B-cell depletion during CD20 immunotherapy in mice. Journal of Immunology. 2008;180:361-371

[44] Martin F, Kearney JF. B-cell subsets and the mature preimmune repertoire. Marginal zone and B1 B cells as part of a "natural immune memory". Immunological Reviews. 2000;175:70-79

[45] Grivtsova LY, Glukhov EV, Chulkova SV, Beznos OA, Fomina AV, Nered SN, Stilidy IS, Tupitsyn NN. Role of splenectomy in peculiarities of peripheral blood B cell sub populations in patients with gastric cancer. Journal of Immunology. 2014;5:279-286

[46] Haas KM, Poe JC, Steeber DA, Tedder TF. B-1a and B-1b cells exhibit distinct developmental requirements and have unique functional roles in innate and adaptive immunity to $S$. pneumoniae. Immunity. 2005;23:7-18

[47] Pillai S, Cariappa A, Moran ST. Marginal zone B cells. Annual Review of Immunology. 2005;23:161-196

[48] Gray D, MacLennan ICM, Bazin $\mathrm{H}$, Khan M. Migrant sIgM + sIgD+ and static sIgM+ sIgD- B lymphocyte subsets. European Journal of Immunology. 1982;12:564-569

[49] Zandvoort A, Timens W. The dual function of the splenic marginal zone essential for initiation of anti-T1-2 responses but also vital in the general fist-line defense against blood-borne antigens. Clinical and Experimental Immunology. 2002;130(1):4-11

[50] Mebius R, Nolte M, Kraal G. Development and function of the splenic marginal zone. Critical Reviews in Immunology. 2004;24(6):449-464

[51] Kraal G, Mebius R. New insights into the cell biology of the marginal zone of the spleen. International Review of Cytology. 2006;250:175-215

[52] Ellmark P, Furebring C, Borrebaeck CA. Pre-assembly of the extracellular domains of CD40 is not necessary for rescue of mouse B cells from antiimmunoglobulin M-induced apoptosis. Immunology. 2003;108(4):452-457

[53] Titov KS. Adaptive immunotherapy in radically operated patients with stomach cancer [Dissertation]. Moscow: N.N.Blokhin National Medical Research Center of Oncology; 2004 


\section{Edited by Mourad Aribi}

Normal and Malignant B-Cell is a collection of harmonious chapters contributed by different authors. This book sets out to describe the B-cell during different stages of ontogeny and the molecular mechanisms of its antigen receptor diversity. It also discusses the main clinical and etiopathogenic aspects when it is transformed into a malignant cell. The book will be interesting and useful for clinicians, biologists, researchers, teachers, and graduate students of both doctoral and master's degrees in the field of immunology. 